El Estudio Etnográfico de la Actividad Textil como aporte a la Caracterización del Modo de Vida en el Pueblo de Molinos y zona de influencia (Provincia de Salta)

Laura Teves

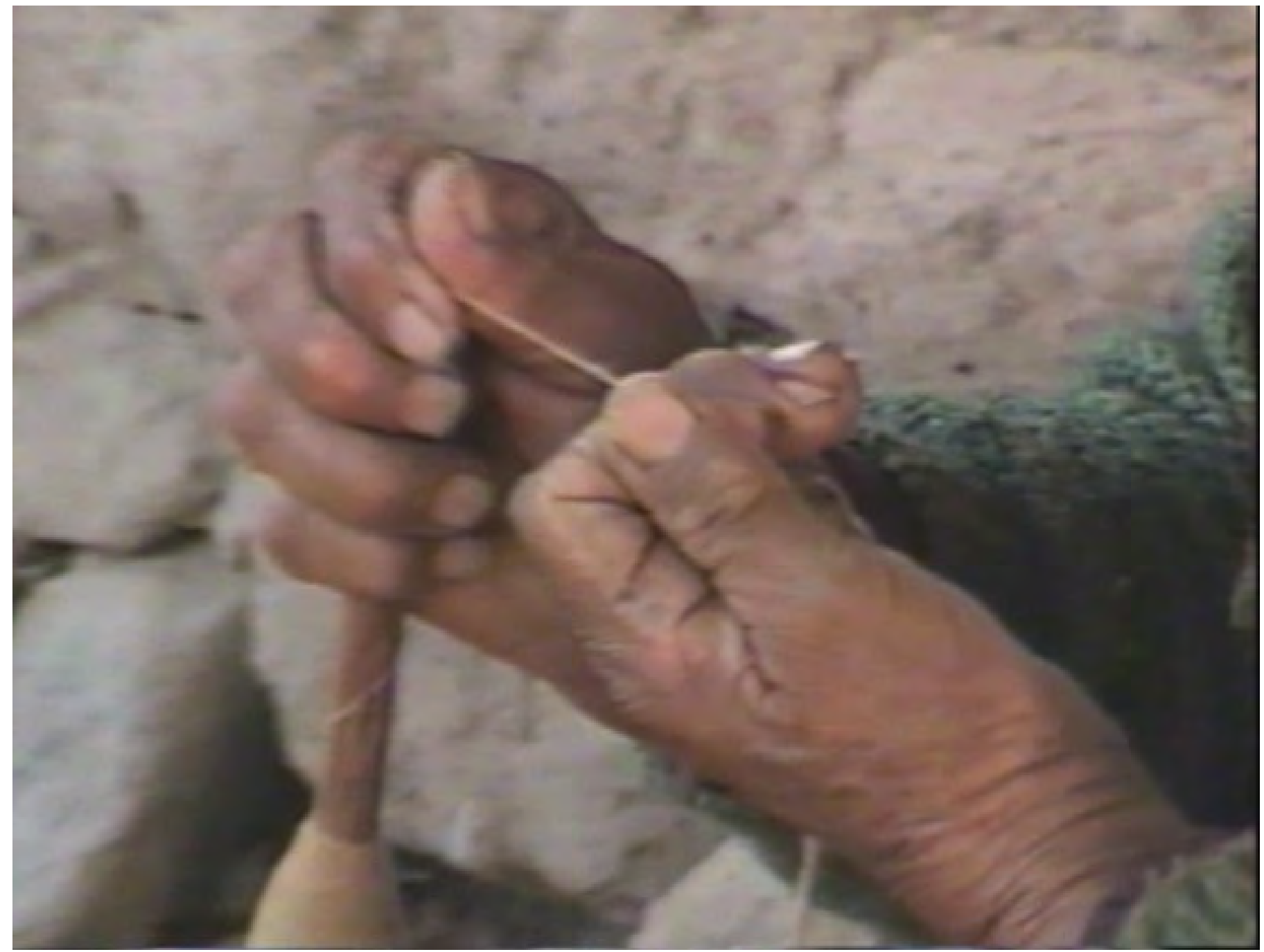


Universidad Nacional de La Plata

200 años

Bicentenario Argentino

\section{Tesis de doctorado}

\section{El Estudio Etnográfico de la Actividad Textil como aporte a la Caracterización del Modo de Vida en el Pueblo de Molinos y zona de influencia (Provincia de Salta)}

Doctoranda: Lic. Laura Susana Teves

Directora: Dra. Marta Crivos Co-Directora: Dra. Diana Rolandi

Jurados: Dr. Juan Pablo Ferreiro (UNJU_CONICET)

Dra. María Gabriela Morgante (UNLP) Dra. Ana María Lorandi (UBA_CONICET)

- La Plata, 28 de marzo de 2011-

Departamento de Postgrado - Carrera de Doctorado

Facultad de Ciencias Naturales y Museo 
Teves, Laura Susana

El estudio etnográfico de la actividad textil como aporte a la caracterización del modo de vida en el pueblo de Molinos y zona de influencia, provincia de Salta. - 1a ed. - La

Plata : Universidad Nacional de La Plata, 2011.

E-Book.

ISBN 978-950-34-0819-3

1. Antropología. 2. Textiles. 3. Tesis de Doctorado. I. Título CDD 306

Fecha de catalogación: 25/11/2011 
El Estudio Etnográfico de la Actividad Textil como aporte a la Caracterización del Modo de Vida en el Pueblo de Molinos y zona de influencia (Provincia de Salta)

A Sofía y Valentín, mis hijos

A Juan Ignacio, Jerónimo, Lucia,

Lorenzo, Lisandro, y Juan,

mis sobrinos 


\section{AGRADECIMIENTOS}

La experiencia de transitar por el trabajo de tesis ha sido de una de las elecciones personales más interesantes de mi vida. Con momentos cargados de excitación o de parálisis intelectual, con mucha curiosidad y lucidez, o con largos períodos de monotonía y rutinas. Pero todo esto no pasó desapercibido, porque jamás estuve sola para permanecer y avanzar al mismo tiempo. Esta ha sido una oportunidad para mi formación y crecimiento académico y un aporte al Equipo de Investigaciones en Etnografía Aplicada de la Facultad de Ciencia Naturales y Museo de la Universidad Nacional de La Plata.

Por todo lo recibido les agradezco a:

A la Dra. Marta Crivos, directora de esta tesis, incansable estimuladora de ideas y celosa supervisora del trabajo de investigación.

A la Dra. Diana Rolandi, codirectora, quien me acogió en el Instituto Nacional de Antropología y Pensamiento Latinoamericano y me entrenó el análisis técnico de textiles.

A la Profesora María Rosa Martínez por introducirme en el trabajo de campo en Molinos, por su invalorable generosidad con el material bibliográfico, fotográfico y documental.

A la Profesora Silvia García por sus oportunas conversaciones y reflexiones.

A mis colega, la Dra. Carolina Remorini por su lectura minuciosa, sus inteligentes recomendaciones; y su acompañamiento personal incondicional.

A la Lic. Ana Lamarche por el apoyo cotidiano, su tiempo extra, su serenidad y visión estratégica.

A la Lic. Lorena Pasarín; a la Dra. Anahí Sy por compartir y desarrollar los mismos intereses en el tópico del análisis de redes sociales.

A la DCV. Laura Benítez y a Matías Rodríguez Cóccaro por el apoyo en el procesamiento del material gráfico y de video.

A las mujeres y hombres de Molinos -tejedores, hilanderas y componedoras del textil tradicional andino-, por su consideración, tiempo y generosidad para enseñarme sus saberes ancestrales.

A la Universidad Nacional de La Plata, el CONICET y el INAPL por el financiamiento de la investigación. 
El Estudio Etnográfico de la Actividad Textil como aporte a la Caracterización del Modo de Vida en el Pueblo de Molinos y zona de influencia (Provincia de Salta)

Laura Teves

A mi familia que es guía y sostén de vida:

Mis abuelos, José y Eveline que trabajaron para un país mejor.

A mi abuela Lidia por enseñar a leer a niños y adultos por más de 40 años y sigue...

A mi padre por transferirme su compromiso político y social, a mi madre por "llevarme de la mano" hacia la Antropología y el Museo.

A mi hermana por ser un ejemplo de buena persona y porqué está.

A Javier mi compañero en todo y de siempre. 
El Estudio Etnográfico de la Actividad Textil como aporte a la Caracterización del Modo de Vida en el Pueblo de Molinos y zona de influencia (Provincia de Salta)

Laura Teves

\section{INDICE}

Dedicatoria

PÁGINA

Agradecimientos

2

Resumen en español

3

Resumen en inglés

INTRODUCCIÓN- los Valles Calchaquíes. Propuesta de estudio de la actividad textil en Molinos desde un enfoque etnográfico

\section{PARTE I- DELIMITACIÓN DEL TEMA Y ENFOQUES TEÓRICOS}

CAPITULO 1- Caracterización del Área de estudio, la localidad de Molinos y su relación con los Valles Calchaquíes y la región del Noroeste argentino (NOA)

1.1- El Entorno Andino y el NOA Introducción

1.1.1- Valles Calchaquíes y el paisaje

Recursos naturales y medio ambiente $\quad 28$

1.1.2- Los Valles Calchaquíes Salteños y los poblaciones indígenas 30

Culturas Prehispánicas o los Indios de Calchaquí 30

Los Incas: caminos y lenguas 32

"Diaguitas de guerra": la visión colonial española 35

1.1.3- Economía en los Valles Calchaquíes: Desarticulaciones entre las comunidades y los recursos naturales

Contrastes e inadecuaciones en el acceso a los recursos naturales 39

1.2- Molinos: un pueblo en los Valles calchaquíes

1.2.1- Parajes y otros asentamientos

1.2.2- La población Vallista Molinista: la visión demográfica y estadística del estado

1.2.3- Actividades de subsistencia y producciones locales: la visión desde las

comunidades molinistas

Las fincas y la producción local

Las unidades domésticas y las actividades de subsistencia $\quad 54$

Arriendos, Mediería, Pastajes y Abrebajes

Capítulo 2- ANTECEDENTES Y ENFOQUES PARA UN ESTUDIO ANTROPOLOGICO DE LA ACTIVIDAD TEXTIL

I.- Los textiles como OBJETOS MATERIALES de valor antropológico

2.1- Introducción

2.1.1-Textiles como patrimonio cultural

2.1.2- Textiles, expresión tangible de los intangibles de la cultura

2.1.3- Las colecciones textiles: más allá de los propósitos científicos

2.2- Lo Andino, una historia de investigación sobre textiles en Argentina

2.2.1- Primeros trabajos empíricos en el NOA y la emergencia de un problema de 
El Estudio Etnográfico de la Actividad Textil como aporte a la Caracterización del Modo de Vida en el Pueblo de Molinos y zona de influencia (Provincia de Salta)

Laura Teves

2.2.2- Inventarios textiles y el folklore calchaquí

2.2.3- Estructuras, Tipologías y avances en los estudios arqueológicos textiles

II.- Los textiles como objetos de valor en CONTEXTOS socio-culturales

2.3- Contextos tecnológicos y mediombientales 76

2.3.1- Textiles, tecnologías sustentables 76

Tecnologías para el desarrollo cultural $\quad 78$

Etnotecnologías y sistemas ecológicos en los Andes argentinos $\quad 80$

2.3.2- Cultura, medio ambiente y economía 81

Los relatos míticos y el valor en la explicación del medio ambiente 84

Adaptación y ecología: el control vertical desde el enfoque de sistemas 85

2.4- Textos y Contextos: el interés por los enfoques metodológico- etnográficos.

2.4.1- Investigación etnográfica en Molinos.

2.4.2- Del listado de costumbres tradionales al relato de casos 91

2.4.3- El énfasis en la perspectiva etnográfica. Pragmática y modo de vida 92

2.5- Contextos Relacionales. Modelos de Interacción Social 95

2.5.1- Individuos, grupos y patrones de relación 95

2.5.2- El Análisis de Redes Sociales (ARS) 98

2.5.3- Trabajos empíricos en NOA: vislumbrando la perspectiva relacional para analizar $\quad 100$

problemas nuevos

\section{PARTE II - DESARROLLOS METODOLÓGICOS: ANALISIS Y RESULTADOS}

CAPÍTULO 3- La Actividad textil: contextos, actores y prácticas 103

3.1- El Análisis Cualitativo de la Actividad Textil. Estrategias teórico-metodológicas 103

$\begin{array}{lr}\text { 3.1.1- Entrada al campo } & 105\end{array}$

3.1.2- Diseño de entrevistas y observaciones $\quad 107$

3.1.3- La información y su procesamiento 109

3.1.4- Preparación de documentos y codificación de categorías 111

3.1.5- Ordenamiento de categorías 112

3.1.6- Instancias en el análisis de los datos: 114

3.1.6.1- Codificación de los datos $\quad 114$

3.1.6.2- Búsquedas, exploración y cambios en la organización 118

3.1.6.3- Mapeo de los Resultados $\quad 118$

3.2- El Dominio Conceptual de la Actividad Textil: términos y sentidos 122

3.2.1- La secuencia operativa en la actividad textil 124

$\begin{array}{ll}\text { 3.2.2.- Hilado } & 125\end{array}$

3.2.2.1- Hilanderas 125

$\begin{array}{lr}3.2 .2 .2-\text { Lanitas } & 129\end{array}$

$\begin{array}{ll}3.2 .2 .3-\text { Instrumentos } & 133\end{array}$

3.2.2.4- Iscanchado o torcido 134

3.2.2.5- Hilos 136

3.2.2.6- Entintar 138

3.2.3- El proceso de Tejer 141

$\begin{array}{ll}\text { 3.2.3.1- Teleros } & 141\end{array}$

3.2.3.2- Espacio y tiempo de tejer 143

$\begin{array}{ll}\text { 3.2.3.3- Urdido } & 144\end{array}$ 
El Estudio Etnográfico de la Actividad Textil como aporte a la Caracterización del Modo de Vida en el Pueblo de Molinos y zona de influencia (Provincia de Salta)

Laura Teves

3.2.3.3.1- Enlisado

146

3-2.3.3.2- Tramada

148

3.2.3.4- Utensilios empleados en el tejido

150

3.2.3.4.1- Piezas textiles

152

3.2.3.4.2- Formas, función y diseños 153

3.2.4- Componer el Textil

154

3.2.4.1- Bordar

155

3.2.4.2- Flecos o chicote

155

3.2.4.3- Rapasejo

156

3.3- Ampliando el campo de la Actividad Textil 157

3.3.1- El paisaje

158

3.3.2- Unidades domésticas del cerro y del valle

159

3.3.3- Trayectorias de los tejedores en Molinos

162

3.4.- Hacia un modelo de la Actividad Textil

166

3.4.1- Contextos: Paisaje y Trayectorias

168

CAPÍTULO 4- ANALISIS DE redes sociales en La actividad textil

170

4.1- El Dominio Relacional de la Actividad Textil

170

4.2- Condiciones sustantivas y fundamentos metodológicos para un análisis de redes sociales $\quad 174$

4.2.1- Nociones básicas

177

4.2.2- Sistematización y formalización de los datos relacionales 179

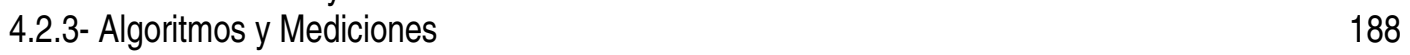

4.3- Hipótesis y datos para un análisis de las redes sociales en Molinos 190

4. 3.1- Formulación de hipótesis relacionales en la actividad textil 190

4. 3.2- Datos para un análisis de redes sociales en la actividad textil 191

4.4- Estrategias analíticas: egoredes, socioredes y su topología 193

4.4.1- Las relaciones personales en las actividades domésticas 193

4.4.2- Los grupos y subgrupos en las redes de actividad 197

4.4.3- Las relaciones sociales en el espacio $\quad 199$

4.5- Conjeturas para el estudio de las redes sociales en Molinos 201

4.5.1- Las unidades domésticas y la red social de Ego 202

4.5.2- La toma de decisiones y los patrones de organización intragrupal 206

4.5.3- Las prácticas cotidianas y la complementariedad ecológica 209

4.6- La Actividad Textil desde los vínculos y patrones 214

PARTE III - Discusión y Conclusiones $\quad 217$

CAPÍTULO 5- La actividad textil como aporte a una etnografía de los valles calchaquíes 217 
El Estudio Etnográfico de la Actividad Textil como aporte a la Caracterización del Modo de Vida en el Pueblo de Molinos y zona de influencia (Provincia de Salta)

Laura Teves

\section{LISTADO DE FOTOS, TABLAS e ILUSTRACIONES}

1.1. Mapa de la Pcia. de Salta y región de los Valles Calchaquíes coloreada

1.2. Vistas de altura de los Valles Calchaquíes

1.3. Vista de ladera del cerro con vegetación local y cultivos

1.4. Tabla de Pueblos indígenas y lenguas

1.5. Vista del pueblo de Molinos, desde el Cerro Overo.

1.6. Cementerio "nuevo" emplazado en el Cerro Overo (Molinos)

1.7. Tipos de viviendas y sectores del pueblo de Molinos

1.8. Vista de la Iglesia San Pedro Nolazco de los Molinos

1.9. Vista de la Iglesia y Antigua Sala Isasmendi

1.10. Vista de "la playa" del Río

1.11. Detalles constructivos, ochabas y fachadas

1.12. Mapa del Departamento de Molinos. Parajes y Asentamientos.

1.13. Tabla comparativa de población censada 1991-2001

1.14. Gráficos Censos 2001.

2.1. Tabla- Conceptos e hipótesis sobre la problemática de los textiles como objetos materiales.

2.2. Tabla- Enfoques locales sobre los textiles como objetos de la cultura material en NOA y Valles Calchaquíes.

2.3. Tabla- Enfoques generales y empíricos sobre textiles en contextos tecnológicos y medioambientales.

2.4. Tabla- Enfoques teórico-metodológicos en los estudios en la comunidad de Molinos.

2.5. Tabla- Conceptos e hipótesis acerca de la actividad textil desde la perspectiva de redes sociales.

3.1. Figura- Secuencia de la Actividad Textil: Primer ordenamiento conceptual.

3.2. Figura- Secuencia de la Actividad Textil y la organización del Sistema Índice.

3.3. Figura- Secuencia de la Actividad Textil: Nodos principales.

3.4. Figura- Secuencia por secciones del Sistema Índice: Etapa 1_Hilado.

3.5. Figura- Secuencia por secciones del Sistema Índice: Etapa 2_Tejido.

3.6. Figura- Secuencia por secciones del Sistema Índice: Etapa 3_Componer.

3.7. Imagen de una Hilandera con puchicana

3.8. Madejas de lana de oveja naturales teñidas

3.9. Preparción del hilo y yuchique en la muñeca

3.10. "Atado"de lanitas e instruementos para tejer

3.11. Puchicanas con tortero de piedra e Iscanchador

3.12. Proceso de teñido y lanas coloreadas

3.13. Tejedora y telar en una habitación cerrada. Telar en galeria

3.14. Secuencia de preparación de la urdimbre

3.15. Tejedora en telar bajo la enrramada

3.16. Tejedor con una caña para enlizar

3.17. Sección de telar, tientos y roldanas

3.18. Ajuntando la urdimbre

3.19. Tejedor en telar con tramero y pala

3.20. Tabla- Comparación entre objeto textil, tipo de instrumento y estructura textil.

3.21. Tabla- Categorías de textiles agrupados por sus funciones y tamaño.

3.22. Poncho con fecos y rapasejo 
El Estudio Etnográfico de la Actividad Textil como aporte a la Caracterización del Modo de Vida en el Pueblo de Molinos y zona de influencia (Provincia de Salta)

Laura Teves

3.23. Tabla- Categorías y procesos para el caso de la actividad textil en Molinos.

4.1. Tabla- Datos relacionales dispuestos en una matriz primaria.

4.2. Figura- Sociograma o representación gráfica de una matriz.

4.3. Figura- Matriz de Incidencia (a): Actores x eventos.

4.4. Figura- Matriz de Adyacencia (b) y Matriz de Adyacencia (c)

4.5. Figura- Grafo Dirigido y su matriz.

4.6. Figura- Diagonal de una matriz simétrica y asimétrica.

4.7. Figura- De la matriz al listado de actores y relaciones.

4.8. Tabla 1- Listado de datos relacionales y atributivos codificados y ordenados para procesar.

4.9. Grafo dirigido o dígrafo: sub-grafo, camino y paso.

4.10. Tabla 2- Articulación de las diferentes etapas de la investigación y su adecuación con un encuadre relacional.

4.11. Tabla 3- Textilería y otras actividades de subsistencia asociadas en términos de los datos para el ARS.

4.12. Tabla 4- Ordenamiento de las relaciones económicas, sociales y espaciales de un ego y sus alteri para la construcción de su red personal.

4.13. Tabla 5- Codificación y ordenamiento de los actores y los vínculos en la red de la actividad textil.

4.14. Tabla 6- Disposición de los datos sobre recursos y lugares en la red de actividades económicas.

4.15. Tabla 7- Listado de pares de localidades referentes a los trayectos en las rutas de circulación de materias primas, mano de obra y comercialización de textiles.

4.16. Tabla 8- Selección de los cálculos para la resolución de los problemas planteados.

4.17. Figura I-Visualización de la Ego_red en base a las variables medidas

4.18. Tabla 9- Medidas de densidad para la red de cada Ego.

4.19. Figura 9. Visualización de la red completa de la AT mostrando a los actores diferenciados por sus especialidades.

4.20. Tabla 10- Matriz Adyacente con datos de localidades en el Dpto. Molinos

4.21. Tabla 10- Matriz de Distancia.

4.22. Figura II- Visualización de la red de caminos o "la ruta del cerro" con puntos de corte (cutpoint).

4.23. Figura III- Visualización de la red total de localidades y rutas de circulación de materias primas, mano de obra y comercialización de textiles.

\section{ANEXOS}

ANEXO 1.1- Carta de Imagen Satelitaria de la República Argentina CACHI 2566-III. Escala 1: 25.000. Instituto Geográfico Militar. Edición 1998. Argentina.

ANEXO 1.2- Carta Topográfica CACHI 2566-III. Escala: 1: 250.000. Instituto Geográfico Militar. Edición 1988. Argentina

ANEXO 1.3- Croquis Pueblo de Molinos y campos aledaños de cultivo. Dirección Nacional de Estadísticas y Censos. Departamento Organización Censal.

ANEXO 1.4- Plano del Pueblo de Molinos. Departamento de Molinos. Provincia de Salta. Escala 1:1.000. Dirección General de Inmuebles. Salta, Febrero de 1979.

ANEXO 1.5- Datos Estadísticos para el Departamento de Molinos. INDEC 1997 y 2001. 
El Estudio Etnográfico de la Actividad Textil como aporte a la Caracterización del Modo de Vida en el Pueblo de Molinos y zona de influencia (Provincia de Salta)

Laura Teves

ANEXO 3.1- Listado de Expertos Tejedores.

ANEXO 3.2- Cuestionario-guía para Entrevistas Abiertas y Semiestructuradas. Relevamiento de la tejeduría tradicional en el área de Molinos- Valles Calchaquíes, Salta, Argentina.

ANEXO 3.3- Planilla de Observación.

ANEXO 3.4- - Formato Tipo para el Encabezamiento de los Documentos.

ANEXO 3.5- Unidades Codificadas a un Nodo.

ANEXO 3.6- Búsquedas de Categorías en un Documento.

ANEXO 3.7- Índice de Documentos.

ANEXO 3.8- Sistema Índice o Árbol de Nodos.

ANEXO 3.9- Diagrama de Árbol General.

ANEXO 3.10- Diagrama de Árbol con Ejemplo.

ANEXO 4.1- Correlación de Variables Relacionales y Redes Personales.

ANEXO 4.2- Análisis de Centralidad y Redes Totales o Sociocéntricas.

ANEXO 4.3- Análisis de Conectividad y Grafos Planares. 


\section{Resumen}

En este trabajo de tesis presentamos los resultados de una investigación etnográfica centrada en el análisis de la actividad textil tradicional en la comunidad de Molinos situada en la región de los Valles Calchaquíes Salteños, Argentina.

El propósito central de este estudio es la caracterización de la secuencia de producción del textil en el ámbito doméstico, la trayectoria individual de los expertos tejedores, las formas de organización social que emergen de la caracterización de esa actividad. Asimismo, nos proponemos realizar una reconstrucción del circuito de producción y comercialización en la región, que incluye el relevamiento de las rutas tradicionales y actuales, así como, el alcance geográfico y la red social involucrada en la producción, distribución y consumo de textiles.

La metodología empleada en el relevamiento de los datos incluye técnicas de observación y de entrevista propias del trabajo etnográfico. En particular se realizaron entrevistas abiertas y semiestructuradas y observación -participante y sistemática- obteniendose un sondeo observacional en punto fijo de las distintas etapas de la actividad. Se cuenta con el registro completo en audio y video de este material. Los datos obtenidos fueron evaluados aplicando la metodología de análisis de datos cualitativos (B. Richards, 1990) y el análisis de redes sociales (S. Borgatti, 1990 ). Teóricamente la tesis se presta como un aporte a los enfoques microanalíticos de la etnografía con referencias a la "grounded theory" (Glaser, A y J. Corbin, 1990) y a los enfoques de análisis de redes sociales (L. Freeman 1994 , A.Wolf, 1978, T. Schweizer, 1997).

La actividad textil (AT) puede modelizarse a partir del análisis de las historias personales de los expertos, teleros, hilanderas y componedoras, como especialistas locales. La actividad textil observada desde cada trayectoria es mucho más que un conjunto de conductas especializadas y desarrolladas por cada individuo, sino que se presenta como un conjunto de conocimientos y acciones inseparables de múltiples relaciones sociales entre los actores. 
La actividad textil y su descripción inicial en el ámbito doméstico permitió un acceso a las rutinas y prácticas cotidianas. Como resultado, se estableció la simultaneidad y complejidad de las acciones que están implicadas conjuntamente con la AT y otras actividades de subsistencia. Las referencias a la división de tareas y sub- especialidades, por género y edad en la AT se ven redimensionada por la destacada y reiterada mención a algunos actores. Esto permite trabajar conjuntamente las descripciones sobre los atributos propios de los expertos con la exploración de las características de los individuos por su localización o posición relativa dentro de una red de relaciones grupales. A priori se podrían establecer jerarquías entre los expertos, sobre la base de una serie de categorías sociológicas no pertinentes a este contexto. La influencia y estructuración de la secuencia de la actividad textil puede visualizarse en su dinámica desde uno o varios niveles de "localización" de los actores.

Las descripciones sobre el manejo de la diversidad de recursos naturales, cuya influencia se percibe en el acceso a una variedad de calidades de materias primas y de tecnologías, ha sido observado a través de las alternativas que permiten decidir en cada momento que pasos seguir en la actividad textil. Pero esto no es azaroso, ni depende solamente de la elección correcta y racional de un solo actor, sino que puede ser estudiado como consecuencia de la influencia y la intervención del conjunto de actores que participan en la actividad textil.

La actividad textil va mucho más allá de la secuencia de operaciones que transforma las materias primas en una pieza textil. En esta instancia es relevante el estudio de los vínculos entre las personas que la realizan y las configuraciones establecidas en una red de vínculos. La información y las alternativas de interacción de la gente están afectadas por su lugar en la red de vínculos que se establecen mediante la actividad textil.

La metodología de redes sociales resulta adecuada a la descripción de las relaciones relevantes a la actividad textil que integran diferentes niveles - local, regional y global- de interacción fundadas en las posibilidades del medio ambiente y en las estrategias de aprovechamiento de sus recursos por parte de los pobladores del Valle Calchaquí.

La teoría de redes sociales y los procedimientos estadísticos de esta metodología, describen importantes propiedades de la red, tales como centralización y cohesión entre 
El Estudio Etnográfico de la Actividad Textil como aporte a la Caracterización del Modo de Vida en el Pueblo de Molinos y zona de influencia (Provincia de Salta)

Laura Teves

los actores y que ayudan al reconocimiento de patrones que pueden visualizarse en correspondencia con la estructura espacial. 


\section{Abstract}

In this paper we present the results of an ethnographic study focused on the analysis of the traditional textile activity in the community of Molinos located in the region of the Valles Calchaquíes Salta, Argentina.

The main purpose of this study is to characterize the sequence of textile production in the domestic sphere, the trajectory of individual expert weavers, the forms of social organization that emerge from the characterization of that activity. We also propose to undertake a reconstruction of the production and marketing in the region, which includes the survey of traditional and current routes and the geographical scope and the network involved in the production, distribution and consumption of textiles.

The methodology used in collecting data, including observation and interviewing techniques, typical of ethnographic work. In particular, open and semi-structured interviews and participant-observation and systematic, thus obtaining a fixed point observational survey of the various stages of activity. We have the full record audio and video material. The data were evaluated using the methodology of qualitative data analysis (B. Richards, 1990) and social network analysis (S. Borgatti, 1990). Theoretically, the thesis is provided as an input to micro-analytical approaches of ethnography with references to "grounded theory" (Glaser, A and J. Corbin, 1990) and approaches to social network analysis (Freeman L. 1994, A. Wolf, 1978, T. Schweizer, 1997).

Textile activity (TA) can be modeled from the analysis of personal stories from experts, weavers, spinners and typesetters, and local specialists. The TA observed from each path is much more than a set of specialized behaviors and developed by each individual, but is presented as a set of knowledge and action are inseparable from social relations among multiple actors.

Textile activity and its housework description allowed access to the routines and daily practices. As a result, concurrency and complex set of actions that are involved in conjunction with the TA and other subsistence activities. References to the division of tasks and sub-specialties, gender and age in the TA are resized by the prominent and repeated reference to certain actors. This allows work together descriptions of the attributes of experts to explore the characteristics of individuals by their location or 
relative position within a network of group relations. A priori it could establish hierarchies among experts, on the basis of a series of sociological categories not relevant to this context. The influence of the sequence and structure of the textile activity can be viewed in its dynamics from one or more levels of "localization" of the actors.

Descriptions of the management of diversity of natural resources, whose influence is seen in access to a variety of grades of raw materials and technologies, has been observed through the alternatives that can always decide what steps to follow in textile activity. But this is not random, and depends only on the correct and rational choice of a single actor, but that can be studied as a result of the influence and involvement of all actors involved in the textile industry.

Textile activity goes far beyond the sequence of operations that transforms raw materials into a textile. In this instance it is relevant to study the links between people who perform it and the settings made in a network of links. The information and options for interaction of people affected by their place in the network links established by the textile industry. The methodology of social networks is adequate to the description of relations relevant to the textile activity that integrate different levels - local, regional and global interaction, based on environmental opportunities and strategies to profit from their resources by Calchaquí Valley residents.

Social network theory and statistical procedures of this methodology, describe important network properties, such as centralization and cohesion among the players and help the recognition of patterns that can be displayed in correspondence with the spatial structure. 


\section{INTRODUCCIÓN \\ Propuesta de estudio de la actividad textil en Molinos desde un enfoque etnográfico}

\section{I.-}

En esta propuesta de tesis de doctorado en la Facultad de Ciencias Naturales y Museo de la Universidad de La Plata me propongo abordar el tema de la actividad textil en la comunidad de Molinos y zona de influencia, en la provincia de Salta. El estudio de los textiles tradicionales constituye una de las investigaciones más profusas y de larga historia en Latinoamérica, fundamentalmente por el genuino interés que la comunidad científica ha mantenido desde el siglo XIX, así como, por la vigencia de la identificación cultural y social que los propios grupos de la región andina manifiestan y actualizan con los objetos textiles.

Estas razones constituyeron los dos ejes que motivaron mi estudio sobre los textiles. El estímulo inicial aparece con el curso de grado de "Arte, Tecnología y Antropología" dictado por la Dra. Carlota Sempé. En este espacio académico vislumbré la relevancia de los textiles como tema de estudio en la antropología argentina, lo que inmediatamente me incentivó, aún siendo estudiante, a desarrollar mis primeros pasos en investigación trabajando con las colecciones de textiles en la División Científica de Arqueología, del Museo de La Plata. Esta experiencia me permitió registrar el primer conjunto de datos, esbozar descripciones sobre los materiales y concluir con un modesto trabajo monográfico sobre textiles andinos. Posteriormente, con el avance en el análisis de las colecciones surgieron cuestionamientos acerca de los problemas que existen cuando queremos fundamentar la existencia de la relación entre los objetos arqueológicos y su adscripción cultural. En definitiva, emergió la preocupación por la búsqueda de respuestas en torno a la asociación entre los datos empíricos y los mecanismos explicativos sobre la pertenencia socio-cultural de los objetos materiales.

La necesidad de ampliar las respuestas acerca de aspectos de la cultura material y atender los planteos críticos tendientes a explorar al vigencia y los contextos de utlización y 
circulación de elementos como los textiles - los cuales integran tanto el registro arqueológico como el etnográfico- me condujo hacia los trabajos sobre teoría y metodología etnográfica de la Dra. Crivos resultantes de sus investigaciones empíricas en comunidades del Departamento de Molinos. La posibilidad de trabajo de campo y de reflexión sobre el tema fue atrapante y marcó un camino para abordar las preocupaciones previas sobre el textil como objeto. Durante el mismo periodo, el trabajo de pasantía en el Instituto Nacional de Antropología y Pensamiento Latinoamericano (INAPL) con la Dra. Diana Rolandi, me permitió profundizar estos mismos planteos, a través del análisis técnico realizado sobre las piezas de la colección arqueológica de textiles de Inca Cueva, Jujuy, y a partir de los intercambios con el equipo de antropólogos sociales trabajando en el poblado de Antofagasta de la Sierra en Catamarca.

Además, esta etapa fue muy intensa en el sentido de la búsqueda bibliográfica en las bibliotecas del Museo de La Plata y del INAPL. El acceso a los artículos y libros específicos sobre el tema me situó en el espectro de enfoques y en la profundidad temporal de los estudios en Argentina y en el mundo. A partir de aquí se planteó el desafío de delimitar mi propio estudio sobre el tema.

Asimismo la experiencia del primer viaje al campo a Molinos en 1997 me ubicó en la situación concreta de acercamiento a la gente del lugar, a la observación/corroboración sobre la vigencia de la actividad textil en la zona, en definitiva a la adecuación de las ideas previas sobre el proyecto de investigación y la factibilidad de desarrollarlo.

En los años siguientes los avances en la propuesta de investigación se vieron complementados con la formación dentro de la Carrera de Postgrado, lo que me llevó a diversos espacios académicos como los de la maestría en estudios de mercado, en la Facultad de Ciencias Económicas. Allí aprendí la relación que existe entre las economías de subsistencia y las de mercado; y su proyección en la articulación de niveles micro y macroeconómicos en la Argentina. Por otro lado, mi paso por el Departamento de Matemáticas de la UNLP y el apoyo de la Dra. Gutierrez constituyó un antes y un después en mi investigación, en el sentido de la puesta en valor de la formalización matemática y su aplicación en problemas concretos. Esto fue posible gracias a sus explicaciones sobre 
los principios de la teoría de grafos como base de la metodología de redes en el dominio de la actividad textil.

\section{II.-}

La formulación de la propuesta de tesis doctoral requirió de un diseño donde quedara definido el dominio de investigación, el problema a investigar, los objetivos de la investigación, los conceptos más relevantes y la metodología adecuada al planteo general del trabajo. Pero esto fue posible a partir de la decisión de fundamentar el plan de tesis sobre un conjunto de supuestos teórico-metodológicos, principalmente aquellos que consideran a la antropología como una disciplina que se aproxima al problema de lo humano desde una visión holística, como una unidad bio-socio-histórica.

En este sentido, consideramos que el estudio etnográfico de las estrategias de subsistencia de grupos humanos como los andinos, que registran una larga permanencia y continuidad en determinadas regiones del globo, es creciente a lo largo de la literatura antropológica en particular. Esto refleja el interés más general en el estudio de modos de vida fundados en una experiencia milenaria de adaptación humana por su valor potencial en relación a la explotación racional y sostenible de recursos en diferentes ecosistemas. Información que ha aportado a la delimitación de por ejemplo, los "Objetivos de Desarrollo Humano del Milenio" acordado por los países miembros de Naciones Unidas, hasta el 2015.

En tal sentido, la factibilidad de abordar el estudio etnográfico de actividades que se realizan -parcial o totalmente- en el ámbito doméstico e involucran el uso de recursos naturales y tecnologías de tipo tradicional, fundamenta mi propuesta de exploración sistemática -desde una perspectiva microanalítica- de la actividad textil en la región de los Valles Calchaquíes, en la Provincia de Salta. De este modo intentamos contribuir a la investigación antropológica de modos de vida de poblaciones humanas en un medio ambiente andino.

Asimismo, consideramos la actividad textil como circunscripta al dominio de las actividades que atraviesan el ámbito doméstico. Con foco en ese ámbito es posible acceder a las 
configuraciones complejas en que saberes y prácticas acerca de la actividad textil, se articulan y adquieren significación.

En investigaciones previas realizamos una primera exploración de diversas actividades en que se emplean tecnologías de tipo tradicional o paleotecnologías y que se desarrollan -parcial o totalmente- en el ámbito de la unidad doméstica. En base a la información resultante, y en relación al objetivo teórico, nos propusimos abordar la caracterización de la actividad textil, tomando como campo de observación inicial "unidades domésticas" correspondientes a los expertos locales. Iniciamos el relevamiento de información acerca de esta actividad a través del discurso de los "expertos" artesanos: fuentes de su saber y habilidades, historia de vida centrada en su trayectoria en el oficio, su pertenencia o no a familias de artesanos. Su caracterización se centró en el dominio técnico concebido como una cadena operativa en la que se transforma la materia prima en un producto, identificando los factores que intervienen en el proceso: aspectos físicos, actores, saber actualizado, contexto y propósito de la actividad, red social involucrada, su relación con ciclos naturales, presencia de otras actividades sincrónicas.

Desde el punto de vista metodológico se utilizaron distintas técnicas de registro tanto observacionales como de entrevistas a fin de testear y compatibilizar la información obtenida a partir de fuentes verbales y no verbales. La utilización de softwares específicos para el manejo de datos culturales -Nudist y Ucinet- facilitó la sistematización y análisis de la información en el sentido de los objetivos propuestos. Con todo esto se intentó una descripción del proceso que da cuenta de la integración y modos de articulación de los factores relevantes a la caracterización de la actividad textil.

Finalmente la investigación constituye un aporte al estudio del medio ambiente andino, considerando estrategias de delimitación y utilización diferencial del espacio y la complementariedad entre regiones ecológicamente diferentes. En este sentido, los circuitos de intercambio y comercialización de materias primas y productos, requieren de información de base acerca de actividades de interés económico en esas poblaciones.

\section{III.-}

La información obtenida en el campo es cuantiosa y su análisis desde el enfoque etnográfico es un abreactor de ideas, pero el trabajo realizado requiere de un esfuerzo de 
organización y sistematización de la información y los resultados deben ser trasmitidos a la comunidad científica a través de un texto claro y conciso. Atendiendo a este propósito, la presentación del trabajo de tesis se desarrollará en tres partes. En la Parte 1, nos proponemos realizar una caracterización del área de estudio, con especial énfasis en la localidad de Molinos y su relación con los Valles Calchaquíes y la región del noroeste argentino (NOA). También abordaremos los enfoques teórico-metodológicos más relevantes para una delimitación y estudio de la actividad textil desde la perspectiva general de la antropología y con especial énfasis en la visión desde la etnografía.

De este modo, el Capítulo1, incluye una caracterización del entorno andino y de la región del NOA que articula datos referentes al medioambiente, la historia regional, información etnolingüística, y los componentes centrales de la organización socio-económica en los Valles Calchaquíes. El objetivo principal es dar cuenta de las condiciones de vida de la comunidad de Molinos, enclave donde una población de características multiétnicas -con origen quechua, cacán y español-, establece sus estrategias de subsistencia accediendo de modo particular a los recursos del valle y la puna.

En este capítulo de la tesis se trabajó especialmente en mostrar en profundidad las diferencias que surgen del análisis de los datos económicos aportados por el Estado y que enfatizan sobre las oportunidades que ofrece el territorio y el potencial de los recursos naturales de la zona, en comparación con una caracterización etnográfica en la que se destaca el valor de la permanecia de las poblaciones locales y su conocimiento y manejo del medio ambiente. En el primer caso se concluye indefectiblemente sobre la inadecuación entre las actividades de las comunidades y sus unidades domésticas con relación al acceso al territorio y a los recursos disponibles. La visión contrapuesta del Estado y las comunidades plantea problemas de escala en la percepción de la subsistencia de estas poblaciones.

En este sentido, se consultaron fuentes que aportaron información de tipo demográfico estadístico e índices económicos, contenidos en informes elaborados por entidades estatales y privadas para el periodo 1997-2007. Entre ellas se destacan el Ministerio de Economía y Producción de la Nación, Secretaría de Agricultura, Ganadería Pesca y Alimentación, el Consejo Federal de Inversiones, los Censos del INDEC; la Universidad 
Nacional de Salta, Secretaría de Ambiente y Desarrollo Sustentable (SAyDS), el Instituto Nacional de Tecnología Agropecuaria (INTA), la Agencia de Cooperación Técnica Alemana (GTZ); y la Comisión Económica para América Latina, Agencia de Naciones Unidas (CEPAL$\mathrm{ONU})$.

Con respecto al Capítulo 2, se propone la presentación de los aportes desde diversos enfoques teórico-metodológicos acerca de los textiles. Cómo se delimita el objeto de estudio, qué aspectos visualiza cada enfoque y cómo esto conduce a la combinación de perspectivas, lo que resulta en una complejización del tema y la apertura hacia la investigación de temas nuevos como los desarrollados en esta tesis. Se revisa la historia de las investigaciones en la región, enfatizando en las características de programas o proyectos de investigación más amplios dentro de los cuales fue generada la información arqueológica y etnográfica.

El análisis de las principales ideas descriptas contribuye a fundamentar y delimitar una perspectiva propia para el estudio de la actividad textil en Andes y particularmente en el área de los Valles Calchaquíes.

Reconocemos como referentes de las primeras investigaciones en textiles una serie de estudios provenientes del campo de la arqueología, pero ponemos mayor y especial énfasis en la búsqueda de los estudios etnográficos, sin dejar de mencionar y reconocer los aportes provenientes del campo de arte.

¿Por qué elijo estos enfoques?

$\checkmark$ Por la relevancia que tienen en el desarrollo de la disciplina

$\checkmark$ Por su vinculación con la exploración de metodologías etnográficas que hacen posible arribar a una presentación de los actores y la actividad textil en el contexto de la vida cotidiana de Molinos y de los Valles Calchaquíes.

$\checkmark$ Por la posibilidad de aportar a los enfoques antropológicos relacionales, centrados en los supuestos cultura-espacio, medio socio-ambiental- recursos, revalorizar el conocimiento situado y el desarrollo local.

Con el objetivo de trazar un camino analítico sobre aquellas líneas de investigación que han sido de interés para el estudio de los textiles en Molinos, expondremos una serie de conceptos, hipótesis y resultados provenientes de aquellos estudios. En definitiva 
daremos cuenta del estado del arte previo al inicio de esta tesis mediante una reconstrucción "orientada" de la historia de la disciplina. Tomaremos aquellos autores y trabajos que consolidaron la problemática de los textiles andinos en un sentido antropológico y que abrieron camino hacia mi propia investigación.

Agruparemos los antecedentes sobre la temática de la textilería desde dos posiciones. Aquella que se centra fundamentalmente en los textiles, considerándolos elementos de la cultura material provenientes del registro etnográfico y arqueológico e incorporados como objetos coleccionables o piezas para exhibición en los Museos. Es decir, objetos que asociados a investigaciones empíricas arrojan datos que evidencian la presencia de una cultura en particular. Una segunda perspectiva considera el textil en el contexto de los conocimientos y prácticas de los actores, observando el sentido y vigencia de estos objetos en las comunidades que aún los elaboran y en los espacios sociales donde adquieren denominaciones y categorías, cumplen una función y son valorados en los circuitos de intercambio entre los grupos que los producen.

Gran cantidad de aspectos y líneas han sido abordados y desarrollados respecto al campo de la textilería, muchos de los cuales son producto de la selección, combinación, complementariedad y crítica entre perspectivas. Aún cuando cada tendencia ha prosperado en diversas especialidades, nuestro trabajo aspira a explorar la actividad y los objetos textiles, como legado y desarrollo de aquellos enfoques, los que serán expuestos en los dos próximos capítulos de la tesis.

Los aspectos metodológicos se presentan en la Parte II: Desarrollos metodológicos. Análisis y Resultados. En esta sección están incluidos el Capítulo 3: La actividad textil: contextos, actores y prácticas y el Capítulo 4: Análisis de redes sociales en la actividad textil. En ambos casos, la metodología se desarrolla en una minuciosa articulación con la información que se obtuvo del trabajo de campo en la comunidad de Molinos situada en la región de los Valles Calchaquíes Salteños, Argentina.

El Capítulo 3 aborda el proceso de elaboración de los textiles, describe el modo de procesamiento de las materias primas hasta terminación de las piezas. Incluye de forma detallada el modo de adquisición de las fibras de lana -su calidad, variedades, disponibilidad-, la elaboración y teñido de los hilos, las diferentes formas de preparación 
del telar, el uso de distintas técnicas textiles, las formas de terminación de las piezas, hasta la obtención del producto final.

La presentación de esta sección está orientada a caracterizar las diferentes etapas de elaboración de las piezas de tejido. Los datos observacionales y los provenientes del registro verbal fueron cotejados a fin de delimitar dentro del proceso de la actividad textil unidades completas y mínimas. En relación a cada una de estas unidades emergen referencias a aspectos de la vida social y económica; a los modos particulares de designación de objetos, instrumentos, personas y lugares asociados a ellas; sus componentes rituales y alusiones a su profundidad histórica a través de la trayectoria de vida de los teleros. De este modo, se ha tratado de especificar el dominio de la textilería y dar cuenta de ella a través de la elaboración de un modelo que contemple sus componentes y procesos.

El Capítulo 4 se refiere a las relaciones sociales, parentales, de amistad y trabajo en el contexto de la actividad textil. Como primer paso metodológico se hace un listado de todos los expertos reconocidos en la zona, y sus relaciones con los abastecedores de materia prima, las personas que intervienen en cada una de las etapas de elaboración, los compradores. Cada uno de ellos tiene su referencia a la función y lugar desde donde participa en esta red social involucrada en la actividad y comercialización de los textiles.

La actividad textil va mucho más allá de la secuencia de operaciones que transforma las materias primas en una pieza textil. En esta instancia es relevante al estudio de esta actividad la consideración de los vínculos entre las personas que la realizan y las configuraciones establecidas por esos vínculos. La información y las alternativas de interacción de la gente están afectadas por su lugar en la red de vínculos que se establecen mediante la actividad textil.

Del mismo modo, la metodología de redes sociales resulta adecuada a la descripción de las relaciones relevantes a la actividad textil que integran diferentes niveles - local, regional y global- de interacción fundadas en las posibilidades del medio ambiente y en las estrategias de aprovechamiento de sus recursos por parte de los pobladores del Valle Calchaquí. 
La teoría de redes sociales y los procedimientos estadísticos de esta metodología, describen importantes propiedades de la red, tales como centralización y cohesión entre los actores y que ayudan al reconocimiento de patrones que pueden visualizarse en correspondencia con la estructura espacial.

Los vínculos entre los tejedores pueden diferenciarse en cuatro tipos: parentales -desde esposos/as con los que se comparte la actividad hasta la mención a los padre, abuelos y tíos que son reconocidos como aquellas personas que les enseñaron los primeros pasos sobre el hilado o tejido. El segundo tipo de relaciones reconocidas por los informantes son las que mantienen con vecinos o amigos que están próximos a su vivienda. En el tercer tipo pueden diferenciarse los vínculos comerciales que se dan en torno al intercambio o compra de materias primas, tecnología, así como las transacciones con las piezas terminadas. Un cuarto tipo de relaciones es posible al identificar los vínculos entre los expertos a través del conocimiento compartido entre los que realizan la misma actividad o sub-actividades.

En el Capítulo 5 nos preguntamos: ¿Qué sabíamos antes y que podemos concluir después de esta investigación acerca de la actividad textil en Molinos? La respuesta destaca el aporte de una primera sistematización de la información sobre el tema de textiles tradicionales en Molinos, vinculada a los saberes y prácticas locales, a su organización sobre la base de la estructura de las relaciones sociales y espaciales, y por último, la consideración del proceso de producción textil tradicional en relación con la problemática de la economía regional, el desarrollo sostenible y su valor potencial en el mercado. 


\section{CAPÍTULO 1}

\section{Caracterización del área de estudio, la localidad de Molinos, su relación con los Valles Calchaquíes y la región del noroeste argentino (NOA)}

\section{1- El Entorno Andino y el NOA}

La región del Noroeste de Argentina -NOA- se encuentra en el extremo meridional de una región mayor que la incluye, el área de los Andes Meridionales de Sudamérica, cuyos límites pueden definirse sobre criterios no sólo geográficos, sino históricos, políticos, económicos y culturales. En este capítulo nos interesa mostrar cómo la elección de estos criterios contribuye a una delimitación y análisis particular de este área de estudio. Del que nos proponemos resulte una descripción contextualizada de las comunidades locales. Para ello atenderemos a los antecedentes que recuperan las raices etnicas e históricas de la población, en la perspectiva de un modo de vida sostenido sobre la utilización de los recursos naturales disponibles en un medio ambiente particular, y en la organización económica, emplazamiento y movilidad de los grupos en el territorio de los Valles Calchaquíes. De este modo, nos proponemos caracterizar las actividades tradicionales de Molinos, tales como la agricultura, ganadería y textilería, sobre la configuración que en principio otorgan los parámetros espaciales y temporales, conjuntamente con los parámetros socioculturales.

La influencia de diversos patrones culturales y los procesos de mestizaje en los Valles Calchaquíes tornan necesaria la consideración pormenorizada de los movimientos o flujos de poblaciones, resistencia y conflictos, así como los repoblamientos desde tiempos arqueológicos e históricos hasta la actualidad.

Un aspecto que se suma a los anteriores, enfatiza la utilización de los recursos del medio ambiente local, la producción y autoconsumo y para la subsistencia de las poblaciones. Aproximación que permite ver el desarrollo de las actividades económicas en relación a la situación de los asentamientos humanos del Valle desde el periodo precolombino, pasando por la conquista española, las encomiendas y la conformación de los estados nacionales. 
La reconstrucción de los procesos que han atravesado la vida de las poblaciones de la región desde la existencia de los grupos originarios, las influencias de otros pueblos andinos, la conquista española y el surgimiento de las poblaciones mestizas hasta el presente, señalan la existencia de visiones contrapuestas respecto a los modos de apropiación del territorio y las formas de explotación y producción de los recursos del área. Actualmente, la situación de las comunidades locales y las posibilidades de acceso a los territorios que ocupan, así como al manejo de los recursos naturales, es desfavorable. En este sentido, resulta imprescindible que la planificación e intervensión del Estado en la economía regional en los valles, genere acciones tendientes a ofrecer nuevas alternativas y oportunidades. De modo que, las unidades domésticas locales superen los niveles de subsistencia, a los que históricamente han estado restringidas.

\subsection{1- Los Valles Calchaquíes y el paisaje.}

Los Valles Calchaquíes ubicados en la región del NOA, se extienden a lo largo de 400 kilómetros en sentido N-S, desde el Nevado de Acay a los 5.716 metros sobre el nivel del mar (en adelante msnm), en la provincia de Salta, hasta Punta de Balasto en la provincia de Catamarca. Atraviesa los Departamentos salteños de La Poma, Cachi, Molinos, San Carlos y Cafayate; el Departamento de Tafí, en Tucumán y el de Santa María, en Catamarca. Las coordenadas geográficas se establecen a los $24^{\circ} 27^{\prime}$ sur y los $27^{\circ}$ de Latitud Sur y desde los $66^{\circ} 14^{\prime}$ Longitud Oeste. (ANEXO 1.1. Carta Imagen Satelitaria de la Pcia. Salta)

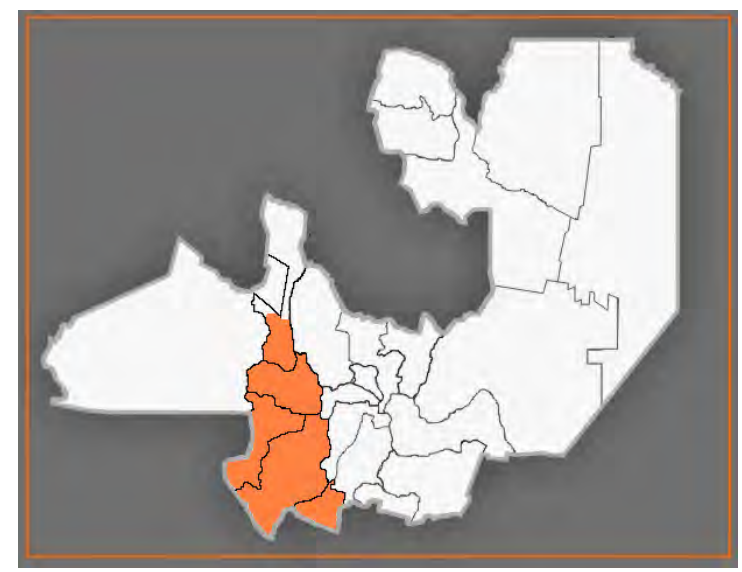

1. Mapa de la Pcia. de Salta y región de los Valles Calchaquíes coloreada 
Los Valles Calchaquíes están constituidos por dos valles principales -el Calchaquí y el Santa María o Yocavil-, perteneciendo ambos a un mismo bolsón, pero surcados por dos ríos diferentes que llevan sus nombres, que corren en sentidos opuestos y que confluyen en el río Cafayate.

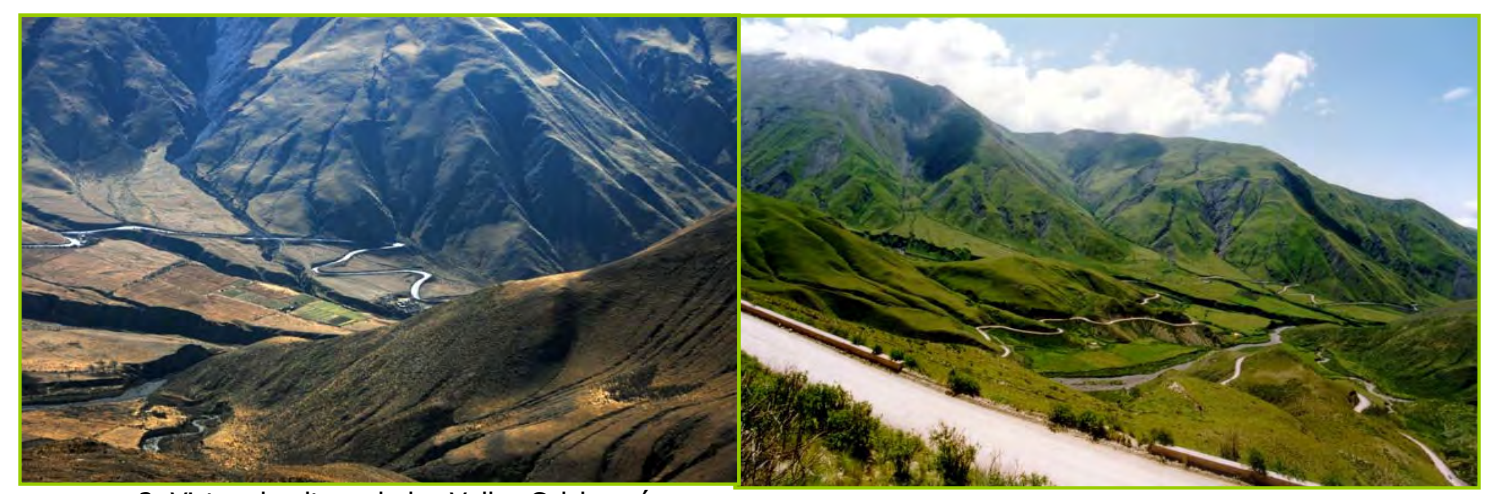

2. Vistas de altura de los Valles Calchaquíes

A lo largo de su recorrido se encuentran importantes cerros y numerosas quebradas con sus ríos, los que en conjunto definen un complejo sistema ambiental. Desde una caracterización geológica, está atravesado por la Coordillera Oriental. Los picos más importantes son más de 20 y alcanzan desde los 3.000 a los $6.000 \mathrm{msnm}$. Entre ellos se destaca el cordón conocido como Nevado de Cachi de 6.000 msnm, Palermo de 6.120 msnm y otros como la Cumbre del Gral. San Martín de 6.380 msnm.

La región de los Valles Calchaquíes, conocida como de las Sierras Subandinas o Valles Centrales, muestra un gradiente altitudinal que va desde los 800 msnm hasta los $2.000 \mathrm{msnm}$, de altitud. La región linda al Oeste con la Puna y hacia el Este con el Valle de Lerma.

A lo largo de 300 kilómetros se desplaza el Río Calchaquí, siendo el principal curso de agua de los Valles. "Este río tiene sus nacientes en el Departamento La

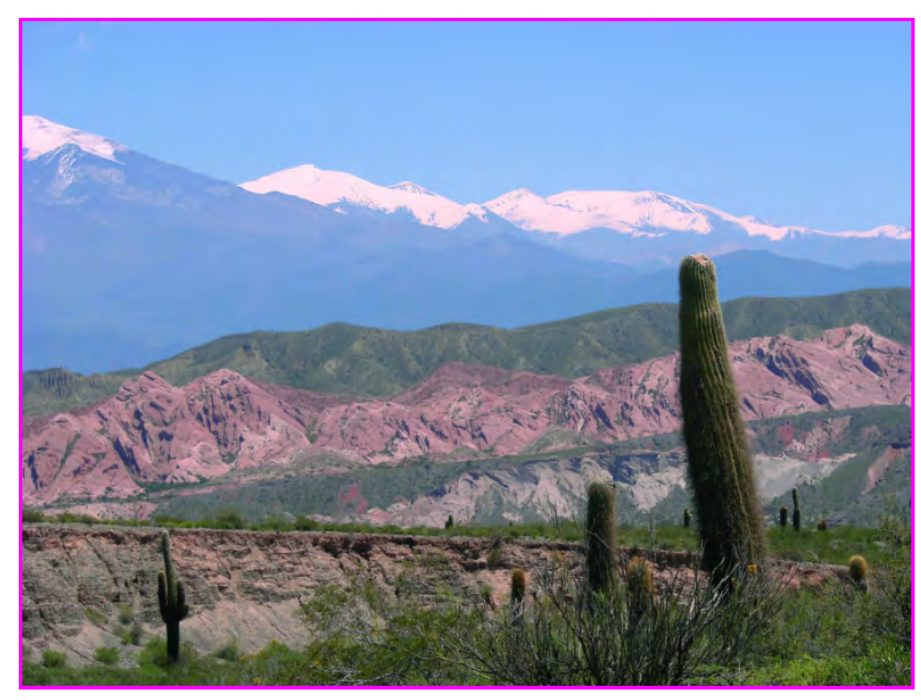


Poma, como consecuencia del deshielo y aguas subterráneas provenientes del Nevado de Acay (5.716 m), Cerro Saladillo (5.378 m), Cerro Peñas Blancas (5.200 m), y Cerro San Miguel $(5.705 \mathrm{~m})$, entre otros. Su curso posee una orientación Norte-Sur y su ancho y profundidad aumenta también en esta misma dirección." (Vitry, 2008:48)

Los ríos poco caudalosos y estacionales que se desplazan por las quebradas se convierten en tributarios del Calchaquí, creando entre todos una red hídrica de especial interés en las poblaciones de la zona. Aquellos afluentes que se originan en el sistema orográfico del lado Oeste, como el Cerro Luracatao (5655 m), Cerro Incahuasi (4847), Cerro Blanco (4680 m), Sierra de Vázquez (5401 m), Nevado de Compuel (4625 m), dan lugar, respectivamente a la Quebrada de Huasayaca, la Quebrada de Condor Huasi, los cursos de agua de esas quebradas son afluentes del río Luracatao; por la Quebrada de Colomé, corre un afluente del Río Humanao, y por las Quebradas de Palan y Quebrada de Sajahuayco, sendos afluentes del Río Mayuco. Sobre el lado Este del Río Calchaquí desaguan directamente los ríos de la Quebrada Los Arce, Quebrada Monte Nieva, Quebrada Algarrobal, Quebrada el Barreal, Quebrada Caseros y Quebrada Piscuyacu (Anexo 1.2- Carta Topográfica Hoja 2566-III- IGM-Argentina).

\section{Recursos naturales y medio ambiente}

Las características geográficas de Salta se corresponden directamente con una gran variedad de climas, suelos y cultivos. La influencia dominante está dada por su ubicación próxima al Trópico de Capricornio y a la Cordillera de los Andes, generando masas de aire con diferentes características, y precipitaciones que provocan la denominada Baja Térmica del Noroeste Argentino. El clima continental explica la alta variación de las temperaturas entre verano e invierno.

Las temperaturas promedio anuales de la región varían entre un máximo de 20 y 25 grados centígrados, y 0 a 5 grados de mínima. En el caso de los Valles Calchaquíes, se suma otro factor, las diferencias de altura sobre el nivel del mar, lo que explica un descenso de temperatura de 1 grado centígrado cada 180 metros en ascenso. De norte a sur del Valle, la diferencia altitudinal es muy marcada, y junto con la condición montañosa 
y la exposición a los vientos convierte a los poblados en ámbitos con microclimas especiales (Vitry, 2008:49).

Las precipitaciones anuales en el NOA van desde $1.200 \mathrm{~mm}$ hasta los $500 \mathrm{~mm}$. En los Valles Calchaquíes no superan los 400 milímetros, y con estacionalidad bien marcada, registrándose durante los meses de verano: diciembre a marzo. Esto afecta directamente a los ríos, en particular al Calchaquí que decrece en invierno y aumenta mil veces su caudal en el periodo estival.

La vegetación autóctona incluye representantes de dos provincias fitogeográficas pertenecientes al Dominio Chaqueño: Provincia de Monte y Prepuna (Cabrera, 1971). Coexisten en forma predominante una combinación de especies de origen andino y chaqueño, estos últimos disminuyen en número en relación con la altitud. Los árboles más difundidos son algarrobo blanco (Prosopis alba), algarrobo negro (Prosopis nigra), algarrobo (Prosopis torcuata), molle (Schinus molle), orco molle (Myrcianthos mato), sauce criollo (Salix humboldtiana), tusca (Acacia caben) chañar (Geoffroea decorticans), churqui (Acacia aroma), brea (Cercidium praecox), mistol (Zizyphus misto), pichanilla (Cassia aphyla), poleo (Lippia turbinata), tala negra, entre otros.

3. Vista de ladera del cerro con vegetación local y cultivos

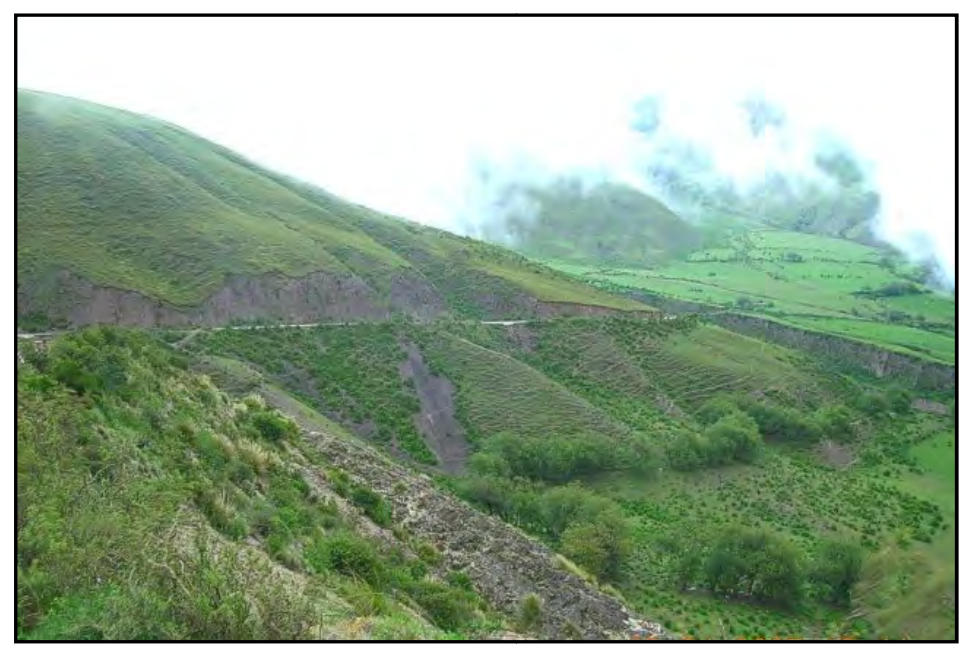

En las laderas rocosas crecen gramíneas duras y diferentes clases de cactáceas como del género trichocereus, sobre todo el cardón (Trichocereus pasacana), variedades de arbustos como la rodajilla (Plectocarpa rougesii), roseta (Plectocarpa tetracantha), retama (Spartium junceum), jarilla (Larrea cuneifolia y Larrea divaricata), cachiyuyo (Atriplex ondulatum). En las orillas de los ríos se pueden identificar jarilla, jume y simbol. 
Entre la fauna autóctona podemos mencionar: los camélidos o auquénidos americanos como la llama (Lama glama), vicuña (Vicugna-vicugna), guanaco (Lama g. Guanicoe), en los cerros de cierta altura vive la taruca o huemul del norte (Hipocamelus antisensis). Entre los carnívoros: zorro, zorrino castaño, gato montés y puma; roedores como la chinchilla o vizcacha de la sierra, cuis o coy, ardilla y comadreja. Entre los desdentados figuran quirquinchos y armadillos. Las aves más conocidas son el ñandú, perdiz, cóndor, en los remansos de agua las garzas, variedad de patos y gansos (Teseira y Sola, 2001).

\subsection{2- Los Valles Calchaquíes Salteños y las poblaciones indígenas ${ }^{1}$}

\section{Culturas Prehispánicas o los "Indios de Calchaquí"}

El poblamiento de los Valles Calchaquíes puede situarse aproximadamente 10.000 años antes del presente (AP) con la presencia de grupos cazadores recolectores ocupando sitios en diversos sectores de la puna salteña. Se trata de pequeños grupos, con alta movilidad, cuya subsistencia dependía del consumo de camélidos silvestres - guanacos y vicuñas- y de la recolección de plantas. (Caggiano y Sempé, 1994) Esta información que proviene de los estudios arqueológicos en la zona permite reconstruir la historia de permanencia de grupos americanos cuyas actividades, según las evidencias arqueológicas, traza nexos con las poblaciones presentes en el valle (Raffino, 1988 Atlas Arqueológico del NOA) Hacia el 3.500 AP aparecen poblaciones con economías agro-pastoriles, complementarias a la caza y la recolección, productoras de cerámica y que habitaban casas circulares con paredes de piedra. Estas poblaciones ocupaban las zonas altas de la puna y quebradas, así como en las cabeceras del río Calchaquí y en el Valle de Santa María. (Caggiano y Sempé, 1994, Raffino, 1988)

Alrededor del 1.800 AP, sitios arqueológicos en zona de La Poma y Cachi Adentro muestran vestigios de asentamientos sobre zonas irrigadas por el río Calchaquí, asociados

\footnotetext{
${ }^{1}$ En adelante adoptaremos la concepción implicita en el témino Indígenas para designar a los pueblos mencionados en las literatura etnohistórica, arqueológica y etnográfica (Convenio 169 Sobre Pueblos Indígenas y Tribales en Países Independientes-OIT 2005. Art. 1)
} 
a cementerios con ajuares, donde la cerámica es notable por su tecnología e iconografia. Los avances arquitectónicos, en metalurgia, cerámica y textiles hacen pensar en la complejidad de la organización social de estos grupos. Sitios como Santa Rosa de Tastil y La Paya muestran el aumento en el tamaño y distribución poblacional, con aldeas pequeñas alrededor de asentamientos comparativamernte más grandes.

Cerca del 1.000 AP los asentamientos se construyen en lugares que están a mayor altura y con muros que los rodean, lo cual induce a pensar en la necesidad de protección frente a situaciones de conflicto. Por otra parte, se observa claramente la utilización complementaria de los diversos ambientes para desarrollar sistemas de cultivos en andenes conjuntamente con obras de manejo del agua para riego. Ejemplos de estos enclaves se observan en los valles paralelos del Toro, Calchaquí y Lerma, siendo el sitio de Tolombón la referencia más destacada en Valles Calchaquíes (Caggiano y Sempé, 1994; Raffino, 1988, Baldini y Villamayor, 2007).

Respecto de las actividades económicas y el aprovechamiento de recursos de diferentes ambientes, un aspecto de particular interés para esta investigación son las numerosas referencias a las caravanas de llamas que aparecen en los reportes sobre arte rupestre de la zona. Estos reportes dan cuenta de pinturas en cuevas y aleros que coinciden con lugares estratégicos para la circulación y transacciones de telas, collares, caracoles, metales y cerámica, entre los valles y la puna. Las redes de intercambio de bienes cubrían distancias que conectaban mediante rutas de circulación, sitios que van desde Catamarca a La Quebrada de Humahuaca y la Puna de Jujuy, pasando por el desierto de Atacama hacia los Valles y Altiplano Boliviano. Del mismo modo, los análisis sobre las culturas del Horizonte Medio en Andes Centrales, coinciden en señalar que durante la misma época es posible probar la existencia de una red vial para la circulación de las caravanas de llamas que partía de Tiahuanacu y cuya influencia llegaba hasta el Valle Calchaquí. La circulación de bienes articulaba tres niveles de trabajo: el doméstico, el local o regional y el translocal (Nielsen, 1997; Lumbreras, 1999; Martel, 2002; Podestá, Rolandi y Sánchez, 2005; Muscio, 2006). 


\section{Los Incas: caminos y lenguas}

Hasta el momento ha sido de interés la perspectiva -fundada en datos arqueológicos y etnohistóricos- que prefiguran la dinámica de los Valles Calchaquíes como una unidad geográfica y cultural posible de ser analizada dentro de un contexto territorial más amplio. En este sentido abordaremos la presencia de los Incas y su cultura en relación al sector de los valles y quebradas que bordean la puna y el altiplano boliviano, considerándolos como una frontera cultural y política con mecanismos propios que pueden ser discutidos desde una visión global. Los Valles Calchaquíes formaron parte de la provincia meridional del imperio incaico o Tawantinsuyo durante un siglo, 1.440 y 1.532 d.C.

Además de los aspectos ecológicos, económicos y sociales, nos interesa presentar el panorama demográfico para esta época por su importancia en relación con uno de los temas centrales en el desarrollo de la antropología del NOA. Se trata del análisis de las poblaciones locales y la dinámica de contacto, tomado a partir de la relación entre las familias lingüísticas y las actividades de valor para la subsistencia de los pueblos del área (Ottonello y Lorandi, 1987; Guzmán et al, 1998).

Con la ocupación Inca a partir de 1.471, la lengua Quechua se extendió rápidamente por el actual territorio argentino a través de los mitimaes, especie de colonos de origen cuzqueños que eran enviados a diversas regiones del Imperio. Su función era controlar a los pobladores de las regiones ocupadas particularmente en las actividades de agricultura, pastoreo y artesanías. Por otra parte, los mitimaes sustituían a jefes de los grupos autóctonos desestructurando los sistemas de liderazgos locales. También obligaban a los grupos étnicos a desplazarse y mezclarse con otros grupos. El quechua oficiaba de lengua para estas situaciones. Del mismo modo, la lengua quechua se tornó con el tiempo en una variedad de dialectos, ya que tomó diferentes matices a lo largo del extenso territorio inca y como consecuencia de la coexitencia con las lenguas que hablaban previamente en la zona. El quechua, como lengua común junto con el conocido "camino del Inca", una red de más de $40.000 \mathrm{kms}$ de rutas que atravesaban el Imperio, garantizaron la comunicación de las poblaciones para el tributo de mercancías (Raffino, 1983; Censabella, 2000).

Durante el siglo XVI en el momento de la llegada de los españoles a los Valles Calchaquíes, se encontraban los diaguitas o diaguitas-calchaquíes, nombre genérico que 
englobaba a un grupo de parcialidades: los pulares, cafayates, famatina, aconquija, tolombones, quilmes y hualfines. La lengua que hablaban era el Kakán, la que perduró hasta el siglo XVII, para luego desaparecer. Aunque algunos estudios reconocen un sustrato Kakán en las poblaciones actuales, que se expresa en la entonación, la acentuación de la primera sílaba de un grupo de vocablos, así como, en la persistencia de voces, algunas de las cuales han permanecido como topónimos en la zona, por ejemplo: Antofagasta, Humanao, Luracatao, entre muchos otros (Nardi, 1979).

Se supone que estos pueblos mantuvieron contacto con muchos grupos andinos y que por este motivo conocían además, la lengua quechua y aymara. Un dato notable es el de la cantidad de sitios arqueológicos relevados en este periodo, los cuales son sustancialmente menores a los identificados y relacionados al periodo histórico anterior. Probablemente el carácter de los grupos calchaquíes no facilitó las relaciones con el imperio Inca. Esto parece ser sólo el comienzo de posteriores alzamientos y resistencias domumentados en la zona del Valle Chalchaquí.

Con la llegada de los españoles, se vuelve a imponer la misma estrategia de conquista y dominación de las poblaciones y territorios que ya habían utilizado los incas: la lengua y los caminos. La lengua quechua sirvió para transmitir la doctrina católica y los caminos facilitaron los desplazamientos de conquistadores y recursos desde el Perú hacia el sur. Actualmente, la designación de Kollas incluye a los descendientes de los grupos anteriomente mencionados, los que se ubican en la zona de Puna y Quebradas de Salta y Jujuy. La población hablante del quechua varia según las fuentes, que estiman entre 98.000 y 180.000 personas (Fabre, 1998 en Censabella 2000; Sichra, 2009). A continuación mostramos un cuadro con información obtenida de la Encuesta Complementaria de Pueblos Indígenas del 2005 (INDEC/ECPI 2005: 2-3) de la que hemos seleccionado los datos sobre los pueblos andinos del NOA y algunos de los ítems asociados al uso de sus propias lenguas. 
El Estudio Etnográfico de la Actividad Textil como aporte a la Caracterización del Modo de Vida en el Pueblo de Molinos y zona de influencia (Provincia de Salta)

\begin{tabular}{|c|c|c|c|c|}
\hline \multicolumn{5}{|c|}{ PUEBLOS INDIGENAS EN ARGENTINA: COMUNIDADES Y LENGUAS } \\
\hline Pueblo Indígena & Región muestraR & $\begin{array}{l}\text { Población que se } \\
\text { reconoce perteneciente } \\
\text { y/o descendiente en } \\
\text { primera generación de } \\
\text { pueblos indígenas }{ }^{3}\end{array}$ & $\begin{array}{l}\text { Población de } 5 \text { años } \\
\text { o más }\end{array}$ & $\begin{array}{l}\text { Población que habla } \\
\text { y/o entiende } \\
\text { lengua/s indígena/s }\end{array}$ \\
\hline \multirow{2}{*}{ Atacama } & Total del país & 3.044 & 2.627 & $(. .)^{4}$ \\
\hline & Jujuy & 2.805 & 2.412 & (..) \\
\hline \multirow{4}{*}{$\begin{array}{l}\text { Diaguita/ Diaguita } \\
\text { Calchaquí }\end{array}$} & Total del país & 31.753 & 28.821 & 5,8 \\
\hline & $\begin{array}{l}\text { Jujuy, Salta y } \\
\text { Tucumán }\end{array}$ & 14.810 & 13.284 & 4,4 \\
\hline & $\begin{array}{l}\text { Catamarca, } \\
\text { Córdoba, La Rioja, } \\
\text { Santa Fe y } \\
\text { Santiago del Estero }\end{array}$ & 6.138 & 5.473 & 5,4 \\
\hline & $\begin{array}{l}\text { Ciudad de Buenos } \\
\text { Aires y } 24 \text { Partidos } \\
\text { del Gran Buenos } \\
\text { Aires }\end{array}$ & 6.217 & 5.885 & 9,7 \\
\hline \multirow{3}{*}{ Kolla } & Total del país & 70.505 & 62.782 & 14,3 \\
\hline & Jujuy y Salta & 53.106 & 46.866 & 10,1 \\
\hline & $\begin{array}{l}\text { Ciudad de Buenos } \\
\text { Aires y } 24 \text { Partidos } \\
\text { del Gran Buenos } \\
\text { Aires }\end{array}$ & 10.829 & 9.772 & 29,9 \\
\hline \multirow{2}{*}{ Maimará } & Total del país & $\ldots^{5}$ & $\ldots$ & $\ldots$ \\
\hline & Jujuy & 178 & 158 & (..) \\
\hline \multirow{2}{*}{ Omaguaca } & Total del país & 1.553 & 1.478 & (..) \\
\hline & Jujuy & 1.374 & 1.302 & (..) \\
\hline \multirow{6}{*}{ Quechua } & Total del país & $\ldots$ & 6.073 & 29,7 \\
\hline & Jujuy y Salta & 561 & 497 & 68,8 \\
\hline & Resto del país & $\ldots$ & & \\
\hline & La Pampa & 4.573 & & \\
\hline & $\begin{array}{l}\text { Ciudad de Buenos } \\
\text { Aires y } 24 \text { Partidos } \\
\text { del Gran Buenos } \\
\text { Aires }\end{array}$ & 1.370 & & \\
\hline & Resto del País & 4.206 & & \\
\hline
\end{tabular}

4. Fuente: INDEC. Encuesta Complementaria de Pueblos Indígenas (ECPI) 2004-2005. Complementaria del Censo Nacional de Población, Hogares y Viviendas 2001.

2 (1) Región muestral integrada por la o las provincias consignadas

3 (2) Alrededor del $1 \%$ de estas personas tiene ascendencia indígena mixta (sus progenitores pertenecen a distintos pueblos) y no se reconocen pertenecientes a ningún pueblo específicamente. En consecuencia, en esta medición, están formando parte de uno y otro pueblo indígena.

4 (..) Dato estimado a partir de una muestra con CV superior al $25 \%$.

5 ... Dato no disponible a la fecha de presentación de los resultados. 


\section{"Diaguitas de guerra": la visión colonial española}

La conquista española en el NOA se inició en el siglo XVI y generó cambios profundos en las poblaciones locales y en los pueblos ya ocupados y dominados por los incas. Los conquistadores hispanos exigieron el control de la mano de obra de los grupos indígenas y de la extracción de los recursos de las diversas regiones del NOA. Muchos de estos pueblos se enfrentaron oponiendo una larga resistencia que en la mayoría de los casos produjo nuevos movimientos y relocalizaciones de las poblaciones. Mientras tanto, el plan de conquista del NOA incluía la fundación de pueblos y ciudades, la introducción de ganado y cultivos europeos. La apropiación y distribución de grandes extensiones de territorio y de los pueblos originarios que lo habitaban, conformaron las haciendas españolas cuya explotación involucró mano de obra indígena. La configuración de la economía y la distribución de las tierras coloniales ha permanecido casi en las mismas condiciones desde aquel momento.

La Gobernación del Tucumán Juries y Diaguitas se crea en 1563 como parte de una estrategia diseñada entre la Audiencia de Charcas (Virreynato del Perú) y Buenos Aires, con el fin de habilitar un acceso al mar desde Charcas. Los mercados y las rutas comerciales estimularon fuertemente este proyecto. El Tucumán Colonial incluía los territorios de las actuales provincias de Jujuy, Salta, Catamarca, Tucumán y Santiago del Estero, pero sus ciudades capitales ya habían sido fundadas como es el caso de Santiago del Estero en 1553, Salta en 1582 y San Salvador de Jujuy en 1593.

El reparto y posesión de las tierras siguió el procedimiento de las donaciones a los conquistadores en nombre del rey de España, bajo la forma de haciendas. La encomienda fue la institución de carácter jurídico y fundamentalmente económico que la colonización española instauró en América y que consistió en la asignación oficial de territorios y poblaciones indígenas o nativas a un grupo de familias españolas mediante gracia 0 merced real. La organización social y económica de las encomiendas se convierte en un instrumento de desestructuración de los grupos indígenas y sus unidades domésticas (Lorandi, 2002; Anello, 2002; Navarro, 2002). Es más, establece pautas que en alguna 
medida, aún hoy, se mantienen y estructuran los modos de relación entre los que poseen la tierra y los que trabajan la tierra (Mata, 2006).

Las ordenanzas sobre el trabajo en las encomiendas reglamentaban que el servicio personal era el mecanismo de servidumbre de los indígenas sin retribución o paga por el encomendero, situación que puede generalizarse para el caso del regimen del Tucumán colonial. En el caso de los grupos ubicados en los valles calchaquíes la incorporación al sistema de encomiendas fue en el siglo XVII, después de terminadas las rebeliones y resistencia de los calchaquíes (Boixados, 2002).

En 1612 se abolió la servidumbre y el servicio personal y se estableció un regimen que imponía una tasa por cabeza que obligó a las comunidades indígenas a pagar en especies, tejidos o hilados, trabajo o dinero. Los pueblos de indios o reducciones fueron los emplazamientos donde se agruparon a las poblaciones dispersas o ayllus indígenas. Este reordenamiento espacial era controlado por un administrador o mayordomo de la encomienda, su función era supervisar el trabajo de cultivo de las tierras comunales, que cumplieran con la mita y que las mujeres hilaran (Boixados, 2002).

Las formas de tributación a los encomenderos fueron de tres tipos, tributo en hilados; tributo en trabajo colectivo en las chacras o sementeras de comunidad, y tributo en servicio personal. Este último fue redefinido, incluyendo consentimiento de trabajo, límites de duración del servicio y remuneración. En muchos casos esto no se cumplió (Boixados, 2002; Farberman, 2002).

La resistencia y el gran alzamiento de los Diaguitas en los Valles Calchaquíes entre 1630 y 1643 constituyó uno de los hechos más trascendentes y de mayor impacto para la administración de las encomiendas en el Tucumán colonial. Este conflicto convirtió en un campo de batalla a toda la Gobernación y puso en peligro los réditos obtenidos de los pueblos indígenas. Hacia finales del siglo XVII, los grupos del valle fueron arrasados y la población sobreviviente fue desnaturalizada, es decir, reubicada en reducciones o pueblos españoles. La conquista del NOA estaba terminada (de Hoyos, 1999).

Hacia finales del siglo XVI, la composición de la población del noroeste argentino toma una configuración social muy especial, ya que se conforma como producto del mestizaje 
entre grupos de yanaconas ${ }^{6}$, indígenas autóctonos, españoles y criollos. Durante el siglo XVIII el tráfico y mercado de mulas desde Buenos Aires hacia Bolivia y Perú, se convierte en la actividad más importante de la centuria, vinculada al comercio de ganado en detrimento de la agricultura. Esto implica un aumento de la población entre 1721 y 1825. Los datos muestran que en los Valles Calchaquíes para 1885 había 31.600 habitantes, conteo realizado para los Departamentos de San Carlos, Molinos, Cachi, Cafayate, La Poma y Santa María (Latzina, 1885 en Atlas Total de la República Argentina, 2008). En cuanto a las poblaciones indígenas, para 1885 queda finalizada la conquista del Chaco, y con esto termina la presión de los grupos mocobíes localizados hacia el este de los Valles. Mientras tanto los indios encomendados y desnaturalizados permanecen en el medio rural en grupos muy reducidos y dispersos.

Las crisis del tráfico de mulas, la revolución de mayo y la independencia del Virreynato, reactiva las estructuras de producción locales a través de las manufacturas textiles, y los viñedos. La economía de subsistencia se generaliza en todo el NOA y va acompañada de una emigración masiva de la población a los centros periurbanos de las ciudades más importantes del país.

El Censo Nacional de 1960 indica que la población de los Valles era de 32.662 habitantes y diez años después, el Censo Nacional de 1970 señalaba una cantidad de 33.580 habitantes, con descensos en algunos Departamentos y aumentando sólo 900 habitantes en una década. Las fluctuaciones de la economía del NOA y de los valles en particular estuvieron relacionadas con la instalación del ferrocarril y posteriormente la extensión de la traza de vías, así como, con la introducción de máquinarias modernas para la producción de azúcar de los ingenios. Al mismo tiempo, la producción de café, tabaco y vid fue en aumento en la zona, pero no pudo competir con la expansión azucarera. La falta de infraestructura en comunicaciones y transporte adecuados condujo a que la competencia para la comercialización desfavoreciera su desarrollo en la zona.

\footnotetext{
6 Yanaconas o yanas, eran indígenas mestizos que compañaban a los españoles y hablaban español y quechua. En ocasiones y debido a la falta de misioneros, se ocupaban de catequizar lo pueblos conquistados. (Censabella, 2000: 29)
} 


\subsection{3- Economía en los Valles Calchaquíes: Desarticulaciones entre las comunidades y los recursos naturales}

En los acápites anteriores hemos realizado una reconstrucción que describe sucintamente a las poblaciones de los Valles Calchaquíes, y que resulta en una caracterización de los procesos económicos propios, en el tiempo y espacio del NOA. Estos antecedentes, pueden considerarse de especial interés al tema de esta tesis, ya que constituyen factores relevantes para el análisis del desarrollo de las actividades de subsistencia de los grupos locales, el alcance de sus interacciones extraterritoriales y las restricción y oportunidades dadas por el contexto socio-político de momentos o hitos históricos relevantes.

En la actualidad, la mayoría de los informes diagnósticos sobre la economía en el área ${ }^{7}$ coincide en que la diversidad de ambientes o zonas ecológicas se traduce en la diversidad de alternativas para la subsistencia y para las oportunidades productivas en la región (Andrada, 2002). La actividad económica se estructura sobre la base de un conjunto relativamente diversificado de actividades primarias que comprenden los cultivos industriales: tabaco, legumbres: distintas variedades de poroto seco; hortalizas y cítricos: en especial el pomelo y la naranja.

La horticultura extensiva tiene fines comerciales y se diferencia de la horticultura tradicional, en que se realiza sobre superficie de terreno a diferencia de los potreritos que habitualmente se utilizan para la subsistencia de las unidades domésticas. La tecnología es mecanizada y en sus plantaciones son incluidas especies no hortícolas. Las legumbres secas son los cultivos de la zona, se producen especialmente porotos negros y colorados, de alubia, arvejas, garbanzos y lentejas, consideradas parte importante de las economías locales. En los valles calchaquíes salteños se genera una variada producción hortícola que además de las legumbres incluye tomate, zapallo, cebolla, zanahoria y pimientos.

\footnotetext{
${ }^{7}$ Los informes consultados fueron elaborados por entidades estatales y privadas para el periodo 1997-2007, entre ellas se destacan el Ministerio de Economía y Producción de la Nación, la Secretaría de Agricultura, Ganadería Pesca y Alimentación; el Consejo Federal de Inversiones; el Instituto Nacional de Estadísticas y Censos (INDEC); la Universidad Nacional de Salta; la Secretaría de Ambiente y Desarrollo Sustentable (SAyDS); el Instituto Nacional de Tecnología Agropecuaria (INTA) y la Agencia de Cooperación Técnica Alemana (GTZ); la Comisión Económica para América Latina, Agencia de Naciones Unidas (CEPAL- ONU).
} 
Usualmente estos productos abastecieron al mercado interno, pero en la actualidad es de gran importancia el volumen de exportaciones al Mercosur y la Unión Europea.

En la zona de los Valles Calchaquíes, particularmente en los Departamentos de San Carlos y Cafayate, la vid y los vinos son parte del mismo tipo de economía dual, la economía de producción tradicional y la comercial. Tal como ha sucedido con la industria vitivinícola mendocina, las empresas salteñas desde el 2001, buscan mejorar la calidad y lograr mayor inserción en los mercados internacionales, a través del posicionamiento del típico vino torrontés.

Finalmente, la actividad turística es la gran apuesta actual, se caracteriza por presentar un importante crecimiento desde hace varias décadas y una marcada estacionalidad, con alcance nacional e internacional. La actividad se ha visto beneficiada por las políticas provinciales y nacionales que han promocionado el turismo a nivel del Mercosur y los países europeos, con inversiones estratégicas en las vías de comunicación y en infraestructura para la prestación de servicios -alojamiento, comidas y esparcimientopara los visitantes (Teseira y Sola, 2001). En la provincia de Salta esta situación es más intensa que en el resto de las provincias del NOA, porque entre sus principales atractivos se encuentra la "Vuelta de los Valles", circuito a lo largo de la ruta nacional Nro. 40, que incluye a los Valles Calchaquíes y los pueblos de las quebradas. En la zona andina, los recorridos se disponen alrededor de varios centros urbanos prehispánicos de valor arqueológico, como Molinos. Junto con el turismo de paisajes y monumentos, aparecen en los últimos 10 años, nuevas propuestas asociadas a las estadías en las antiguas "salas" o casas principles de las haciendas o fincas; comidas y vinos locales y las artesanías tradicionales andinas (Andrada, 2002).

\section{Contrastes e inadecuaciones en el acceso a los recursos naturales}

De la descripción anterior se desprende el altísimo nivel de riquezas en recursos naturales, culturales e históricos que están disponibles en la zona. Pero las poblaciones rurales tienen muy poco que ver con la producción a gran escala y con los volúmenes de dinero que circulan en los canales de comercialización en estos sectores. En la región de los Valles, la 
población local se inserta principalmente en la producción agrícola y ganadera, aportando mano de obra para el trabajo en el campo o a pequeña escala en los arriendos y parcelas propias. El turismo es otro modo de participación en la producción regional, e incluye a quienes conocen y elaboran artesanías textiles, cueros, cerámica, cestería y madera. La posibilidad de comercialización de los productos artesanales depende -en la mayoría de los casos, de las alternativas que los propios artesanos logran articular con los mercados por ellos conocidos.

Consignandos 5 Departamentos y 9 Municipios a lo largo de los Valles Calchaquíes ${ }^{8}$ observamos que los datos cuantitativos en la zona señalan una baja productividad, trabajo y consumo; pocos locales de negocios y bajos puestos de trabajo en los Municipios. La población local permanece empleada hasta edades avanzadas porque no tiene aportes, ni seguros sociales. La población tiene el $75 \%$ de las necesidades básicas insatisfechas. (Fuente: INDEC. Programa de Información Estadística y Apoyo a los Municipios (PRINEM) en base a datos del Censo Nacional Económico 1994)

Los proyectos y programas diseñados por los gobiernos provinciales, nacionales e internacionales han vislumbrado el valor político, social y económico que tiene la promoción de las poblaciones locales. Reconocen que el conocimiento y la experiencia de las poblaciones locales sobre el manejo de los recursos naturales es indispensable para el desarrollo sostenible de los recursos humanos y comunitarios. La articulación entre los procesos productivos y las economías de mercados implican reconocer y diferenciar qué rol desempeñan los actores locales. En los Valles Calchaquíes, los diagnósticos requieren de información que contemple particularmente a aquellos grupos que intervienen desde valores y contextos culturales diferentes.

Los tejedores que participan en los circuitos turísticos de ventas de sus productos, son tipificados como artesanos y sus manufacturas como artesanías. Esta caracterización básicamente económica es la que recogen los informes de instituciones que se ocupan de las políticas públicas e inversiones. Identifican la textilería a través del reconocimiento de artesanos y artesanías del tejido, información que es relevante al estudio de esta tesis ya que aporta datos acerca de la situación de una actividad basada en el conocimiento

\footnotetext{
${ }^{8}$ Incluye los departamentos de La Poma, Cachi, Molinos, San Carlos y Cafayate, las localidades del mismo nombre, además de otras como Payogasta, Seclantás, Angastaco y Animaná.
} 
tradicional de los pueblos del Valle y en los cambios que implica funcionar dentro de este y futuros contextos económicos. Al mismo tiempo, introduce el interés más general de las políticas públicas por aproximar e insertar a estos grupos en la economía formal tomando en consideración la promoción comercial de los productos y la identificación de mercados.

\section{2- Molinos: un pueblo en los Valles Calchaquíes}

Molinos es una hermosa comunidad salteña ubicada a $2020 \mathrm{msnm}$. Sus coordenadas geográficas la situan entre los $66^{\circ} 01^{\prime} 30^{\prime \prime}$ y $66^{\circ} 58^{\prime} 10^{\prime \prime}$ de longitud oeste y los $25^{\circ}$ $08^{\prime} 10^{\prime \prime}$ y $25^{\circ} 58^{\prime} 20^{\prime \prime}$ de latitud sur, en los Valles Clachaquíes. La bordean el cerro Overo y otras elevaciones de variadas alturas y colores. Está emplazada en las proximidades de los ríos Luracatao y Amaicha, ambos confluyen originando el río Molinos, un poco distante de la ubicación del asentantamiento. El municipio de Molinos junto al municipio de Seclantás conforman el Departamento de Molinos.

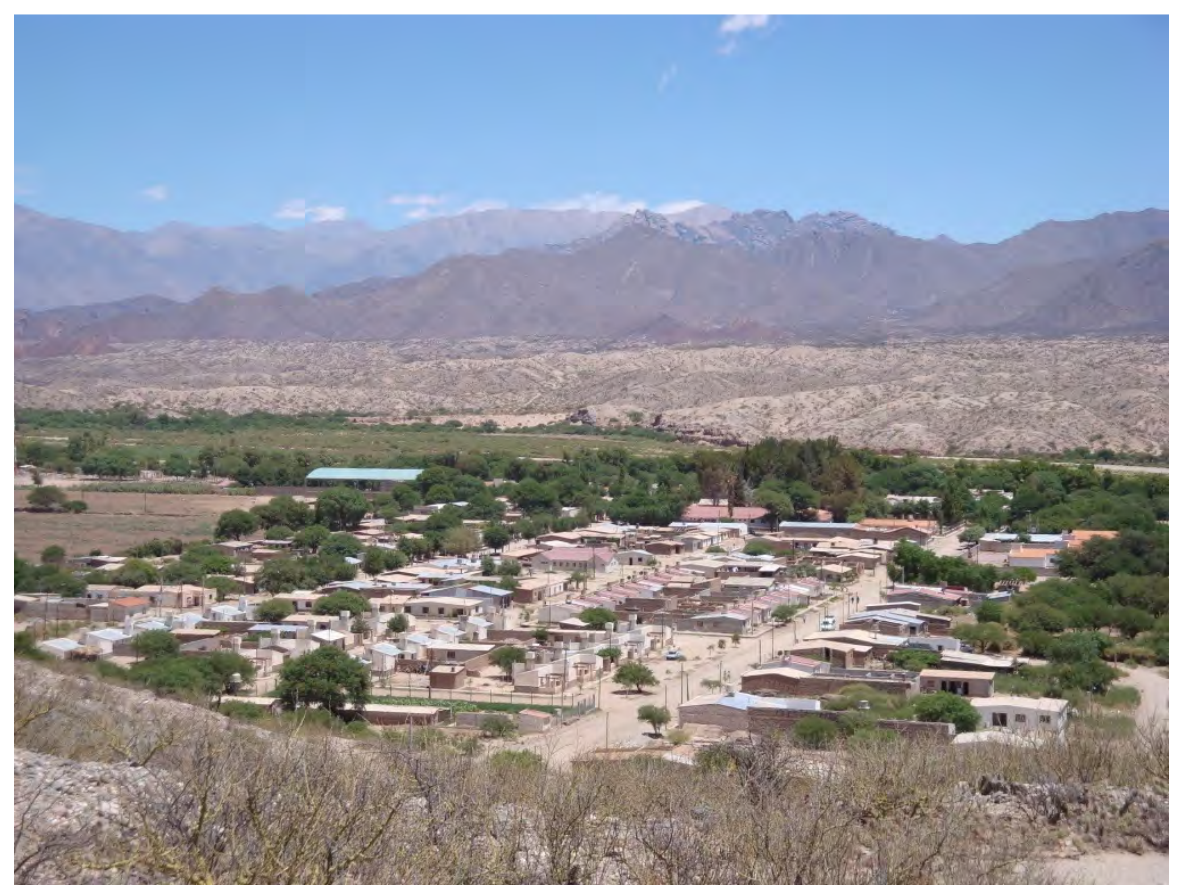

5. Vista del pueblo de Molinos, desde el Cerro Overo.

El acceso desde la ciudad capital de Salta se realiza por la conjunción de varias rutas, la nacional Nro. 68 que llega hasta El Carril donde empalma con la ruta provincial 33, la cual 
atraviesa la quebrada de Escoipe hasta la localidad de Payogasta, este tramo es sinuoso, va en ascenso y con camino de ripio. A partir de la recta de Tin Tin, en el Parque Nacional Los Cardones, la ruta es asfaltada y a la altura de Piedra de Molino a los 3.628 msnm, empalma con la ruta nacional 40 (RN40), las que bordean los cerros y llegan hasta la entrada misma de los pueblos de Cachi, Molinos, Angastaco y Cafayate. En este último pueblo se vuelve a unir con la RN40 permitiendo el regreso a la Capital a través de la Quebrada de las Conchas. Desde la provincia de Tucumán, se puede acceder en sentido sur-norte atravesando los pueblos de Tafí de Valle, Amaicha y Tolombón hasta llegar a Cafayate.

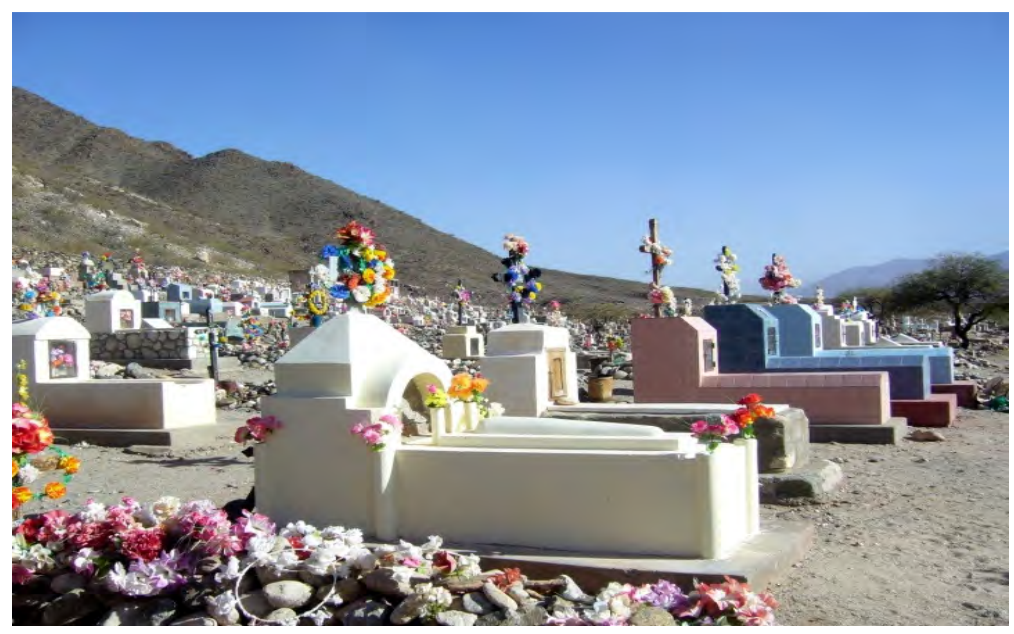

6. Cementerio "nuevo" emplazado en el Cerro Overo (Molinos). (c) Remorini

El trazado del pueblo mantiene su propio diseño ya que la construcción de las viviendas sigue un eje Norte a Sur y de Este a Oeste, en relación al río. Las casas se ordenan en lotes a lo largo de varias calles paralelas y transversales desde las cuales se avisora en perspectiva, el hermoso paisaje molinisto. Los accesos más importantes son la Avenida Rivadavia, Alberdi, 9 de Julio, Sarmiento, perpendiculares a estas, son las calles Belgrano, San Martín, Abraham Cornejo y Entre Ríos. Las calles son de ripio consolidado y las centrales están asfaltadas, las pequeñas aceras tienen líneas de árboles que las reparan y están iluminadas por faroles de hierro y luminarias públicas. 
El Estudio Etnográfico de la Actividad Textil como aporte a la Caracterización del Modo de Vida en el Pueblo de Molinos y zona de influencia (Provincia de Salta)
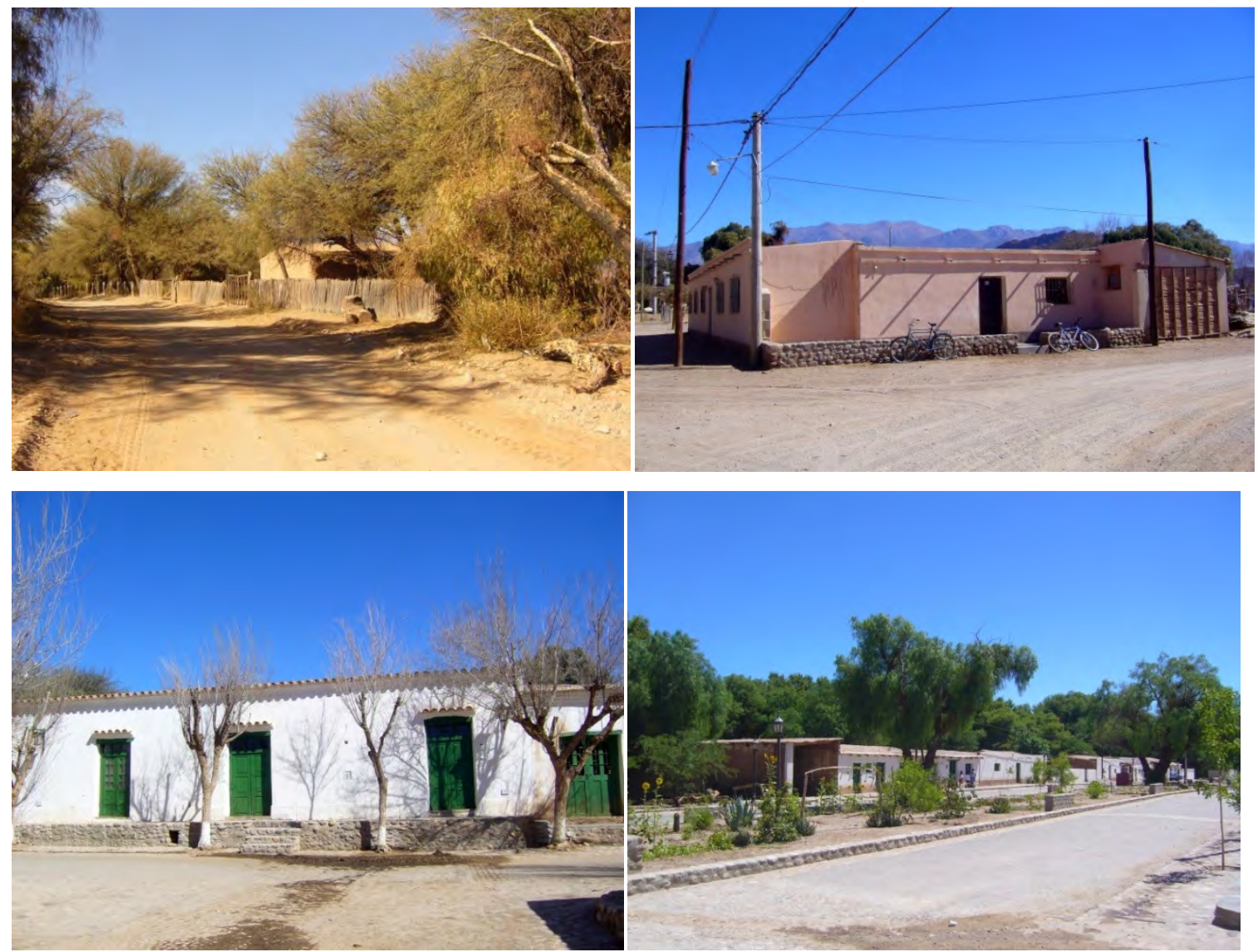

7. Tipos de viviendas y sectores del pueblo de Molinos. @Remorini

Las construcciones más antiguas son las que están próximas al río, mientras que el barrio de construcción más reciente, dista varias cuadras ubicándose en lo que anteriormente fueran campos de cultivo de la Finca "Hacienda Molinos", en sentido sur y oeste. (Anexo 1.3 y Croquis Pueblo de Molinos y Anexo 1.4 Plano del Pueblo de Molinos. Dirección General de Inmuebles, Pcia. Salta).

8. Vista de la Iglesia San Pedro Nolazco de los Molinos

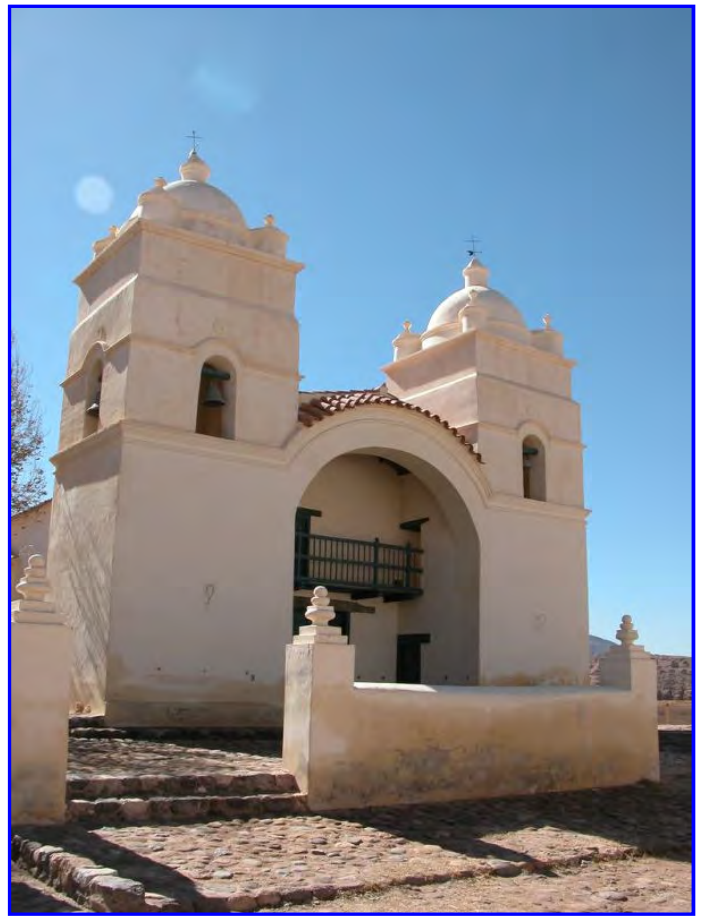


Entre los edificios más destacados por su relevancia institucional se hallan la Escuela Provincial "Indalecio Gómez Nro. 148"; la Sede del Gobierno Municipal, la casa Parroquial con su Archivo, el Hospital, el Cementerio "viejo" y el actual, el Destacamento Policial, el Complejo Deportivo Municipal, el Registro Civil y Juzgado de Paz.

La Iglesia de Molinos es el principal referente histórico y arquitectónico del lugar cuyo edificio data del siglo XVII y despliega el típico estilo colonial cuzqueño. En 1942 fue declarada Monumento Nacional. Muy próximo, a la iglesia, se haya el Hostal de Molinos, antigua casa de la Finca Isasmendi cuya antigüedad remite al siglo XVIII.

Su posterior transformación la convierte en un alojamiento especial para quienes circulan por los valles.

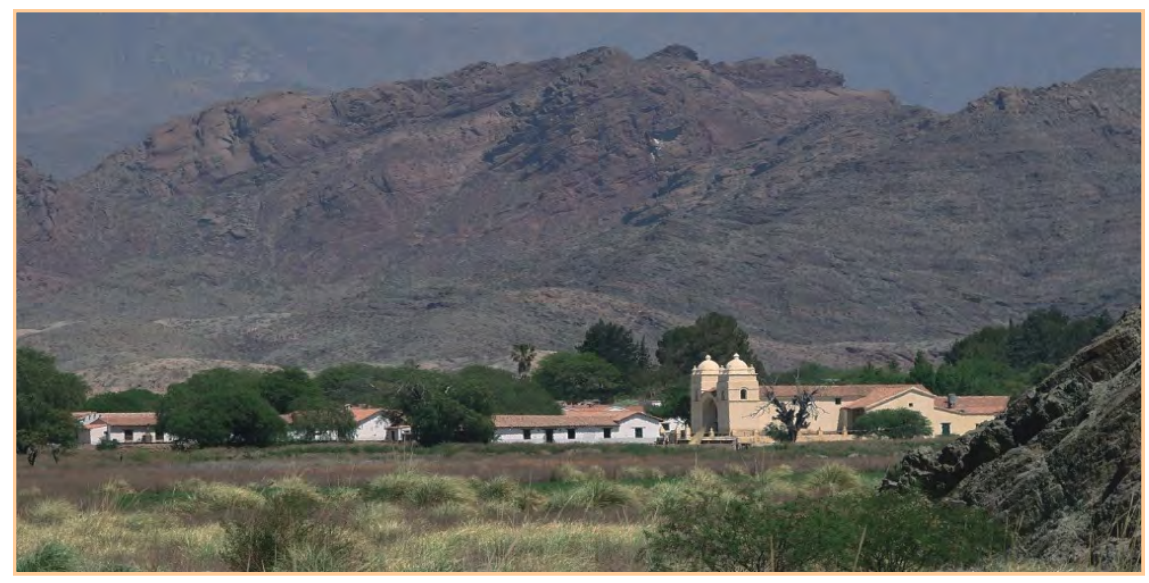

9. Vista de la Iglesia y Antigua Sala Isasmendi. CHostal Molinos

Las casas se ubicaban a lo largo de la playa del río, con excepción de un grupo de viviendas que se dispone alrededor de la plaza, la escuela, el hospital y la municipalidad. Atípicamente, la Iglesia no fue construida en las proximidades de la plaza como es habitual en estos pueblos.

En los últimas décadas el cauce del río ha cambiado el curso de desplazamiento natural, y en la actualidad corre muy próximo a las casas y en un cauce que prácticamente queda al mismo nivel en que se ubican las construcciones del pueblo. Esta situación se escucha habitualmente en las conversaciones cotidianas y expresa una gran preocupación entre los lugareños en especial por las consecuencias que se observan en las casas de familia y edificios próximos e históricos como la Iglesia de Molinos. 


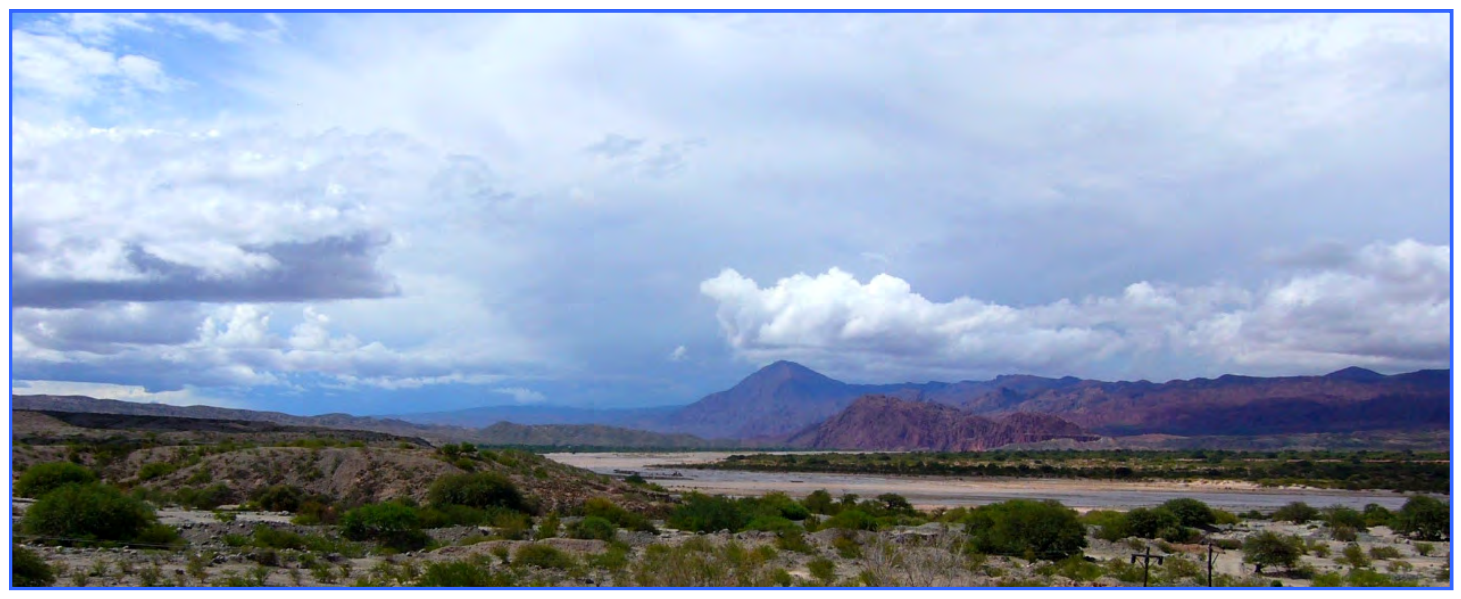

10. Vista de "la playa" del Río

Las casas más antiguas del pueblo guardan un tipo de construcción característico en la región, con gruesas paredes de adobe con y sin revestimiento, techos de caña recubiertos en tejas o tortas de barro, mamposterías de cardón y algarrobo. En algunas viviendas se destacan las galerias con arcadas y en otras las puertas de madera, de gran tamaño. No ocurre lo mismo con las ventanas, muchas viviendas, sólo las tienen muy pequeñas y por lo general con vista a amplios patios internos. Algunas mantienen a la vista los ladrillos de adobe, mientas que otras están terminadas con reboques que se pintan de un blanco intenso, los colores oscuros se utilizan para las aberturas. La mayoría está fundada sobre bases de piedra bola, las mismas que se utilizan para construir cercos y veredas, en los alrededores de las viviendas.
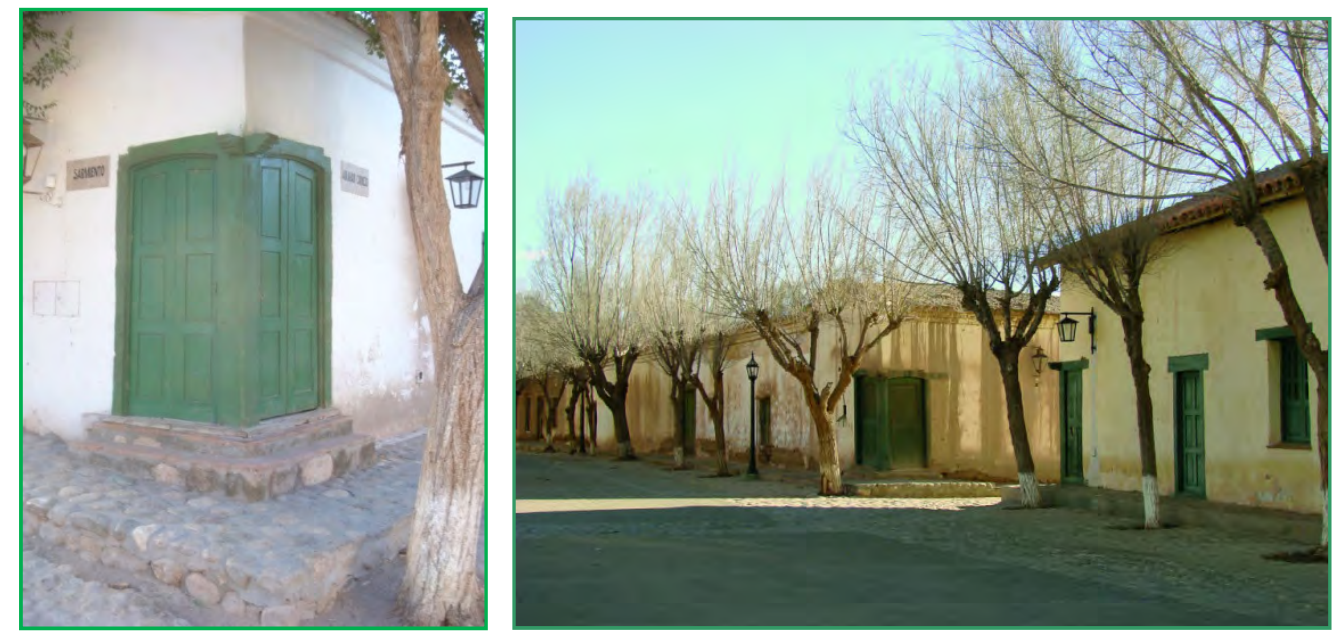

11. Detalles constructivos, ochabas y fachadas 
El Estudio Etnográfico de la Actividad Textil como aporte a la Caracterización del Modo de Vida en el Pueblo de Molinos y zona de influencia (Provincia de Salta)

Laura Teves

\subsection{1- Parajes y otros asentamientos}

Las poblaciones están asentadas a orillas de los cursos de agua o en terrazas aluviales y conos de deyección. De este modo, "los ríos y quebradas se convierten en elementos articuladores y ordenadores del espacio geográfico. A éstos se asocian los asentamientos, cultivos, animales, manto vegetal, caminos, molinos, y pequeñas generadoras hidroeléctricas, entre otros componentes fundamentales para la vida y el emplazamiento de poblaciones." (Vitry, 2008: 49)

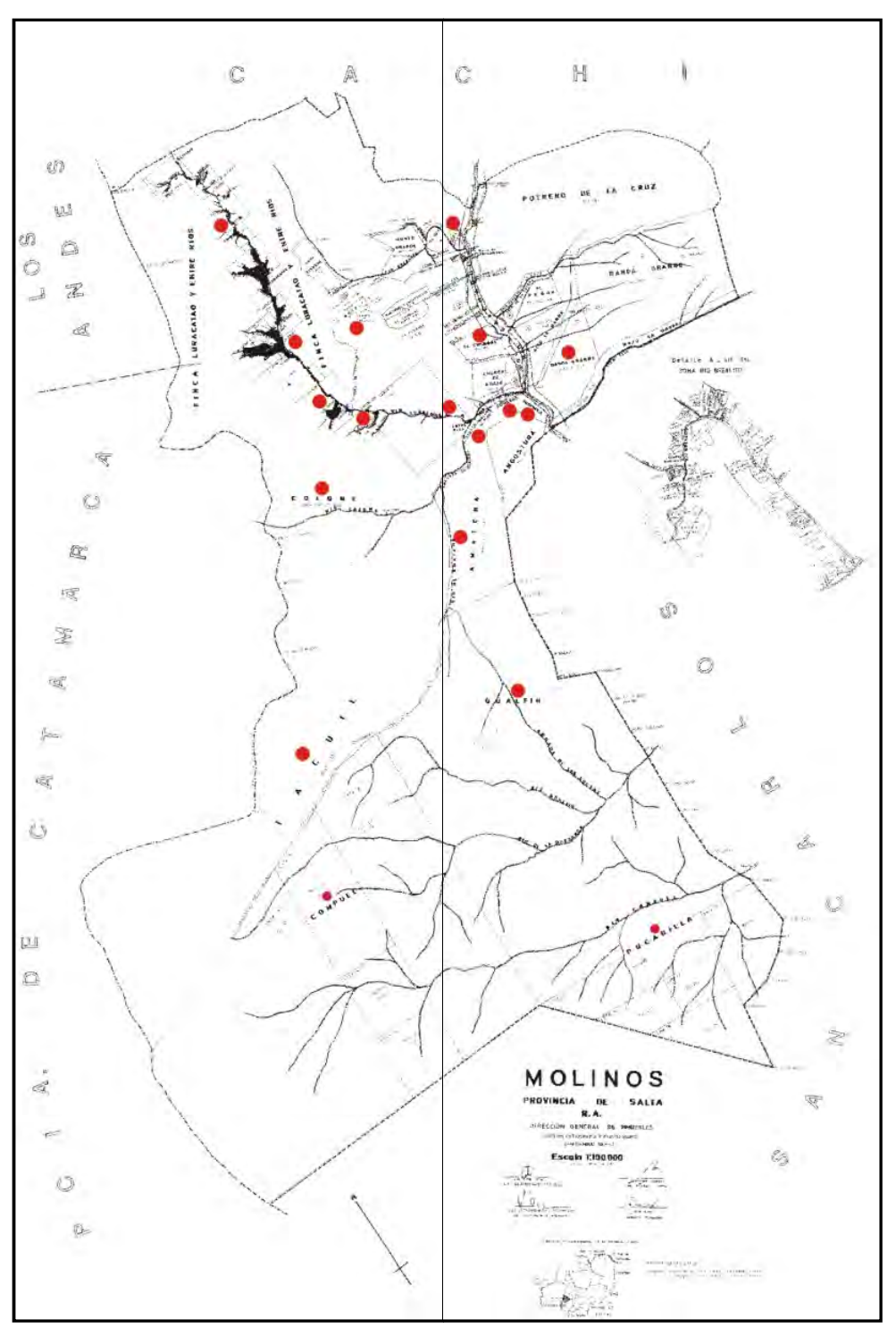

En las zonas linderas a 1 o 2 $\mathrm{km}$ del centro de Molinos se encuentran un grupo de parajes que podríamos consideran cómo la zona de contacto e influencia directa del pueblo de Molinos. Ellos son los caseríos de Tomuco, Entre Ríos, Santa Rosa, El Puente. Otra serie de parajes muy vinculados, pero a mayor distancia del pueblo se ubican próximos a las quebradas que desembocan en el Calchaqui: Humanao, Banda Grande, La Angostura, La Arcadia ( margen Este), El Churcal, La Angostura, Colomé, Amaicha y Tacuil;

12. Mapa del Departamento de Molinos. Parajes y Asentamientos 
Mayuco, Barrancas (margen Oeste) y al Norte, camino a los cerros: San Lucas, Aguadita, Cuchiyacu, El Refugio, La Puerta, Luracatao y Alumbre. Los parajes se caracterizan por ser lugares donde habitan pocas familias ubicadas en pequeños grupos de dos o tres casas y muy distanciadas de otros agrupamientos de casas. Por lo general, estas familias ocupan lotes más grandes que las del pueblo de Molinos, disponiendo de tierras de cultivo o chacras y potreros o corrales para la cría de ganado. Históricamente, en estos pequeños asentamientos han vivido familias con un fuerte vínculo social y económico con las fincas y sus dueños. Esta disposición parece representar en la actualidad lo que otrora fueran las condiciones de surgimiento del mismo Pueblo, con las primeras familias que dependían y trabajaban para la Hacienda Molinos.

\subsection{2- La población Vallista Molinista: la visión demográfica y estadística del Estado}

La población del Departamento de Molinos constaba de 5.074 habitantes para la década del '90. En el término de diez años la población aumentó en 491 personas, dando un total de 5.565 habitantes para el 2001, y en 2006 la población se calcula alcanzó los 5.865 habitantes, lo que señala un constante crecimiento de su propia población, más allá de la movilidad habitual en estos pueblos del NOA. Según el área de residencia el $23.18 \%$ de la población vive en el ámbito urbano y el $76.82 \%$ en el rural. La proporción de los habitantes por género es de 51,07\% población masculina y 48,93 población femenina. En Molinos para los '90 se calcula que existían aproximadamente 92 viviendas en la que convivía el grupo familiar con una composición promedio de 5 a 6 personas por hogar

\begin{tabular}{|c|c|c|c|c|c|}
\hline \multirow{3}{*}{ Localidad } & \multirow{3}{*}{ Departamento } & \multicolumn{4}{|c|}{ Año } \\
\hline & & \multirow[t]{2}{*}{1991} & \multicolumn{3}{|c|}{2001} \\
\hline & & & Total & Varones & Mujeres \\
\hline Total Provincia & & 866.153 & 1.079 .051 & 534.140 & 544.911 \\
\hline Molinos & Molinos & 507 & 927 & 478 & 449 \\
\hline Seclantás & Molinos & 183 & 306 & 157 & 149 \\
\hline La Puerta & Molinos & --- & 265 & 143 & 122 \\
\hline Población rural dispersa & & 135.501 & 117.480 & 63.274 & 54.206 \\
\hline
\end{tabular}

13. Fuente: INDEC. Censo Nacional de Población y Vivienda 1991 y Censo Nacional de Población, Hogares y Viviendas 2001. 
El promedio de edad de la población de Molinos es de 24 años para los hombres y 26 años, las mujeres. Se observa que la mayor disminución del porcentaje de población ocurre en el grupo etario que incluye a los jóvenes de 20 a 29 años. Estos es equivalente en la disminución de los porcentajes de la población masculina (1.117 Hab.) y la fememina (1.070 Hab.). El 99,95 de la población es nacida en la Argentina, y sólo el 0,18 pertenece a otros países, no limítrofes.

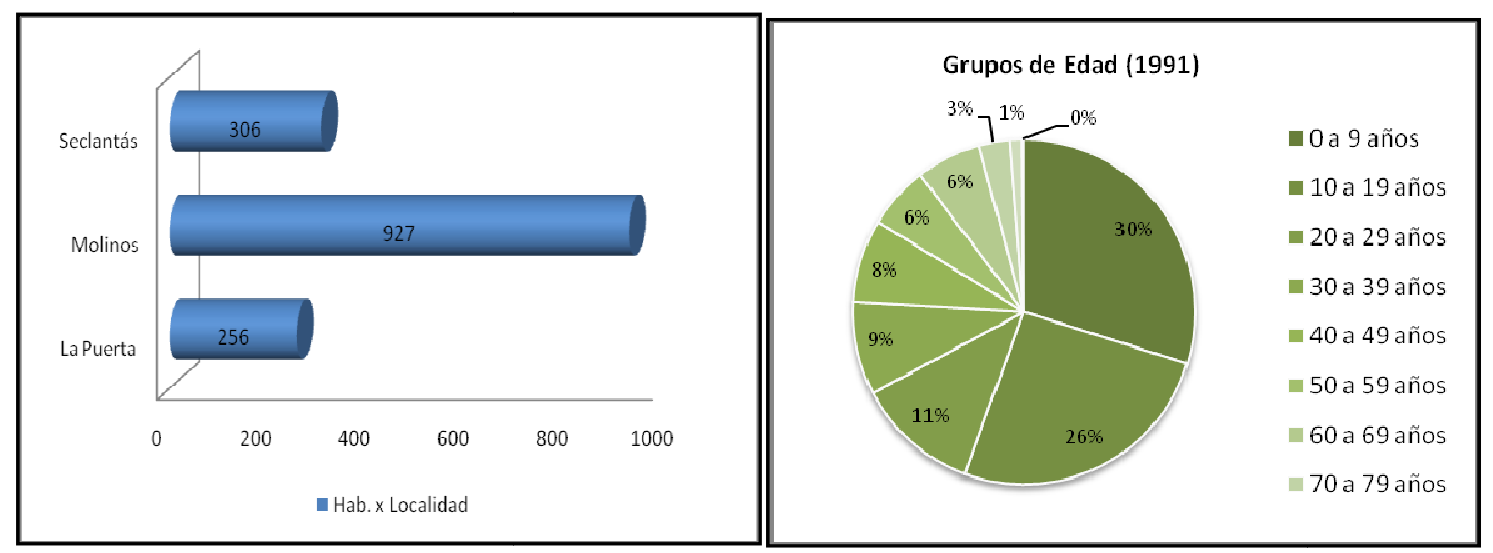

14. Fuente: INDEC. Censo 2001.

Con respecto a los cuidados de la salud, el $64,93 \%$ de los habitantes de Molinos no tiene cobertura de salud.

Según el nivel de asistencia escolar alcanzado un $18,42 \%$ de la población nunca asistió a la escuela, mientras que el 2,62\% de los habitantes tienen asistencia escolar ignorada 0 desconocida. El $51,60 \%$ de la población que asistió a la escuela tiene estudios primarios completos. 


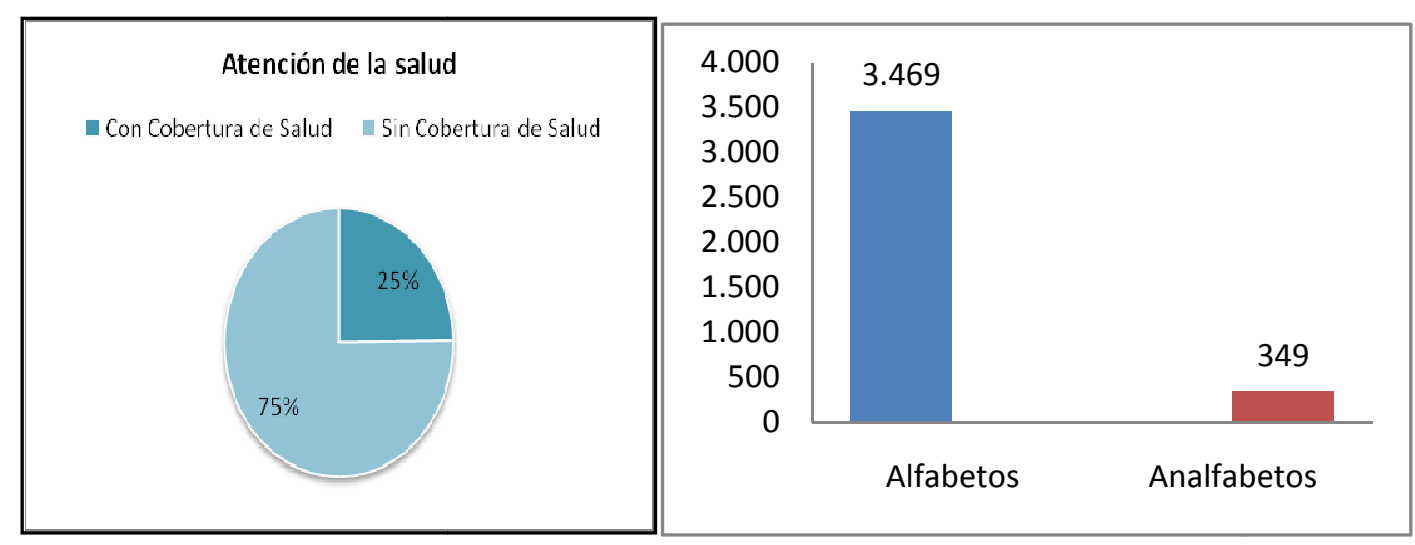

Fuente: INDEC. Censo 2001.

La población de 14 años y más años, que es activa económicamente, está representada por un total de 1.283 personas de las cuáles sólo el 70,77\% es activa. De las 897 ocupadas con trabajo, el $40 \%$ tiene categoría ocupacional de "trabajador familiar sin remuneracion fija"; el $34,45 \%$ es obrero o empleado y $26,53 \%$ es trabajador por cuenta propia o patrón. En Molinos esto está representado por 300 puestos de trabajo formalizado.

No se registran datos sobre puestos de trabajo en la industria manufacturera provincial, ni puestos o locales públicos de la industria manufacturera, no hay declarado puestos de trabajo con o sin salario. Por ejemplo, el comercio local cuenta con 7 puestos comerciales, 8 puestos de trabajo, no asalariados. Los planes de trabajo del gobierno, desde los ' 90 a la actualidad, son una alternativa complementaria de las unidades domésticas, la opción para los hombres se relaciona con ocupaciones como "cortar adobe" y limpiar acequias, ente otros.

En el Municipio de Molinos existen aproximadamente 354 viviendas, un 26\% tiene agua corriente de red y el 67,23 de otra procedencia. En las zonas rurales, según los informes realizados por el INTA y la ONG alemana CTZ, en la región "no existe infraestructura básica para la captación, el almacenamiento y la distribución de agua para consumo humano. El acceso al agua es a través de vertientes, arroyos o ríos, compartiendo con las haciendas estas fuentes de aprovisionamiento, con la gran cantidad de problemas sanitarios que esto acarrea. En las comunidades la tarea de recolección de agua es responsabilidad, en su gran mayoría, de las mujeres y los niños de las familias, para lo 
cual deben recorrer significativas distancias." (Failde de Calvo, V., Ramilo D. y Red Valles de Altura, 2004:7)

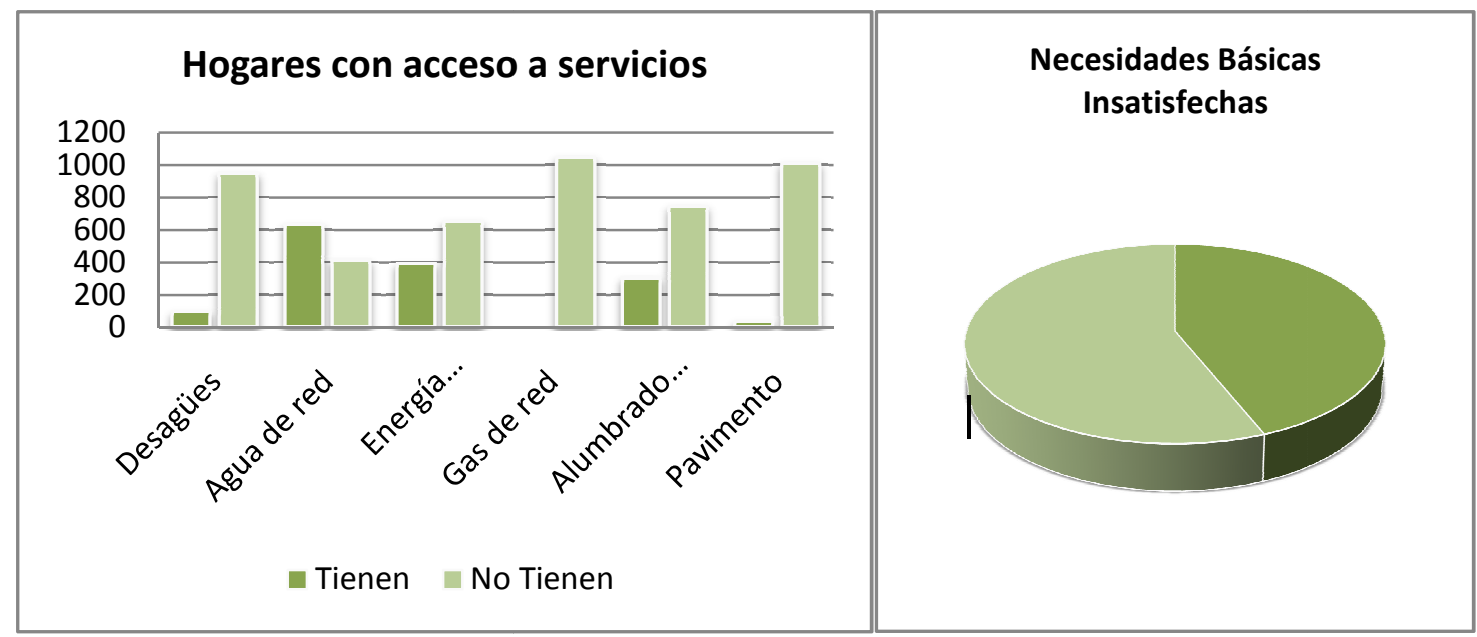

Fuente: INDEC. Censo 2001.

\subsection{3- Actividades de subsistencia y producciones locales: la visión desde las comunidades molinistas}

\section{Las fincas y la producción local}

Las fincas o haciendas constituyen las denominaciones locales que los pobladores dan a las unidades de producción económica, fundamentalmente de tipo agrícolo-ganadera y que son comunes al modo de producción en otras áreas de la región del noroeste argentino.

Estas unidades dividen toda la superficie del Departamento de Molinos, limitan entre ellas y ocupan extensas superficies que recorren grandes cantidades de territorio. En algunos casos, las fincas extienden sus límites sobre diversos ambientes ecológicos propios de la zona de valles y serranias. La propiedad de estos territorios pertenece a generaciones de una misma familia de hacendados, legado que puede rastrearse a lo largo de los siglos, desde la conquista española a la actualidad. 
El modelo de trabajo de la tierra y el usufructo de la producción tiene sus orígenes en la encomienda española, y por ende algunas de sus características y relaciones actuales son las que hemos presentado en los acápites anteriores bajo la modalidad de servicio a un patrón o dueño. En este sentido, analiza Caro Figueroa, reconocido historiador salteño: "La posesión de tierras entregadas en donación en nombre del rey de España, bajo la forma de chacras, fincas y estancias, no sólo modelará su actividad económica (en los territorios salteños) sino que tendrá gran influencia en el manejo del poder y prestigio social. Al lado de enormes latifundios, como la hacienda de Molinos, de casi 6 millones de hectáreas, propiedad de Nicolás Severo de Isasmendi, comenzaron a surgir medianas y pequeñas propiedades, (...) La progresiva valorización de las tierras dependía de un conjunto de factores. Entre ellos, el cese de la guerra con los Calchaquíes (1669)." (Caro Figueroa, 2008)

La encomienda "de Calchaquí de Indios Pulares y Tonocotés" fue otorgada a Don Domingo de Isasi Isasmendi en el siglo XVIII (1737) como herencia de su esposa, quien la legara de su padre, Diego Diez Gomez, poseedor de la misma desde 1659. La hacienda a la que va a vivir el matrimonio recibe el nombre de "San Pedro Nolasco de Molinos", y en su época constituyó una de las propiedads más extensas, comprendiendo a las "fincas de Molinos, Amaicha, Luracatao, Colomé, Tacuil, Banda Grande, Churcal, Hualfin y Compuel (en el actual Departamento de Molinos) y las de Pucará, Angostura y Jasimaná del Departamento de San Carlos". (Gálvez, 1999:4.)

Junto a la hacienda de Molinos se forma el pueblo de Molinos, a la manera feudal, en el sentido de subordinado o al servicio de la hacienda. Para este siglo se convierte en una de las fincas de mayor prosperidad económica, proveía de harinas de trigo de molinos propios, fabricaban velas y jabón, por supuesto, vinos propios y disponían de herrería, carpintería y hornos, fabricaban dulces de su cosecha de frutales como manzanos, membrillos, duraznos y ciruelos.

En 1767, Nicolás Severo de Isasmendi toma posesión de la encomienda de su padre Domingo. Lo hace "ante el Curaca Vicente Pistán, su hijo Valeriano Pistán y el indio Felipe Guantais" bajo la autoridad de Fernández Cornejo, Maestre de Campo de la Corona española. En 1794, Nicolás Severo compra a sus hermanos todas las estancias que 
poseían en los valles quedando dueño de ganados y viñedos desde la zona comprendida por el Valle de Santa María en Catamarca, al sur y lindando con la hacienda del Marquéz de Tojo en Jujuy, por el norte. En 1802, vivían en la hacienda La Angostura " 70 familias de colonos o arendatarios que cultivaban trigo y maíz. (....) Tacuil y Colomé -con sus potreros, acequias y tierras de sembradíos donde vivían 83 familias de colonos- Hualfín donde pastaban 980 cabezas de ganado vacuno, mular y caballar- Jasimamá- la más extensa, cruzaba ríos, manantiales, lagunas y ojos de agua, en cuya Puna brava se criaban vicuñas, guanacos, ...., además de 1828 vacas, 2300 ovejas y 170 yeguas y caballos- y finalmente Luracatao .... Que aún hoy se caracteriza por los excelentes trabajos de sus tejedores o teleros, vivían por entonces 33 familias de colonos con sus ganados, rastrojos para toda clase de cultivos, huertos arbolados, que tejían en sus telares (....) produciendo toda clase de telas, de las que cuenta el investario: "mil quinientas varas de tucuyo, setecientas varas de ropa azul, trescientas varas de bayetones, veintinco fresadas y veinticinco ponchos ordinarios ..." (Gálvez, 1999: 9)

A mediados del siglo XIX, la hacienda Isasmendi es comprada por Indalecio Gómez, vecino del pueblo. La posibilidad de adquirir las tierras se debe a la fortuna legada de su famila, quienes se dedicaran a los negocios de minería.

En adelante, el régimen de distribución de la tierra estará influenciado por el sistema de la hacienda de la época colonial. Después de la independencia, las grandes propiedades, cada una de varios miles de hectáreas, se fueron subdividiendo por herencia familiar. En los departamentos que componen los Valles Calchaquíes cerca de $75 \%$ de la superficie está bajo el régimen de propiedad personal y el resto bajo otras formas de tenencia: propiedad familiar o sucesión indivisa, arrendamiento, aparcería, contratos, ocupación con y sin permiso, y otros. (Instituto Nacional de Estadística y Censos (INDEC), Censo Nacional Agropecuario (CNA) 1988)

Hoy, el caso de Molinos es diferente al resto de los departamentos de los Valles Calchaquíes, "donde existen un conjunto de 18 empresas agropecuarias no familiares que tienen una superficie de aproximandamente 28.000 hectáreas cada una. En promedio, las explotaciones familiares de menos de 25 hectáreas representan $80 \%$ del número total, pero cuentan sólo con $1 \%$ de la tierra." (Popp y Gasperini, 2003: 249, 252) 
El Estudio Etnográfico de la Actividad Textil como aporte a la Caracterización del Modo de Vida en el Pueblo de Molinos y zona de influencia (Provincia de Salta)

Laura Teves

En cuanto a la producción agrícola, no hay modificaciones respecto al tipo y modalidad de cultivos de los ya descriptos desde la época de las encomiendas. En los valles de arriba, se destacan el pimento (Capsicum sp.), alternado con cultivos maíz (Zea mays L.), trigo (Triticum aestivum L.), alfalfa (Medicago sativa L.) y cebolla (Allium cepa L.), orientados a la demanda local. Los frutales son importantes y se destacan las manzanas, damasco, duraznos, higos que gerealmente se consumen como frutas secas, junto con las nueces. Entre las aromáticas, el comino (Cuminum cyminum L.) albahaca (Ocimum basilicum L.), y menta (Mentha aquatica L., Mentha x rotundifolia; Mentha spicata L.). En los valles de abajo, la luminosidad solar (heliofanía) es mayor, debido a la altura, sequedad del aire y diafanidad del cielo. Estas características, junto con las escasas lluvias, la salinidad del suelo y el agua favorecen el sabor y la maduración de los frutos como la vid, así como, el secado de pimiento para pimentón; dos productos básicos de la economía regional (Teseira y Sola, 2001; Vitry, 2008)

En cuanto a la producción textil, no puede dejar de mencionarse a la Finca Luracatao y el impulso que desde principios de siglo le dio uno de sus dueños, Robustiano Patrón Costas, alentando especialmente la fabricación de alfombras, tapices y barracanes tejidos en telar ${ }^{9}$, así como promoviendo la adaptación de hacienda de ovinos: Correidale, Merino y Karakul, especiales por la calidad de su lana (Sweeney y Domínguez Benavides, 1998).

En los últimos, 25 años existe en los valles de la región del NOA, otro tipo de emprendimientos, son los criaderos de vicuñas en semicautividad. Esta actividad se relaciona con el concepto de manejo sustentable de esta especie, que actualmente está protegida der la caza indiscriminada que sufriera en otras décadas, y del peligro de inmimente extinción. ${ }^{10}$ La esquila de vicuñas provee lana o fibra muy fina que se destina a la confección de artesanías y vestimenta ecológica de un alto valor en el mercado nacional e internacional. En el caso de la localidad de Molinos, una sesión de tierras de la Finca

\footnotetext{
${ }^{9}$ Con las décadas, esta actividad resultó en una organización de tejedores a destajo, bajo el control de un administrador de la Finca Luracatao, a la que familias enteras de la finca Luracatao proveían mano de obra para la elaboración de cantidades de tejidos con diseños provistos desde Francia, que se vendían en un negocio de artesanías en la capital salteña y en Francia. (Comunicación personal de los pobladores de Molinos e investigadores en la zona)

10 Las provincias del NOA han sido beneficiadas a mediados de la década pasada, por una disposición de la Convención Internacional de Especies Amenazadas de Flora y Fauna (CITES) que levantó la prohibición de comercializar la fibra a nivel internacional, lo que, a su vez, permitirá la obtención de créditos para el desarrollo de la actividad. (Censo Agropecuario INDEC 1993; 1999)
} 
Luracatao permitió conformar la Asociación San Pedro Nolazco de los Molinos, donde un grupo de Agricultores y Artesanos se organizan para desarrollar estas actividades.

\section{Las unidades domésticas y las actividades de subsistencia}

Las unidades domésticas en Molinos están involucradas en la actividad económica de las fincas y por otra parte, en la agricultura y cría de ganado de altura para la subsistencia del grupo familiar. Para realizar estas actividades es indispensable la proximidad a los ríos y al manejo del agua. Las acequias o canales son construcciones que permiten el encausamiento de los cursos de agua desde las zonas de deshielo. La distribución para riego se ve favorecida por las pendientes naturales del terreno en un área que alcanza cientos de kilometros cuadros. El mantenimiento o limpieza de estos canales y la distribución de los turnos de agua de riego a los diferentes sectores, depende de una intrincada organización. El Tomero es la persona que tradicionalmente se hace responsable de esta tarea en cada población.

Durante la década de 1990 algunas de las fincas familiares fueron vendidas y adquiridas por capitales extranjeros, fundamentalmente europeos. Esta situación podría hacernos pensar sobre algunos cambios en el modo de organización e incorporación de tecnologías para la producción. Sin embargo, antes como ahora los finqueros mantienen el control de recursos en los territorios de sus propiedades, incidiendo fundamentalmente en el acceso al agua de regadio y en el control de la mano de obra local involucrada en los trabajos de producción.

La modalidad de distribución y tenencia de la tierra en los Valles Calchaquíes afecta "la productividad y los ingresos de los pequeños productores. Como el mercado no es aquí uno de compraventa, sino, en lo fundamental, de cesión de los derechos de uso, ni el arrendatario (el pequeño productor) ni el arrendador (el propietario) invierten mayormente en los predios. En algunas localidades, por ejemplo, se pierde una parte considerable del agua del turno de riego, porque los arrendatarios usan sólo aquella necesaria para sus cultivos y no almacenan la restante, sencillamente porque no han construido embalses, dado que cualquier mejora en el predio alquilado quedaría en manos del propietario al término del contrato respectivo. Tampoco es rentable hacer esas 
inversiones en el caso de los medieros y aparceros, porque los contratos son de muy corto plazo." (Popp y Gasperini, 2003: 266)

La agricultura es una actividad que también se desarrolla a escala de las unidades domésticas y con la función de garantizar la subsistencia del grupo familiar, el consumo y el intercambio es la prioridad entre las familias de los sectores altos y bajos del valle.

La cría de ganado está directamente vinculada a la producción artesanal de tejidos e implica un importante incremento en los ingresos familiares, de lo cual surge un creciente interés de los tejedores por la obtención de materias primas. En este sentido se explica el por qué las familias tienen contactos permanentes en los sectores de valles y cerros. En los cerros se ubican los arriendos y los potreros de pastajes donde se practica la ganadería de cabras, ovejas y camélidos andinos, principalmente llamas. La cría se hace a escala familiar y de modo extensivo, desplazando los rebaños por extensas zonas de pastos naturales. La actividad de cría se complementa con la obtención de subproductos, tales como leche y derivados -en especial quesos y el charqui.

\section{Arriendos, Mediería, Pastajes y Abrebajes}

Históricamente, las fincas de Molinos como grandes unidades de producción agrícolaganadera emplazadas en amplios territorios de miles de hectáreas y diversos medio ambientes, pertenecían a un sólo propietario con su familia. Al mismo tiempo albergan a muchos grupos familiares que trabajan a su servicio. El servicio al patrón incluía tareas diferentes para los hombres y las mujeres. Ellas atendiendo los quehaceres domésticos en la Sala o casa principal de la hacienda, así como la cocina para los peones, el trabajo de lavado e hilado de lana, y el apoyo en las tareas de cosecha. Ellos como peones en el trabajo de la tierra y en la cría de animales. Cada familia que prestaba servicio para la finca permanecía de por vida sujeta a esta relación, inclusive adquiriendo compromisos laborales para las generaciones siguientes, la de sus hijos y nietos.

En las últimas décadas, el regimen de tenencia de la tierra ha cambiado. Los dueños de las fincas ya no residen en el lugar, sino que viven en Salta capital, quedando las tierras como su parte de su propiedad personal o como legado familiar, por sucesión indivisa a los pariente directos. En tanto, las familias de campesinos o puesteros cambiaron su 
relación de trabajo con los finqueros a través de acuerdos para el arriendo de la tierra, el usufructo compartido de la producción o el pago por el pastaje para la cría de animales. (Popp y Gasperini, 1999:30)

La creación del Parque Nacional Los Cardones, en la zona NE del Departamento de Molinos, es un caso que documenta la relación de las poblaciones locales y los finqueros. Los informes de la Administración de Parques Nacionales describen a la población que habita el territorio protegido del siguiente modo: "Antes de su creación (en 1997) estaba constituido por once predios rurales pertenecientes en su gran mayoría a la Sucesión Viñuales. Los antiguos propietarios no radicaban en el lugar y explotaban la tierra directamente, utilizándolas como sitios de pastoreo de ganado vacuno (aproximadamente 650 cabezas) tipo criollo; e indirectamente, por medio de arriendos a "pastajeros 0 yerbajeros" quienes se dedicaban a la cría de ganado menor principalmente (cabras y ovejas) y eventualmente ganado mayor (vacunos), pagando una vez al año el derecho de

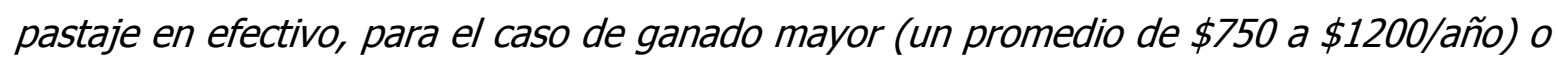
un porcentaje (generalmente el 13\%) en especie de ganado menor (Neuman, 1987). Estos "pastajeros" habitaban el área desde hace muchos años, incluso desde varias generaciones y constituyen los verdaderos pobladores del área al momento de crearse el Área Protegida y hasta la fecha". (Administración de Parques Nacionales (APN), 2007:72) A lo descripto anteriormente, se suma la adquisición de tierras por parte de los campesinos, antiguos peones, quiénes después de varios intentos pudieron adquirir las parcelas que ocupaban en los puestos de las fincas, convirtiéndose en pequeños propietarios. El caso de la Finca Luracatao ejemplifica actualmente esta situación, ya que parte de sus tierras fueron cedidas en 2004. Mediante una ley del estado provincial pequeñas parcelas de aproximandamente entre 2 y 4 hectáreas fueron otorgadas en favor de un grupo de 213 familias, quienes tomaron titularidad de la propiedad de las tierras que históricamente ocupaban en esta finca. El convenio firmado entre la provincia y los dueños de la tierra incluyó el derecho al pastaje y abrebaje a perpetuidad, así como la sesión al Estado de los caminos de acceso a la finca y otros terrenos para al construcción de escuelas y servicios para las comunidades. (LEY No 7304 Promulgada por Decreto No 1668 del 21/07/04. Sancionada el 01/07/04. Convenio Pcia. de Salta y firma Campo Rosario S.C.A. Regularización de ocupación de tierras - venta, cesión, transferencia de 
El Estudio Etnográfico de la Actividad Textil como aporte a la Caracterización del Modo de Vida en el Pueblo de Molinos y zona de influencia (Provincia de Salta)

Laura Teves

inmueble. Fincas Luracatao y Entre Ríos, Dpto. Molinos. B.O. No 16.945. Expte. No 9113.575/04 y Proyecto de Declaración S-1742/04, Senado de la Nación, República Argentina).

El estímulo individual y de las políticas públicas del Estado nacional y provincial junto con la capacidad de trabajo personal y familiar muestran que en los últimos años se han organizado "grupos de pequeños productores del valle calchaquí" que desarrollan la vitivinicultura, el cultivo de aromáticas como menta mitchan o inglesa, y lavandin (Camisa, 1990; Elechosa y Juárez, 2002) y quinua ${ }^{11}$ (Chenopodium quinua Willd). Las Comunidades Unidas de Molinos (CUM) ${ }^{12}$, en la zona del Luracatao, representan a otros grupos de organizaciones familiares que realizan proyectos para mejoramiento de las huertas, los rebaños, comercialización de las artesanías y aprovisionamiento de agua, botiquines sanitarios, y reparaciones de caminos, viviendas, y escuelas. La Feria Campesina y Muestra Ganadera de Cuchiyaco es un ejemplo de estos recientes desarrollos en Molinos.

Este nuevo escenario requiere de una puesta en valor del conocimiento de las poblaciones locales, de probadas raíces indígenas, cuya relevancia e impacto en la producción económica a micro escala es reconocida, promocionada y financiada por las políticas públicas del gobierno provincial y nacional, así como de algunas Agencias No Gubernamentales locales e internacionales. Entre los proyectos de mayor ingerencia se pueden mencionar los del Ministerio de Ciencia y Tecnología (MINCyT) ${ }^{13}$, y de la Secretaría de Agricultura, Ganadería y Pesca (SAGyP), se suman las propuestas de desarrollo como el Programa Pro-Huerta y de la Pequeña Agricultura Familiar, del Instituto Nacional de Tecnología Agropecuaria, INTA (Cáceres 2007) y el Ministerio de Desarrollo Social de la

\footnotetext{
11 Las experiencias exitosas con el cultivo de quinua coinciden con los resultados de las investigaciones arqueológicas en la cuenca del Río Molinos, realizada por Lidia Baldini y Virginia Villamayor, del Museo de la Plata (UNLP). En sus trabajos se advierte sobre la potenciadad productiva referida entre otros al cultivo de quinua por las poblaciones de la región en época prehispánica (Baldini y Villamayor, 2007).

${ }^{12}$ Las Comunidades Unidas de Molinos (CUM) tienen un Blog con información detallada y disponible en: http://lacum.blogspot.com/

${ }^{13}$ Actualmente, y reconociendo las oportunidades del mercado, los pobladores de Molinos se han interesado frente a propuestas como los proyectos de "Incorporación de tecnología para mejorar la eficiencia en la actual cadena productiva, industrialización y comercialización de especies aromáticas", pertenece a la línea de Proyectos Federales de Innovación Productiva Eslabonamientos Productivos (PFIP-ESPRO) del Consejo Federal de Ciencia y Tecnología del Ministerio de Ciencia y Tecnología (COFECyT-MINCyT, 2010).
} 
El Estudio Etnográfico de la Actividad Textil como aporte a la Caracterización del Modo de Vida en el Pueblo de Molinos y zona de influencia (Provincia de Salta)

Laura Teves

Nación. Entre las ONGs: la Agencia Alemana de Cooperación Técnica (GTZ), el Fondo de Canadá para las iniciativas locales y la Red Valles de Altura. 


\section{CAPÍTULO 2 \\ De los Textiles... Antecedentes y enfoques para un estudio antropológico de la actividad textil}

\section{Introducción}

Con el objetivo de trazar un camino analítico sobre aquellas líneas de investigación que han sido de interés para el estudio de los textiles en Molinos, expondré una serie de conceptos, hipótesis y resultados provenientes de tales estudios. En definitiva daré cuenta del estado del arte previo al inicio de esta tesis mediante una reconstrucción "orientada" de la historia del tema. Analizaré aquellos autores y trabajos que delimitaron y consolidaron la problemática de los textiles andinos en un sentido antropológico y que abrieron camino hacia mi propia investigación.

Propongo que los antecedentes sobre la temática de la textilería sean agrupados desde dos perspectivas. Primero, aquellas que se centran fundamentalmente en los textiles como objetos de la cultura material, provenientes del registro etnográfico y arqueológico, e incorporados como piezas coleccionables o para exhibición en los Museos. Es decir, objetos que asociados a investigaciones empíricas arrojan datos que evidencian la presencia y pertenencia a una cultura en particular.

Un segundo grupo de antecedentes serán agrupados bajo criterios contextuales, estas perspectivas consideran al textil en el contexto de los conocimientos y las prácticas de los actores, observando la vigencia de estos objetos en las comunidades que aún los elaboran y en los espacios sociales donde adquieren denominaciones, cumplen una función y son valorados en los circuitos de intercambio entre los grupos que los producen.

Gran cantidad de aspectos han sido abordados respecto al campo de la textilería, muchos de las cuales son producto de la selección, combinación, complementariedad y crítica entre perspectivas. Aún cuando cada tendencia ha prosperado en diversas especialidades, este trabajo aspira a explorar los objetos y la actividad textil como legado y desarrollo de aquellos enfoques iniciales o clásicos que expondré a continuación. 


\section{I- Los textiles como OBJETOS MATERIALES de valor antropológico}

Los conceptos mismos de "artefacto textil", "pieza textil", toman dimensión y alcance con las primeras descripciones y clasificaciones de los registros materiales. Algunas de las tendencias pioneras emergen del contexto de recolección arqueológico, etnográfico y museístico, cuyos desarrollos han sido motivados por hipótesis acerca del origen y la historia de los pueblos; por la implementación de una metodología científica para abordar el estudio de las culturas americanas, y por la representación y proyección estética de los elementos culturales que facilitan el acceso a las "culturas exóticas". En adelante, cualquier análisis antropológico sobre textiles dependerá necesariamente de los datos provenientes de la arqueología y la etnografía y de otras disciplinas como la historia, la semiología y la iconografía.

El énfasis está puesto en una selección de autores y publicaciones que resultan de la tradición de investigación de los naturalistas del siglo XIX; luego, se examina la producción de los antropólogos profesionales de la última mitad del siglo pasado y por último, la de los antropólogos contemporáneos que actualmente continúan trabajando y reflexionando sobre estas tendencias.

No puede dejarse de lado, una revisión sobre el estudio antropológico de los textiles, basada en la relación surgida por el interés científico de algunos grupos de investigadores que articularon los intereses académicos con ciertas ideas sociopolíticas de la época, en instituciones vinculadas a Museos. A mi entender este perfil de investigadores, concepciones y ámbitos constituyó el medio propicio para el desarrollo de estas primeras investigaciones antropológicas en la Argentina.

\subsubsection{Textiles como Patrimonio Cultural}

Desde el comienzo, la mayoría de los estudios sobre textiles han sido realizados por arqueólogos. Una visión muy consolidada entre ellos es que las piezas textiles pueden ser tratadas como portadoras de un carácter cultural inmanente. La búsqueda de parámetros que permitan delimitarlo como entidad bajo estudio podrá hallarse dentro de los límites 
materiales del mismo objeto. La relación con otros objetos es la de un elemento más, que se agrega a un conjunto cultural de entidades coleccionables.

Los antecedentes de estas ideas pueden situarse en los enfoques que sostienen que los hallazgos culturales consisten en la recolección de objetos de la cultura material y en la observación de hechos etnológicos (Márquez Miranda en Graebner, 1940). El conjunto de bienes, conformados por elementos de la vida material, la vida social y la vida mental, conforman patrimonios. El estudio de lo patrimonios permiten el estudio de la cultura. (Imbelloni, 1953)

En el mismo sentido, Graebner (1940) en su texto Metodología Etnológica instala en el centro de las investigaciones de su tiempo, a las piezas de alfarería, al arte parietal, la vivienda, el matrimonio, el chamanismo y por supuesto a los textiles, entre otros elementos culturales relevantes para la descripción de una cultura.

La cultura material tiene una importancia fundamental ya que son los "testimonios directos" de la cultura. Mientras que las fuentes literarias y otros documentos, históricos y etnohistóricos, se constituyen en subsidiarias en la investigación antropológica.

En lo que se refiere a la cultura material el significado y uso del instrumental es fácilmente perceptible. Así una serie de criterios se convierten en el método para estudiar estos materiales. El ojo experto confiere al especialista habilidad para analizar el material, la técnica y especialmente la forma de los objetos. Así como es de interés la observación de los hechos, también lo es la conexión de los elementos culturales (Imbelloni, 1953). Aunque este tipo de conexión refiere a una asociación de elementos más que a una explicación de sus interrelaciones.

La observación mediante un proceso de inferencia, lleva directamente a apreciar o valorar la autenticidad de los vestigios materiales, garantizando la identificación de las falsificaciones o imitaciones. Comparativamente, por ejemplo, pueden diferenciarse la confección de los objetos textiles tradicionales, de aquellos elaborados por máquinas, por metros de tela y teñidos con anilinas industriales. En el caso de la alfarería permitiría identificar las copias de estilo con pretensiones de autenticidad.

Los criterios para la determinación de la localización de los objetos culturales son tan relevantes como aquellos para identificar la autenticidad. Por ejemplo, un criterio a considerar es el material del que están elaborados y la relación con los lugares de 
provisión de recursos. Otros criterios apuntan a las técnicas, las que permiten identificar el lugar de origen y la forma del objeto. Asociados a estos, la ornamentación y las normas del estilo determinarán inequívocamente el origen y la "pureza de la cultura".

\subsection{2- Textiles, expresión tangible de los intangibles de la cultura}

No todas las aproximaciones a los estudios sobre textiles implican una visión circunscripta al objeto como instancia que induce de modo directo a la caracterización cultural. Otras concepciones basadas en el trabajo etnográfico como la de Boas con los grupos Kwakiutl de la Isla Vancouver, en Canadá, ofrecen alternativas respecto al tratamiento del registro de la cultura material. En la revisión de las notas previas a la visita que entre 1897 a 1902 realizara a las costas de la British Columbia, como parte de la Jusep North Pacific Expedition, afirma: "we divined what a wealth of thought lay hidden behind the grotesque masks and the elaborately decorated utensils of this tribus"114 (Boas, 1909:307)

La etnografía sobre los Kwakiutl remite solamente a los aspectos materiales de su cultura, pero la concepción sobre la etnografía y el trabajo de campo son evidentes en la descripción desarrollada a lo largo de 215 páginas a propósito de los siguientes ítems: "Industria", "Casa y mobiliario", "Comida", "Viajes y transporte", "Vestimenta y Ornamentos", "Pesca y Caza de animales marinos" y "Caza de animales terrestres y Pájaros" (Boas, 1909:301-302-303)

Una etnográfica de recolección de objetos e historias que recuperan tradiciones culturales y cuya descripción de los artefactos se encuentra necesariamente vinculada a la descripción de la manufactura, el proceso, los métodos, es decir, mientras en otras aproximaciones la descripción se concentra en el objeto mismo, con Boas, la descripción del objeto es inseparable de una idea culturalmente relevante, es decir, los objetos, son la expresión tangible o emergente de las ideas asociadas a un modo de pensamiento particular de los grupos estudiados.

\footnotetext{
${ }^{14}$ Parte de los resultados de su estudio son publicados en el V Volumen de las Memorias del Museo Americano de Historia Natural de Nueva York, en 1909.
} 
Pero la apuesta es aún más desafiante cuando junto a la descripción detallada de cada artefacto aparecen un serie de ilustraciones de objetos y escenas culturales, cuyo estilo constituye un arte en si mismo y cuyo propósito da lugar a las bases metodológicas de una etnografía científica. Al mismo tiempo, se recogen y publican algunos relatos de los propios Kwakiutl, los que son transcriptos en su lengua y encolumnados en un texto en paralelo. La traducción es aportada por Mr. George Hunt, en calidad de colaborador e intérprete de Boas en las tareas de campo. La relación entre Boas y Hunt precede a la técnica de "investigador-informante clave", modalidad metodológica en las futuras etnografías.

La visión de las posibilidades resultantes del estudio de los materiales colectados bajo esta perspectiva puede sintetizarse en este fragmento:

"...resulta que todo arreglo de objetos es sólo la presentación sumamente fragmentaria de la vida real de un pueblo. Todos los objetos, en primer lugar, son expresiones incidentales de los complejos procesos mentales, que son en sí el tema de la investigación antropológica. Finalmente, las relaciones psicológicas e históricas de la cultura no pueden expresarse con un pequeña parte de la vida étnica como se presenta con objetos en los museos." (Boas en video, 1980)

Desde este punto de vista, comenzó a considerarse a los objetos como portadores de una tradición o carácter folk, al mismo tiempo como elementos de la cultura que mediante su estudio pueden dar cuenta de los procesos de transformación que indefectiblemente remiten a los cambios históricos y de contacto por los que atraviesan sus hacedores y la sociedad en conjunto. (Boas, 1909; Wissler, 1910, Kroeber, 1952)

"In I897 Mr. Morris K. Jesup organized, at my suggestion, a thorough investigation of the tribes of the North Pacific coast, the results of which are embodied in the series of volumes of which the present paper forms a part. It fell naturally to my share to continue the ethnological investigation of the tribes of Vancouver Island. It seemed to me well to make the leading point of view of my discussion, on the one hand an investigation of the historical relations of the tribes to their neighbors, on the other hand a presentation of the culture as it appears to the Indian himself. 
For this reason I have spared no trouble to collect descriptions of customs and beliefs in the language of the Indian, because in these the points that seem important to him are emphasized, and the almost unavoidable distortion contained in the descriptions given by the casual visitor and student is eliminated. For many years I have advocated a more extended application of this method in our studies of the American aborigines. That excellent results may be obtained in this manner is shown, for instance, by the description of the Ewe tribes of West Africa given by Mr. Spieth, and by the records of Samoan industries and customs published by a number of authors in recent years." (Boas 1909:309)

\subsection{3- Las colecciones textiles: más allá de los propósitos científicos}

El modo de acceso y estudio sistemático de textiles etnográficos y arqueológicos prácticamente se limita a los especímenes o piezas de textiles que investigadores de gran prestigio han colectado y se hallan a resguardo en instituciones públicas. Ese conjunto de piezas o fragmentos han sido custodiados y preservados en la mayoría de los casos por los museos. Esas colecciones, en particular las americanas, se constituyeron a partir de la mitad del siglo XIX, específicamente las del Museo de La Plata fueron ingresadas en el período que va de 1850 a 1920 . Muchos años pasaron hasta que estos materiales fueran revisados y analizados bajo nuevas preguntas e intereses ${ }^{15}$.

En cuanto a las exhibiciones de museo, la cuestión acerca de la presentación de los objetos en las salas, así como el problema de justificar la interrelación entre ellos, pareció resolverse en base a criterios espaciales y culturales que permitieron delimitar grupos nativos según patrones culturales y ordenamientos territoriales. Los aspectos materiales y sociales se agruparon por áreas según los siguientes componentes constitutivos, los que aseguraron una comparación sobre similitudes morfológicas y funcionales de rasgos entre las culturas nativas:

15 Las colecciones de textiles, como algunas de cerámica, no siempre fueron obtenidas del trabajo de excavaciones científicas. La mayoría fue adquirida por compra a coleccionistas privados quiénes las ofrecían a los Museos prestigiosos. 
"food, domesticated animals and transportation, textiles, ceramics, decorative arts, tools, fine arts, social organization, social regulation (such as marriage customs), ritual, mythology, language, and physiology."(Wissler, 1917: 53).

Las colecciones textiles en los museos internacionales, como en Argentina son reflejo de una concepción científica de la época. Estas instituciones se constituyen en ámbitos de estudio y exhibición de objetos de colección, poniendo en valor y motivando el inicio de investigaciones etnográficas. Al mismo tiempo, las colecciones de los museos forman parte de un proyecto institucional más amplio. Tomando el caso del Museo de La Plata, podemos decir que esta institución acompañó el "proceso de expansión científica ... como expresión local del gran movimiento museístico que a partir de 1850 comenzó a verificarse en el mundo occidental" (Arenas, 1991:67). Además, estas instituciones de investigación se sumaron al proyecto político argentino, de movilizar a la opinión pública de las ciudades en torno a las necesidades educativas que debía alcanzar la nación, sobre la aspiración de lograr una homogeneización ideológica de los grupos de inmigrantes que llegaban de todo el mundo y de las "poblaciones" del interior del país. (Arenas, 1991; Podgorny, 2000; Andermann y Fernández Bravo, 2003)

A partir de 1970 se retoma el interés por las antiguas colecciones de textiles como un reservorio que inspira una verdadera tradición de investigación en los textiles andinos, en la que se integran y complejizan aspectos técnicos, estilísticos y de conservación conjuntamente con planteos de problemas etnográficos, arqueológicos y museísticos. En ese sentido, el Congreso Internacional de Textiles de 1976 resulta en un encuentro de expertos que evalúan el estado actual de los estudios sobre textiles etnográficos en el hemisferio occidental (Emery, et al (eds). 1976). En esta etapa, los trabajos de investigación de Irene Emery, Annmarie Seiler- Baldinger, Junius Bird, Ann Rowe, William Conklin; Teresa Gisbert, pueden considerarse los principales precursores de las tendencias actuales de investigación sobre textiles a nivel internacional, destacándose su pertenencia 
El Estudio Etnográfico de la Actividad Textil como aporte a la Caracterización del Modo de Vida en el Pueblo de Molinos y zona de influencia (Provincia de Salta)

Laura Teves

a centros académicos de excelencia y a Museos como los de Perú, Bolivia, Chile, Estados Unidos, Suecia, Alemania ${ }^{16}$.

Para este periodo los aspectos centrales son el análisis y la taxonomía de textiles arqueológicos e históricos de colecciones de museos (Bird, 1951; Fung de Pineda, Solanilla, 2002). Otros autores toman como base de trabajo los apuntes de Raoul D'Harcourt (1977) e Irene Emery (1980) y se ocupan del análisis estructural de las técnicas textiles (Rowe, 1984).

El siguiente esquema sintetiza los aportes de las tendencias generales que conceptualizan e hipotetizan sobre la problemática de textiles como objetos materiales.

2.1. Tabla- Conceptos e hipótesis sobre la problemática de los textiles como objetos materiales.

\begin{tabular}{|c|c|c|c|}
\hline \multicolumn{4}{|c|}{$\begin{array}{c}\text { TEXTILES como Objetos Materiales } \\
\text { Enfoques Generales }\end{array}$} \\
\hline Conceptos & Hipótesis & Resultados & Escenarios \\
\hline Patrimonios & $\begin{array}{l}\text { Objetos son hechos y por } \\
\text { lo tanto testimonios } \\
\text { directos de la cultura }\end{array}$ & $\begin{array}{l}\text { Descripción y } \\
\text { clasificación del acervo } \\
\text { cultural }\end{array}$ & $\begin{array}{l}\text { Investigaciones } \\
\text { académicas } \\
\text { Europa } \\
\text { Latinoamérica }\end{array}$ \\
\hline $\begin{array}{l}\text { Tradiciones } \\
\text { Culturales }\end{array}$ & $\begin{array}{l}\text { Objetos son expresiones } \\
\text { visibles de los complejos } \\
\text { procesos mentales de un } \\
\text { pueblo }\end{array}$ & $\begin{array}{l}\text { Descripción de los } \\
\text { aspectos materiales de } \\
\text { un cultura particular }\end{array}$ & $\begin{array}{l}\text { Investigaciones } \\
\text { académicas en } \\
\text { Norteamérica } \\
\text { Trabajo de campo } \\
\text { etnográfico }\end{array}$ \\
\hline $\begin{array}{l}\text { Colecciones } \\
\text { de Museo }\end{array}$ & $\begin{array}{l}\text { Objetos de un } \begin{array}{r}\text { grupo } \\
\text { nativo }\end{array} \\
\text { pueden }\end{array}$ & $\begin{array}{l}\text { Descripción de los } \\
\text { objetos materiales, }\end{array}$ & $\begin{array}{l}\text { Investigaciones en } \\
\text { Centros Académicos }\end{array}$ \\
\hline
\end{tabular}

${ }^{16}$ Instituciones que en adelante se convertirán en referentes no sólo por promover estudios sobre textiles en América, sino por sus prestigiosas publicaciones especializadas en el tema, así las revistas del Royal Ethnographical Museum of Berlin; Museum für Völkerkunde, Basel, Publicaciones de Ultramar del Museum Bremen; Paideuma de la Wolfgang Johann Goethe Universidad. Instituto Frobenius. Sociedad Alemana para la morfología cultural, Stuttgart, Alemania; catálogos y papers de Etnografiska Musset, Goteborg, Suecia; del American Museum of Natural History, New York; The Textile Museum, Washington DC; U. S National Museum, Washington DC; Peabody Museum of Archaeology and Ethnology, Harvard University; y del Pitt Rivers Museum, University of Oxford, Inglaterra. 


\begin{tabular}{|l|l|l|l|}
\hline & $\begin{array}{l}\text { interrelacionarse cuando } \\
\text { se delimitan criterios de } \\
\text { forma, función y y } \\
\text { ordenamiento territorial }\end{array}$ & $\begin{array}{l}\text { conservación } \\
\text { exhibición }\end{array}$ & y América \\
\hline
\end{tabular}

\section{2- LO ANDINO, una historia de investigación sobre textiles en Argentina}

Las líneas de investigación sobre textiles que pueden identificarse a nivel nacional se inician como resultado de viajes y prospecciones de naturalistas viajeros. Algunos aficcionados y autodidactas, otros sólidamente formados como: Lafone Quevedo, Adán Quiroga; Erland Nordenskjöld, Eric von Rosen, Eric Boman, Carlos Bruch, Vladimir Weiser, Germán Burmesister, Juan B. Ambrosetti, Robert Lehmann Nitsche, quienes próximos al fin del siglo XIX y las primeras décadas del XX se ven motivados a observar e inferir, describir y comparar las culturas circunscriptas al espacio andino, en Argentina. Estos precursores en los estudios de la cultura material y las costumbres de los pueblos indígenas de lo que hoy llamamos región del $\mathrm{NOA}^{17}$, lo hicieron en el contexto de la consolidación de una Nación cuya preocupación política era la anexión de territorios, el establecimiento de límites y divisorias con los países vecinos y la explotación económica, fundamentalmente agrícola (Benedetti, 2005). Bajo esta situación, las exploraciones o expediciones fueron encomendadas entre 1900 y 1914, con carácter de misión con el fin de obtener conocimientos acerca de las poblaciones y recursos naturales y minerales disponibles en estas zonas, e informar a las autoridades del momento sobre las características de todo lo observado en terreno. Entre quienes se se hicieron cargo de esta tarea estaban Holmberg E (h), Ambrosetti, J, Boman E., Hubert A., Künh F., Seckt H, y otros (Benedetti, 2005).

Esta generación de investigadores se ocupó de la recolección de piezas de valor cultural, su primera catalogación y conservación, contribuyendo a la conformación y sistematización de las colecciones de importantes museos e institutos nacionales y provinciales dependientes de las Universidades de Jujuy, Salta y Tucumán, Buenos Aires y La Plata.

${ }^{17}$ Para 1900 la región compuesta por las provincias de Jujuy, Salta, Tucumán, Santiago del Estero, Catamarca, La Rioja, Mendoza, San Juan y San Luis conformaba el Territorio Nacional de Los Andes. (Benedetti, 2005) 
Las descripciones sobre el ámbito geográfico, las costumbres y actividades productivas de las poblaciones en la puna o valles resultan de minuciosos informes de viajes de campo por encargo del gobierno. Mientras que otras descripciones surgen de las notas de viajeros y exploradores que realizan los primeros viajes de reconocimiento y estudio en la zona, en muchos casos estos relatos despliegan sus condiciones literarias y hasta poéticas sorprendidos por el paisaje y su gente (Von Tshudi, 1966, Ambrosetti, 1896)

De este modo, varias tradiciones científicas -con sus esbozos de temas, hipótesis y metodologías-, comienzan a vislumbrarse a través de los documentos y publicaciones resultantes. Estas trayectorias que fueran impulsadas desde $1862^{18}$, se han desarrollado por más de un siglo, deviniendo y consolidándose en las actuales disciplinas académicas de arqueológica, etnografía, folklore, y aportando datos para los campos de la lingüística, geografía humana e historia Argentina y Latinoamericana.

\subsubsection{Primeros trabajos empíricos en el NOA y la emergencia de un problema de investigación: la Cultura Calchaquí}

Puntualizaremos ahora en los investigadores que trabajaron en el valle calchaquí y a partir de los cuales podremos entender cómo -sobre la base de los aspectos geográficos, etnográficos, arqueológicos e históricos- se fue construyendo el concepto de cultura calchaquí. Asumiremos en adelante que la noción que hoy manejamos de cultura calchaquí surge como consecuencia de los resultados de aquellas primeras investigaciones empíricas que conjugaron aportaron datos sobre el espacio territorial y el enclave ambiental de los valles calchaquíes (Boman, 1908); junto con la identificación de grupos étnicos y sus parcialidades (Quiroga 1903; Boman, 1908); con el registro de términos en las lenguas cacán, quechua, aymara y castellano; con las numerosas colecciones de artefactos Ambrosetti, (1902, 1904, 1907); Lehmann Nitsche (1902); Boman (1908); y con la recopilación y sistematización de documentos históricos referidos al momento de la conquista y otras crónicas (Quiroga, 1903).

18 Coincide con la creación del Museo de Ciencias Naturales de Buenos Aires, primero en Sudamérica y dirigido entre 1862 y 1892 por Karl H. K. Burmeister. (Arenas, 1991) 
Para ilustrar los estudios pioneros sobre los valles calchaquíes presentaré los aportes empíricos de uno de los más destacados representantes de esos momentos, Eric Boman, quien a propósito de la descripción de los textiles en la zona del NOA, contribuyen a una primera delimitación del tema de los valles calchaquíes como una problemática de interés antropológico. En 1908 Boman publica los resultados de dos viajes, uno en 1901 a la Cordillera argentino-boliviana y al Gran $\operatorname{Chaco}^{19}$ y el siguiente en $1903^{20}$ por la región andina chileno- boliviana. El material colectado fue comparado con las "antigüedades" de la región Calchaquí y con otras de América del Sur y especialmente del Perú basándose en la bibliografía y documentación sobre todos los hallazgos arqueológicos en NOA. Para ese momento, la hipótesis principal de Boman estaba centrada en la idea que los límites de la "Civilización Calchaquí" podían establecerse a partir de la relación con las civilizaciones andino-peruanas (Monné, Soria y Ruiz, 2001).

En su paso por Susques, realiza observaciones pormenorizadas sobre la vestimenta de los "indios" y "mestizos". Establece diferencias entre ellos en base a la herencia pre-hispánica, a la influencia de la moda europea y a los elementos que se consiguen en la ciudad o se traen de Bolivia. Alude a los materiales o lanas con los que se confeccionan los textiles, los instrumentos y la función o utilidad que cumplen, la composición y disposición de los telares, y los instrumentos para tejido calificándolos de "primitivos". Recupera los términos con que se designan en la legua los instrumentos personales para tejer y presenta una secuencia de ilustraciones con figuras muy detalladas acerca de un atado o paquete de elementos personales para tejer.

Su preocupación por una teoría sobre el origen de los telares lo lleva a la búsqueda de la explicación del telar "tipo del pacífico", y su difusión desde el Asia a Perú y luego a la Puna. También reconoce la presencia de telares a pedal "tipo mediterráneo" introducidos por la Misión Sueca en la zona. Respecto a los grupos del sur dice: "Los indios de Susques no hacen tejidos con la lana muy bella y muy fina de la vicuña, con la que las mestizas de Salta y Catamarca hacen verdaderas obras de arte textil." (Boman, 1908: 449- 450)

\footnotetext{
19 Boman participó en la expedición sueca dirigida por Erland Nordenskiöld que atravesará las tierras de Salta y Jujuy para luego pasar a territorio de boliviano.

${ }^{20}$ Boman forma parte de la Expedición Francesa bajo las órdenes de Crequí de Monfort y Senegal de La Grange.
} 


\subsection{2- Inventarios textiles y el folklore calchaquí.}

Cuando las colecciones de objetos estuvieron suficientemente organizadas y revisadas en los Museos; cuando cada disciplina se fue consolidando en el espacio de las universidades y un número abundante de publicaciones dejaba un legado suficiente de monografías y trabajos de investigación, en cientos de páginas de descripciones, mapas, fotos y notas de campo; entonces devinieron épocas de nuevas preguntas y debates científicos.

Para mediados del siglo $\mathrm{XX}$, un grupo de investigadores comienza a profundizar en los aspectos estructurales y funcionales de los tejidos, los trabajos se ocupan de estudiar y comparar piezas colectadas en el periodo anterior o las que obtienen en nuevas exploraciones de campo. Alfredo Taullard (1949), Delia Millán de Palavecino (1981), Susana Chertudi y Ricardo Nardi (1960) describen tanto materiales arqueológicos, etnográficos como históricos y hasta lingüísticos, ocupándose de actualizar los inventarios de técnicas y vocabulario para la elaboración, instrumentos, materiales y teñido, formas o diseños y el uso de la indumentaria aborigen. Las áreas estudiadas son de muy diferentes escalas, incluyendo el continente sudamericano, o circunscribiéndose a las poblaciones que habitan las regiones de Puna, las provincias de Santiago del Estero o el sur del país. Los períodos para el análisis textil van desde la prehistoria hasta la época colonial y criolla en Argentina.

Reiteradamente en los títulos de las publicaciones aparece la noción de folklore vinculada al análisis del arte textil. El concepto de arte textil, expresa el modo de abordar los tejidos como manufacturas, artesanías o fabricación, aquello que requiere atención en la manera de realizarse.

El concepto folklore ya había sido utilizado por Adán Quiroga, Robert Lehmann Nitsche y otros, al referirse al interés por la recopilación de temas culturales, de la vida material, espiritual, social y económica. En sus publicaciones se ve claramente el atractivo por la recopilación de relatos orales, las tradiciones festivas, creencias religiosas y la música. A través de estos temas los autores descubren y advierten un campo de estudio caracterizado por fenómenos culturales particulares. El objetivo es que algunos aspectos de las culturas contemporáneas al investigador, deben ser recogidos, ya que se caracterizan por conservar las raíces de una tradición a la vez que manifiestan influencias 
de las culturas coloniales que han modificado la originaria. El investigador observa e identifica en los elementos culturales la permanencia de la cultura aborigen y por tanto originaria, mientras que sus cambios pueden ser vistos como producto del contacto entre grupos con diferente acervo cultural ${ }^{21}$ (Vega, 1960).

En este sentido Delia Millán de Palavecino realiza un análisis comparativo de las telas textiles y las formas de la vestimenta en diferentes momentos y periodos de tiempo, para los grupos ubicados en los variados hábitats del territorio argentino. Desde este análisis comparativo delimita áreas y el alcance de un estilo textil. También se ocupa de los diseños textiles mostrando cada grupo con los propios, y como resultantes del modo en que los aborígenes expresan su relación con el ambiente, así como, las formas tradicionales que se conservan en el tejido frente a los cambios de la cultura folk:

"la indagación efectuada sobre el periodo colonial, en la lectura de los documentos, las formas particulares de la vestimenta, la producción y el comercio de los tejidos indios, son las fases de análisis que consecuentemente llevan de manera clara y sistemática hacia su carácter criollo o folk' (Millán, 1981:130).

\subsection{3- Estructuras, tipologías y avances en los estudios arqueológicos textiles}

En la década del '70, una nueva perspectiva sobre el abordaje de los textiles se revela desde el ámbito de la arqueología del Museo de La Plata. Estos estudios son realizados por la Dra. Diana Rolandi y pueden considerarse como el inicio de una línea de trabajo sistemática, tipológico-descriptiva, y científica sobre textilería andina, en cuanto aplica una metodología basada en la identificación y análisis de técnicas y estructuras textiles. Esto conlleva la introducción de criterios específicos para la nomenclatura de los tejidos en la zona del NOA, basadas sobre las designaciones técnicas utilizadas a nivel internacional.

\footnotetext{
${ }^{21}$ La noción de Folk remite a un pasado remoto, las culturas folk son vistas como culturas estancas, sin posibilidad de cambio. Y como representan el pasado hay que rescatarlas, por eso los folkloristas iban al rescate de esas tradiciones del pueblo para que no se pierdan.
} 
Las investigaciones de la Dra. Rolandi fueron dirigidas por el Dr. Mario Cigliano y resultaron del trabajo de un grupo interdisciplinario, y como parte de los proyectos de la División Antropología de la Facultad de Ciencias Naturales y Museo de la Universidad Nacional de La Plata. Los resultados provienen de su conocido trabajo de campo en Salta, una serie de excavaciones -que desde el año 1967 hasta 1970, se realizaron en el sitio Tastil, en el valle de Lerma (valle paralelo al valle de Molinos en la zona de alcance y circulación de los habitantes de la región, por varios períodos, según describimos en el Capítulo 1).

Los materiales provenientes del hallazgo incluyen un amplio rango de elementos de la cultura material: cerámicas, instrumentos de metal, madera y piedra, y textiles; arte rupestre; restos de material botánico, así como materiales osteológico humano y animal.

Los resultados del estudio arqueológico de este sitio plantearon hipótesis sobre relaciones interpoblacionales en las "subregiones vecinas como lo son la puna, los valles, selvas occidentales y las quebrada". Este proceso de desarrollo cultural y de unificación regional entre las subáreas de la Quebrada del Toro, La Cuevas, los valles Calchaquíes, Santa María y Humahuaca, tipifica el período tardío. (Cigliano, 1973)

El análisis del material textil fue realizado por la Dra Diana Rolandi, su descripción de las piezas se basó en criterios estructurales, es decir, en la relación espacial y cuantitativa de las fibras, que como elementos manufacturados constituyen las unidades mínimas o básicas de la estructura de los tejidos. También se estudiaron los elementos que intervienen en la conformación de los tipos de estructurales y en el diseño de los textiles.

De este modo, el análisis permitió determinar los tipos de fibras animales utilizadas, identificándose fibras de llama, alpaca y vicuña, mediante examen microscópico. En cuanto, a las técnicas de hilado, se reportan hilos en dirección S y Z o hilo lloq'e, el tejido, trenzado y de mallas, correspondientes a piezas clasificadas como gorros, hondas, bolsas, ponchos y mantos; y finalmente telas de fardos funerarios.

La Dra. Rolandi establece que los textiles tastileños pertenecen al período Tardío y que mediante el análisis técnico es posible comparar estos materiales con las piezas textiles pertenecientes a otros sitios arqueológicos. De este modo, arriba a conclusiones que explican las relaciones de origen, procedencia e influencia cultural de los tejidos salteños, 
atribuyéndoselas a las migraciones en el área andina comprendida por el NOA, Norte de Chile, Perú y Bolivia. (Rolandi de Perrot, 1973)

Sobre el mismo sitio, el Dr. Néstor Palma, describe las actividades de la población actual y los productos artesanales tejidos de lana de llama y oveja y "hasta hace muy poco de vicuña, ahora prohibida su caza con severas medidas punitivas. La esquila, el hilado y el tejido, se efectúan con métodos muy primitivos". La comercialización de los productos junto con la sal que se obtiene en los inmensos salares puneños, suele realizarse a través del trueque que se orienta a los Valles Calchaquíes, Valle de Lerma, Quebrada de Humahuaca, Abra Pampa, Yavi y Bolivia. Los productos que se logran en dicha comercialización son el maíz y la harina, que contribuyen a conformar las exigencias de una alimentación basada en principios tradicionales; otros productos como el alcohol, azúcar y hojas de coca, forman, también parte de este trueque." (Palma, 1973:42)

El trabajo que desarrolló Eduardo Cigliano y su equipo de investigadores del Museo de La Plata, en la ciudad de Tastil, Salta, introduce tempranamente algunas ideas novedosas, que abren nuevos caminos hacia futuras líneas teóricas y metodológicas en las problemáticas sobre las culturas prehispánicas en el NOA. En lo que se refiere a textiles, toman relevancia los estudios de los objetos en contexto arqueológico, superando las descripciones aisladas, someras y casi con interés exclusivo en los aspectos estilísticosdecorativos. Asimismo y sobre esta base, se profundizan los estudios cerca de los objetos materiales y la vida de los pueblos indígenas; así como la producción textil y su relación con diferentes grupos sociales involucrados en la elaboración y en la utilización de los textiles (Rolandi, 1973). Se plantean hipótesis sobre la factibilidad de considerar los objetos materiales a partir de los cuales se puede inferir la estructura social, la organización económica, y la relación con los individuos y su desempeño en tareas especializadas. Sobre estos supuestos, las manufacturas textiles muestran la existencia de técnicas elaboradas y especializadas y por ende puede asociarse a la idea de un desarrollo social y cultural basado en la complejidad de la tecnología (Cigliano, 1973). 
El Estudio Etnográfico de la Actividad Textil como aporte a la Caracterización del Modo de Vida en el Pueblo de Molinos y zona de influencia (Provincia de Salta)

Laura Teves

Profundizando en el análisis de los resultados de estas investigaciones, emergen otras ideas que adquieren valor como antecedentes en esta tesis, y que se expresan ${ }^{22}$ mediante supuestos ecológico-sistémicos. Esta tendencia teórica posibilita un nuevo encuadre de los estudios antropológicos sobre textiles, de este modo, la relación entre los conceptos de cultura, medio ambiente y producción se asocian y complementan. Si los recursos económicos se ajustan a las necesidades de subsistencia, entonces es posible un crecimiento demográfico de la población en áreas locales. En suma, por primera vez se delimitan y establecen relaciones entre factores tecnológicos y ambientales los que habilitan explicaciones dinámicas acerca de las culturas en Argentina (Cigliano, 1973).

El siguiente esquema sintetiza los enfoques locales sobre los textiles como objetos de la cultura material en el NOA y Valles Calchaquíes.

2.2. Tabla- Enfoques locales sobre los textiles como objetos de la cultura material en NOA y Valles Calchaquíes.

\begin{tabular}{|c|c|c|c|}
\hline \multicolumn{4}{|c|}{$\begin{array}{c}\text { TEXTILES como Objetos Materiales } \\
\text { Enfoques Empíricos }\end{array}$} \\
\hline Conceptos & Aportes & Estudios y escenarios & Investigadores \\
\hline $\begin{array}{l}\text { Cultura } \\
\text { Calchaquí }\end{array}$ & $\begin{array}{l}\text { Se define como unidad geográfica y } \\
\text { cultural a través de datos geográficos y } \\
\text { de los grupos y parcialidades, las } \\
\text { lenguas y artefactos de la cultura } \\
\text { material. }\end{array}$ & $\begin{array}{l}\text { Relevamientos de campo } \\
\text { organizados pos las } \\
\text { Expediciones Sueca y } \\
\text { Francesa al NOA y otros } \\
\text { territorios }\end{array}$ & $\begin{array}{l}\text { Eric Boman } \\
1901 \text { y } 1903\end{array}$ \\
\hline $\begin{array}{c}\text { Artesanías } \\
\text { Folk en el } \\
\text { NOA }\end{array}$ & $\begin{array}{l}\text { El carácter folk o criollo de los tejidos } \\
\text { indígenas se halla en los cambios de la } \\
\text { forma de la vestimenta, producción y } \\
\text { comercio a partir del periodo colonial }\end{array}$ & $\begin{array}{l}\text { Análisis comparativos de } \\
\text { la vestimenta en } \\
\text { diferentes grupo y } \\
\text { periodos de tiempo en } \\
\text { todas las áreas y culturas }\end{array}$ & $\begin{array}{c}\text { Delia Millán de } \\
\text { Palavecino } \\
1957\end{array}$ \\
\hline
\end{tabular}

22 Desde la década del '70 hasta los '90 no se volvieron a realizar este tipo de estudios interdisciplinarios tan característicos del perfil de formación de los antropólogos del la FCNyM de la UNLP) 


\begin{tabular}{|c|l|c|c|}
\hline Estructuras y & El análisis técnico de los elementos & Estudios en Santa Rosa & Diana Rolandi \\
Actividad & permite clasificar y comparar tipos & de Tastil; Salta & Homero Palma \\
Textil en Salta & $\begin{array}{l}\text { estructurales en textiles arqueológicos. } \\
\text { La textilería es una actividad vigente } \\
\text { cuyos productos se intercambian } \\
\text { mediante trueque. }\end{array}$ & & 1973 \\
& & & \\
\hline
\end{tabular}

\section{II- Los textiles como objetos de valor en CONTEXTOS socio-culturales}

La mínima o nula consideración a las nociones que en adelante definiremos como contexto social, actores y prácticas introduce una diferencia significativa en los estudios etnográficos futuros. Las mismas han sido consideradas como conceptos a desarrollar en esta tesis, ya que atienden a la demanda de nuevos interrogantes de investigación, aquellos que han surgido de las reflexiones y críticas a los enfoques tratados en la etapa inicial de la investigación sobre textiles, en la que nos concentramos en comparar formas, estructuras y hasta motivos textiles, como parte de las distintas tradiciones culturales. La formulación de preguntas como: ¿Qué indicadores nos permiten afirmar que existe una relación entre los textiles y una adscripción cultural determinada?; ¿Qué relevancia tienen los actores en la actividad de tejer? ¿Cuán importante es la terminología para designar y significar la actividad textil?, ¿Cuál es la relación entre las poblaciones y aquellos sujetos que efectivamente los elaboran?, ¿Cuáles son las relaciones que se establecen en torno a la producción de las piezas textiles?; ¿En qué sentido las piezas textiles pueden agruparse junto a otros elementos de la misma cultura?, ¿Con qué propósitos se realiza la actividad de tejer, entre otras actividades de relevancia sociocultural?, ¿Quiénes tienen y trasmiten conocimientos sobre la actividad de tejer? Entre otras...

Estas preguntas no encuentran respuesta sobre la formulación de supuestos que asocian directamente objetos a culturas y desde los cuales la observación, descripción y comparación de las piezas de tejido son la única perspectiva y metodología de trabajo en el tema. Por el contrario, estas preguntas implican una visión de los textiles como objetos 
que intermedian entre los sujetos y sus contextos. Es decir, aquellas perspectivas que consideran al textil como un objeto cultural que simultáneamente adquiere definición y significación en tanto forma parte de un dominio lingüístico-discursivo; se integra a un conjunto de otros objetos materiales e inmateriales; y circula en el espacio social de relaciones interpersonales, económicas, tecnológicas y ecológicas. ${ }^{23}$

\section{3- Contextos tecnológicos y medioambientales}

\subsection{1- Textiles y tecnologías sustentables}

En estrecha relación con el interés de la Arqueología y la Etnografía surgen durante la década del '70 líneas de investigación centradas en los aspectos tecnológicos y culturales. Estos desarrollos son de interés en mi investigación de los textiles andinos, ya que contribuyen a proponer una concepción de tecnología que va más allá de un conjunto de técnicas que aplican un conocimiento especializado. Desde este punto de vista, no se está pensando solamente en los modos prácticos de implementar una técnica, o en la obtención de un producto en un proceso tecnológico (Bunge, 1981).

Las teorías que hemos explorado son aquellas que en sentido general, conciben a la tecnología en el centro de la relación hombre/naturaleza, poniendo especial énfasis en su potencial para el desarrollo sostenible de los sistemas biológicos y el paisaje. En un sentido empírico, las teorías que consideran la tecnología en el contexto de las actividades de subsistencia de grupos humanos en diferentes ecosistemas culturales.

En principio, contaba con la perspectiva sobre la "Tecnología" y las "Industrias" de Marcel Mauss, un referente insoslayable de la etnografía clásica, con una concepción universal de la cultura; quien define el estudio de las técnicas como acciones efectivas y tradicionales que aplicadas sobre la materia solucionan problemas prácticos. En conjunto forman las industrias, las cuales satisfacen necesidades de consumo, se adecuan a fines

\footnotetext{
${ }^{23}$ Las implicancias metodológicas de estos supuestos se desarrollan en los capítulos 3 y 4 de esta tesis, a partir de los datos sobre actividad textil colectados en Molinos.
} 
concretos y condicionan la economía de un pueblo. Los estudios de los tejidos son incluidos dentro de las "Industrias de la protección y el confort" (Mauss, 1974:116).

Entre los ' 80 y '90 se gesta una antropología de la tecnología (Lemonnier, 1992). Sus aportes van en el sentido que: "Las tecnologías no son sólo cosas y medios utilizados por la sociedades para actuar sobre el medio físico. Para el etnólogo, y para el arqueólogo y el historiados también, las tecnologías - como los mitos, las prohibiciones matrimoniales, o los sistemas intercambio- son producciones sociales en sí mismas." (Lemonnier, 1992:12) En el mismo sentido, resulta útil la noción de "secuencia operativa", "operational sequense" o "chaîne opératoire" definida como "una serie de operaciones las cuales llevan la materia prima desde su estado natural a un estado manufacturado". Pero algunos ajustes al modelo básico de Cresswell (1976) transforman el concepto de secuencia operativa en una "secuencia operacional" o "cadena de trabajo" (Cresswell y Godelier, 1981:211; Lemonnier, 1992:25). Esto implica que cada paso en una secuencia comprende: Indicadores o criterios de actividad, elementos constitutivos, relaciones tecnológicas y relaciones sociales.

En definitiva, un antropólogo de la tecnología debe saber que "la tecnología abarca todos los aspectos de los procesos sobre la materia... pero las técnicas no son sólo cosas y medios utilizados por la sociedades para actuar sobre el medio físico", sino que además de la acción tecnológica incluye una dimensión social, un contexto que relacione los sistemas tecnológicos y otros fenómenos sociales (Lemonnier, 1992).

En un campo próximo a la textilería, como es el de la cerámica andina, Bill Sillar (1996) publica los resultados de su trabajo empírico y dice: "la manufactura de cerámica actual en los Andes Sudcentrales se compara con otras actividades de subsistencia en el área para mostrar cómo las técnicas pueden ser usadas en un amplio rango de diferentes contextos sociales. Esto ha imbuido a las técnicas de significados culturalmente específicos, que afecta la elección de contextos en los cuales ellas se consideran apropiadas." (Sillar, 1996:259). El autor sostiene el argumento que·"La dimensión cultural de la tecnología y su importancia como unidad de referencia analítica en los estudios arqueológicos y etnográficos acerca de la cultura material debe ser defendida: "Los usos de materias primas, herramientas y técnicas son siempre elecciones socialmente 
informadas que surgen a lo largo de tradiciones históricas. Cuando la gente se enfrenta a nuevos problemas retoma ese conocimiento cultural en un proceso creativo donde conceptos, materiales, herramientas y técnicas son constantemente retrabajados... Considerando críticamente esto, los estudios de cultura material pueden dar profundidad a nuestra comprensión de la fascinante interdependencia entre el mundo material y la comprensión de la cultura." (Sillar, 1996: 290, 291)

\section{Tecnologías para el desarrollo cultural}

En los '80 surge un concepto que resalta un aspecto de la tecnología que es de interés para los antropólogos, el de las paleotecnologías o tecnologías de origen prehispánico o nativo. Esta noción pone el énfasis en las tecnologías que no son modernas, ni convencionales, sino en aquellas que se caracterizan por la explotación de materias primas locales, obtenidas por trueque de recursos naturales renovables, no requieren de maquinarias, ni fuentes de energía procesados (carburantes, electricidad, etc), ni de otros factores ajenos a la experiencia autóctona local. El uso de estas tecnologías está orientado a reducir los riesgos de la economía doméstica familiar y fomentar una estabilidad ecológica a largo plazo, más que buscar rentabilidad económica inmediata (Vreeland, 1986).

En Chile, Bolivia y Perú una línea de trabajos parece tomar esta dirección pero definiendo aspectos sensibles a las ideologías y realidades históricas de los pueblos andinos (Vankees, 1997; Dávalos, Cereceda y Martínez, 1992; Appfel-Marglin, 2003). Estos enfoques aportan la visión actual de los grupos étnicos con sus propias concepciones acerca de sí mismos y el entorno, basadas en concetos agrocéntricos acerca del mundo. De este manera, lo trabajos de Juan Vankees de IECTA ${ }^{24}$, Iquique, postulan la idea de que los estudios antropológicos sobre las tecnologías y el desarrollo deben considerarse desde una racionalidad andina, partiendo "de siete principios: (1) Su núcleo principal es el carácter relacional de todo acontecer y ser, la cual está opuesta a cualquier aislamiento y absolutización del individuo. (2) Desde el punto de vista práctico este sistema de relaciones aparece como una ética cósmica y una conciencia ecológica. Resalta dos formas

\footnotetext{
${ }^{\mathbf{2 4}}$ Instituto para el Estudio de la Cultura y Tecnología Andina, Iquique, Chile.
} 
particulares de relacionamiento: (3) la complementariedad y (4) la reciprocidad. Estos son una garantía para el andino de una economía sostenible y una tecnología cuidadosa y benévola de la ecología. Los tres otros principios apoyan y refuerzan la conciencia ecológica del andino; son: (5). El concepto de tiempo que es básicamente cíclico; la pretensión de alterar el ciclo del tiempo, que es el ciclo de la vida, sería torpe, e insano. (6) El principio de la correspondencia entre el orden cósmico y humano, en la que se manifiesta la conciencia de la afinidad principal entre todos los seres; la coexistencia y la convivencia ecológica de los Runa con su entorno natural; y (7) la llamada conciencia natural que se manifiesta en una actitud de cuidado y profundo respeto del ser humano hacia la totalidad de la naturaleza." (Vankees, 1997:14)

Un aplicación de esta perspectiva, que recupera los saberes locales y los pone en relación a los intereses culturales y económicos de las propias comunidades andinas es la actual consolidación del Programa Textil Jalq'a - Tarabuco (Dávalos, Cereceda y Martínez, 1992), que se iniciara en 1986 en dos microregiones del centro y sur de Bolivia, en los Departamentos de Chuquisaca y Potosí. El punto de partida fueron los estudios antropológicos sobre textiles iniciados por la Dra. Verónica Cereceda en las comunidades rurales de la zona, los que por un lado, permitieron la recuperación de técnicas y diseños textiles tradicionales de los grupos Jalq'a y Tarabuco. Por otro lado, permitieron la realización de proyectos productivos cuyos beneficios resultan de la comercalización de productos artísticos-artesanales.

La conjunción de la investigación antropológica, etnohistórica y arqueológica centrada en expresiones del arte -como las que se manifiestan en el textil, la música y la danza-, se asocia con las iniciativas que las comunidades indígenas quieren llevar adelante para su propio mejoramiento económico, difusión y por ende, revalorización de las culturas locales. La expresión de esta cooperación entre conocimiento científico e indígena se concreta en "ASUR- arte indígena", espacio físico del Museo, y sala de ventas de piezas de textiles y cerámicas de la Fundación para la Investigación Antropológica y el Etnodesarrollo "Antropólogos del Surandino ASUR < http://www.asur.org.bo/es/> 


\section{Etnotecnologías y sistemas ecológicos en los Andes argentinos}

A partir de los trabajos de Mario Ravey y sus investigaciones en el NOA, los conceptos de tecnologías apropiadas ${ }^{25}$ y estilo andino de desarrollo popular introducen la perspectiva de etnodesarrollo en el debate antropológico argentino. Estas nociones muestran, por un lado, que las tecnologías surgen de "la combinación de conocimientos provenientes del sistema mundial de ciencia y tecnología con otros provenientes de tradiciones culturales locales y regionales, aprovechando simultáneamente la capacidad de crear conocimiento y generar innovaciones tecnológicas que poseen las poblaciones aborígenes, campesinas y urbanas pobres" (Rabey 1986).

Por otro lado, los estilos de desarrollo describen cómo los sectores populares de los países latinoamericanos resuelven sus necesidades de subsistencia dependiendo de "sistemas productivos y tecnologías que han ido construyéndose durante muchos años -incluso siglos o milenios- y cuya durabilidad es una primera evidencia de su racionalidad en la gestión de los recursos naturales" (Rabey 1990: 5). El autor remarca la idea de que el desarrollo despliega estilos populares acordes a los ecosistemas regionales, y esto es consecuencia de las estrategias propias que las comunidades construyen a lo largo de la historia, en los espacios en que se hallan instaladas. El "estilo andino de desarrollo popular" implica una estrategia de uso de recursos naturales, organización socioeconómica y de generación de tecnología" (Rabey, 1990: 18)

En definitiva, los complejos tecnológicos locales o sistemas tradicionales de conocimiento y producción permiten establecer interrelaciones con los sistemas ecológicos y los sistemas organizacionales (instituciones sociales mayores y producción). Al mismo tiempo, que se diferencian estas instancias, Ravey establece criterios para el análisis de casos concretos, como los sistemas ecológicos de puna y quebrada o valles de altura, en la provincia de Jujuy. Los cuatro aspectos que deben observarse al momento de analizar problemas y

${ }^{25}$ El enfoque de la tecnología apropiada surge en los '70 como una alternativa a la concepción de la transferencia de tecnología moderna y a sus problemas. Representa el tipo de tecnología más habitualmente utilizada por las Organizaciones No Gubernamentales en sus proyectos de desarrollo y lucha contra la pobreza en Latinoamérica y otros países. El concepto fue formulado por E. F. Schumacher en su libro Lo pequeño es hermoso, publicado en 1973. 
soluciones productivas son: (1) el sistema tradicional de uso de los recursos y sus dificultades actuales; (2) las respuestas institucionales convencionales que intervienen en el marco de una concepción dominante de desarrollo; (3) las respuestas generadas desde el marco del estilo andino de desarrollo popular; (4) las resultados experimentales surgidos de los proyectos propuestos por el antropólogo y las comunidades locales, que combinan el conocimiento popular y el conocimiento científico-tecnológico institucional. (Rabey, 1994)

Los modelos alternativos de desarrollo son en definida la estrategia que a nivel local y regional permite adaptar a las condiciones externas 0 factores transnacionales dominantes. Siendo el conocimiento y las prácticas tecnológicas locales aquellas que pueden adecuar y articular los componentes naturales y sociales en la dinámica de desarrollo mundial. Más aún, "el estudio comparado acerca del uso tradicional de los recursos naturales en los ecosistemas de montaña tropical puede convertirse en uno de los casos principales para formular esos criterios generales, a la vez que constituir un insumo fundamental para el diseño y ejecución de modelos de desarrollo ecológicamente sostenibles y socialmente satisfactorios para esas regiones." (Rabey, 1994:11,12)

\subsection{2- Cultura, medio ambiente y economía}

Los enfoques arqueológicos, etnohistóricos y culturalistas clásicos se han aproximado al estudio de las estrategias de los pueblos andinos aportando explicaciones sobre el modo de subsistencia, la organización social y política, las creencias religiosas o el arte, como aspectos de la tradición de estos grupos desde sus orígenes y a lo largo de su historia. Pero muchos investigadores a partir de la década del ' 70 y con la publicación del texto de John Murra, tomaron la tesis de la "complementeriedad vertical" para entender la articulación territorial y económica entre las poblaciones andinas en diferentes zonas ecológicas como el cerro, el valle y la yunga. Los investigadores que en el área de la antropología han realizado estudios de las comunidades rurales campesinas o aborígenes en el NOA, tomando en consideración la hipótesis de la complementariedad, lograron transformar aquellas visiones fragmentarias en interpretaciones de los procesos culturales actuales. 
Desde que ha sido enunciada, la "complementeriedad vertical" no ha sido más que corroborada por numerosos estudios que confirman su vigencia por más de 30 años. En las investigaciones del NOA esta visión no sólo no pierde vigencia sino que se amplia y complejiza, mostrando problemáticas nuevas. En este sentido, las manifestaciones culturales y sus relaciones entre pueblos de tierras altas y bajas, a nivel local, regional y trasnacional han captado el interés antropológico por su trascendencia con relación a diversas problemáticas actuales. Me refiero a varias estrategias vinculadas a:

-la diversificación de la economía como mecanismo para la subsistencia y el acceso al dinero,

-la combinación y utilización de las prácticas de salud propias y estatales, -la incorporación en diferentes labores y roles a mujeres, niños y ancianos, -la adhesión a los cultos locales y mediáticos, -la participación y apropiación de los discursos tradicionales y los discursos estandarizados, las relaciones de complementariedad expresadas en la narrativa y la historia oral.

Como sostiene Murra en su modelo para la explicar el desarrollo de las sociedades andinas, desde el análisis de fuentes etnohistóricas, arqueológicas y etnográficas, la economía de las poblaciones en estas áreas se ha desarrollado a través de la estrategia del control vertical de un máximo de pisos ecológicos. Esta hipótesis reconoce antecedentes en las ideas del biogeógrafo alemán Carl Troll, quien estuvo en América del Sur entre 1925 y 1929, las que plantean que las variaciones de altura y la lejanía al Ecuador ocasionan diferencias en la producción agrícola del área andina (Murra, 1972) La utilización de múltiples pisos ecológicos por una o varias etnías (quechua y aymaras) distantes entre sí y distintas en cuanto a su organización política y económica, supone un patrón de movimiento territorial. Por consiguiente el control efectivo de tierras ubicadas en los distintos pisos ecológicos ofrece el acceso a bienes suficientes y diversificados para lograr el autoabastecimiento de un grupo.

El universo andino fue concebido de este modo, como un conjunto de pisos ordenados "verticalmente" uno encima del otro, formando una macro adaptación, un sistema de 
relaciones ecológicas netamente andinas. La circulación y los asentamientos de los habitantes en zonas altas y bajas implicaban el manejo de clima, fauna y flora muy diferentes.

En la década del '60 una serie de estudios en comunidades americanas da inicio a una perspectiva diferente para el estudio de los textiles. El Dr. Flores Ochoa y un grupo de investigadores de la Universidad de Cuzco, se interesan por los pastores de alpacas de los Andes y la estrategia económica que desarrollan estos grupos mediante las nociones de ecosistema o hábitat de la puna. Los trabajos son publicados en 1977 como una compilación de textos cuya visión hace hincapié en la postulación de un modelo de pastoreo en el ecosistema de la puna. Esta concepción no puede separase de las nociones de ecología, recursos naturales, organización social y tecnología.

La vida en la alta puna relaciona las poblaciones humanas con los recursos vegetales y animales mostrando la dependencia del sistema económico a las condiciones ambientales, pero esta relación debe ser entendida no como una explotación del medio, sino en una continua modificación hombre-naturaleza. En ese sentido, los sistemas de irrigación son un ejemplo de manipulación del ambiente para potenciarlo: "el paisaje natural se convierte y transforma en paisaje cultural por medio de la irrigación de los "bofedales" (especie de campo de pasturas para el ganado) (Flores Ochoa, 1977: 169).

La adecuación de los pastores a la altura implica una adaptación biológica y socio-cultural. "Lo que se pone de manifiesto en los cambios estacionales de vivienda; los patrones de poblamiento disperso; los viajes interzonales para obtener productos agrícolas; la especialización en el tejido; y también en las ceremonias mágico religiosas del tipo propiciatorio" (Flores Ochoa, 1977: 212).

En cuanto a los textiles, estos son descriptos desde el trabajo etnográfico en los Andes peruanos como un producto inserto en la vida pastoril que "diversifica y complementa la economía". La actividad de pastoreo mediante la textilería proporciona vestimenta, bienes para el intercambio o trueque y facilita el trasporte de cargas para el comercio con recuas de llamas entre zonas y poblados. "... en torno al pastoreo existe una red de actividades económicas entre las que sobresalen el intercambio, como relación complementaria básica, y el tejido, como actividad derivada." (Flores Ochoa, 1977: 133-140). 


\subsection{3- La hipótesis de Murra: desde los mitos a los sistemas ecológicos}

\section{Los relatos míticos y el valor en la explicación del medio ambiente}

Un interesante estudio realizado por el Ing. Agr. Augusto Cardich, en las cabeceras del río Marañón Amazonas, en los Andes Peruanos se fundamenta al igual que el trabajo de Murra, en datos de tipo paleoclimatológicos, arqueologógicos, etnohistóricos y etnográficos. Su enfoque demarca las zonas ecológicas de yungas, jalcas, cordilleras, anti o selvas, costa y su utilización para cultivo por las poblaciones. Me interesa destacar en este caso, un aspecto novedoso referido a la utilización de los mitos para la explicación de la ocupación de los diferentes niveles ecológicos. "El mito (de Puscanturpa) tendría relación con el conocimiento ancestral de que se habría producido en tiempos anteriores un ascenso de las posibilidades de los cultivos en tierras cada vez más altas, cuando el clima se iba tornando caluroso." (Cardich, 1981:111). Puscanturpa, es una señora que venía hilando desde la costa, acostumbrada a los climas cálidos donde se cultiva maíz y calabaza y al subir por la cordillera de Huayhuash se paró para tomar aire y descansar, al darse vuelta para ver el camino recorrido se quedó petrificada formando el peñón de Puscanturpa. Si hubiera alcanzado la alta cuenca del Marañón, se hubiera llegado a cultivar las plantas de la yunga en las punas. Ahora Puscanturpa quedó aprisionada entre las nieves, aunque es de esperar que con el tiempo esto cambie. Si ella recomienza su marcha, entonces se podrán cultivar maíz, calabazas y frutas, en esas punas y cordilleras (Cardich, 1981).

Dos aportes son importantes a partir de estos trabajos, el valor de los relatos orales andinos como memoria de los pueblos sobre su realidad y experiencia. Asimismo, la idea de que el estado del personaje mítico no es permanente como tampoco lo es el estado de la naturaleza y que de ella depende el desplazamiento de los pueblos, la disponibilidad de recurso y su densidad poblacional. (Cardich, 1988; 2000) 


\section{Adaptación y ecología: el control vertical desde el enfoque de sistemas}

A fines de los '70 se inició una investigación interdisciplinaria en los andes meridionales, promovida por el Museo Nacional de Etnología de Osaka, el tema general de investigación era la adaptación y aprovechamiento ecológico del medio ambiente. Los resultados derivaron en una compilación de artículos, publicados por la Universidad de Tokio durante los '80 (Masuda, 1986, 1988). En este grupo de trabajos, se destacó el artículo de Rodolfo Merlino quien junto a sus colegas retoman el modelo del "control vertical" de Murra, pero lo consideran limitado en su carácter explicativo (Merlino, Sanchéz Proaño y Ozcoidi, 1988). El análisis propuesto se plantea para una amplia región que va desde el sur de Bolivia hasta los Valles Calchaquíes en Argentina. A diferencia de los desarrollos anteriores, este trabajo incorpora sobre la base de unidades ecológico-culturales dos escalas de análisis, un nivel macro y un nivel micro, señalando la articulación entre ambos mediante "las estrategias productivas de las poblaciones humanas" (Merlino, Sanchéz Proaño y Ozcoidi, 1988:305). El aporte fundamental está en el énfasis puesto en la identificación de factores o parámetros que explican la articulación entre los sistemas, factores que además permiten describir las condiciones en que se mantiene la diversidad ecológico-cultural y a la vez, los mecanismos de complementariedad que se entablan a través de "cadenas" y "redes" de interrelaciones y flujos "de recursos o productos, trabajo e información cultural" (Merlino, Sanchéz Proaño y Ozcoidi, 1988: 306, 314, $321,335)$.

El siguiente esquema, recoge sucintamente los principales conceptos que emergen de los enfoques generales y de los estudios empíricos desde una perspectiva tecnológica y sustentable, de la actividad textil. 
El Estudio Etnográfico de la Actividad Textil como aporte a la Caracterización del Modo de Vida en el Pueblo de Molinos y zona de influencia (Provincia de Salta)

Laura Teves

2.3. Tabla- Enfoques generales y empíricos sobre textiles en contextos tecnológicos y medioambientales.

\begin{tabular}{|c|c|c|c|}
\hline \multicolumn{4}{|c|}{$\begin{array}{c}\text { TEXTILES en Contextos Tecnológicos y Medioambientales } \\
\text { Enfoques Generales y Empíricos }\end{array}$} \\
\hline Conceptos & Aportes & $\begin{array}{l}\text { Estudios y } \\
\text { escenarios }\end{array}$ & Investigadores \\
\hline $\begin{array}{l}\text { Tecnologías } \\
\text { apropiadas }\end{array}$ & $\begin{array}{l}\text { Concepto amplio que incluye más que } \\
\text { herramientas para actuar sobre el } \\
\text { medio físico. } \\
\text { Incluye paleotecnologías o tecnologías } \\
\text { nativas. } \\
\text { Se adecuan al medio y constituyen } \\
\text { estrategias adaptativas y sustentables. }\end{array}$ & $\begin{array}{l}\text { Estudios de } \\
\text { manufacturas de } \\
\text { valor arqueológicas. } \\
\text { Trabajos empíricos } \\
\text { en andes chilenos, } \\
\text { bolivianos y } \\
\text { argentinos }\end{array}$ & $\begin{array}{c}\text { Mauss, } 1967 \\
\text { Schumacher, } 1973 \\
\text { Sillar, } 1996 \\
\text { Vankees, } 1997 \\
\text { Cereceda et al, } \\
1992 \\
\text { Appfel-Marglin, } \\
2003 \\
\text { Ravey, 1990, } 1994\end{array}$ \\
\hline $\begin{array}{l}\text { Secuencia } \\
\text { Operativa }\end{array}$ & $\begin{array}{l}\text { Serie de operaciones que implican más } \\
\text { que la transformación de la materia } \\
\text { prima. } \\
\text { Concepto que incluye ítems como } \\
\text { tradiciones tecnológicas, relaciones } \\
\text { sociales, conocimiento y prácticas, } \\
\text { creatividad para resolver problemas e } \\
\text { innovar }\end{array}$ & $\begin{array}{l}\text { Estudios teórico- } \\
\text { metodológicos sobre } \\
\text { la producción de } \\
\text { manufacturas en } \\
\text { diversos contextos. }\end{array}$ & $\begin{array}{c}\text { Cresswell, } 1976 \\
\text { Conklin, } 1982 \\
\text { Lemmonier, } 1992\end{array}$ \\
\hline $\begin{array}{l}\text { Flujos de recursos } \\
\text { y productos, trabajo } \\
\text { e información } \\
\text { cultural }\end{array}$ & $\begin{array}{l}\text { Concepto que permite articular la idea } \\
\text { de zonas ecológicas altas y bajas } \\
\text { constituyendo un modo de organización } \\
\text { social y económico típicamente andino. } \\
\text { La vigencia explicativa de este modelo } \\
\text { se afianza con aplicaciones en } \\
\text { diferentes regiones de los Andes. Así } \\
\text { como con su consistencia con los } \\
\text { principios explicativos de la } \\
\text { complementariedad vertical. }\end{array}$ & $\begin{array}{l}\text { Enclaves en: } \\
\text { Andes peruanos, } \\
\text { Andes argentinos y } \\
\text { Región de los Valles } \\
\text { Calchaquíes }\end{array}$ & $\begin{array}{l}\text { Murra, } 1972 \\
\text { Flores Ochoa, } \\
\quad 1977 \\
\text { Merlino, Sánchez } \\
\text { Proaño y Ozcoidi, } \\
\quad 1988\end{array}$ \\
\hline
\end{tabular}




\section{4- Textos y Contextos: el interés por los enfoques metodológico- etnográficos.}

Desde los inicios de la Antropología como disciplina los antropólogos se han interesado en la recolección de textos. Específicamente nos referiremos a Franz Boas y sus discípulos, para quienes los textos: como las lenguas nativas o las imágenes, constituyeron una de las más importantes fuentes de información sobre las culturas indígenas. El inmenso corpus colectado y registrado sobre miles de páginas de reportes de campo, textos en lengua nativa, grabaciones y filmaciones constituyó el soporte de las primeras etnografías relevantes en América (Boas, Kroeber, Lowie, Mead, Sapir en Bohannan, 1993).

En adelante, los enfoques de análisis de materiales recuperados en lenguas nativas formarán parte de la metodología etnográfica. El trabajo del etnógrafo será obtener personalmente o con la ayuda de informantes un conjunto de narraciones y sus traducciones, las que describirán el estilo de vida de los grupos estudiados. Este trabajo se hizo por más de 50 años y es la base sobre la que se han desarrollado una, otras, y nuevas tendencias disciplinarias, "pero todas ellas dependieron primero de la colección de montañas de textos" (Bernard, 2006:473)

Esta tradición conduce en la década del '50 a la concreción de una línea de trabajo denominada etnociencia o antropología cognitiva, que se desarrolla hasta hoy. El foco está puesto en las "investigaciones sobre el conocimiento cultural, conocimiento que está impregnado en las palabras, historias y artefactos, y el cual es aprendido a partir de y compartido con otros humanos" (D'Andrade, 1995:xiv). Su principal aspecto de diferenciación es el énfasis puesto en la metodología para la validación de los datos, y consecuentemente en el diseño de técnicas de investigación etnográfica:

"The field of cognitive anthropology is distinguished not so much by its focus on cognitive phenomena as by its methodology and approach. Early practitioners of cognitive anthropology attempted to increase the validity of ethnography by using "interview techniques and analytical processes to bring out native categories of 
thought instead of imposing the analyst's own cultural system on the data" (Colby, Fernández y Kronenlfed, 1981: 209-211).

Los usos del lenguaje resultan centrales para los estudios antropológicos ya que se asume que las expresiones y las formas lingüísticas están relacionadas con categorías culturalmente significativas. Durante los '70 se adicionaron a la agenda de la antropología cognitiva los modelos de toma de decisión y las gramáticas narrativas. En los ' 80 se sumó la semántica del discurso, las técnicas de la teoría fundada o grounded theory, el análisis de consenso y aplicaciones de inteligencia artificial. Finalmente las tendencias de hoy conducen hacia los estudios de las emociones y su interés en la salud y el bienestar, el simbolismo religioso y el análisis de discurso asistido por computadoras (D'Andrade, 1995; Bernard, 2006).

En particular, me interesa destacar la aplicación que una serie de conceptos y métodos ha tenido en las investigaciones etnográficas en Molinos, principalmente se trata de las nociones de dominio cultural, modelos y taxonomías folk y estructuras de conocimiento, entre otras, las cuales remiten al análisis de textos y a la identificación y organización de temas culturales.

En este punto, resulta relevante a esta investigación el enfoque del análisis de dominio cultural. Un dominio comprende un conjunto de ideas o ítems relacionados, que forman parte de una categoría más amplia. En conjunto, describen el modo de pensar de un grupo acerca de las cosas que se relacionan o se asocian. El contenido de un dominio es diferente entre grupos de personas de una cultura y otra. Se identifica, en términos lingüísticos mediante un set de palabras, conceptos o sentencias, que por contrastación, se las señala como pertenecientes al mismo nivel lógico y remiten a una esfera conceptual única. Los ítems individuales dentro de un dominio logran parcialmente su significado desde su relación con otros ítems en un sistema mutuamente interdependiente reflejando el modo en el cual un lenguaje dado o una cultura clasifican la esfera conceptual relevante (Weller and Romney, 1988; Spradley, 1979; Borgatti, 1994)

Otro aspecto a considerar desde este enfoque teórico y metodológico, es el interés en el trabajo de campo con "informantes", el acceso del investigador a textos en su propio lenguaje es irreemplazable al momento de definir los ítems del dominio. El propósito de obtener respuestas de los informantes para definir el dominio es que el antropólogo por sí 
sólo no puede ser capaz de delinear completamente los límites del dominio. En otras palabras, las categorías del investigador no pueden igualar a las de la cultura o lenguajes de los grupos que están siendo estudiados.

\subsection{1- Investigación etnográfica en Molinos.}

En la década del 70 se inician las primeras investigaciones sistemáticas en el pueblo de Molinos y zona de influencia, área de los valles calchaquíes salteños septentrionales. El grupo de investigadores es dirigido por el Dr. Vivante y Palma, y compuesto por las antropólogas Marta Crivos, Estela Ferrarini, Amalia Eguía, quienes pertenecen a la Facultad de Ciencias Naturales y Museo de la Universidad de Nacional de La Plata ${ }^{26}$. Los trabajos de campo se inician inmediatamente, el primero lo realiza Marta Crivos en 1977, modalidad que continuará durante las siguientes tres décadas.

En principio estas investigaciones se orientaron en la perspectiva de las costumbres y tradiciones folklóricas y se desarrollaron alrededor del tema de la medicina popular en la zona. En los trabajos publicados donde se presentan los primeros resultados obtenidos de esta etapa, se advierte claramente un nexo con conceptos y enfoques teóricos de la escuela histórico cultural en antropología. Perspectiva teórica con profundos nexos en el medio académico local27:

"...folklore es un término que debe ser definido desde un punto de vista antropológico. En este caso, el hecho folklórico es un hecho cultural y, por lo tanto, contextual; pero esto no es suficiente para hacerlo objeto de estudio de una disciplina especializada. Así, es necesario señalar alguna característica de este tipo de hecho que lo particularice y lo distinga de un hecho cultural en general, así como se distingue un hecho arqueológico o un hecho etnográfico.

\footnotetext{
${ }^{26}$ El NOA ha sido un área históricamente relevante y profundamente estudiada por naturalistas y arqueólogos de la FCNyM, como ya lo hemos planteado en la sección I de este capítulo.

27 Las relaciones y posicionamientos teórico-académicos: maestro-discípulo, investigación y docencia en Antropología, y cargos políticos en el Museo y la Universidad han sido abordadas por Crivos y Martínez (1996) y Soprano (2007).
} 
Podríamos definir como hecho folklórico todo hecho cultural descontextuado de su cultura de origen y que es funcional en otra cultura, es decir, que está recontextuado; son hechos cuyas raíces deben ser referidas a otras capas 0 estratos culturales que no son en los que se los observa; son hechos diacrónicos si se toman como referencias su nivel de base y su nivel actual. (...)

Partiendo de estas premisas teóricas podemos intentar definir el área típicamente antropológica de la medicina folklórica: medicina folklórica es aquella rama especializada de la antropología que estudia los hechos médicos como hechos diacrónicos, descontextuados de su cultura de origen y recontextuados en nuestro nivel cultural." (Vivante, Crivos y Eguía, 1979:2)

En conjunción con estas ideas acerca de la medicina tradicional y del folklore, se asocian las provenientes de la antropología cultural norteamericana, en particular el trabajo de más de tres décadas de George Foster en Tzintzuntzan, México ${ }^{28}$. En el que se hace hincapié en el trabajo etnográfico en comunidades campesinas definiendo el carácter etnoantropológico de los estudios culturales. Toman relevancia en ese momento, variables estructurales como la economía. Desde esta perspectiva, lo microeconómico se ve desde una concepción similar a la actual, considerando su influencia a escala macro o global, y con un grado de incidencia destacado en las situaciones de cambio cultural de los pueblos estudiados. Por último, esta dimensión económica se relaciona con otra idea, la de "lo bueno limitado", que explica de qué manera la consideración de aspectos centrales de la vida de los campesinos como el amor, la salud, la masculinidad, el honor, la amistad; se dan en cantidades limitadas, y no son suficientes para todos. La imagen de lo bueno como limitado se propone como modelo que lienta políticas de distribución en Latinoamérica y hoy puede aplicarse a los grupos marginados, pobres y desfavorecidos socialmente. Otra de las influencias de Foster -en los inicios de los estudios en Molinos- es la importancia que adquiere la aplicación del conocimiento antropológico como aporte a la solución de problemas en las propias comunidades. De este modo, la antropología aplicada es posible cuando el antropólogo hace trabajo etnográfico clásico y a partir de allí puede

\footnotetext{
${ }^{28}$ Las influencias de este enfoque se refuerzan a partir del contacto académico mantenido entre Crivos y Foster a través de correspondencia escrita y visitas en Berkeley.
} 
facilitar información o realizar recomendaciones a las comunidades estudiadas. Pero, en el caso de que ellas tomen sus propias decisiones, el antropólogo deberá considerar la posibilidad de que su aporte no sea tenido en cuenta porque como señala Foster: "a veces la gente no quiere cambiar. $Y$ pueden tener buenas razones para no cambiar".... (Foster, 1965:307, Crivos, 2003:127).

\subsection{2- Del listado de costumbres tradicionales al análisis de relatos de casos}

En 1982, la antropóloga María Rosa Martínez se suma al trabajo de investigación en Molinos, su interés se centra en el conocimiento y prácticas de las comunidades del Valle que involucran recursos naturales y su utilización medicinal (Martínez y Eguía, 1983; 1986). La temática de las plantas como recursos naturales y sus aplicaciones terapéuticas va delineando los desarrollos etnobiológicos en la zona de valles calchaquíes. Esta línea se consolida cuando se incorpora la antropóloga y etnobotánica la María Lelia Pochettino, quién articula su perspectiva desde el Laboratorio de Etnobotánica y Botánica Aplicada de la FCNyM (LEBA). En adelante los estudios etnográficos en la zona no se apartarán del enfoque que implica una mirada integrada de los aspectos bio-socio-culturales. Una línea de trabajo interdisciplinaria se pone en marcha (Martínez y Pochetino, 1989)

Trascurridos los primeros 10 años de investigación ininterrumpida en el pueblo de Molinos, surgen con fuerza nuevas ideas producto de una revisión crítica de la información de campo y los trabajos realizados hasta ese momento. La recopilación de categorías que caracterizan las costumbres o tradiciones son insuficientes, no alcanzan para un estudio antropológico en Molinos. En cambio, si esas categorías se reconocen en el contexto de los relatos, es posible "acceder a un conjunto articulado de elementos que exceden el marco de los supuestos" acerca de lo "folk", lo "tradicional", o lo "rural" (Crivos y Martínez, 1989:2).

Los relatos incluyen referencias a las estrategias de los pobladores de Molinos que provienen de diferentes "tradiciones culturales" pero que aparecen integrados en una misma práctica, en definitiva, los relatos dan cuenta de actividades que remiten a 
diversos aspectos de la vida de un grupo, no sólo del campo estrictamente médico o económico.

Los expertos informantes y sus experiencias son identificados a partir de las actividades o secuencia de acciones. "... los elementos que integran la secuencia, ... , constituyen actualizaciones de prácticas y concepciones cuyas raíces exceden los marcos de una tradición cultural." (Crivos, 1978:8; Crivos y Martínez, 1989:1).

Por último, la metodología antropológica basada en el trabajo de campo conduce a la problematización del investigador que generalmente ve limitado el campo de observación por circunscribir su interés a un único objeto antropológico:

"Es a partir de esta perspectiva metodológica, centrada en la descripción de actividades, que se plantea la ruptura de la dicotomía tradicional/oficial como base de la caracterización de las prácticas médicas. En otra investigación en el dominio de la artesanía en Molinos, el empleo de esta metodología nos ha permitido trascender la dicotomía tradicional/moderno en el marco de las actividades económicas a través de la integración de elementos que se atribuyen a uno u otro campo en el seno de la actividad artesanal. A partir de la aplicación de esta metodología a dominios particulares que se integran en el dominio general de lo "rural" planteamos la posibilidad de una ruptura de la dicotomía rural-urbano, a ser explorada en otros aspectos de la vida comunitaria." (Crivos y Martínez, 1989:3)

\subsection{3- El énfasis en la perspectiva etnográfica. Pragmática y modo de vida}

La relevancia que adquiere la metodología etnográfica en este grupo de investigación conduce hacia profundas reflexiones en torno a los supuestos que operan en la base del registro etnográfico, y las actividades que permiten delimitar unidades significativas en ese registro; el lenguaje o aspectos culturales considerados como tales y sus relaciones con las formas de vida particulares. La búsqueda de estos fundamentos y su análisis comienza a plantearse durante los noventa cuando Marta Crivos se vincula al Departamento de 
Filosofía de la Universidad Nacional de La Plata, y junto a un grupo de universitarios de diversas disciplinas, se forman en el campo de la Epistemología.

En este ámbito académico fueron centrales las lecturas y debates sobre la obra del filósofo Ludwing Wittgenstein, de las que resultan una conexión fuerte entre su teoría de los Juegos del Lenguaje y las experiencias y problematizaciones emergentes del trabajo de campo etnográfico. En este punto son trascendentes las influencias y aplicaciones que Marta Crivos sugiere a partir de la comparación de las obras de antropólogos como Malinowski y Geertz con el pensamiento de Wittgenstein.

En lo sucesivo, varios conceptos se instalan en los estudios en Molinos y se convierten en las nociones claves que definen la perspectiva que guiará las investigaciones del grupo, fortaleciendo una línea de interés a desarrollar en la antropología local (Crivos, Martínez, Pochettino, 1997), las mismas influencias pueden considerarse en las investigaciones que darán lugar a las recientes tesis de doctorado en enclaves institucionales y de pueblos indígenas (Noceti, 2007; Remorini, 2008; Sy, 2008).

En adelante, es clara la influencia que esta línea de trabajo ejercerá sobre la formulación de las investigaciones en Molinos, entre ellas esta tesis planteada sobre la noción de modo de vida, la cual permite una aproximación a la caracterización de una forma de vida particular, como lo es la de las comunidades del Valle Calchaquí en Salta. Empíricamente esto se logra a través de la relación entre significados y contextos, lenguajes y actividades culturales, en este caso la actividad textil. Se trata entonces de trabajar sobre las relaciones que son posibles de establecer entre los juegos del lenguaje, definidos como el "todo formado por el lenguaje y las acciones con las que está entretejido" (Wittgenstein 1988 en Crivos, 1995:248), y los supuestos sobre los que yace la metodología etnográfica.

Recuperar la idea de que el significado del lenguaje descansa sobre su uso se instala al nivel de las actividades en cuyo seno es utilizado mediante términos que adquieren de este modo un significado. Lo mismo se aplica para todos los aspectos del comportamiento humano los cuales pueden ser considerados como signos que adquieren sentido en el contexto de sistemas de significación cultural (Crivos, 1995) 
La propuesta desarrollada aquí trasciende el análisis lingüístico para centrarse en una correcta traducción del sentido de las expresiones étnicas/nativas y comprender su significado en el marco de las actividades en las que son utilizadas. Las palabras quedan de este modo indefectiblemente ligadas a las actividades en las que se profieren o expresan y a los contextos en las que son utilizadas. Esta función pragmática del significado a través de la observación del empleo del lenguaje en situaciones prácticas ha sido ampliamente explicitada por Malinowski y coincide con los planteos de Wittgenstein lo que lleva a delinear los siguientes supuestos (Malinowski (1923) 1964):

1. Que la matriz generadora de significado está ligada a un modo de vida

2. Que el lenguaje descansa sobre un consenso de acción, no de creencia

3. Que el contexto de las actividades dan sentido a las expresiones

4. Que la expresiones tienen un carácter instrumental

5. Que el significado de las expresiones cumple una función pragmática,

6. Que implica la idea que las acciones humanas son concertadas

7. Que la tarea del etnógrafo es hacer inteligibles las expresiones en el marco de una actividad humana concertada.

El siguiente esquema muestra los enfoques teórico-metodológicos desarrollados en los estudios en la comunidad de Molinos y área de influencia, junto a la producción en publicaciones durante tres décadas. 
El Estudio Etnográfico de la Actividad Textil como aporte a la Caracterización del Modo de Vida en el Pueblo de Molinos y zona de influencia (Provincia de Salta)

Laura Teves

2.4. Tabla- Enfoques teórico-metodológicos en los estudios en la comunidad de Molinos.

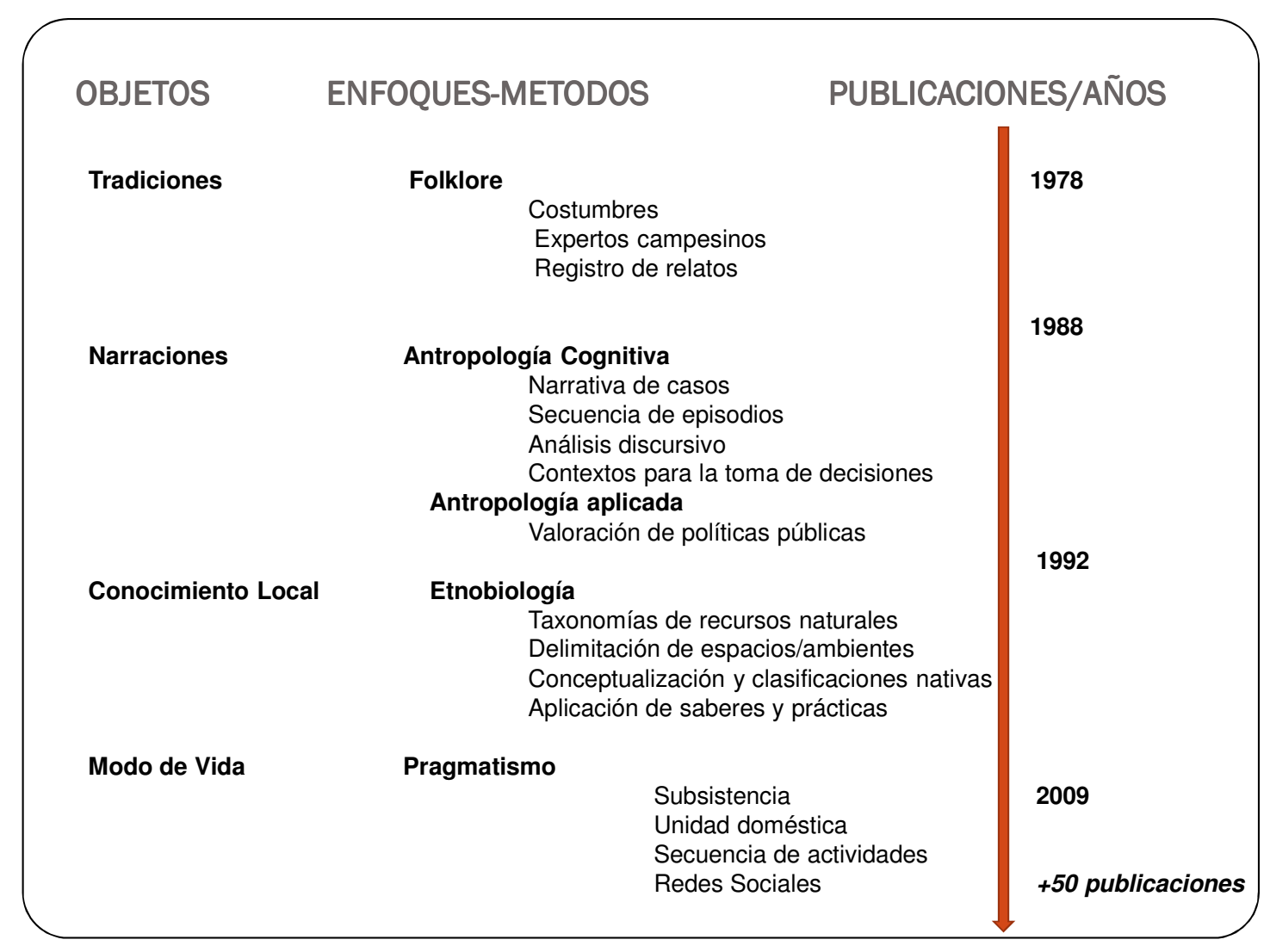

\section{5- Contextos Relacionales. Modelos de interacción social}

\subsection{1- Individuos, grupos y patrones de relación}

Los textiles son objetos que se han definido a partir de diversas perspectivas teóricas y disciplinarias. Como hemos mostrado en este capítulo, podemos trazar un recorrido que se inicia en la definición de los textiles como objetos materiales y se desplaza hacia los supuestos que sostienen la relevancia de los contextos discursivos en ámbitos domésticos, donde también se observan las acciones individuales asociadas a las actividades cotidianas, principalmente aquellas vinculadas a la subsistencia. De este modo, las 
actividades domésticas se convierten en la primera delimitación conceptual y operativa, a partir de la cual identificamos a los actores y sus interacciones en la actividad textil. El foco pasa de los objetos textiles a los actores y a las relaciones que se entablan con sus parientes, vecinos y amigos. Se vuelven importantes los lazos personales que se constituyen en medios o canales sociales a través de los cuales circulan conocimientos y recursos, se intercambian o comercian bienes y servicios, y se complementan espacios y se diversifican las actividades. En este punto, los contextos son más amplios y de diferente alcance, y por lo general, las relaciones sociales articulan más allá de las situaciones cotidianas e individuales para conectar ámbitos socio-culturales y territoriales que exceden las unidades domésticas y las localidades, integrando una amplia red de grupos y territorios.

Existen varios enfoques generales relativos al estudio de las relaciones sociales y en ellos están implícitas las diferentes formas de conceptualizarlas. El enfoque de las teorías interaccionistas se define tanto en el campo de la antropología como en el de la sociología. Este análisis emerge, en un caso, del trabajo de campo etnográfico en África y pone el foco sobre el concepto de las relaciones sociales como resultado de los intercambios o transacciones más que como parte de una estructura social pre-existente y cuyo significado depende de la cultura de los actores participantes. Desde la perspectiva de la interacción social, son relevantes las acciones individuales, las instituciones y los grupos o esferas de intercambio (Mauss, (1954) 1979; Malinowski 1922; Evans Pritchard, 1940; Barth, 1976).

Desarrollos paralelos son los que acontecen para la teoría sociológica, intentando explicar cómo las instituciones surgen de patrones de interacción, considerando como supuestos fundamentales la motivación, la cognición y la estructura social (Cook, 1990). El orden social, el sistema social, emerge de la interacción de los individuos quienes persiguen sus propios intereses, en tanto, las relaciones sociales son generadas por intercambio de bienes (Lévi-Strauss, 1961). El análisis de la interacción social desde la perspectiva de las estrategias individuales permite abordar el problema de la relación entre individuos y estructura social (Blau; 1977; Cook, 1990).

Esta orientación teórica ofrece, en un mismo marco, la posibilidad de incorporar y trabajar con ambos conceptos, el de actor y el de estructura. La antropología, la sociología y la 
psicología no necesariamente han vinculado los niveles de análisis implícitos en esos dos términos, por ejemplo, el cambio social ha sido explicado sólo por fuerzas de la historia o por causas que modifican la estructura; mientras que los actores pueden ser entendidos como individuos fuera de contextos sociales y culturales particulares. Por otra parte, han surgido dudas acerca de la importancia directa que pueden tener variables tales como la clase social, la educación, la edad y el género sobre los procesos sociales y el cambio de las estructuras. Una última consideración, surge de la necesidad de abordar el abismo conceptual y empírico que existe entre las nociones de "'sociedades de masas', organizaciones y actores individuales, o entre las estructuras sociales formales y las informales" (Cook, 1990 en Requena Santos, 2003).

De este modo las consideraciones expresadas anteriormente, introducen mediante el enfoque de las teorías del intercambio, el problema de la articulación de los niveles micro y macrosociales, atendiendo a uno de los planteos centrales en la discusión antropológica y sociológica de los últimos 30 años.

En esta tesis, el propósito de describir la actividad textil a escala doméstica y las rutas de producción, comercialización y consumo de textiles, que remiten a circuitos que conectan otras áreas y países -a través de redes regionales y nacionales, es uno de sus objetivos principales. Las redes como patrones de relaciones no sólo permiten resolver el objetivo de caracterizar la circulación de textiles en el NOA, sino también abordar el problema del alcance social y espacial de la actividad.

En este sentido, Karen Cook (Cook, 1990 en Requena Santos, 2003:481 a 483) expresa a través de cinco supuestos básicos la posibilidad de articulación entre actores y estructuras $^{29}$ :

"1- Los procesos de intercambio son el resultado de los intentos de los actores por realizar y satisfacer sus necesidades". Supuesto "motivacional"

\footnotetext{
${ }^{29}$ Las formulaciones de Cook se basan en las discusiones en torno a si las necesidades refieren a aspectos económicos (Frazer, 1919), psicológicos (Malinowski, 1922), o sociales (Mauss, 1954), y si el énfasis se pone en los individuos o en los grupos como unidades de los procesos de intercambio (Mauss, 1954 y Lévi-Strauss, 1961)
} 
2. "Los procesos de intercambio conducen a la institucionalización o la formación de pautas de interacción, cuando producen beneficios para los implicados"(Turner, 1978:201 en Cook)". Supuesto Institucional

3. "Tales redes institucionalizadas de interacciones no sólo satisfacen las necesidades de los individuos, también constriñen los tipos de estructuras sociales que pueden surgir posteriormente en un sistema social" (Turner, 1978:201 en Cook)" Supuesto sobre fuerza de los sistemas de intercambio o patrones "institucionalizados"

4. "Los procesos de intercambio funcionan de modo que diferencian individuos y grupos en "términos de su acceso relativo a los productos valorados, generando diferencias de poder, prestigio y privilegio"(Turner, 1978:201 en Cook)

5. Las relaciones de intercambio se extienden más allá de las relaciones diádicas directas e incluyen el intercambio "indirecto" y los sistemas o redes complejas de intercambio. "Se amplían las formas de reciprocidad: la reciprocidad generalizada y la unívoca (Ekeh, 1974 en Cook).

\subsection{2- El Análisis de Redes sociales (ARS)}

Las propuestas teóricas que venimos tratando se van desarrollando en varias disciplinas simultáneamente. Con el tiempo se suman aportes provenientes de la matemática y la psicología, la economía, y más tarde la biología y la informática. Desde la década del '50 comienza a tomar fuerza una tendencia que discute los enfoques del momento, y que actualmente se la conoce como análisis de redes sociales. Se trata de un conjunto de ideas teóricas y métodos que se ocupan de los modelos o patrones de relaciones y que resultan en una propuesta sólida que da fundamentalmente respuesta a problemas empíricos.

En las décadas del ' 60 y '70 ya se instala la problemática acerca de lo que hoy reconocemos como procesos de mundialización o "globalización" (Mitchell, (1966) 1999; 
Wolfe, 1996; Schweizer, 1997). Las expresiones o términos como actores y micro y macro estructuras, y finalmente el proceso de globalización hacen referencia indefectiblemente a problemas de la vida social de interés para la antropología. Claramente, la expectativa de abordar y analizar los casos etnográficos desde un enfoque que incluya al sistema mundial moderno es una alternativa posible. Se fundamenta en las tendencias estructuralfuncionalistas con un grado de formalización y operacionalización que va desde los desarrollos de la teoría de grafos y el análisis estadístico hasta las técnicas de representación y visualización que generan las herramientas computacionales.

Los contextos históricos diversos, el cambio y la identificación de un sistema mundial que incide en los ámbitos locales se vuelven imprescindibles para el encuadre de las hipótesis sobre textiles en esta tesis. La idea de mapear los actores en una red, la posibilidad de saber quiénes tienen una actuación central o periférica en un grupo, o quiénes ejercen mayor intermediación en una estructura, son nociones claves desde la teoría de redes sociales que permiten conceptualmente avanzar en la comprensión de las redes de actividad.

Desde un aspecto operativo, el ARS guía el análisis hacia el registro de datos sobre las relaciones sociales y sus patrones. A partir de ello se puede evaluar su incidencia sobre las posibilidades y restricciones que operan en la toma de decisiones individuales, el alcance en ámbitos y escalas espaciales, y en definitiva, acerca de cómo las redes resultan diferentes en el contexto de cada caso de estudio etnográfico. Como señala 156

"El análisis de redes sociales es una ciencia interdisciplinaria de la conducta. Está basada en la observación de que los actores son independientes y que los vínculos entre ellos tienen importantes consecuencias para cualquier individuo. Por ejemplo, los vínculos entre los actores permiten el flujo de bienes materiales, información, afecto, poder, influencia, soporte social, y control social. Ellos proveen a los individuos de oportunidades $y$, al mismo tiempo, restricciones potenciales sobre la conducta." (Freeman, 2004:156) 


\subsection{3- Trabajos empíricos en NOA: vislumbrando la perspectiva relacional}

Los trabajos empíricos en el NOA introducen la perspectiva relacional como una estrategia para analizar problemas nuevos. Durante la década del los ' 90 podemos reconocer dos líneas relevantes en la temática sobre economías locales y comunidades del NOA. Una primera línea vinculada al campo de antropología económica y la ecología cultural, en el marco de un análisis basado en el modelo de toma de decisiones en situaciones de riesgo e incertidumbre. En estos estudios, a las fluctuaciones impredecibles sobre las condiciones ambientales, se suman las situaciones propias de los actores que se supone deben disponer de suficiente información sobre las condiciones socioeconómicas del mercado. Los datos empíricos surgen del trabajo con comunidades de pastores de la puna Jujeña (Göebel, 1998).

Otra línea surge de los estudios que focalizan sobre la producción de textiles y su valor en la subsistencia de las comunidades de la puna catamarqueña. Las actividades en torno al procesamiento de materias primas y tejidos están a cargo fundamentalmente de las mujeres, quiénes aportan al sostenimiento de las familias como actividad principal o complementaria. Por otra parte las relaciones de autogestión y cooperación generan un mecanismo de intercambio basado en los vínculos entre "padres, hijos, hermanos, compadres y comadres" (García y Rolandi, 1999).

Ambos estudios etnográficos coinciden en la importancia del análisis de los viajes a lomo de mula o las caravanas de intercambio como estrategia tradicional y actual de comercio entre las comunidades de la puna jujeña y catamarqueña y los valles salteños (Göbel, 1998; García y Rolandi, 1999). Las autoras coinciden en que las transformaciones sociales en el mundo contemporáneo impactan en las economías regionales de los agricultores y pastores de puna y valles del NOA. Desde la perspectiva de las relaciones de intercambio y las redes de comercio sostienen que los actores sociales "tratan de aprovechar las oportunidades que les brinda el mercado", y que "la organización de las caravanas como parte de una estrategia general de diversificación de los campesinos, les permite moverse flexiblemente entre la economía capitalista y estructuras de intercambio más tradicionales" (Göbel, 1998:868). 
El análisis de los datos arqueológicos, las fuentes documentales y el trabajo de campo etnográfico conducen a García y Rolandi a sostener la hipótesis sobre la existencia de caravanas de llamas que durante los siglos XV y XVI, constituían una red vial. Esta "ruta al Perú" conectaba las zonas de Antofagasta en Catamarca a través de los Valles Calchaquíes Salteños. Los documentos de principios del siglo XX muestran vínculos de parentesco entre las familias de arrieros, troperos y las asentadas a la vera de las rutas de comercio, mostrando que es posible reconstruir una red no sólo de caminos sino también de lazos sociales. Por último, en la década de los '90, los pobladores de la zona siguen intercambiando, al menos dos veces al año, sus productos entre la zona de Puna y de los Valles de altura o Quebradas. Claramente esta estrategia permanece vigente en el presente, pero con un alcance regional reducido en comparación con otras épocas.

El siguiente esquema sintetiza los conceptos e hipótesis acerca de la actividad textil desde la perspectiva de las redes sociales.

2.5. Tabla- Conceptos e hipótesis acerca de la actividad textil desde la perspectiva de redes sociales.

\section{LA ACTIVIDAD TEXTIL y ARS}

Enfoques Generales y Empíricos

\begin{tabular}{|c|c|c|c|}
\hline Conceptos & Hipótesis & Estudios y Escenarios & Investigadores \\
\hline $\begin{array}{l}\text { Estructura de las } \\
\text { relaciones sociales }\end{array}$ & $\begin{array}{l}\text { Una estructura social está formada por } \\
\text { relaciones sociales pautadas entre } \\
\text { individuos y grupos. } \\
\text { Las redes de intercambio son la causa } \\
\text { y consecuencia de una estructura } \\
\text { social de relaciones. }\end{array}$ & $\begin{array}{l}\text { Trabajo etnográfico en } \\
\text { comunidades de África, y } \\
\text { Asia }\end{array}$ & $\begin{array}{c}\text { Malinowski, } 1922 \\
\text { Mitchell, } 1966 \\
\text { Wolfe, 1978-1996 } \\
\text { Hage y Harary, } \\
1991 \\
\text { Schweizer, } 1997\end{array}$ \\
\hline $\begin{array}{c}\text { Actores, estructura } \\
\text { y procesos de } \\
\text { mundialización }\end{array}$ & $\begin{array}{l}\text { Las interrelaciones entre los individuos } \\
\text { de un grupo constituyen las } \\
\text { mircroestructuras y las interrelaciones } \\
\text { entre estos grupos y otros niveles de } \\
\text { organización más amplios conformando } \\
\text { la macroestructura }\end{array}$ & $\begin{array}{l}\text { Trabajos sociológicos } \\
\text { sobre relaciones de } \\
\text { mercado, consumo, } \\
\text { amistad, parentesco }\end{array}$ & $\begin{array}{c}\text { Blau; } 1977 \\
\text { Coleman, } 1977 \\
\text { Emerson, } 1972 \\
\text { Homans, } 1961 \\
\text { Cook, } 1990 \\
\text { Freeman, } 2000\end{array}$ \\
\hline
\end{tabular}


El Estudio Etnográfico de la Actividad Textil como aporte a la Caracterización del Modo de Vida en el Pueblo de Molinos y zona de influencia (Provincia de Salta)

Laura Teves

\begin{tabular}{|c|c|c|c|}
\hline $\begin{array}{c}\text { Toma de decisión } \\
\text { riesgo e } \\
\text { incertidumbre } \\
\text { y redes sociales en } \\
\text { el NOA }\end{array}$ & $\begin{array}{l}\text { Las relaciones de intercambio y las } \\
\text { redes de comercio permiten } \\
\text { flexibilizar la economía de los } \\
\text { campesinos articulando la } \\
\text { economía capitalista con las } \\
\text { estructuras tradicionales. }\end{array}$ & $\begin{array}{l}\text { Estudio del comercio de } \\
\text { caravaneros desde Susques, } \\
\text {-Puna Jujeña- a las regiones } \\
\text { lindantes }\end{array}$ & $\begin{array}{c}\text { Barbara Göebel } \\
1998\end{array}$ \\
\hline $\begin{array}{c}\text { Actividad textil, } \\
\text { comercio y redes } \\
\text { sociales en el NOA }\end{array}$ & $\begin{array}{l}\text { Las transformaciones sociales a } \\
\text { nivel global impactan en las } \\
\text { economías campesinas, la red de } \\
\text { caminos y de lazos sociales } \\
\text { sostenidas durante siglos facilita el } \\
\text { comercio y el intercambio de } \\
\text { productos }\end{array}$ & $\begin{array}{l}\text { Estudio del comercio de } \\
\text { caravaneros desde } \\
\text { Antofagasta de la Sierra, - } \\
\text { Puna Catamarqueña- a las } \\
\text { regiones lindantes }\end{array}$ & $\begin{array}{c}\text { Silvia García } \\
\text { Diana Rolandi } \\
1999\end{array}$ \\
\hline
\end{tabular}




\section{CAPÍTULO 3}

\section{La actividad textil: contextos, actores y prácticas}

\section{1- El análisis cualitativo de la actividad textil: Estrategias teórico- metodológicas}

En este capítulo focalizaremos en el análisis de la actividad textil a partir de los datos cualitativos provenientes de entrevistas y observaciones realizadas durante nuestro trabajo de campo etnográfico en el pueblo de Molinos y zona de influencia en los valles calchaquíes salteños. Desde un enfoque teórico- metodológico denominado "grounded theory ${ }^{\prime \prime 30}$ esperamos realizar una caracterización de la textilería tradicional ${ }^{31}$ basada en los conocimientos, prácticas y experiencias de los actores sociales, en el contexto de la actividad textil ${ }^{32}$.

Los tejedores son personas reconocidas localmente como expertos en la tejeduría tradicional de los Valles Calchaquíes, y fueron entrevistados como informantes especializados o claves (Hammersley, 1994; Bernard, 2006). En esta investigación participaron 20 tejedores expertos, 10 mujeres y 10 hombres, con un rango de edades que va desde los 35 a los 75 años, quienes desarrollan en la actualidad la actividad textil de modo continuo y de tiempo completo o con dedicación parcial. En este último caso se ocupan circunstancialmente en otras actividades de carácter estacional, complementarias y de interés económico (Anexo 3.1. Listado de Expertos).

Los entrevistados han nacido en el Departamento de Molinos y forman parte de familias cuyos apellidos pueden ser rastreados en los archivos parroquiales y en los registros civiles

\footnotetext{
${ }^{30}$ Recordamos que en el Capítulo 2 definimos este enfoque como una metodología ampliamente utilizada para analizar textos. El énfasis está puesto en el descubrimiento y etiquetado de conceptos (variables) y en la construcción de modelos basados sobre un análisis iterativo de los datos. (Bernard, 2006).

31 Los textiles tradicionales son manufacturas realizadas en fibras tejidas, cuyos elementos esenciales, urdimbres y tramas, se entrecruzan en ángulo recto. Esto los diferencia del proceso de entrelazamiento oblicuo, tal como se produce con el método del trenzado, manipulando simultáneamente un grupo de elementos (Emery, 1980).

${ }^{32}$ En adelante para referirnos a la actividad textil utilizaremos el acrónimo AT.
} 
del pueblo homónimo. En este sentido, la prospección de fuentes documentales, que datan del siglo XVIII, nos permite reconocer la profundidad temporal del asentamiento de estas familias en los parajes y localidades cercanas a Molinos.

En cuanto a las unidades domésticas y su composición parental, podemos decir que el núcleo familiar está integrado generalmente por la pareja, ambos de la misma zona, con varios hijos -entre 5 y $6-$, nietos y tíos o abuelos muy ancianos. Algunos grupos familiares están conformados sólo por adultos y sus nietos. En estos casos los ancianos asumen la crianza debido a que los padres del niño han muerto, o sus madres se han ido a la ciudad a trabajar, o han formado nuevas parejas. Esto hace que las relaciones entre los miembros de diferentes generaciones en las familias consideradas sean muy estrechas. Asimismo, la gran frecuencia de lazos parentales reales se ve reforzada por relaciones de parentesco ficticio como el compadrazgo ${ }^{33}$.

La mayoría de los expertos ha recibido instrucción primaria básica en la escuela del pueblo de Molinos, pero algunos de los más ancianos son analfabetos. Ellos se perciben a sí mismos como personas "de mucho trabajd", cuya faena ocupa jornadas completas, que tanto incluyen las horas de día como, en muchos casos, las de la noche. Las tareas habituales incluyen la agricultura, cría de ganado, venta de pequeñas manufacturas y trabajo asalariado, alternando según las variaciones locales del cíclico anual. Las rutinas de trabajo en el ámbito doméstico y en el servicio a las fincas, son actividades a las que se integran desde la niñez.

Desde pequeños todos ellos han aprendido, en el ámbito de sus unidades domésticas, el manejo del ganado, la agricultura y la manufactura de tejidos. Han conformado sus parejas y familia permaneciendo en la zona y actualmente realizan la actividad textil como parte de la rutina cotidiana inserta en las estrategias económicas locales.

Sus historias laborales y familiares incluyen el desplazamiento permanente por la zona de los valles calchaquíes salteños y áreas aledañas en la provincia de Catamarca, así como frecuentes viajes a la capital salteña.

\footnotetext{
33 Parentesco ritual que supera que constituye uno de los componentes de la estrutura de parentesco andino. Es símbolo de la autoridad mestiza. Crea lazos de parentezco espiritual y relaciones de ayuda mutua. (Laumonier, Rocca y Smolensky, 1983)
} 
Periódicamente los tejedores recorren diferentes unidades domésticas emplazadas en los cerros y en el valle. Las constantes visitas motivadas por la actividad textil, señalan y refuerzan vínculos de amistad, parentesco y comerciales. Es posible reconocer así circuitos de la actividad que mantienen las unidades domésticas relacionadas por largo tiempo e integradas territorialmente, aún cuando se hallen muy distantes unas de otras.

En un contexto más amplio, las trayectorias de trabajo de los tejedores los vinculan a la producción agrícola, ganadera y artesanal de las grandes fincas del Valle Calchaquí, en su doble condición de puesteros en el cerro y de mano de obra al servicio de las fincas. En los últimos 30 años, los cambios en la economía regional y en las condiciones de trabajo han modificado las actividades de subsistencia. Algunos de ellos continúan en los puestos del cerro o en asentamientos del valle como arrenderos o medieros en relación a la producción agrícola, otros adquirieron con el tiempo la propiedad de las parcelas en las que residen y continúan trabajando en ellas de forma independiente para su subsistencia, mientras que el resto se ha establecido en el pueblo de Molinos y sus alrededores empleados en la administración y servicios municipales, en el transporte público, en la construcción y en los ámbitos de educación y salud ${ }^{34}$. (Anexo 3.1.- Tabla con datos acerca de cada informante, edad, lugar de origen)

\subsection{1-. Entrada al campo}

El grupo inicial de tejedores fue seleccionado en base a los registros y notas de campo de las investigaciones previas en el área ${ }^{35}$. En una primera etapa se realizaron visitas y entrevistas a los estos tejedores. En una segunda etapa, ampliamos la muestra inicial mediante la técnica de muestreo "bola de nieve" o snowballing sample (Wasserman y Faust, 1999), que consiste en solicitarle a los informantes de la muestra inicial que

\footnotetext{
34 En este sentido, las hilanderas, tejedores y componedoras de Molinos se encuadran en la misma situación laboral que hemos desarrollado minuciosamente en el Capítulo 1.

35 El inicio de esta investigación contó con el invalorable material registrado en cuadernos de campo, audios y fotografías, colectados por las antropólogas Marta Crivos y María Rosa Martínez, en Molinos entre las décadas de 1970 y 1990.
} 
mencionen a las personas relacionadas con la actividad textil, conocidas por ellos, quienes fueron incluidos en nuestra muestra de informantes.

La mayoría de los tejedores seleccionados fueron contactados y entrevistados en sus casas del pueblo de Molinos o en los parajes de Tomuco, Entre Ríos, El Puente, Santa Rosa. Otros fueron entrevistados en el pueblo pero procedían de las localidades de Humanao, La Banda Grande, Luracatao. Al respecto, es frecuente el desplazamiento de los habitantes de los Valles hacia las zonas urbanas, ya sea para visitar a sus parientes, para comprar y vender mercaderías, para realizar consultas en los centros de salud, o ubicar a sus niños y adolescentes en la casa de parientes y albergues durante el periodo escolar. La mayoría de estas entrevistas fueron casuales y se acordaron espontáneamente. (Ver Cap1 Mapa (1.12) del Departamento de Molinos. Parajes y Asentamientos)

En los dos períodos de trabajo de campo ${ }^{36}$ realicé varias entrevistas a cada uno de los informantes elegidos quienes mostraron excelente disposición para conversar y narrar sus experiencias personales. Asimismo, realicé observaciones durante el desarrollo de las entrevistas y en diversas circunstancias a lo largo de los días que permanecí en el campo. La permanencia junto a las personas me brindó la posibilidad de compartir momentos de la vida diaria y observar escenas relevantes a esta investigación. Así, estas observaciones de tipo participante me permitieron reconocer de qué manera la elaboración de los textiles se articula con las tareas cotidianas, como por ejemplo, el aprovisionamiento de leña, preparación del pan, el cuidado de los niños, reuniones y conversaciones espontáneas entre vecinos, consultas médicas ${ }^{37}$ y la recepción de visitantes ocasionales.

\footnotetext{
${ }^{36}$ El trabajo de campo se llevó a cabo durante los años 1997 y 1998, en el mes de marzo-abril y julio-agosto, respectivamente. Contó con la financiación de la Universidad Nacional de La Plata (UNLP), el Consejo Nacional de Investigaciones Científicas y Técnicas (CONICET), y el Instituto Nacional de Antropología y Pensamiento Latinoamericano (INAPL).

37 Varios de los tejedores entrevistados son conocidos en el lugar como "médicos campesinos", es decir, son reconocidos y consultados por sus vecinos como especialistas en la medicina tradicional de los Valles Calchaquíes (Martínez y Pochettino, 1989; 1992, 2004; Crivos y Martínez, 1996, 1998, 2006).
} 


\subsection{2- Diseño de entrevistas y observaciones}

Las entrevistas abiertas y semiestructuradas fueron diseñadas como un instrumento para obtener información sobre la AT desde la perspectiva de cada uno de los informantes seleccionados. La aplicación del concepto de secuencia operativa, fue muy importante desde el punto de vista metodológico ${ }^{38}$ porque contribuyó a delimitar el campo inicial de la AT, y luego, orientar la observación y registro de la actividad. En este sentido, partimos de la definición de actividad textil ${ }^{39}$ como una secuencia de tareas específicas que se inicia con la obtención de las materias primas y finaliza con el producto textil terminado. A su vez la definición de secuencia de operaciones introduce un grupo de instrucciones ${ }^{40}$ para relevar los datos de cada etapa de la actividad. Entonces es posible, dentro de esta cadena operativa de acciones tendientes a un propósito, delimitar sub- etapas como unidades menores que la conforman. Asimismo, es posible establecer la simultaneidad de acciones técnicas que intervienen en cada sub- etapa mostrando las variantes organizativas alrededor de la actividad y consecuentemente la variación de elementos tecnológicos en la secuencia operativa. Más aún, es posible establecer a través de las relaciones entre las etapas delimitadas, la dirección que sigue la información garantizando la ejecución de la secuencia total (Cresswell, 1976; Lemonnier, 1992).

El objetivo de describir la AT fundado en el análisis del conocimiento y la experiencia de cada uno de los expertos se alcanzó implementando dos modalidades de entrevista:

- Entrevistas abiertas, y

- Entrevistas semiestructuradas, con base en un cuestionario que incluía preguntas acerca de las consabidas etapas de elaboración de las piezas textiles en la región.

\footnotetext{
${ }^{38}$ La actividad textil queda definida por el concepto de secuencia operativa, el cual constituirá la principal variable a describir. Más referencias sobre este concepto se hallan en el capítulo 2, acápite 2.3.1- "Textiles y tecnologías sustentables".

39 La definición conceptual de una variable consiste en un conjunto de "abstracciones, articuladas en palabras, que facilitan su entendimiento." (Bernard, 2006:37)

${ }^{40}$ Además de definir la secuencia operativa de modo conceptual, también lo podemos hacer de modo operativo, es decir, dispondremos "de un grupo de instrucciones sobre cómo medir una variable que ya ha sido conceptualmente definida." (Bernard, 2006:38)
} 
El cuestionario se construyó sobre la base de una guía elaborada por la Dra. Diana Rolandi para el relevamiento de la tejeduría tradicional en el área de la Puna Argentina-Boliviana. Esta guía consta de 248 preguntas ordenadas en 7 grupos según criterios técnicos y económicos (Rolandi, 1975). Para nuestro estudio de los textiles en Molinos, el cuestionario fue orientador, pero debió ser abreviado y adaptado al interés de caracterizar la AT desde las vivencias de cada uno de los tejedores entrevistados. (Anexo 3.2. Diseño de Entrevista Semiestructurada)

Respecto de las entrevistas abiertas, estas consistieron en conversaciones abiertas mantenidas con los tejedores durante el proceso mismo de elaboración de un textil, donde se formularon preguntas que emergían de la observación e interacción con los propios tejedores. La posibilidad de participar, por ejemplo, en el momento de preparación de las materias primas para elaborar los hilos o en la manipulación de los instrumentos para tejer, condujo a un ordenamiento y ajuste de las preguntas formuladas con anterioridad y a su reemplazo por las que resultaban relevantes al dominio de la textilería local (Spradley; 1979).

Luego, la estrategia de observación consistió en el registro en tiempo real de las acciones que forman parte de las tareas tendientes a la elaboración de las piezas textiles. Las planillas diseñadas a tal fin incluyen 3 columnas. En la columna "Hora" se registra el horario de inicio y finalización de un conjunto de acciones. Los lapsos de tiempo no son fijos y se toman por reloj, con una duración que oscila, según las tareas observadas, entre 1 y 30 minutos. La columna "Actividades", permite apuntar información sobre las acciones que el observador percibe y reconoce por su interés para caracterizar la actividad textil en una serie temporal. Por último, la columna "Contexto" incluye anotaciones sobre aquellas circunstancias o eventos que acontecen simultáneamente y en el mismo espacio de ejecución de las tareas de interés central para el observador. (Anexo 3.3. Planilla de Observación). Si bien la observación no ha sido la estrategia utilizada con mayor énfasis en esta investigación, los datos aportados por esta técnica validan el carácter secuencial de la actividad textil ya que sitúan temporalmente cada tarea y cada etapa.

El registro escrito de la información observacional se complementó y amplió mediante el registro audiovisual -fotografía y video filmación- con el propósito de captar diferentes 
escenas cotidianas en las unidades domésticas. A partir de estas imágenes pudimos describir las posturas, gestos y maniobras de los expertos durante el desarrollo de la AT e incorporar estos aspectos al análisis de la actividad.

\subsection{3- La información y su procesamiento}

De ambos viajes al pueblo de Molinos se obtuvo información empírica que compone un corpus integrado por el material discursivo registrado en 32 horas de grabación y por imágenes producidas durante 4 horas de filmación, así como, notas que contienen el registro diario de las experiencias de investigación in situ. El relevamiento en el campo estuvo orientado por los siguientes objetivos:

- La caracterización de la actividad textil: mediante la descripción de la secuencia de realización de cada textil; la identificación de etapas y actores involucrados en la actividad; recursos, tecnología y productos

- La organización para el desarrollo de la actividad en la unidad doméstica y sus proyecciones a otros ámbitos

- La reconstrucción de circuitos de intercambio, comercialización y consumo de los productos textiles

Rápidamente advertimos que la información registrada, aunque circunscripta a un dominio específico como el de la AT, tenía la particularidad de los textos ${ }^{41}$ producidos en las investigaciones etnográficas. Estos se caracterizan por una variedad de tipos de registros en bruto, fundamentalmente orales y visuales, cuya riqueza y complejidad de contenido requiere de insight y comprensión. Por este motivo, en este estudio consideramos necesaria la aplicación de una metodología que explore adecuadamente cada línea de las entrevistas, cada fragmento de escena observada y cada detalle en las notas de campo. Asimismo aquellos aspectos que no son evidentes en los textos orales registrados y que requieren de una revisión minuciosa, identificación y cotejo con el conjunto de todos los datos disponibles, incluidos los de la bibliografía de referencia.

\footnotetext{
41 "la mayor parte de la información que recuperamos acerca del pensamiento y la conducta humana en las sociedades complejas ocurre mediante textos: .... Artefactos..., imágenes ..., conductas ... y eventos ... son textos... Todas estas cosas nos llegan en bruto, en forma cualitativa." (Bernard, 2006:463) Traducción y resaltado propio.
} 
Las investigaciones etnográficas de este tipo, plantean además una dificultad importante a resolver, que es el adecuado manejo de la gran cantidad de datos producidos. Esto implica disponer de un medio eficaz para compilarlos e historiar su procedencia, ya que de otro modo la información suele quedar dispersa e inabarcable para realizar posteriormente un análisis minucioso.

Por las razones antes expuestas, es que evaluamos la conveniencia de procesar los datos del corpus mediante el soporte del software para computadoras, NUD*IST $4^{42}$. Esta es una herramienta específica para asistir al investigador en el análisis de datos de tipo no numérico o cualitativo y no estructurado, es decir, aquellos cuyo formato puede ser leído por computadoras sólo como un bit o partícula en el documento como un todo, es decir que no tienen contenido a priori.

El término datos no-estructurados hace referencia a grandes masas de información computarizada, un documento de texto en Word, un e-mail, una página WEB HTM, datos de audio y video. Estos datos no tienen estructura por lo cual son fáciles de leer por las computadoras. Tomando como ejemplo a los documentos de textos, las palabras son solo palabras, no contienen conceptos, ni definiciones, en este entorno funcionan como "objetos" sin forma y requieren de la intervención humana para ser "legibles" o interpretables. El proceso de estructuración de los datos (adding structure) implica una pérdida de información y un aumento de significación y contextualización (Weglarz, G. 2004, Rozenfeld, J. 2007)

Asimismo, en nuestro caso, los diferentes aspectos y temáticas introducidos por los expertos en sus relatos -que a priori podrían parecer inconexos- requirieron de una correcta identificación y ordenamiento. Ello fue posible gracias al mecanismo de identificación y codificación de categorías que provee NUD*DIST4 ${ }^{43}$.

42 El software NUD*IST4 fue lanzado en marzo de 1997, resultado de la revisión de versiones anteriores y en respuesta de los avances metodológicos y las ideas aportadas por más de 10.000 investigadores de todo el mundo quienes han obtenido resultados en investigaciones empíricas y aplicadas en el campo de las ciencias sociales (Richards, 2005)

${ }^{43}$ En adelante utilizaremos el acrónimo N4 para referirnos al software NUD*IST4. 
Una vez resuelto el primer paso analítico, esto es, la delimitación, organización, sistematización y la sistematización de la información, el N4 permite avanzar hacia las etapas analíticas posteriores, las de búsqueda, modelización y teorización basada en los datos de los expertos.

\subsection{4- Preparación de documentos y Codificación de Categorías}

De acuerdo a los mecanismos estipulados, se inició el procesamiento de los datos obtenidos en la investigación en terreno y se prepararon para ser incorporados y manejados como "archivos importados" a NUD*IST 4. Las entrevistas fueron transcriptas siguiendo un conjunto de instrucciones, que incluyen la incorporación de un encabezado específico que permite la identificación de cada documento (Anexo 3.4. Transcripción y Encabezado de Documentos). Una vez realizado este paso, las entrevistas fueron importadas dentro del programa, el cual procede automáticamente diferenciando cada uno de los fragmentos del discurso como unidades de texto. El límite de estas unidades de texto está dado por el párrafo. Cada unidad codificada debe ser asignada y ubicada en nodos. Los nodos corresponden a categorías que se considera relevantes al tema analizado y que se constituyen en receptores de las múltiples unidades textuales identificadas en el conjunto de documentos o entrevistas ingresadas al programa (Anexo

3.5. Unidades y Nodos). Los primeros nodos que se crearon permitieron anexar las unidades textuales a categorías utilizadas por los expertos y por el investigador, al referir a las etapas de la actividad textil (Gahan \& Hannibal, 1999)

El material de entrevistas, así como el resto de los documentos tipeados y digitalizados sobre la actividad textil se organizaron dentro del entorno del programa como archivos o ficheros internos y externos para luego vincularse en forma de un Índice de Documentos, (Anexo 3.7. Índice de Documentos) cuyo contenido fue aportado por:

- las entrevistas a los expertos en textiles;

- las notas de campo;

- los registros de observación;

- el registro videograbado de la realización del textil en sus diferentes etapas, en las unidades domésticas; 
- la descripción de los instrumentos técnicos utilizados en la textilería;

- la descripción y clasificación de recursos, insumos, plantas tintóreas, fragmentos de textiles de acuerdo a los criterios utilizados en la zona y

- los dibujos y fotografías; mapas del pueblo y área circundante.

\subsection{5- Ordenamiento de categorías}

El ordenamiento de este material permitió elaborar un Sistema Índice (Anexo 3.8. Árbol N4), es decir, un sistema o árbol estructurado de categorías o nodos. Estos nodos tienen la particularidad de incluir categorías conceptuales menores o sub-categorías cuyo contenido emergió de las búsquedas en diferentes entornos del programa:

- Búsqueda dentro de los documentos: se cargaron 23 entrevistas, 40 archivos con notas de campo, 45 archivos con imágenes (fotos y dibujos) sobre técnicas y tecnología, 14 archivos con observaciones, 22 documentos con bibliografía sobre Molinos, 1 archivo con léxico técnico y con designaciones locales sobre textiles, 3 mapas del Departamento de Molinos, 1 imagen satelital de los Valles Calchaquíes.

- Búsqueda entre categorías y unidades textuales vinculadas a ellas: se combinaron y recombinaron nodos, se cambiaron los nombres de algunas categorías logrando el agrupamiento de nodos en dos sub-árboles, uno que contiene datos básicos sobre los informantes y referencias a otras actividades cotidianas en la región; y otro sub-árbol que incluye unidades de texto referidas a la secuencia de tareas para la elaboración de textiles, a los expertos -teleros, hilanderas y componedores-, a las unidades de organización de la actividad: unidades domésticas, cooperativa, fincas y al contexto espacial: valle y cerro.

Los resultados de las búsquedas permitieron por un lado, almacenar información en nuevos nodos, por otro, reorganizar la estructura del árbol de categorías en los casos necesarios y por último, obtener nuevas hipótesis sobre la actividad que resultaron del interjuego de la información provista por la gente y el investigador. Adicionalmente, el programa posibilitó la creación de memos o notas que vincularon los textos seleccionados a los nodos, permitiendo de forma complementaria registrar el proceso de análisis. Esta 
característica de vinculación también permitió relacionar el texto a archivos ya cargados en el programa que contienen imágenes y gráficos (Anexo 3.6. Búsqueda de Categorías en un Documento)

Finalmente, la estructura de árbol codificada y generada por este proceso pudo visualizarse y los nodos fueron movidos o ligados a otros diferentes. Tales cambios estructurales para los datos se registraron mediante informes que permiten desarrollar las ideas emergentes del análisis de los datos y dan por resultado un modelo de la actividad textil en Molinos.

El sistema índice provee un mapa del desarrollo del proyecto, cuya construcción es el resultado de la elaboración y re- elaboración de la información obtenida a través de los pasos seguidos durante el proceso de análisis (Anexo_3.9 Diagrama-Árbol). El mapa muestra:

- las ideas que orientan la búsqueda: qué es lo que se sabe en relación a la AT; (incluye la visión de los tejedores y el investigador)

- la delimitación de las categorías y subcategorías del sistema: cuáles son los conceptos utilizados para dar cuenta de la AT;

- Ios dominios culturales: campos conceptuales relacionados entre sí a partir de de la AT. Implican la delimitación de categorías y subcategorías que describen aspectos o dominios diferentes pero vinculados a la AT;

- las hipótesis emergentes con relación a la organización de la AT en Molinos; el agrupamiento y clasificación de los expertos por sexo, edad y parentesco; el uso complementario de tecnologías tradicionales y actuales para la elaboración de las piezas de tejido; la articulación de la AT con relación a las rutinas diarias y a otras actividades cotidianas y estacionales; la continuidad de la AT en la historia personal o biografía de los tejedores; y el nexo ambiente-recursos en la realización de la textilería.

\subsection{6- Instancias en el análisis de los datos:}




\subsubsection{1- Codificación de los Datos}

El primer ordenamiento de los datos consiste en su codificación, es decir, en la selección de unidades textuales identificadas en cada documento que se vinculan a una categoría, las que a su vez se hallan anexadas en el Sistema Índice.

A- Diseño del Árbol de Nodos con el material colectado en el campo durante el primer viaje:

A.1- Todos los nodos se colocan sin agrupar, como nodos Libres, es decir, sin vinculación entre ellos.

A.2- Primera ubicación de nodos en el Sistema Índice:

El primer agrupamiento y ubicación de nodos en el Sistema Índice se realizó sin mediar relaciones jerárquicas. El criterio utilizado fue el de pertenencia al mismo dominio conceptual, es decir, el dominio de la secuencia de la actividad textil. Este incluyó los sub-nodos: obtención de materias primas, hilado, tejido, teñido y composición.

A.3- Creación de un segundo grupo de nodos en el Sistema Índice, conteniendo los Datos Básicos de los expertos: edad, género, estado civil, ocupaciones, estudios y residencia. 
El Estudio Etnográfico de la Actividad Textil como aporte a la Caracterización del Modo de Vida en el Pueblo de Molinos y zona de influencia (Provincia de Salta)

Laura Teves

\section{1-Secuencia de la AT en Construcción}

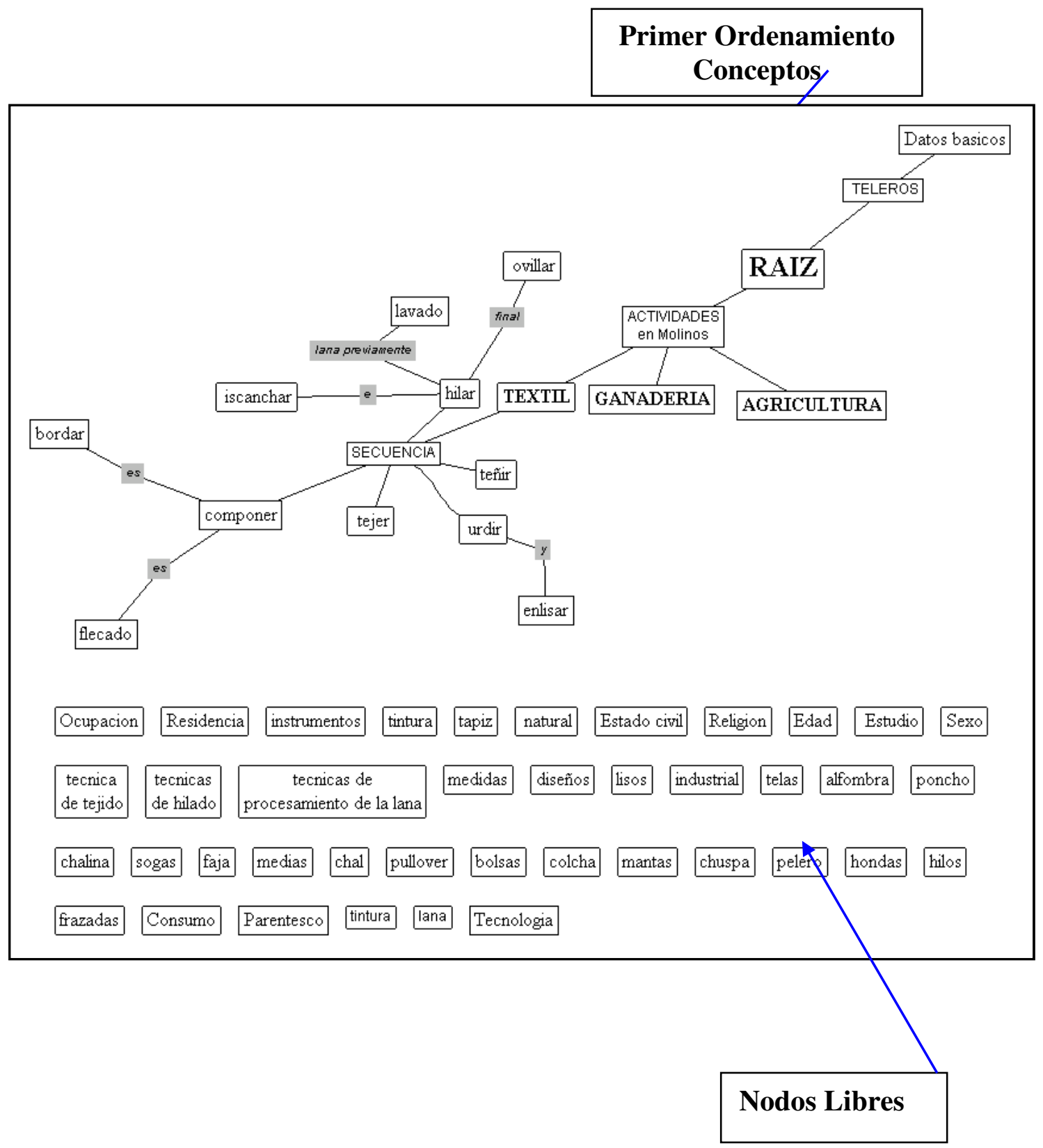


B- Cambios en el diseño del Árbol de Nodos como consecuencia del ingreso del material del segundo viaje.

B.1- La ampliación de las categorías del Sistema Índice se da fundamentalmente por la identificación e incorporación de subcategorías nuevas que se vinculan entre sí por la relación de inclusividad. Por ejemplo, el Sub-árbol 1 contiene las siguientes subcategorías:

- Secuencia de la actividad textil: hilar; urdir; enlisar; tejer; teñir; componer: bordar, coser; manipular instrumentos.

- Expertos: roles femeninos y masculinos, aprendizaje, autopercepción.

- Espacio de la actividad: Unidades domésticas del valle: espacios para tejer, rutas a los centros comerciales, intercambios. Unidades domésticas del cerro: recursos del ambiente: materias primas, rutas de distribución.

- Organización de la actividad: trayectorias de trabajo: fincas, mercado de artesanías, contratación y asociación de artesanos. 
El Estudio Etnográfico de la Actividad Textil como aporte a la Caracterización del Modo de Vida en el Pueblo de Molinos y zona de influencia (Provincia de Salta)

Laura Teves

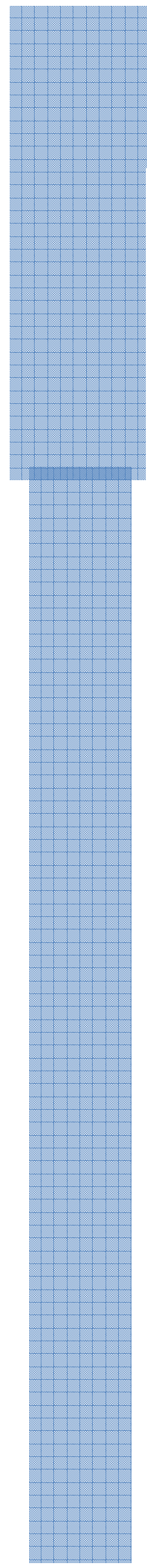

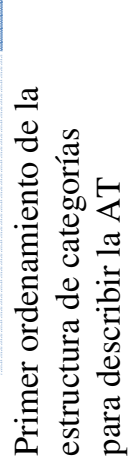

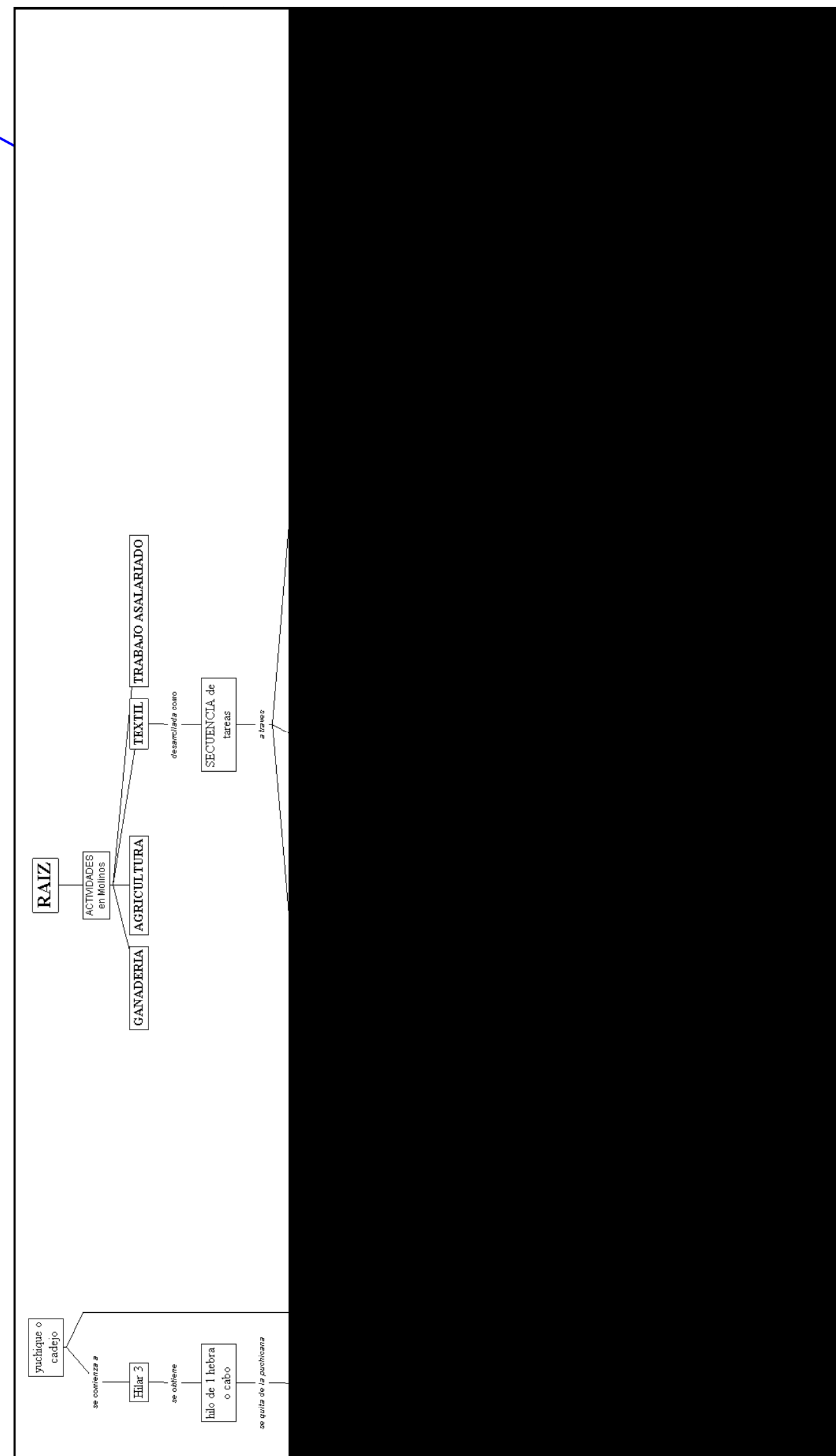


El Estudio Etnográfico de la Actividad Textil como aporte a la Caracterización del Modo de Vida en el Pueblo de Molinos y zona de influencia (Provincia de Salta)

\subsubsection{2- Búsquedas, Exploración y Cambios en la Organización}

B.2- La ampliación de categorías en el Sistema Índice justifica la creación del SubÁrbol 2 en el que almacenaron y sistematizaron los:

Datos básicos de los Expertos: se agregaron al Sistema Índice datos sobre otras personas involucradas en la actividad textil que no habían sido entrevistadas con anterioridad.

\section{3-Síntesis de la Secuencia}

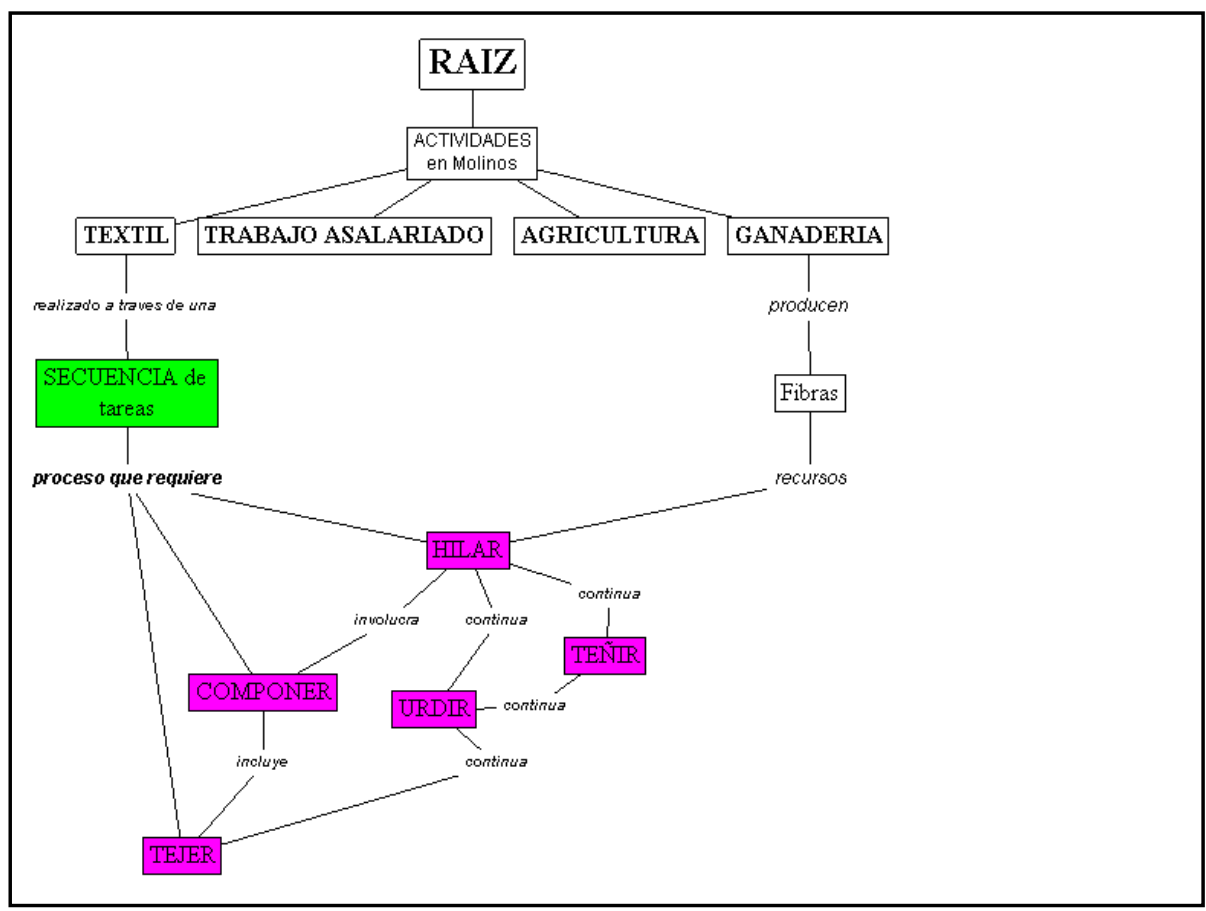

\subsubsection{3- Mapeo de Resultados}

C- Obtención del Diseño Final del Sistema Índice. La estructura de categorías adquiere su configuración final sobre la base del ordenamiento y relación entre ellas. Este mapa representa un modelo de la AT para la muestra de expertos seleccionada y el corpus de 
El Estudio Etnográfico de la Actividad Textil como aporte a la Caracterización del Modo de Vida en el Pueblo de Molinos y zona de influencia (Provincia de Salta)

Laura Teves

información disponible. La visualización gráfica del Sistema Índice muestra los resultados del análisis alcanzado:

C.1- Los diagramas del Sistema Índice puede presentarse completos o de modo sectorizado. La posibilidad de seleccionar y focalizar sobre áreas más restringidas de los nodos que lo componen permite ver en detalle las subcategorías y nexos que las conectan.

La representación del mapa o diagrama-árbol de categorías se realizó con un programa específico para representar mapas conceptuales ${ }^{44}$. De esta manera pudimos tomar las categorías relevantes a la AT almacenadas y ordenadas en N4 y visualizarlas haciendo explícitos los conectores entre ellas. También pudimos observar cada detalle del diagrama árbol por sectores. Los siguientes esquemas son el resultado de esta operación:

3.4- Secciones del Sistema Índice - Etapa 1_Hilado

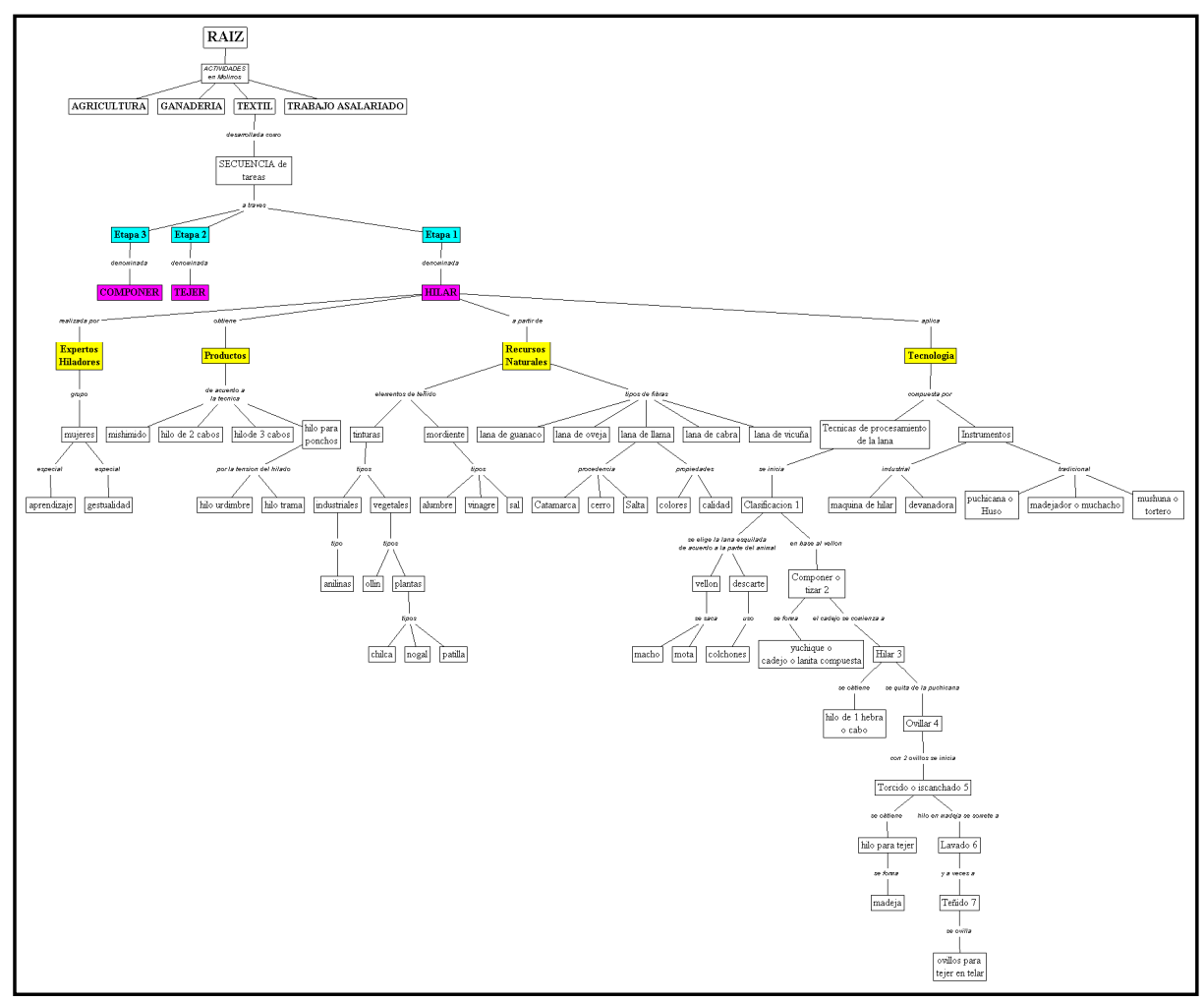

${ }^{44}$ El software es denominado Concept Map Tools. Version 2.9.1. Desarrollado por el Institute for Human and Machine Cognition (IHMC Map Software). University of West Florida. De distribución libre <http://cmap.coginst.uwf.edu/> 
El Estudio Etnográfico de la Actividad Textil como aporte a la Caracterización del Modo de Vida en el Pueblo de Molinos y zona de influencia (Provincia de Salta)

Laura Teves

3.5-Secciones del Sistema Índice - Etapa 2_Tejido

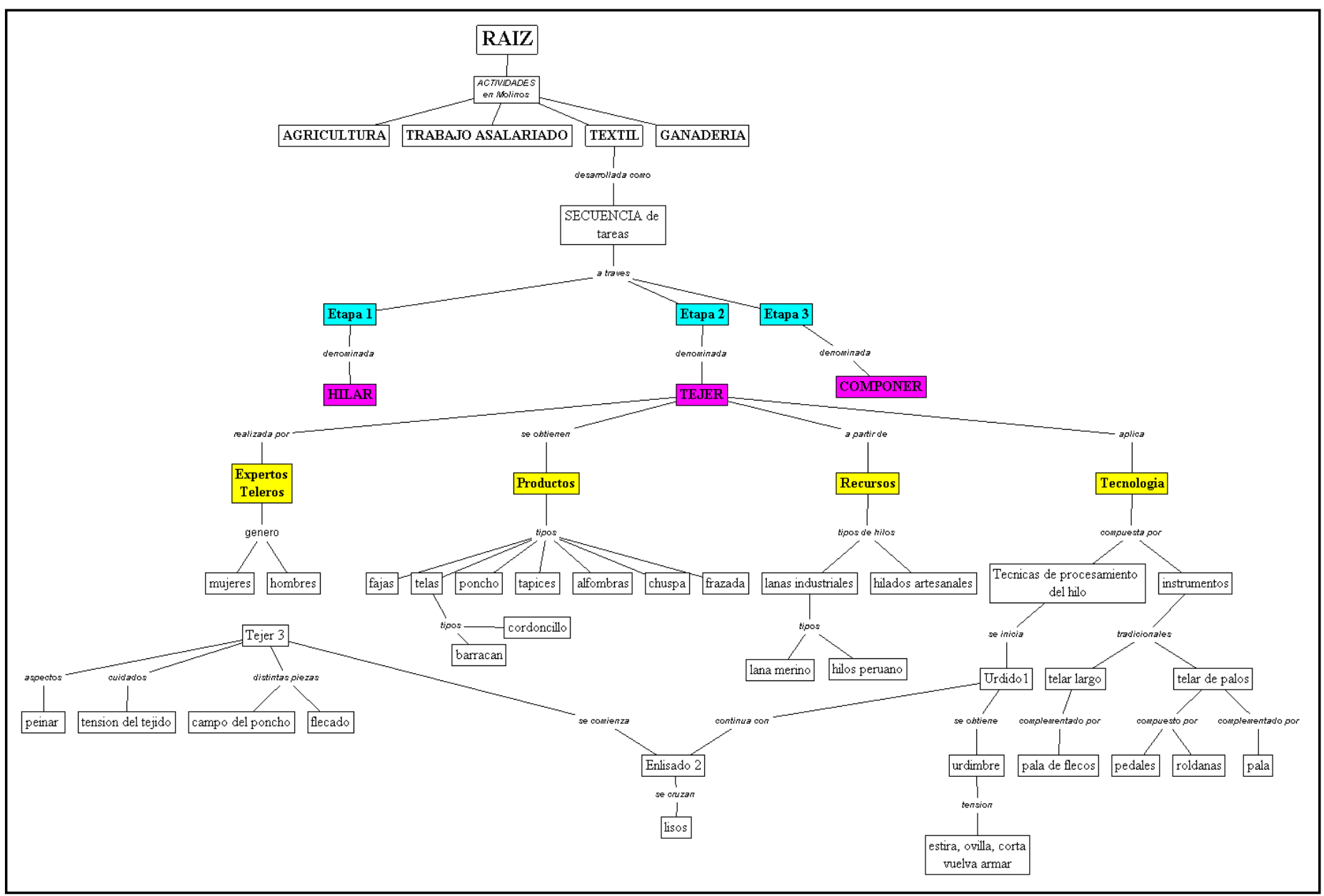


El Estudio Etnográfico de la Actividad Textil como aporte a la Caracterización del Modo de Vida en el Pueblo de Molinos y zona de influencia (Provincia de Salta)

Laura Teves

\section{6- Secciones del sistema Índice- Etapa 3_Componer}

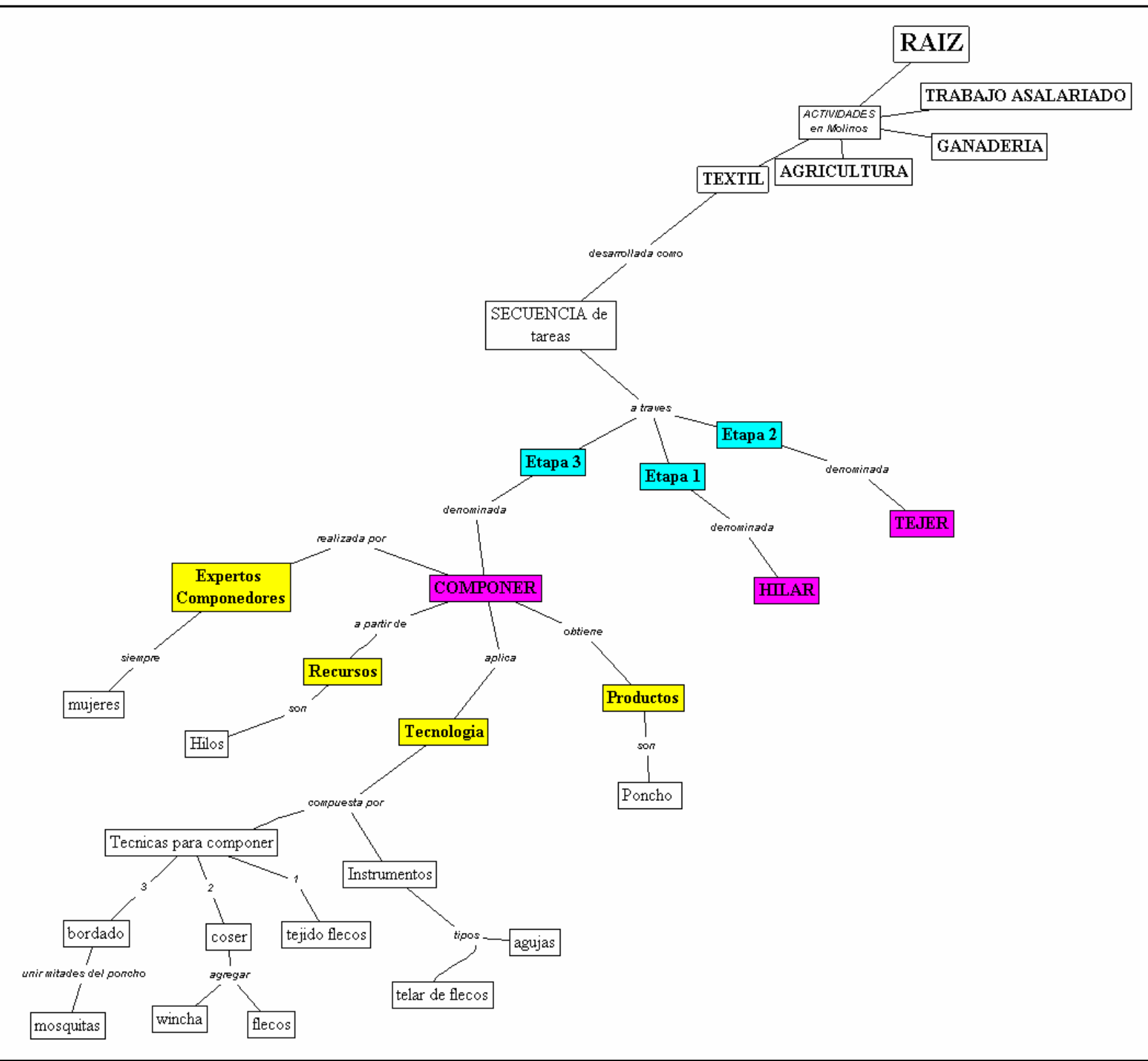




\section{2- El Dominio Conceptual de la Actividad Textil}

La aplicación de los conceptos descriptos en las páginas iniciales de este capítulo secuencia operativa de tareas, expertos y unidad doméstica resultaron metodológicamente estratégicos para aproximarnos a la caracterización de la AT. En principio, este grupo de conceptos introdujo una serie de variables o parámetros ${ }^{45}$ (Ver ítems a relevar en el formato de entrevistas del Anexo 3.2), los que permitieron organizar la información sobre el proceso de tejer y la división en etapas o eventos; los actores y sus acciones; los recursos; las técnicas e instrumentos utilizados, y la producción de objetos o piezas textiles.

Los gráficos 1 , 2 y 3 presentados en el acápite anterior muestran la construcción de la secuencia operativa representada mediante un modelo básico de operaciones: Etapa 1, Etapa 2 y Etapa 3 y sub- operaciones: etapa1a: hilar, etapa1b: torcer, etapa1c: madejary sub-sub-operaciones, como, e1.1a: hilar el primer cabo, e1.2a: hilar el segundo cabo. El esquema toma una forma arbórea en la cual se reconocen relaciones de sucesión e inclusión. La enumeración de las operaciones en el diagrama es similar a la que existe en una secuencia que denominaremos completa.

Los diagramas de árbol -presentados como 4, 5 y 6- ilustran y muestran de manera sectorizada la secuencia textil. En el esquema, la proximidad a la "RAÍZ" indica que las categorías de la AT comparten aspectos comunes, mientras que los sectores que se alejan por sus brazos, dan cuenta de aspectos en los que ellas presentan mayores diferencias entre sí. Cada grupo de pequeños brazos por sectores puede señalar diferencias acerca de los criterios utilizados en la clasificación de los brazos mayores. Más que un ordenamiento jerárquico de niveles de información; estos diagramas dan cuenta de los recorridos que

\footnotetext{
45 "Variables ( ...) no son otra cosa que conceptos susceptibles de ser divididos en categorías, se los puede clasificar según su función lógica en la proposición y según su nivel de medida." (Korn y Asúa, 2004:154). Una "variable es algo que puede tomar más de un valor. Los valores pueden ser palabras o números." (Bernard, 2006:28)
} 
llevan a las sucesivas transformaciones de las materias primas y señalan las múltiples direcciones por donde fluye el conocimiento entre los actores involucrados.

El conjunto ampliado de categorías relevantes para la descripción de la AT, finalmente incluye la siguiente asociación de variables:

*actores, lugar y tiempo de la acción;

*división del trabajo, tareas por edad y sexo, aprendizaje y parentesco;

*materias primas y productos: clasificación, proporciones, color, tipos de fibras, densidad, tensión, absorción de tintura, estructuras textiles; transformación a través de estados sucesivos;

*herramientas utilizadas, sus partes, articulación, nombres y técnicas;

*tipos de operaciones manuales y el movimiento de cuerpo;

*imaginarios, aprensiones y afecciones involucradas en los textiles;

*los contextos espaciales y temporales.

De este modo a partir del relevamiento de la información sobre la base de la secuencia inicialmente postulada, el análisis permitió un mayor número de categorías relevantes a la AT, incluyendo las aportadas por los mismos expertos y aquellas propuestas por el investigador. En su conjunto, las categorías iniciales y las nuevas, pueden considerarse y agruparse bajo dos tipos de criterios: los que hacen referencia a los elementos 0 componentes de la AT y los que hacen referencia a la idea de proceso o secuencia. Los componentes están representados por los actores, la tecnología y los productos; el proceso por las relaciones entre los componentes, es decir, las relaciones sociales, tecnológicas y de objetos-bienes. 


\subsection{1- La secuencia operativa en la actividad textil}

La descripción del proceso de elaboración de textiles en el pueblo de Molinos y zona de influencia en los Valles Calchaquíes basada en el modelo de la secuencia operativa, contiene una serie de tareas y eventos distribuidos en etapas. Cada una de ellas eonstituye se diferencia de las otras por el tipo de recursos utilizados; la participación de un experto en algún aspecto de la AT y sus conocimientos acerca de las tareas involucradas; por la tecnología específica, así como por los productos obtenidos.

El orden que se establece desde la obtención de la materia prima hasta el producto final queda constituido por el encadenamiento y sucesión de las tres etapas. Aún cuando éste es el proceso esperado, constituye un modelo ideal de AT, ya que desde el punto de vista de cada especialista, el proceso se inicia con su actividad específica y muchas veces él o ella no sabe bien dónde termina. En este sentido, las etapas serán abordadas como unidades completas y mínimas (Fischer, 2008) y se referirán al hilado, tejido y composición de los textiles.

La condición de los actores es doble, por un lado, son conocedores y hasta organizadores que median en el proceso completo de la AT, y por otro, expertos, con carácter de especialistas independientes si consideramos alguna etapa particular del proceso de elaboración de un textil. Una evaluación comparativa del porcentaje de conocimiento de los actores sobre cada una de las etapas de la secuencia completa, avala este resultado.

La denominación y descripción de los eventos de la secuencia requiere de especial cuidado respecto a los términos utilizados. Presentamos aquí las voces locales que serán correlacionadas con la terminología técnico-académica sobre el tema. ${ }^{46}$

\footnotetext{
46 Los términos que se destacarán en letra cursiva son términos propios de la textilería en Molinos, muchos de ellos son voces en lengua quechua, aymara o cacán (Sóla, 1975). Estos términos también pueden vincularse por su significado a términos equivalentes en las clasificaciones técnicocientíficas (Emery, 1966; Rolandi, 1978; Iriarte, 1987, Fung Pineda, 1998)
} 


\title{
3.2.2- HILADO
}

La primera etapa de la secuencia que consideraremos es la del hilado, desarrollada por las expertas hilanderas, las cuales organizan y ejecutan una serie de tareas que culminan con la elaboración de los hilos. Este proceso se inicia con la obtención y selección de las fibras para tejer, continua con el tizado ${ }^{47}$ o composición de la lana, la elaboración del hilo o hilado propiamente dicho; la formación de ovillos u ovillado; e/ torcido o iscanchado para obtener el hilo. Luego, la formación de madejas de hilo para el lavado, teñido y nuevamente ovillado del hilo para tejer.

La tecnología para esta etapa conjuga, por un lado, el conocimiento y manejo de técnicas de procesamiento de las materias primas y por otro, el soporte de los instrumentos adecuados para su elaboración.

El producto principal resultado de esta etapa es el hilo, material que da comienzo a la siguiente etapa, la del tejido.

\subsubsection{1- Hilanderas}

Las hilanderas, son el grupo de expertas en el hilado. Actualmente, estas tareas incluyen solamente a las mujeres, aunque en otras décadas se han observado a los hombres hilando con máquinas a pedal ${ }^{48}$.

\begin{abstract}
"por eso yo nunca he aprendido a hilar, ni torcer, no puedo, eso es trabajo de mujeres. Es muy difícil que un hombre le vaya a hilar, yo, yo quería aprender por curiosidad, para saber todo, ¿me entiende? todo el proceso, para bueno hilar, bueno, así se hila. Pero nunca he podido aprender, eso ya es una cosa innata de la mujer, el varón no, el varón ya hace otro trabajo
\end{abstract}

\footnotetext{
47 Esta voz proviene del quechua tticsay = sacar el pelo, cardar. Según el diccionario de regionalismos salteño. (Solá, (1949) 1975: 322)

48 En las notas de campo de María Rosa Martínez aparecen mencionados dos hombres del pueblo de Molinos que hilaban con máquinas a pedal (Martínez, 1980).
} 
más rudo. Dice que en Catamarca peinan las mujeres, por eso es que el poncho es menos compacto" (LZ, 52 años, Tejedor, Molinos)

Las unidades domésticas ${ }^{49}$ de los expertos han sido el campo de observación preliminar para el aprendizaje de de la actividad, en el que les fue posible desde niños acceder a las prácticas y saberes pertinentes, a la información acerca de quienes están involucrados en la AT en la zona, a los criterios que orientan y justifican la división y complementariedad del trabajo entre mujeres, niños y hombres. Al mismo momento reconocer el tiempo y el esfuerzo que se dedica a la actividad en el marco de las restantes actividades de subsistencia de los grupos domésticos.

De este modo, el entrenamiento para ser una buena hiladora se inicia desde niña, alrededor de los 5 o 7 años. Se aprende de las mujeres mayores de la familia, madres, tías y abuelas. Se comienza mirando y participando gradualmente en tareas que van de menor a mayor complejidad. Por ejemplo, se inician en el hilado con retazos de lana de oveja para frazadas, del cual se obtiene un hilo grueso. Luego, cerca de los 12 años, se aspira a obtener hilos de lana de camélidos, de llama para ponchos y chalinas y por último, lana de vicuña, para obtener hilos de muy poco grosor.

"A hilar aprenden desde chiquitas, pero ahora ya no, en el cerro si, si, pero aquí en el pueblo ya no, ninguna, pregunta a las chicas de la escuela, ninguna sabe hilar porque ya no. $Y$ tendrán 5 años, tranquilamente andan hilando" (GTR, 69 años, Hilandera, El Refugio)

El hilado no es una actividad de tiempo completo, pueden pasar varios días sin ocuparse de hilar, porque hay muchas actividades domésticas que atender. Otras veces se realiza simultáneamente con las tareas cotidianas.

49 Las unidades domésticas son consideradas como una "unidad compleja que incluye tres componentes: social (grupo de personas unidas o no por lazos de parentesco y que comparten la residencia), espacial (el espacio físico que habitan), y económico (actividades de subsistencia del grupo realizadas total o parcialmente en ese ámbito)." (Crivos, M. y M. R. Martínez, 1996:14). 
"Hilar sentada, parada, andando, caminando. Las mujeres que hilan, lo hacen andando o sentada, de cualquier forma...y a veces cuando están así, cuando están pasteando la oveja, si están cuidando la oveja..." (DLGA, 78 años, Hilandera, Molinos)

"Así yo cuando salgo para el Pueblo, yo llevo mi puchicana voy, tengo lanita compuesta y agarro la, esta lana voy hilando" (LCH, 71 años, Hilandera y Componedora, Pucará)

"Hilan de noche, se sienta en el rinconcito por allá, he puesto la luz en la mesa y me he sentado en una silla y me he puesto a hilar. Los chicos ya se han ido a dormir. No pienso, tranquila hilo, hilando. Buen! digo, aprovecho y ya doy más porque a veces ya, ya no hilo por hacer otras cosas y pierdo ya de trabajar esto, pero para mí no es nada como no es ogro, uno tiene que hacerlo." (LCH, 71 años, Hilandera y Componedora, Pucará)

"Hilo caminando cuando va a buscar la leña. Eso de caminar era de antes, ahora no ya puedo voy a hilar un solo. Yo cuando era más joven, yo sabía ponerle así, prender el fuego a leña, le pone las maderas y ardiendo yo me sabía sentar a hilar, hasta la una, hasta las dos, las tres de la mañana, ... ese para poncho, bien finito". (DLGA, 78 años, Hilandera, Colomé)

Las hilanderas sienten que en la tarea de fabricar los hilos ellas están transfiriendo una parte de sí mismas, el trabajo de sus propias manos se proyecta hacia otros sitios del valle por donde se vende el textil. La elaboración de una pieza textil por la hilandera tiene implicancias materiales, pero al mismo tiempo psicológicas y socioculturales:

“Es que no me gusta pues andar de gana así. Tengo que salir siempre haciendo algo, ya para andar sin hilar, sin hilar le digo eso no?, sin hacer nada, le digo: - 'zas andan tonteando', le digo, con las manos, parecen lívido, no más. Acostumbrada ya, anda vergüenza de andar así no más digo: - ¿qué andará haciendo esa tonta, digo, que va por ahí, con las manos sin saber que decir?' (LCH, 71 años, Hilandera y Componedora, Pucará) 
“En Cafayate están mis manos. En serio, a veces Salta, y para más allá, ¿cómo se llama esa parte? No me acuerdo cómo se llama ..., pero para ahí también he hilado. ¿Ande andarán mis manos del hilao? " (LCH, 71 años, Hilandera y Componedora, Pucará)

"Hay un lugar donde están los trabajos. Están cada uno con su nombre, los trabajos. Anda mi nombre rondando por todos lados". (SCHG, 46 años, Hilandera y Tejedora, Tomuco)

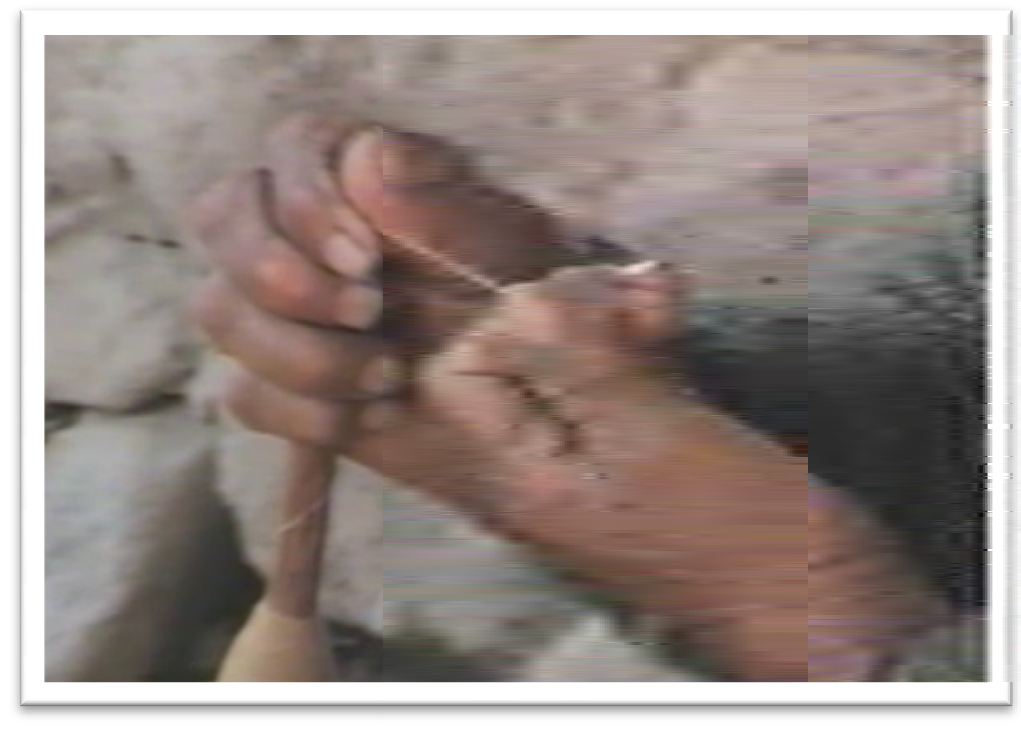

3.7. Hilandera con puchica

El hilado también implica una relación con los sentidos, con la percepción y transformación del cuerpo por la actividad, vinculando la trayectoria de tejedora con su trayectoria de salud. Se asocian también explicaciones y representaciones propias. En los relatos aparece la lana como un elemento que con el paso de los años y el trabajo del hilado produce afecciones físicas en las hilanderas:

"La lana es muy airienta y es así cuando, cuando usted se ha estado hilando y empieza a amotinar todo, como si fuera viene cansancio, amortigao, así se hace, ... (GTR, 69 años, Hilandera, El Refugio) 
Las lanas son un elemento que también aparece en otros contextos, como la Señalada. Esta una práctica ${ }^{50}$ que se realiza anualmente y consiste en ponerles marcas al ganado que se cría en las unidades domésticas ubicadas en los sitios de altura. Además de darle una identificación a cabras, chivos y ovejas, la gente invita a sus amigos y vecinos y pasa todo el día en los corrales festejando este evento. Las lanas teñidas de múltiples colores se ponen en las orejas o cuerpos de los animales y las que sobran se entierran junto con la coca y el alcohol.

La evocación a esta festividad a partir de la actividad textil, introduce un tema de especial interés para el estudio de las sociedades del NOA, como es el reconocimiento y ofrenda a la Pachamama. Un ser sobrenatural representado por una viejita que es dueña de la puna, los valles y todos los animales que la habitan, y que controla el multiplico o reproducción del ganado doméstico y la apropiación y consumo que los hombres hacen de camélidos silvestres en la zona.

\subsubsection{2.-Lanitas}

La preparación del trabajo para el hilado comienza con la clasificación de las materias primas. En la zona del Valle Calchaquí se utilizan principalmente fibras naturales de origen animal. Las que están representadas por una variedad de tipos y calidades.

En relación con la calidad de las materias primas, los expertos señalan diferencias entre las fibras más suaves y más ásperas, las más livianas, las más gruesas y las más resistentes. La clasificación de las lanas en base a estos criterios está vinculada a la procedencia de distintas especies animales en la zona: oveja merino, oveja criolla, vicuña, guanaco, cabra y llama.

La diferencia de colores es otra cualidad tenida en cuenta y se vincula con las posibilidades de teñido y a la cantidad disponible para elaborar determinadas piezas. La distinción que los tejedores establecen sobre la calidad de las piezas está

\footnotetext{
50 Una descripción detallada de la Señalada en García, 1998 y García y Rolandi, 2000.
} 
fundamentalmente vinculada a la valoración de color y longitud de la "mecha"de la fibra. Por ejemplo, la lana de vicuña es de tres colores, la parte del lomo es beige, la parte de la panza es color blanco, pero es de una calidad inferior, por ser áspera. La parte intermedia, se denomina "mezquelillo", o sea, es una mezcla de los otros dos. Entre la parte del lomo y la parte de la panza hay una franja no tan suave como el lomo, pero más suave que la panza. La lana que se obtiene de las patas del animal es más corta del mismo modo que la de la panza, la más larga es la del lomo. El poncho de vicuña más preciado es el que lleva lana beige y el más modesto es el elaborado con lana blanca. Si tomamos como ejemplo la lana de oveja, se clasifica según proceda de ovejas tipo merino, del que se obtienen fibras más suaves y de oveja criolla, fibras más ásperas, cerdosas, con pelo y que no puede teñirse junto con la tipo merino porque toma más tintura. ${ }^{51}$

La clasificación de las fibras también resulta de la necesidad de obtener un tipo de hilo adecuado para una determinada clase de tejido. La obtención de diferentes hilos para la elaboración de los textiles depende de la selección e identificación de estos tipos de fibras así como de la habilidad de la hilandera para obtener un grosor y tensión requeridos por las técnicas de tejido y diseño que formarán parte de las tramas, urdimbres y flecos de un poncho.

\footnotetext{
$\mathbf{5 1}$ Los datos aportados por las investigaciones en Huancar, en la puna jujeña sobre el manejo de las llamas dan una explicación a esto a través de la selección que los pastores hacen de los machos reproductores de acuerdo a al tipo y color de lana: "Preferentemente eligen a un añacho chumpi (marrón claro), marrón y blanco", además debe tener buena cantidad de lana y sin mota ni sina" (Göbel, 2001).
} 


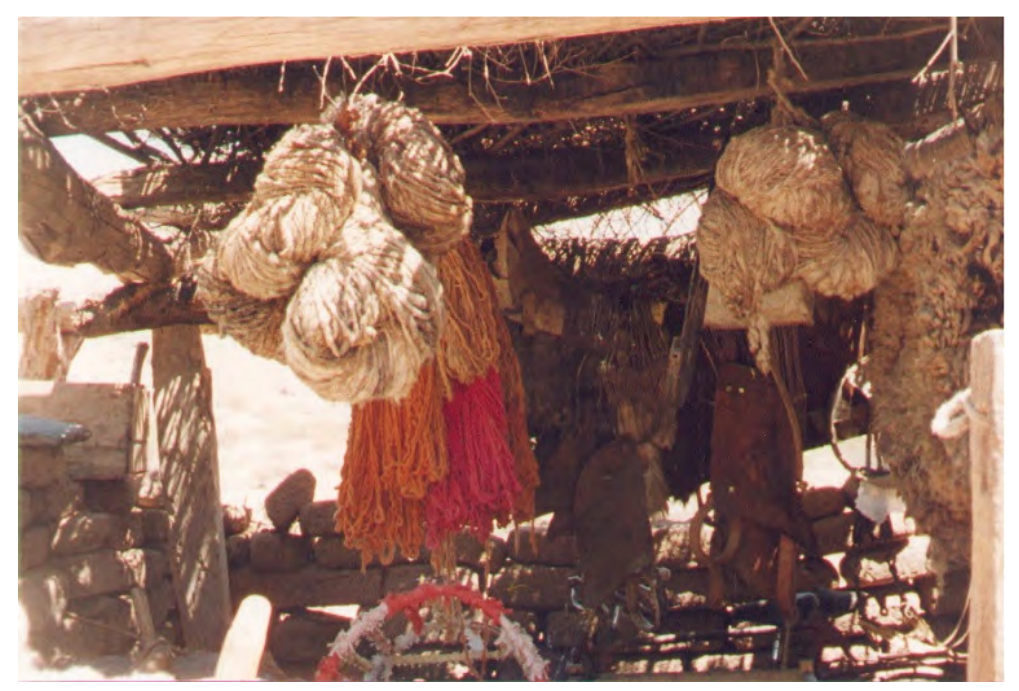

3.8. Madejas de lana de oveja naturales teñidas

El cálculo de las proporciones es otro de los aspectos que da cuenta del conocimiento y manejo de los expertos en la AT. De cada vicuña se obtienen 200 gramos de lana, para ello el animal a esquilar debe tener dos años. La lana de vicuña es muy liviana y de ella se obtienen dos colores definidos y uno combinado. En cambio, de la lana de una oveja se sacan de 1 a 2 kilos, y de una llama se obtienen 3 o 4 kilos de lana. En el caso de estas últimas, los colores de mayor a menor proporción son el marrón, marrón claro y negro y blanco. Por último, la lana de alpaca es blanca y se obtienen dos kilos de lana, por esquila y por animal. Esta lana es más suave que la lana de llama, pero menos suave que la de vicuña.

La clasificación de la lana consiste en esta etapa en la separación de las partes óptimas de aquellas que van a descarte por su mala calidad. De la primera selección se obtiene el "vellón", porciones de fibra que en el caso de la lana de oveja necesita ser depurada nuevamente, quitándole las impurezas o la "mota"y el "macho". En el caso de la lana de vicuña se le saca el pelo duro. Con una porción menor del vellón se forma el "yuchique"o "cadejo", que colocado en la mano -alrededor de la muñeca- permite ir trabajando y manipulando pequeñas cantidades de fibras que se transformarán en las hebras ${ }^{52}$ del hilo.

\footnotetext{
${ }^{52}$ Hebras son los ramales, cabos o elementos que forman parte del hilo.
} 
"Si va a hilar, hay que componer la lanita y después comienza a hilar. Va envuelto aquí en la mano y después van hilando así, ve que usted lleva así, y después ya van largando ahí, y después entonces ya va con este y van estirando. El yuchique o cadejo, va envuelto aquí en la mano y después van hilando así ¿Ve que usted lleva así?, y después ya van largando ahí, y después entonces ya va con este y van y van ..." (LCH, 71 años, Hilandera y Componedora, Pucará)

Para la elaboración del hilo o "hilado"la más importante es la posición de los brazos y los movimientos de la mano de la persona que lleva adelante esta tarea. Comienza con el huso suspendido en el aire y con un impulso dado por los tres dedos -pulgar, índice y anular- se pone a girar el huso. La velocidad el giro que toma el huso se va moderando poco a poco mientras recorre, suspendido por la lana la distancia que media entre la mano y el piso. Finalmente apoya en el piso e inmediatamente queda quieto, o en el aire mismo se va desacelerado o vuelve a recibir un impulso de los dedos que los pone a girar nuevamente. Mientras tanto la mano izquierda tiene a la altura de la muñeca el "yuchique" y entre el dedo pulgar y el índice va tomado y dejando pasar un pedazo de "lanita compuesta" que unos centímetros más adelante se transformará en un primer esbozo de hilo. Cuando el huso para de girar, la hilandera la toma entre sus dedos y se hace un pequeño nudo en el extremo superior. Esto marca un punto de inicio y de apoyo para que la hebra comience a torcerse, adquiriendo con las sucesivas vueltas la estructura de una hebra. Cuando la hebra ha tomado la forma y tensión necesaria, se enrosca en el centro del huso y se avanza con el resto de la hebra para torcer. 


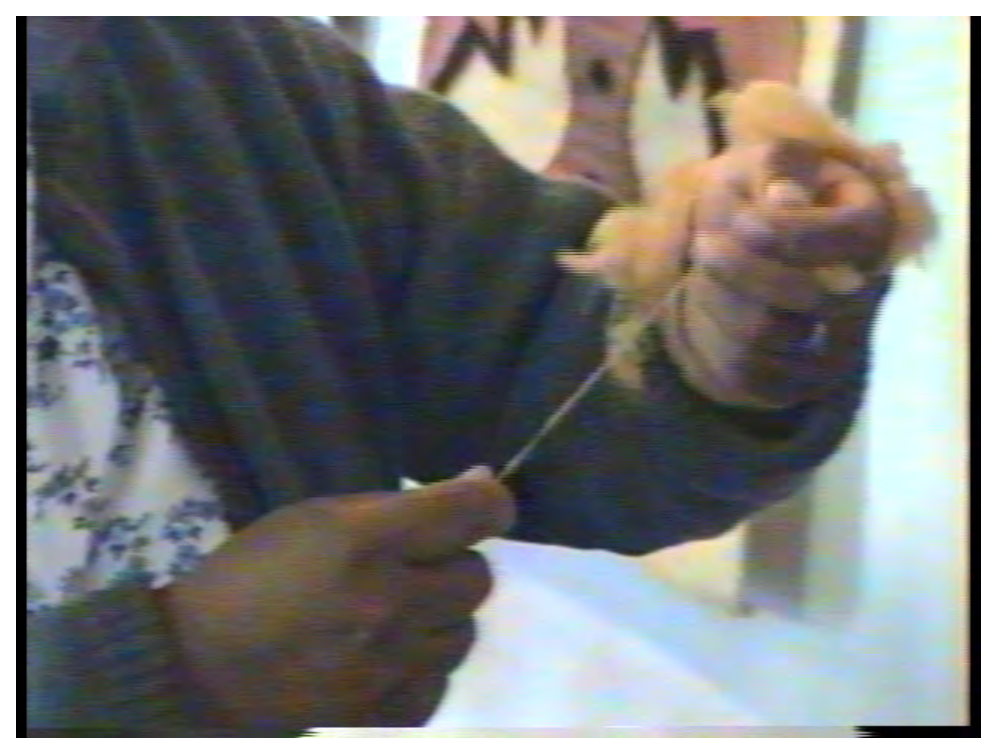

3.9. Preparción del hilo y yuchique en la muñeca

\subsubsection{3- Instrumentos}

Los instrumentos indispensables para realizar el hilado son la "pushicana", huso o "maderita", junto con la "mushuna'54 o tortero, que va colocado en el extremo distal inferior de la "pushicana"y que cumple la función de contrapeso favoreciendo el aumento de grosor del hilo.

Los instrumentos para hilar -así como para tejer y componer-, son propiedad de cada especialista y por lo general se han obtenido de los padres o abuelos como parte de un preciado legado textil familiar. En otros casos, se mandan a construir por encargo a los carpinteros, herreros, o ceramistas de la zona. En ambas situaciones son utilizados únicamente por el experto y raramente se prestan o se intercambian.

53 La mayoría de los instrumentos, así como los procesos involucrados en la textilería utilizan vocablos de origen quechua y aymara. Según el diccionario de Regionalismo de Salta "Puiscana: Huso primitivo de los puneños y calchaqueños, con el que se hila el vellón de lana tizada. Consta de un palito al que se le agrega, a manera de volante, la muyuna o tortero. Es voz quichua phuskkay (pushcani) $=$ hilar. O también phuskka= huso, y na= sufijo de derivación nominal". Solá, (1945) 1975:272.

54 "Pequeño disco de madera, piedra o barro cocido perforado en el centro y que encaja en la puiscana para que le sirva de volante. Llámanlo asimismo puisquero y tortero. Del quechua muyuy= andar a la redonda, girar; muyunáyay = deseo de dar vueltas; muyu = redondo, cicular." Solá, (1945) 1975:228-326. 


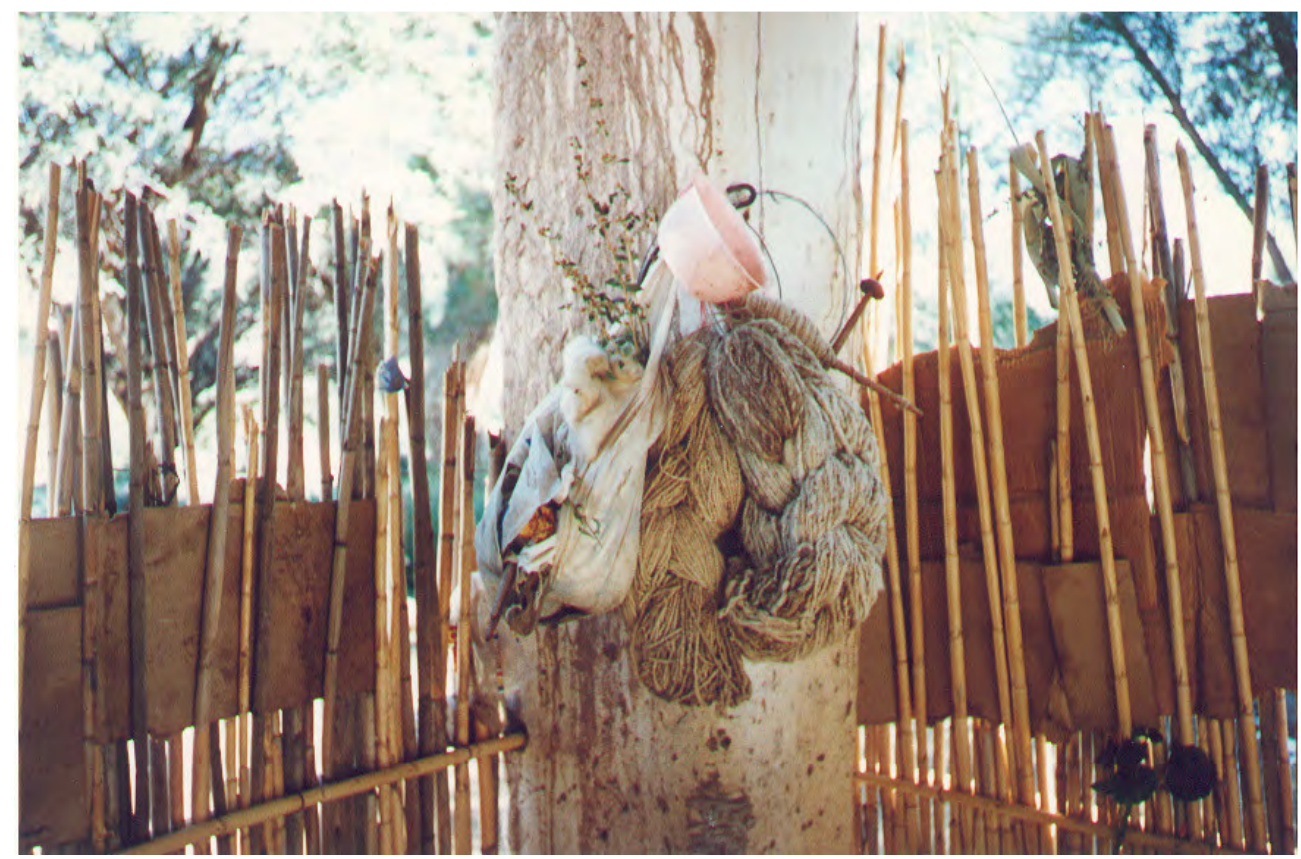

3.10 "Atado"de lanitas e instrumentos para tejer

\subsubsection{4- Iscanchado o torcido}

"Torcer" o "iscanchar" consiste en el retorcido de dos hebras que ya han sido torcidas o hiladas. Es una tarea que se realiza con la misma mecánica que la del hilado pero los giros de estos dos elementos, se hacen en el sentido contrario. Como instrumento también se utiliza la "pushicana".

“Porque para hilar se da vuelta esto así, para este lado, y para torcer va para el otro lado. Hilando para la derecha, y es para la derecha, así es... Para torcer, va para la izquierda." (ML; 30 años, Hilandera y Tejedora, Luracatao)

Y si lo vemos en un ejemplo es más sencillo:

“Tengo que hilar diez, diez maderitas, tengo que llenar, y después de las diez recién comienzo a iscanchar, a hacer el ovillo. Tiene que hacer diez ovillos, diez este, pushicanas, diez pushicanas se llama esto, llenas. Y 
después usted lo iscancha al hilo y pone de 2 ramales y le sale 5 madejitas y le quedan 5." (LCH, 71 años, Hilandera y Componedora, Pucará)

El mecanismo es el mismo que en el hilado. Lo más importante es el movimiento impulsado por los dedos de la mano, la velocidad de giro de la "puchicana", la coordinación entre la mano derecha y a la izquierda para el paso de las hebras de lana. Mientras la "puchicana" sigue un recorrido hacia arriba y abajo, por momentos queda suspendida en el aire por el hilo que se va formando. En lo posible el movimiento debe ser continuo, parejo y nunca debe detenerse. Por esto, cuando la "puchicana"toca el piso y parece que lentamente va a parar de girar, la hilandera hace un chasquido con los dedos sobre el huso y rápidamente comienza a tomar velocidad.

Si la "puchicana"tiene el tortero este proceso se vuelve muy pesado y entonces, el hilo se va engrosando.

"Y esto ya cuando ya está pesado esto usted tiene que sacarle el tortero porque si no se tuerce mucho el hilo y se corta y ya no da lugar a igualar la lana. En la oscuridad ya lo hago desparejo al hilo. Ya tengo que agarrar el otro, torcer el hilo." (RV, 70 años, Hilandera, Pucará)

Los hilos para tejer que se obtienen después del "iscanchado ${ }^{155}$ se sacan de las "puchicanas"y se forma un "ovillo". Otros pasan directamente el hilo torcido desde las "puchicanas" a un instrumento llamado "iscanchador" o "madejador". Una vez que el hilo es traspasado a estos aparatos, se saca y se obtienen las madejas. Mediante esta disposición el hilo queda preparado para la siguiente etapa, la del teñido.

“Toma pedazos de lanita y hace el hilo que poco apoco va colocando en la puchicana. Después agrega más. En dos días llena una puchicana. Para

\footnotetext{
${ }^{55}$ Iscanchar/ Hiscanchar/Iskaychay: voz quechua que indica la acción de doblar, duplicar. Separar de dos en dos. Solá, (1945) 1975:175-185.
} 
El Estudio Etnográfico de la Actividad Textil como aporte a la Caracterización del Modo de Vida en el Pueblo de Molinos y zona de influencia (Provincia de Salta)

completar una puchicana con dos lanitas compuestas ya completa la puchicana. Luego completa otra puchicana y después se tuercen los hilos y ya hace el ovillito." (GTR, 69 años, Hilandera, El Refugio)

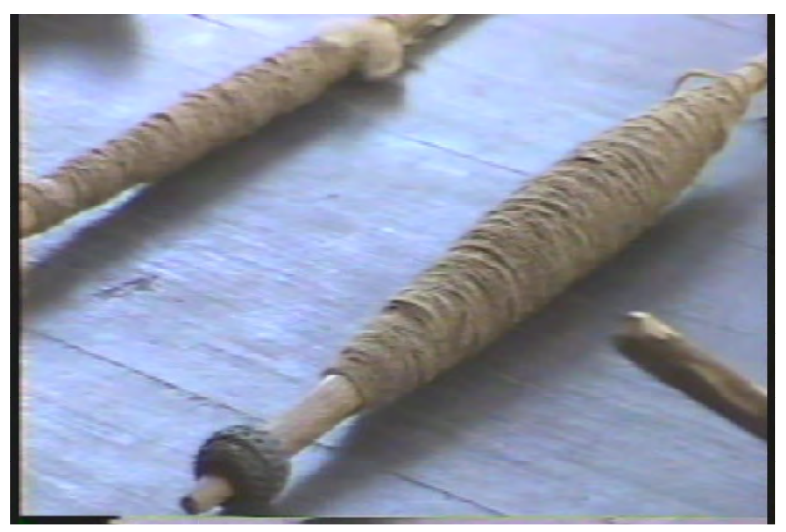

3.11. Puchicanas con tortero de piedra e Iscanchador

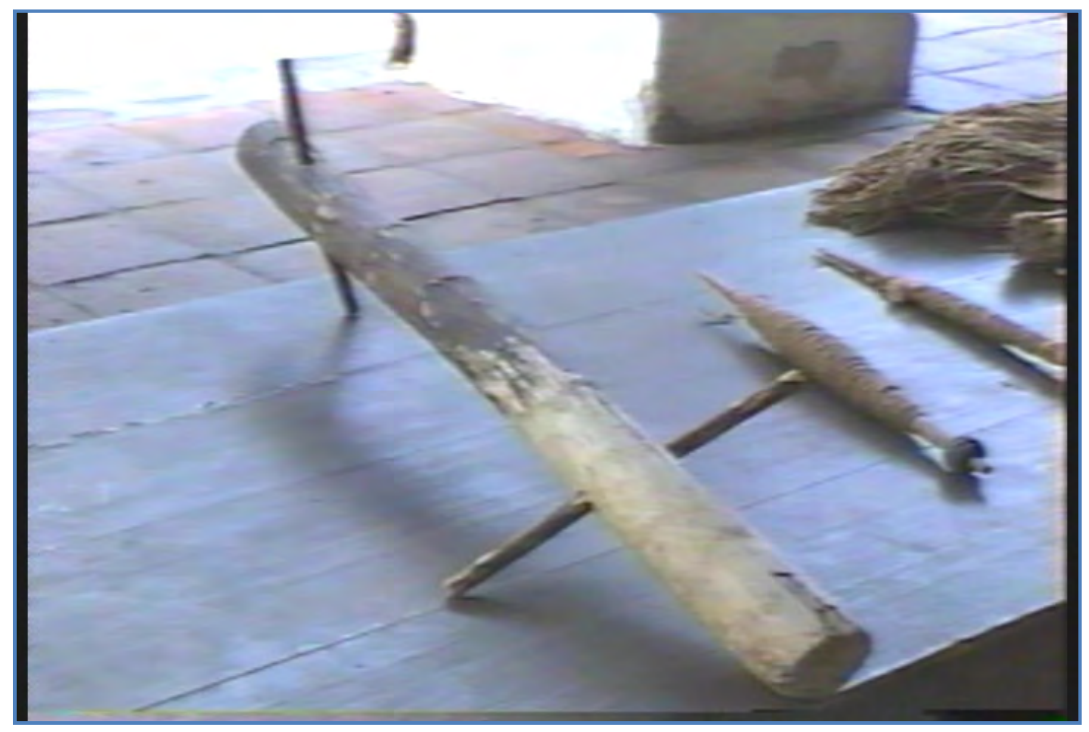

3.2.2.5- Hilos

Los productos obtenidos de esta etapa son diferentes tipos de hilos que se clasifican de acuerdo a la técnica y cantidad de cabos o ramales que tienen en su estructura: de un cabo, dos cabos y tres cabos. La cantidad de ramales define el cuerpo del hilo. La tensión 
del hilo, es otra condición que determina cuál será su aplicación posterior, es decir, si se utilizará para la trama, o para la urdimbre o si es para bastidor. Por ejemplo; el hilo finito se usa para urdimbre de frazada. La calidad de la pieza terminada también depende de las condiciones del hilado:

"El tejido queda parejito cuando es más gruesito el hilo, cuando es de una sola mano pero cuando hacen de dos manos, por ejemplo, yo estoy hilando un poco y usted está hilando otro poco y entonces ya no sale parejo la prenda, así es tiene que ser hilado de uno solo, entonces sale parejito" (RV, 70 años, Hilandera, Pucará)

El hilo de 1 hebra o cabo por lo general se une a otra cabo mediante el "ischanchado"o torcido y forma el hilo de dos cabos. El hilo de 2 cabos es el que habitualmente se teje para los ponchos. A su vez estos hilos de dos cabos pueden diferenciarse por su grado de tensión en el torcido, según sean para la trama -menos tensos- o para la urdimbre, -más tensos. El hilo "mishmido" ${ }^{156}$ es un hilo de de un cabo muy poco tenso, tiene un aspecto intermedio entre la lana compuesta en el cadejo y un hilo de un cabo. Se realiza con un huso muy largo y se coloca en el "bastidor" para la confección de peleros, pieza tejida que integra el sudadero, sobrepelo o apero de montar (Solá, 1975; Rolandi y García, 1997).

El "mishmido"también se utiliza para los trenzados ${ }^{57}$. Estos no constituyen exactamente un textil en el sentido en que lo hemos venido utilizando y definiendo. El mishmido para trenzado generalmente se hace de lana de llama y se toman 3 cabos para pegar, es decir, manipular y formar una trenza de aspecto tubular. Son muy llamativas por la combinación de lanas blanca y marrón oscuro con las que se forman diferentes diseños. Entre estos artefactos los más habituales son las sogas o cuerdas cortas que se utilizan para amarrar objetos o para que los teleros sujeten las partes de los instrumentos para tejer, palos y

\footnotetext{
${ }^{56}$ Mishmiña o mismiña es voz aymara que significa torcer una soga. Solá, (1945) 1975:221

57 Estas piezas no constituyen exactamente un textil en el sentido en que lo hemos venido utilizando y definiendo. Pueden ser considerados como "tejidos", un tipo especial de textil cuyo proceso de tejido ocurre por entrelazamiento oblicuo manipulando simultáneamente un grupo de elementos. Esto marca una distinción en la clasificación con los textiles, por el criterio de elaboración de sus elementos.
} 
pedales de lisos. Otras sogas se usan como parte del bozal en los caballos ensillados o las más largas, de varios metros, para sujetar y trasportar proveeduría o alimentos, lana, mantas, sal en los burros de carga o para atar las pilas de leña y cargarla sobre la espalda de las mujeres, niños u hombres que salen a recolectar. Las hondas ${ }^{58}$ son un tipo de sogas utilizadas para cazar, arrear y bolear animales.

\subsubsection{6- Entintar}

Teñir o entintar es el procedimiento para dar color a los hilos. Entre los recursos naturales requeridos para teñir se utilizan tinturas vegetales que se recolectan en la zona de Molinos. El proceso incluye, además el uso de mordientes o fijadores que ayudan a la absorción, potencian la intensidad y evitan la pérdida de color en los hilos. Entre los recursos industriales, las lanas de tipo mercerizadas ${ }^{59}$ y las anilinas o colorantes químicos también han sido incorporadas en mayor o menor medida según el acceso a los centros de distribución y comercialización y a las pautas de consumo del mercado de artesanías. En este sentido, en la actualidad, activada por el turismo se percibe una tendencia que promueve la utilización de tinturas naturales en relación a una idea del producto textil como un objeto auténticamente salteño.

Las tinturas naturales provienen en su mayoría de yuyos o árboles de la zona. Un listado de los más utilizados, son, la chilca (Flourescencia riparia) ${ }^{60}$ que se recolecta como planta con propiedades para teñir los hilos. Se utilizan las hojas y luego mediante el procedimiento habitual (que describiresmos a continuación) se obtienen hilos de color

\footnotetext{
58 Ver diseños arqueológicos en Rolandi, 1978 en página 29 y etnográficos en Hoces de Guardia Ch y Rojas Z. 2003 página 69 a 71.

59 El mercerizado es uno de los tratamientos químicos industrializados que se realizan sobre las fibras para mejorar sus propiedades. Este proceso aumenta el brillo, la fuerza, y la afinidad de las fibras a la tintura.

${ }^{60}$ La determinación de las especies tintóreas utilizadas en Molinos se ha realizado en el Laboratorio de Etnobotánica y Botánica Aplicada (LEBA_UNLP) y una parte de ellas han sido publicadas en trabajos sobre etnobiología en Valles Calchaquíes. Otras especies han sido determinadas mediante catálogos específicos y a partir del nombre vulgar. (Marzocca, 1959; Cannon y Cannon, 1994)
} 
verde. Con la patilla ${ }^{61}$ se utiliza la raíz y se obtiene un color beige. El árbol negro, (algarrobo negro o Prosopis nigra) se tiñe mediante procesamiento de la raíz y da color negro. El nogal (juglans nigra) es un árbol cultivado en la zona que puede estar en la huerta familiar, se utiliza el fruto. La gente del lugar dice la cascarita (mesocarpio) indicando la parte del fruto que sirve como tintura. Se necesitan varios kilos de nueces para poder teñir, por ejemplo, alrededor de 5 kilos de cáscaras para dar color al hilo de una colcha. Para piezas más chicas entre $1 / 2$ y 1 kilo. Para la preparación hay que moler las partes del fruto y luego hervir la molienda en agua dentro de un recipiente con capacidad para 50 litros. Luego se cuelan y se sacan las cáscaras de nuez y se vuelve a hervir. Otra alternativa para obtener la tintura es introducir en el agua mientras hierve, las cáscaras envueltas en un paño bien atado, entonces empieza a largar la tintura y se evita que la nuez triturada como una especie de arenilla, se mezcle con el hilo. Luego, se suelta el hilo en ese líquido y se mezcla con un instrumento de madera hasta que tome el color. Esta última etapa toma entre 3 y 5 minutos y termina al sacar el hilo teñido para lavar y secar. El color que se obtiene es marrón claro, según dicen los tejedores: da el color de la llama y para este método de teñido no se utilizan mordientes.

El molle (Schinus polygamus) es otro árbol que se utiliza para teñir. Son necesarios entre 2 o 3 kilos de las hojas que se colocan en agua hasta hervir y luego se dispone el hilo para teñir. El churqui (Mimosa farinosa) se recolecta para teñir y se utiliza el fruto. Previamente se coloca en una pecana o mortero de piedra que sirve de recipiente y se muele con la mano, otra piedra que cumple la función de triturar el fruto. Después de molido se echa al recipiente de teñido con agua y varios kilos de hilo. Del árbol del algarrobo (algarrobo blanco o Prosopis alba) puede utilizarse su fruto. Se toma la vaina o fruto de la algarroba se coloca en una base grande y se muele. Luego se la coloca con agua en otra vasija y se deja asentar. El agüita toma todo el gusto de la algarroba y esto es lo que se utiliza para teñir. Así el agua de la algarroba sirve para entintar. Luego se saca de allí y se coloca a hervir. Por último, se ponen los hilos a teñir. A esto se le llama talvina.

61 Patilla puede ser pata, Ximenia americana, pata viene de pagta que es tintura en quechua. Planta identificada para el Valle de Lerma. (Comunicación personal de M. L. Pochettino) 
El hollín, es decir, la carbonilla de las chimeneas en las unidades domésticas se utiliza como tinta para dar color negro a los hilos.

Las anilinas o tinturas sintéticas son difíciles de utilizar y son engañosas con los tonos en que colorean al hilo. Asimismo, son costosas y de difícil adquisición. De la esquila de lana de llama se obtiene lana blanca y en menor cantidad lana negra, marrón y una gama de jaspeados. Por lo general estas fibras no se tiñen. La lana de oveja se tiñe fácilmente con tinturas naturales y anilinas. Estas tinturas proveen una amplia gama de colores, en especial las tonalidades de rojo ${ }^{62}$ y varios tipos de verde- oscuro y claro, también el naranja, el amarillo. Se aplicaban al teñido de hilos que luego servirán para tejer bolsos, tapices, en el caso de los ponchos, siempre se utiliza el rojo y negro, marrón o azul.

El teñido puede realizarse en cualquier época del año, durante el día, en especial durante la mañana. El procedimiento requiere de los hilos dispuestos en madejas y de abundante cantidad de agua caliente colocada hasta la mitad de un recipiente. El agua debe hervir para colocar la tintura. Una vez que vuelve a dar el hervor se coloca el hilo. El agua permanece hirviendo, pero no durante demasiado tiempo, ya que se puede cocinar el hilo y desintegrarse las fibras. Luego de que durante media hora aproximadamente, las madejas de lana con la tintura hierven en forma conjunta, se coloca el mordiente o fijador del color. Para esto se utilizan los siguientes compuestos minerales y otras sustancias como alternativos: sal y agua de limón, sal y vinagre blanco, o alumbre (sulfato mineral natural). La persona que realiza este procedimiento calcula el tiempo de teñido en base a las constantes pruebas que realiza, va observando y sacando el hilo del agua con la tintura, lo exprime y se ve la intensidad del color que va absorbiendo una hebra. La tonalidad depende de la proporción de tinta o yuyos colocadas. Por último, se saca el hilo del recipiente con tintura, se enfría y se enjuga con agua limpia hasta que las madejas no tienen restos de tintura. Después del lavado, se procede a escurrirlas y secarlas.

\footnotetext{
62 La práctica ancestral de teñido con la cochinilla (Dactylopius coccus) especie de insecto que vive en la base de las espinas de tuna y que procesado se utiliza para obtener tonalidades de rojo reaparece en los últimos años. Su uso data de la cultura Paracas, en Perú hace 2.000 años.
} 

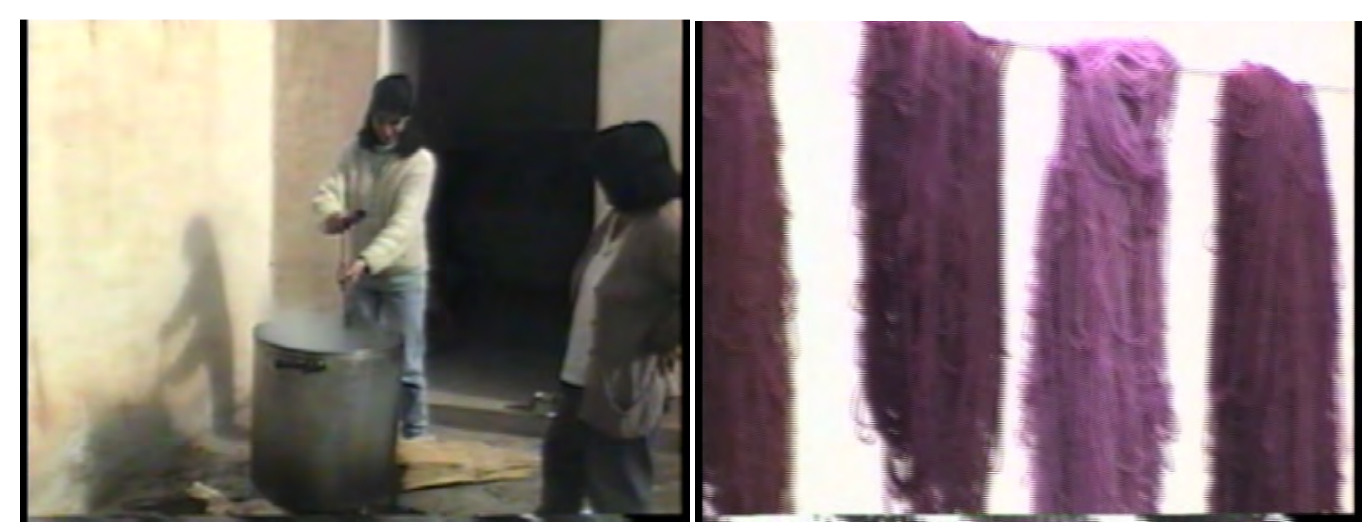

3.12. Proceso de teñido y lanas coloreadas

\subsection{3- El proceso de TEJER}

El proceso de tejido es la continuación de las operaciones realizadas en las etapas ya descriptas. Luego, la aplicación de diferentes técnicas establece operaciones complejas y el uso de utensilios especiales, y requiere de una serie de tareas rítmicas y repetitivas. Para comenzar a tejer se necesita disponer de los hilos artesanales o industrializados, los que conformaran la urdimbre y la trama, los dos elementos fundamentales de un textil. El manejo de los hilos de la urdimbre y la trama implica la utilización y conocimiento de técnicas de urdido, montado de la urdimbre en el telar, el enlisado y el tejido propiamente dicho.

\subsubsection{1- Teleros}

Los expertos tejedores son conocidos en el lugar como los teleros y se encargan de la confección de las piezas de textil tradicional. Esta designación, en particular, hace referencia a los especialistas en la manufactura de los ponchos ${ }^{63}$. El poncho es una pieza textil que se utiliza para la vestimenta habitual en la región andina. El diseño en color rojo y negro identifica a los habitantes de la zona de Salta y por eso es conocido como poncho salteño.

${ }^{63}$ Su origen es claramente andino y aparece mencionado por primera vez en 1737 en documentos escritos. (Garavaglia, 2002) 
Los tejedores de ponchos son hombres, ellos también tejen varios tipos de telas y tapices. En el caso de las mujeres es habitual que participen en el tejido de tapices, a veces, trabajan junto a los hombres en la ejecución de estas piezas. También hacen mantas, chales o rebozos ${ }^{64}$, fajas y flecos.

En sus relatos, los teleros refieren haber pasado por un entrenamiento desde niños y tener experiencia en la realización de los textiles con técnicas y habilidades progresivamente más complejas con la edad. Sin embargo, algunas mujeres entrevistadas han aprendido de adultas y a través de cursos municipales para promover el tejido como artesanía. Los teleros, en cambio afirman que forman parte de familias de tejedores:

“Yo le decía a mi señora - ¿Cuándo empezamos a tejer? Pero no quiere, porque ella no es de familia de artesanos, entonces no lo puede hacer. Por gusto lo hacía, por necesidad.

Porque mi padre tejía dos metros y medio por hora, ¿no?, y yo nunca he podido llegar a eso, porque esto viene ya de familia, ¿no? de familia...

Aprendí de mi papá claro, y mi papá de mi abuelo, y así supongo que mi abuelo de su padre y así, ¿no?, como dicen, de familia” (LZ, 52 años, Tejedor, Molinos).

El entrenamiento para ser un buen telero se adquiere en el ámbito de la unidad doméstica aprendiendo de los padres o abuelos, mirando y participando en tareas de asistencia y gradualmente en las que requieren mayor experticia. En el caso de los hombres, se inician tejiendo frazadas, luego ponchos y por último, barracán y cordonsillo. Los niños, varones o mujeres, comienzan a la edad de 7 años haciendo ovillos, a los 12, 13 años ya se ejercitan con sus primeros a textiles:

64 Rebozo: los expertos dicen que "al chal" antes lo llamaban rebozo y sirve como abrigo y para cargar a un bebé. En la literatura sobre tejidos andinos esta pieza es conocida como aguayo o lliclla: voz quechua, frazada o manta pequeña. (Solá, (1945) 1975:) 
“... para aprender empezaba por ovillar, después se comienza a urdir, yo comencé así, no? a urdir y después a enlisar que es lo más difícil para uno ya es instintivo, puede estar conversando y estar haciendo, es como manejar, va manejando un vehículo y conduciendo un vehículo y no sabe si, no se da cuenta si pisa el freno, el embrague, si hace los cambios, nada ya es una cosa, eso mismo, lo mismo es el tejido, usted está urdiendo, porque hay que cruzar los hilos en parte, ¿no? Usted ya no tiene que estar pensando que tiene que hacer eso, instintivamente lo hace, después de eso ya viene del enlisado el tejido ya viene, ahora el tejido es también es bastante difícil como de aprender, ¿no? Porque al principio las orillas una tira mucho el hilo y va quedando como serrucho, así entonces, para que quede parejito, parejito que quede el hilo en una tensión y eso digamos es difícil. Igual que para urdir, al principio estira y un hilo está en el piso otro está arriba hasta que se aprende así es, hay que urdir, ovillar, urdir, ovillar ..." (LZ, 52 años, Tejedor, Molinos)

\subsubsection{2- Espacio y tiempo para tejer}

Los espacios para tejer están delimitados por el lugar dónde se ubica el telar, así como por las condiciones climáticas de determinadas épocas del año. Las estaciones cálidas son mejores que el invierno. Aunque el viento también es un factor que condiciona las épocas del año, los momento del día y los lugares tanto del hilado como del tejido. El telar puede colocarse debajo de una enramada o armazón de cañas construido especialmente para instalarlo, alejado de las unidades habitacionales; en las galerías o espacios semicubiertos anexados a los lados de las casas y en habitaciones cerradas con ventanas y puerta. Para algunos tejedores los horarios de tejer se adecuan y alternan al ritmo de las actividades cotidianas dentro de la unidad doméstica, o con otras actividades fuera, como los trabajos de albañilería, siembra, cría de animales. Para otros, es más rutinario y día a día tejen para terminar la pieza por encargo. 


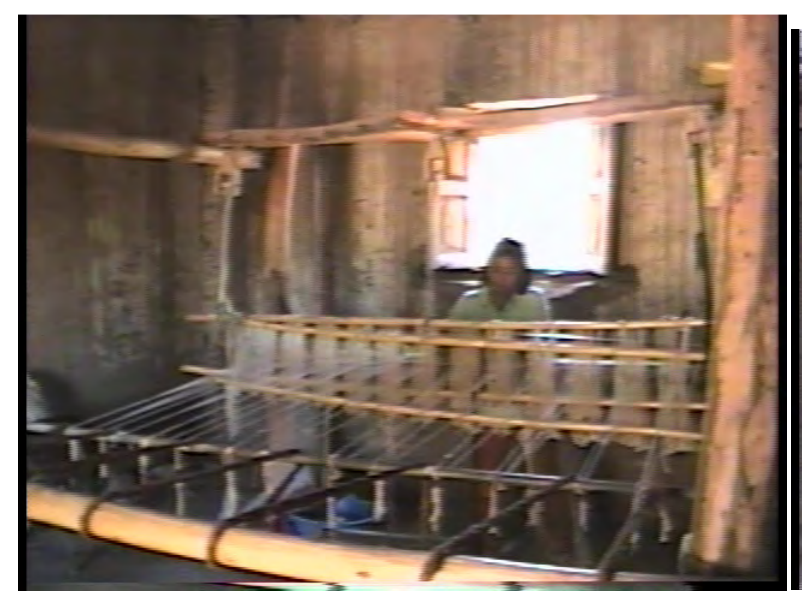

3.13. Tejedora y telar en una habitación cerrada

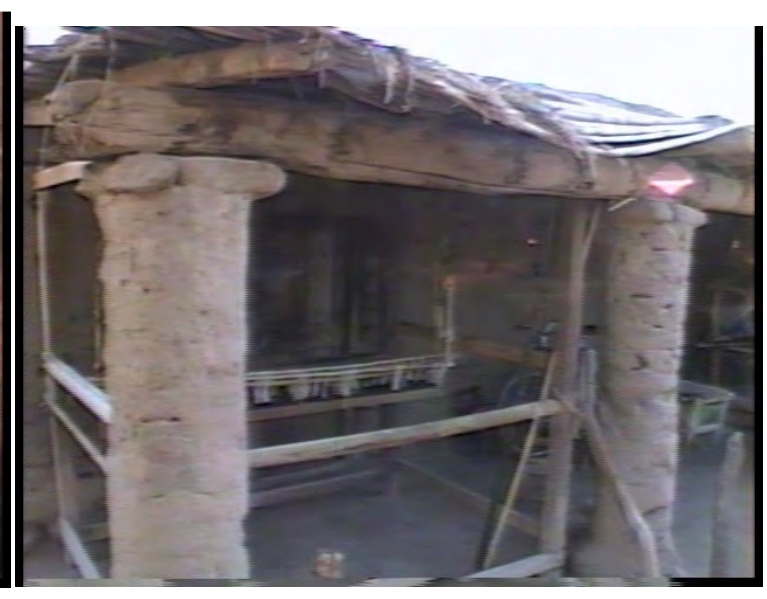

Telar en galeria

\subsubsection{3- Urdido}

El urdido es una tarea que se realiza previamente al tejido y consiste en el arreglo y disposición de los hilos que formarán la base de la pieza textil o urdimbre. La urdimbre se prepara fuera del telar, generalmente se prepara a ras del piso y en espacios abiertos ya que muchas veces toma grandes dimensiones longitudinales. Generalmente en el patio próximo a las galerías semicubiertas de las casas, se colocan dos estacas o tres con una distancia que se calcula en relación al largo esperado de la pieza a tejer. Allí se tiende la urdimbre, se toma el hilo, se pasa por la estacas y se entrecruza formando un ocho. El urdido puede llevar un día completo de trabajo. El proceso de urdido termina cuando se saca la urdimbre de las estacas y se guarda formando una trenza o encadenada. En otras ocasiones, terminado el urdido, la urdimbre se transporta, se extiende y se coloca sobre lo estructura del instrumento para tejer. 

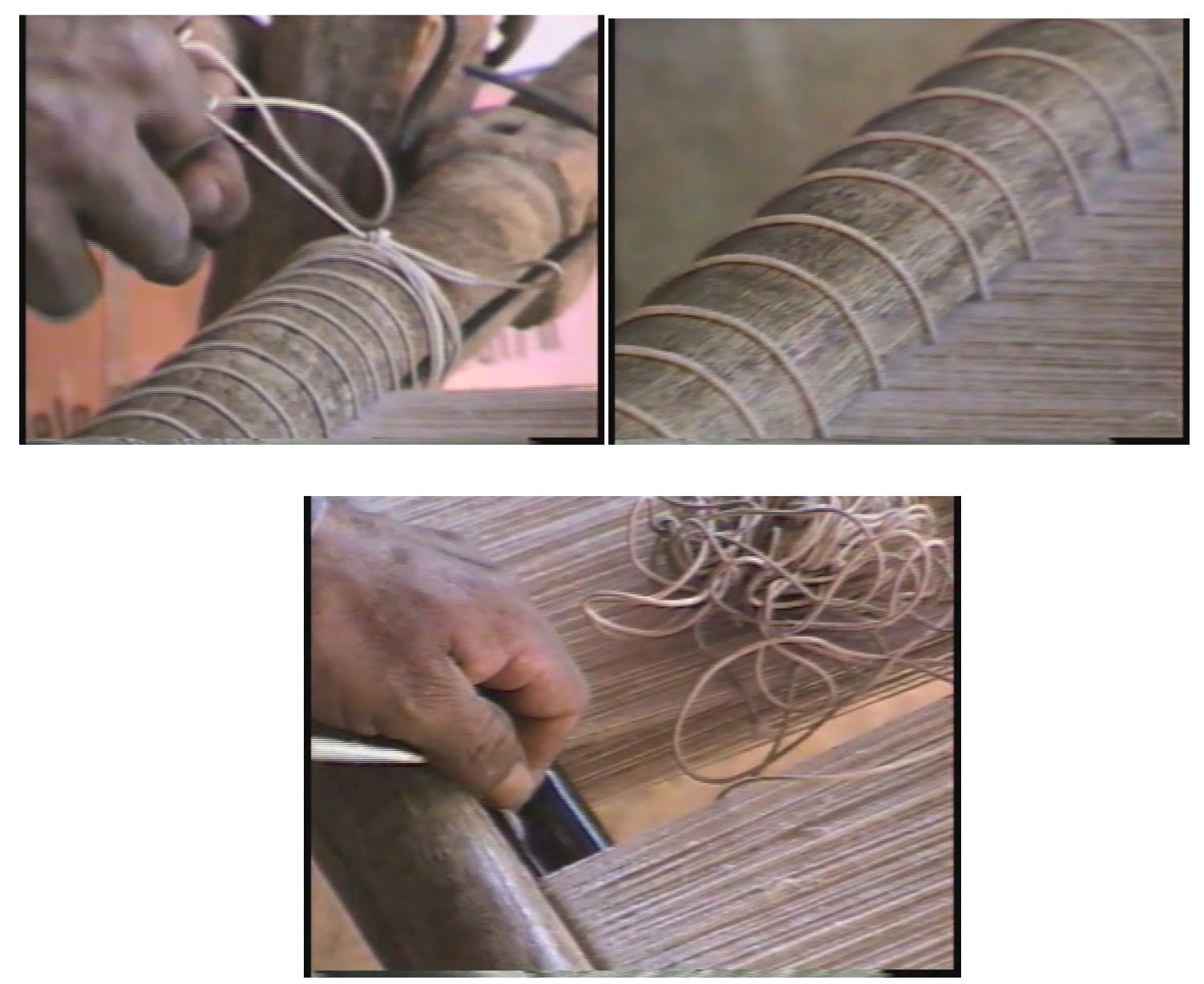

3.14. Secuencia de preparación de la urdimbre

Dispuesta ya en el instrumento para tejer, se habla de los hilos de abajo, para mencionar a la urdimbre. En esta instancia los hilos son contados, acomodados a distancias iguales unos de otros y estirados por los extremos mediante los rodillos del instrumento para tejer. Así, se aprecia el tamaño o ancho de la urdimbre, el cual depende de las proporciones de la pieza que se quiera obtener. La cantidad de hilos colocados puede alcanzar hasta los 300. En el urdido el hilo no debe cortarse, ni unirse, debe ir continuo y la materia prima preferida es la lana de oveja hilada de modo más retorcido. 
La urdimbre muchas veces lleva marcas, es decir, se señala en algunas partes mediante un nudo para indicar la mitad del hilo, o se le colocan hilos de otro color para indicar distancias proporcionales en las que se reitera el diseño.

El cuidado de la urdimbre es una tarea continua, que no finaliza con el extendido sobre el telar. En este sentido, se observa frecuentemente a los tejedores sopesando el estado de estiramiento de los hilos, evaluación que hacen reiteradamente, en particular cuando ya avanza el tejido de la pieza. Esta tarea requiere que el tejedor salga de su posición frente al instrumento de tejer, recorra la urdimbre poniendo la mano sobre ella y mueva los dedos entre los hilos. La vibración de la urdimbre al tacto le permite evaluar la tensión general de los hilos.

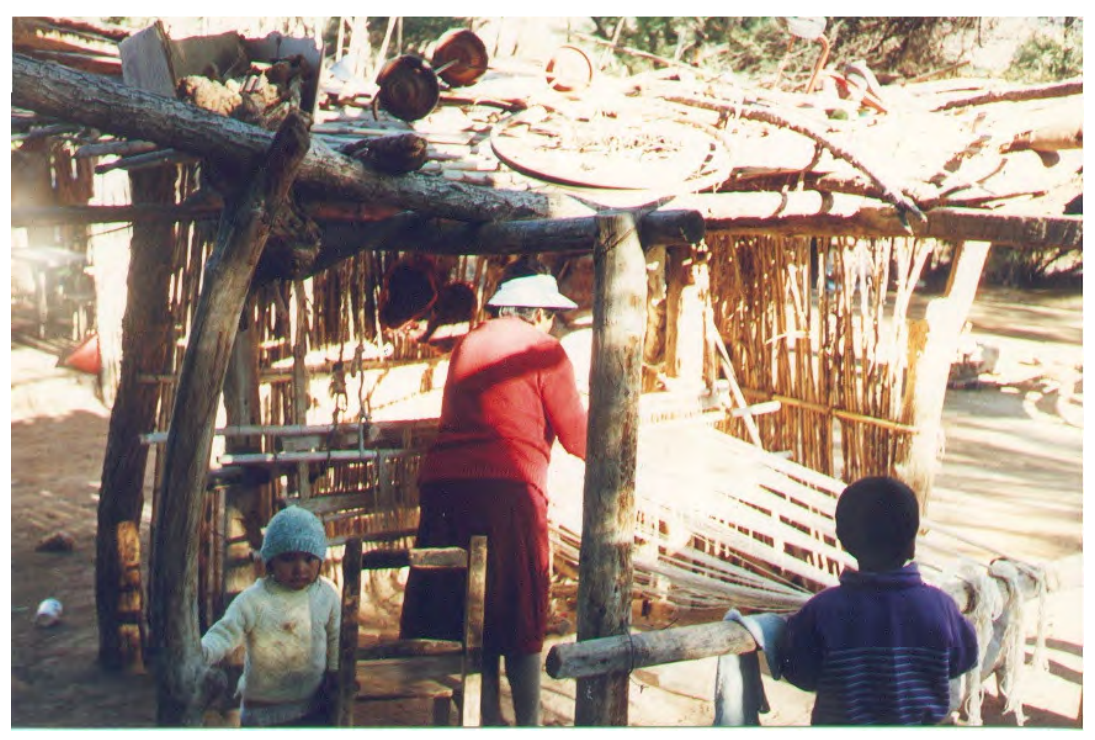

3.15. Tejedora en telar bajo la enrramada

\subsubsection{1-Enlisado}

El enlisado consiste en la colocación de lisos sobre la urdimbre. Cada liso es un elemento que está formado por una serie continua de hilos. Presenta dos extremos, por uno de ellos, toma y sujeta a los hilos de la urdimbre. Por el otro extremo, el liso queda amarrado a una barra de madera fija. En ambos casos, los lisos articulan mediante roldanas o pedales a la estructura del instrumento para tejer. 


\begin{abstract}
“Claro, la voy atando (a la urdimbre) para que no se vaya desparramando y se vuelve a atar (en la otra punta) y luego se saca para ir tejiendo. Se ponen cuatro lisos, se pone en el telar (la urdimbre) y se ponen dos lisos para arriba y dos para abajo. Los lisos de abajo llevan los pedales, entonces cuando tiene que hacer una tramada pisa un pedal y cuando tiene que hacer la otra pisa el otro, y así (...)". (MF, 30 años, Tejedor, Tacuil)
\end{abstract}

La función de estos lisos es diferenciar los hilos de la urdimbre en dos planos entrecruzados. Esta tarea debe hacerse antes de comenzar a tejer y garantiza la separación de los espacios para donde se van a colocar los hilos transversales que formarán la trama del textil. En el caso de la confección de ponchos, el enlisado se puede hacer antes de colocar la urdimbre en el instrumento para tejer; en cambio, en el caso de las mantas, se hace como parte de los procedimientos realizados sobre el propio instrumento de tejer. Para confeccionar mantas, los hilos de la urdimbre deben pasarse por un peine, instrumento generalmente metálico o de caña que tiene el ancho de la urdimbre y sirve para ordenar de modo horizontal y en espacios simétricos, cada par de hilos, los mismos que luego se ubicarán hacia arriba y abajo mediante el soporte de los lisos.

La tarea manual de poner los lisos es asistida por un instrumento clave, que se denomina caña de enlisar, esta sirve de apoyo o de guía maestra para la paciente colocación del liso en cada uno de los hilos a tejer. 


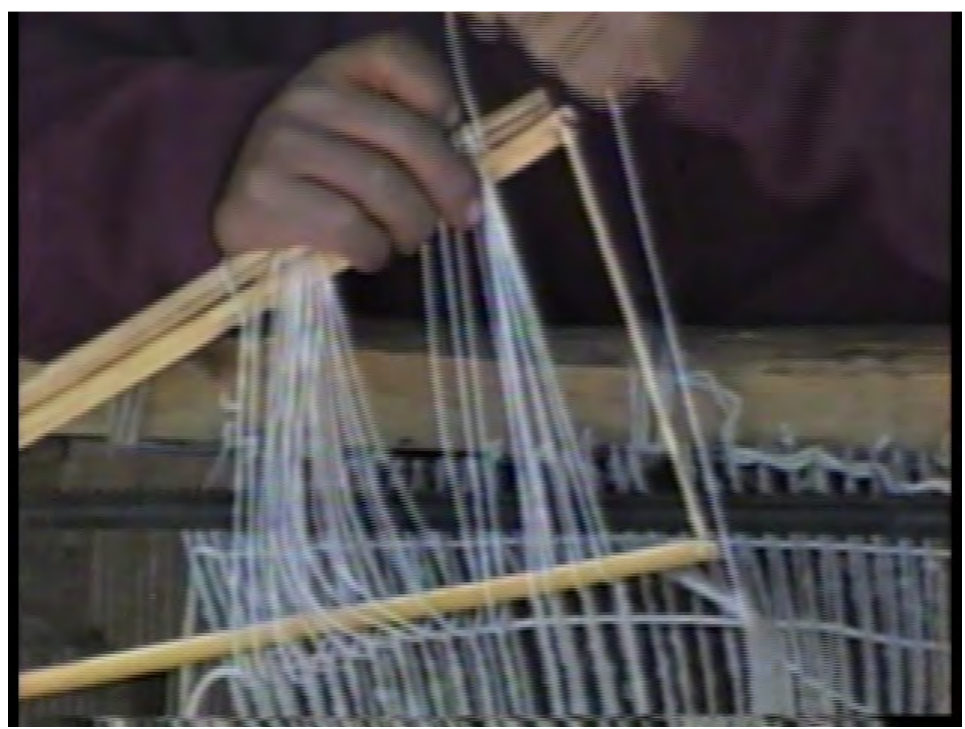

3.16. Tejedor con una caña para enlizar

\subsubsection{2- Tramada}

En el momento de elaboración de la trama de un textil, o como dicen en Molinos la tramada, el tejedor realiza una serie de tareas rítmicas y repetitivas que comienzan luego del montado de la urdimbre en el telar y se observan con el movimiento de tracción del peine, la pala y la alternancia de los lisos. Estas acciones se realizan de pie o sentados, pero cualquiera sea la disposición hacia los utensilios y los hilos, la actitud del experto es de un silencio sostenido y de gran concentración con la mirada fija en las manos y la tela, tal como se evidencia en el siguiente fragmento, resultado de mi observación de esta actividad en el campo:

“Mientras observaba cómo Francisco movía el peine del telar me cuidé de no insistir con más preguntas. Sólo se sentía el golpe de la pala sobre el tejido y el crujir de los palos del telar. Era tal la armonía y coordinación de sus movimientos y la intensidad del silencio que ya no cabía preguntar" (Notas de campo, sábado 25 de julio, página 19) 
Otro aspecto directamente vinculado al relato y observación sobre la confección de ponchos y telas es el de las técnicas que se reconocen en los textiles salteños, los que se circunscriben al grupo de los textiles con estructuras de dos o más grupos de elementos. Dentro de esta clasificación basada en el entrecruce de urdimbres y tramas tenemos dos tipos de técnicas, la de entrecruzado simple o faz de urdimbre, técnica característica del tejido andino y que implica la alternancia de encima y debajo de cada unidad de urdimbre por cada unidad de trama; y la técnica de tejido flotante.

Los ponchos, chales y mantas están tejidos con la técnica de tejido simple o plain weave. Este término genérico designa a la estructura con un entrecruzado muy simple, alternando de forma variable el paso encima y debajo de cada unidad de trama (Emery, 1980)

Las telas de barracán y cordoncillo están elaboradas mediante la técnica de tejido llano balanceado. El tejido llano balanceado presenta una estructura en donde se visualizan las urdimbres y las tramas, guardando espacios equivalentes que son "idénticos 0 aproximadamente iguales respecto al tamaño y la flexibilidad" (Emery, 1980) Consecuentemente tendrán la misma cantidad de hilos de trama y urdimbre por unidad de medida escogida. Usualmente es de $1 \mathrm{~cm}^{2}$.

La sarga tejido flotante o float weaves es una estructura lograda por la organización de las alternativas al entrecruzar los elementos de forma que los hilos de urdimbre y trama quedan flotando en los intervalos establecidos. Los hilos flotantes adoptan una alineación diagonal. De acuerdo al aspecto y a los motivos que forman los hilos flotantes se conocen muchas variantes de sarga, en Molinos aparecen la sarga diagonal y el espigado irregular.

Los tejedores son muy precisos en el manejo del tiempo y la cantidad de metros tejidos durante un determinado lapso de tiempo. La habilidad y expertitud aparece reiteradamente en el relato sobre quienes alcanzan a hacer piezas completas en el menor tiempo. 


\subsubsection{4- Utensilios empleados en el tejido}

Los instrumentos para tejer en Molinos son llamados telares y bajo esta designación presentaremos la descripción de varios utensilios cuya función es tejer, si bien algunos de ellos, como el telar de flecos, no pueden definirse como telar propiamente dicho, porque su construcción no

tiene partes integradas que permitan mover los lizos (Fisher, 2000). El telar de palos funciona mediante mecanismos de articulación de lisos y con partes móviles como las estacas. Este telar parece resultado de una innovación tecnológica que conjuga componentes de instrumentos para tejido de origen español ${ }^{65}$ con otros de tradición andina ${ }^{66}$.

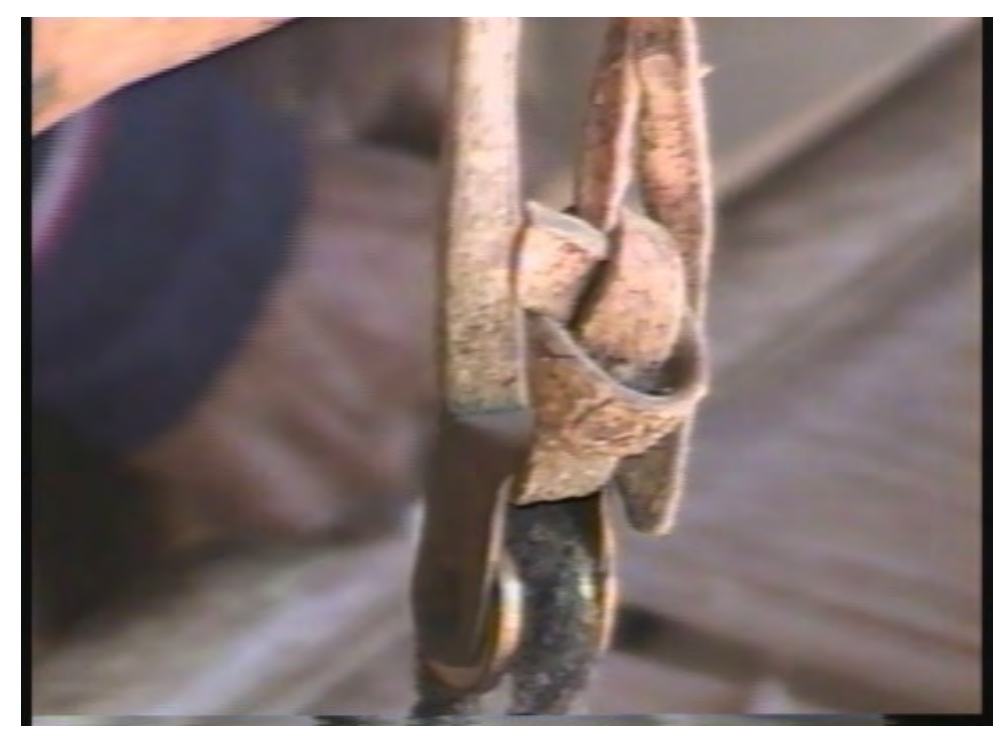

3. 17. Sección de telar, tientos y roldanas

El telar horizontal es el clásico telar tipo español con pedales, peine, rodillos y aparejos para los lisos.

El telar de palos, es un telar para tejer de modo horizontal compuesto por una estructura de palos y de estacas de madera que se fijan al suelo. Estos elementos también pueden anexarse mediante sogas y tientos, como es el caso de los pisadores o pedales que mueven los lisos. En general, no son estructuras fijas, ni demasiado articuladas, sino que se arman al momento de la intervención del tejedor. Previamente a verlos en

\footnotetext{
${ }^{65}$ La introducción de telares de origen español en la zona del NOA data del siglo XVI. Pedro Sotelo de Narváez relata acerca de los obrajes dedicados al hilado y tejido par el Tucumán colonial en 1583. (Rolandi, 1978)

66 Una revisión acerca de los datos arqueológicos sobre los instrumentos para tejer se hallan en Gisbert, Arze y Cajías, 1987; Rolandi, 1978; Rolandi y Jiménez de Puparelli, 1985.
} 
funcionamiento, los telares de palos no son más que un conjunto de maderas, tientos, sogas, pequeños aparejos y enrejados metálicos o peines. .

Las observaciones realizadas sobre el armado del telar muestran que su estructura va tomando forma a medida que el tejedor progresa en el sentido de los mecanismos de transformación, por ejemplo, de los hilos en urdimbre, y de esta en el momento que se debe colocar tendida en el telar, o por ejemplo, en el momento en que hay que diferenciar la urdimbre de la trama y deben colocarse los lisos y los correspondientes pedales. Cuando se ha avanzado más en la tarea de tejido algunos elementos del telar ya no son requeridos y entonces se van retirando sin afectar el funcionamiento del conjunto.

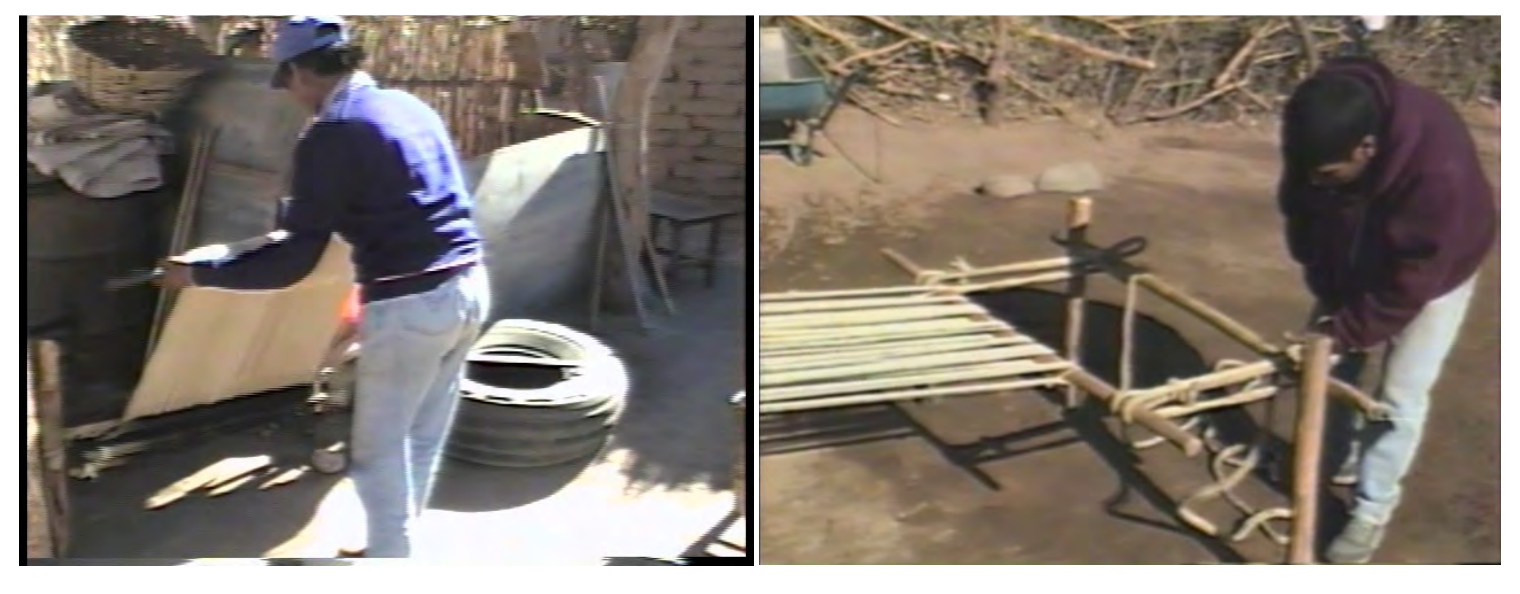

3.18. Ajuntando la urdimbre

Otros utensilios complementarios, pero no menos importantes incluyen la pala para golpear los ponchos que es un instrumento cuya función es apretar y compactar cada hilo nuevo que se incorpora con cada trama de tejido. Los peines para tejer mantas, que son instrumentos por los que se atraviesan los hilos de la urdimbre y se utilizan sólo en el caso de tejido de mantas o tapices. Los pisadores o pedales, que son palos que van apoyados en el piso y se mueven con los pies, subiendo y bajando los lisos, es decir, el sistema que mueve una serie de hilos por los que se pasa la trama. Otro es el tramero, un instrumento de madera muy afinado, similar a un huso, que sirve para pasar el hilo de la trama de un lado a otro de la urdimbre. 


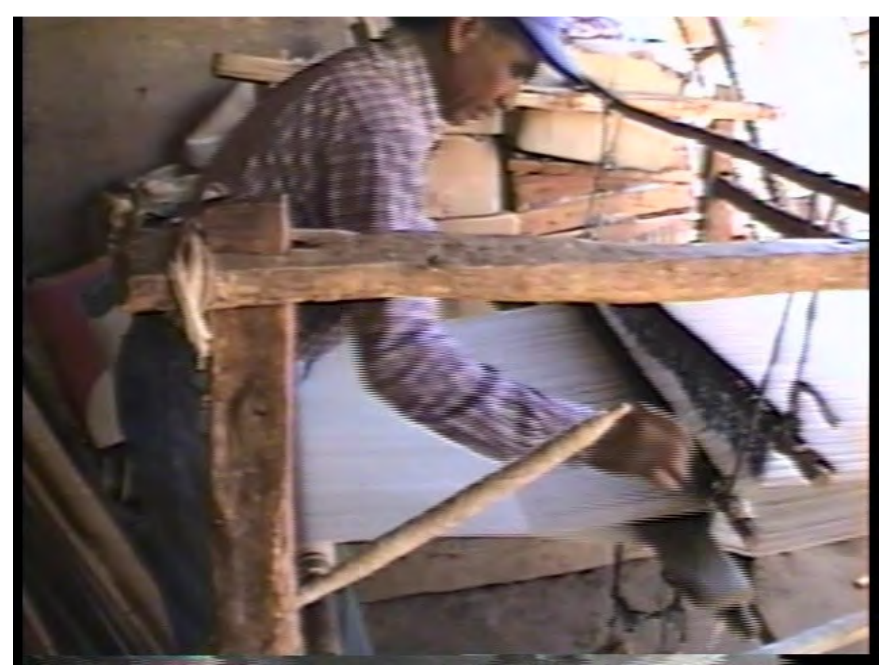

3.19. Tejedor en telar con tramero y pala

\subsubsection{1- Piezas textiles}

Los textiles producidos en esta etapa son los ponchos, chales o mantas, alfombras, tapices, fajas, chuspas y telas. A continuación mostramos la correspondencia entre el tipo de pieza textil, el instrumento para tejer y la estructura del textil, basándonos en que la tecnología para la elaboración de un textil requiere el manejo de una técnica específica y de la disponibilidad de los instrumentos adecuados para desarrollar esas técnicas.

\begin{tabular}{|c|c|c|c|c|c|c|c|}
\hline \multirow{2}{*}{ Objeto textil } & \multicolumn{4}{|c|}{ Tipo de instrumento para tejer } & \multicolumn{3}{|c|}{ Estructura del textil } \\
\hline & $\begin{array}{c}\text { Telar de } \\
\text { palos } \\
\text { y estacas }\end{array}$ & $\begin{array}{c}\text { Telar } \\
\text { tipo } \\
\text { Español }\end{array}$ & Bastidor & $\begin{array}{c}\text { Telar de } \\
\text { flecos }\end{array}$ & Faz de T-U & Sarga & Torcido \\
\hline $\begin{array}{l}\text { Poncho (con } \\
\text { flecos) }\end{array}$ & $\mathrm{X}$ & & & $\mathrm{x}$ & $\mathrm{X}$ & & \\
\hline $\begin{array}{l}\text { Reboso-Manta } \\
\text { (con rapasejo } \\
\text { y/o flecos) }\end{array}$ & $\mathrm{x}$ & & & $\mathrm{x}$ & $\mathrm{X}$ & & \\
\hline Frazada & & $\mathrm{x}$ & & & $\mathrm{X}$ & & \\
\hline
\end{tabular}


El Estudio Etnográfico de la Actividad Textil como aporte a la Caracterización del Modo de Vida en el Pueblo de Molinos y zona de influencia (Provincia de Salta)

Laura Teves

\begin{tabular}{|l|l|l|l|l|l|l|l|l|}
\hline Barracán & & $\mathbf{X}$ & & & & & & \\
\hline Picote & & & & & & \\
\hline
\end{tabular}

\subsubsection{2- Formas, función y diseños}

Otra forma de clasificar los textiles en Molinos es tomando como criterio la función de estas piezas, en el siguiente cuadro se pone en correspondencia el tamaño, el uso al que se destinan los textiles y la forma de designarlos.

\begin{tabular}{|c|c|c|c|c|}
\hline \multirow{2}{*}{$\begin{array}{l}\text { Categorías textiles definidos por el } \\
\text { uso }\end{array}$} & \multicolumn{4}{|c|}{ Categorías textiles definidos por el tamaño } \\
\hline & Pequeño & Mediano & Grande & muy grande \\
\hline $\begin{array}{l}\text { Prendas de vestir de cuatro puntas } \\
\text { compuestos por una o más partes } \\
\text { rectangulares }\end{array}$ & & Rebozo & Poncho & $\begin{array}{l}\text { poncho } \\
\text { pullo }\end{array}$ \\
\hline $\begin{array}{l}\text { Telas para prendas de } \\
\text { compuestos por una sola pieza } \\
\text { rectangular }\end{array}$ & & & $\begin{array}{l}\text { Barracán } \\
\text { Picote }\end{array}$ & \\
\hline $\begin{array}{l}\text { Recipientes-compuestos por una sola } \\
\text { parte rectangular doblada y cosida por } \\
\text { los bordes con correa portadora }\end{array}$ & Chuspa & & & \\
\hline Cinturón o cinta & & $\begin{array}{l}\text { Faja de } \\
\text { mujeres }\end{array}$ & Faja de varones & \\
\hline
\end{tabular}


Montura de burros, caballos

Alfombra

\section{Pelero}

\section{(1)}

(1)

El valor de las piezas utilizadas como vestimenta se relaciona directamente con las diferencias de género y las particularidades de la identidad local salteña y regional andina. Si bien los trajes compuestos por piezas textiles se usaban a diario y conformaban toda la vestimenta en el pasado, actualmente, se reducen a ponchos y chales. También se exhiben durante los desfiles patrios y procesiones religiosas. Esta característica de los textiles de asociarse a las personas en su vida cotidiana y a las festividades o rituales tradicionales puede analizarse en comparación con el valor que adquieren para los tejedores esos mismos textiles cuando son manipulados como objetos artesanales en contextos como el de los mercados turísticos (García Canclini, 1984; 1992; Esteva, 2000)

\subsection{4- COMPONER}

La tercera etapa en una secuencia de actividad textil en Molinos es la de componer o arreglar y se refiere a la finalización o terminación de lo que llamaremos una pieza textil. Componer es una actividad de mujeres o componedoras, muchas de las cuales trabajan complementariamente en la misma unidad doméstica con sus maridos, que son teleros.

Componer implica, por un lado, el acabado o cierre de una pieza textil que se ha terminado de tejer en un telar, y consiste en el atado de los hilos y costura de los bordes. Este procedimiento se aplica a ponchos, tapices o alfombras. Por otro lado, también incluye tareas decorativas y de incorporación de accesorios que se realizan con fines decorativos sobre el cuerpo y los bordes de las piezas tejidas, como por ejemplo, ponchos, chales o rebozos.

Los instrumentos utilizados son el telar de flecos, que consiste en un pequeño telar que consta de un palo largo que sirve para tejer el fleco y una pala pequeña y varios tipos de agujas y tijeras. 


\subsubsection{1- Bordar}

Las técnicas para componer un poncho implican el proceso de coser las dos partes principales que forman el campo de color rojo de la vestimenta, y en cuyos extremos tienen tejida una guarda de color negro. Sobre la dos piezas ensambladas se deja una abertura que se ribetea con otra pieza tejida de color negro que se denomina wincha ${ }^{67} \mathrm{o}$ boquilla del poncho y que es el espacio o abertura para colocarse el poncho por la cabeza y el cuello y que quede suspendido de los hombros de quien lo viste. Otra pieza que se teje en lana negra es el moño, adorno que se cose en al aparte frontal de la pieza. Por último, el bordado de las mosquitas del poncho, decoración que adorna el frente y espalda en la unión de las dos piezas centrales que componen un poncho. Los bordes que recorren los extremos de un poncho ya cosido llevan una pieza tejida de 8 metros de largo aproximadamente denominada fleco o chicote. Todos los adornos superpuestos sobre la tela se realizan en color negro. Otras piezas textiles, como los chales y las chalinas, Ilevan una terminación con un tipo especial de fleco llamado rapasejo.

\subsubsection{2- Flecos o chicote}

Los flecos se tejen en un telarcito o telar de flecos, que consiste en un palo largo y se utilizan hilos como lisos y una pala de flecos. El hilo del fleco debe urdirse y luego se teje formando una faja del fleco. Se utiliza también la puchicana para ir torciendo el hilo que forma el fleco. Para tejer un par de flecos se necesitarán dos o tres días.

“... y lo sigue tejiendo, usted tiene unos palitos así que yo los voy pisando y me siento a la silla y voy manejando los pies nomás y estiro con la manos así la...y voy pasando esto, poniendo en una tablita esto, se llama pala, así que va poner todo esto así y cuando se llene la maderita entonces usted lo

${ }^{67}$ De huincha, voz quechua que designa el borde del poncho; lo que va sobre el fleco. (Solá, (1949) 1975:180) 
saca para tras, lo pone aquí en la mano y lo sigue separando, uno por uno, uno por uno lo va separando, largan lo va haciendo así y lo largan y después cuando ya lo saca del telar entonces usted ya lo arrolla así y moja en un balde todo, bien mojadito y pega una estirada" (LCCH, 71 años, Hilandera y Componedora, Pucará)

\subsubsection{3- Rapasejo}

Del mismo modo que el fleco es una pieza que se hace para darle una terminación a los bordes del poncho, el rapasejo cumple una función similar en la decoración los rebozos o chales y bufandas. Se trabaja sólo con las manos y requiere de la división y agrupamiento de los hilos y posteriormente de un conteo y atado de los hilos. Se elabora siguiendo diferentes tipos de diseños, como los llamados nido de abeja, con rombos o kenkos y con flores.

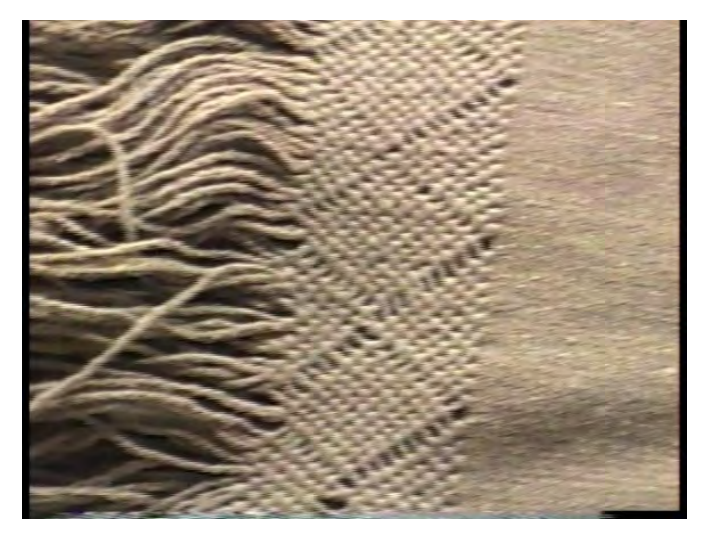

3.22. Poncho con fecos y rapasejo

Por último, las piezas textiles que se han observado y descripto como producto de la AT en Molinos no presentan cortes, ni reparaciones; si costuras que unen partes proporcionalmente menores, considerando la pieza completa, como es el caso de los ponchos y la confección de prendas mediante las telas de barracán y picote. Esta característica es común a la concepción de unidad indivisible en los textiles tradicionales de los andes bolivianos y peruanos (Desrosiers, 1992; Fischer, 2003) 


\section{3- Ampliando el Dominio de la Actividad Textil}

La descripción de la actividad textil en Molinos presentada en este capítulo, es el resultado del análisis cualitativo y no estructurado llevado adelante con el soporte de Nudist 4. Las categorías que hacen mención a las diferentes tareas se vinculan en una secuencia de etapas mediante la reconstrucción del proceso de elaboración de los textiles que emerge del relato de los tejedores y de la observación del proceso por parte del investigador. El análisis de las categorías y del contexto en el que son producidas provén además información adicional referida a la secuencia que amplía y enriquece nuestro análisis de la AT en su articulación con otros aspectos de la vida cotidiana en los valles.

De este modo, el dominio conceptual de la AT se extiende más allá de la secuencia de tareas para la elaboración de un textil, ya que, mediante las referencias extraídas del mismo corpus discursivo y de observación podemos establecer nexos con otro tipo de categorías y contextos. Este encadenamiento de categorías que amplía los límites de la secuencia de la AT focaliza sobre dos aspectos. El primero se refiere a la asociación de la actividad con el ambiente, la naturaleza o paisaje, mostrando la importancia de situar la actividad en los espacios cotidianos de ejecución, de obtención de recursos, así como la interacción con el ambiente mediante el trabajo y circulación de productos. Un segundo aspecto permite recuperar la experiencia de vida de los expertos a partir del trabajo en la textilería, es decir, proyectar desde la secuencia de la AT, el valor que tienen algunos eventos o sucesos de la biografía en la trayectoria personal y grupal de los tejedores.

Recordamos que la proximidad de los campos conceptuales fue identificada mediante las operaciones de búsquedas contextuales, búsquedas restringidas y las cadenas de categorías, dentro de cada documento y en el sistema de documentos ${ }^{68}$. De esta manera, las categorías se observan en su relación con el texto inmediato vinculado a ellas, es decir, los párrafos o fragmentos discursivos más amplios que en conjunto remiten a campos

\footnotetext{
${ }^{68}$ Ver Capítulo 3, Acápite 3.1.4- "Preparación de documentos y codificación de categorías", y Acápite 3.1.5- "Ordenamiento de categorías".
} 
conectados por relaciones de inclusión u otras. Estas asociaciones conceptuales basadas en la identificación de categorías que emergen en el contexto de los relatos, pueden ser explicitadas a partir de esta estrategia metodológica.

\subsection{1- El paisaje}

El paisaje esbozado en el discurso de los expertos se compone a partir de las marcas o hitos que en lengua cacán, quechua, aymara o castellano ${ }^{69}$ designan a los espacios físicos de la zona y sus características en cuanto al conocimiento y manejo de la vegetación, la fauna y la topografía de la zona. El cerro y el valle emergen en este escenario como ambientes (Cabrera, 1971; Cardich, 1988) bien diferenciados por los senderos, el alto y el bajo, el clima, el viento punoso y la incidencia solar (Crivos y Martínez, 1997; Merlino y Sánchez Proaño, 1996-1997)

“... la puna es, porque estos cerros tienen puna y como el aire y todo eso viene ya con puna, todo y es que toma usted el aire de arriba o sea de abajo, ¿ha visto? porque corren los vientos así, cuando corre de allá es de abajo, es el frío y cuando corre de aquí entonces es caliente y trae mucha tierra" (LCCH, 71 años, Hilandera y tejedora, Pucará)

Las unidades domésticas emplazadas en este entorno se distribuyen alternando entre estos dos ambientes. A través de ellos los pobladores de Molinos los transitan históricamente seleccionando y complementando los recursos de uno y otro lugar (Murra, 1972). Sobre la base de vínculos sociales de parentesco, amistad y trabajo intercambian y distribuyen distintos tipos de bienes, entre ellos los recursos naturales y humanos necesarios para la producción y comercialización de los textiles.

\footnotetext{
69 En la designación topográfica de los sitios del valle calchaquí -localidades, cerros, aguadas- y otros próximos a estos, aparecen términos en diferentes lenguas antiguas y actuales que pueden encontrar traducción en el Diccionario de regionalismos de Salta, Solá (1949); Martín (1964); y Nardi (1979).
} 
La rica descripción de la circulación de materias primas permitiría bosquejar un primer mapa de actividad donde a lo largo de la extensión del los ríos Molinos, Calchaquí, Luracatao, y Hualfín en sentido norte- sur y en un radio de no más de 170 kilómetros los tejedores se provén de fibras y algunas de las tinturas utilizadas. Las unidades que crían hacienda y son abastecedoras de lanas están generalmente asociadas a los espacios de las Fincas y los Puestos de altura (Garreta y Sola, 1992; Göbel, 2001). La mayor parte de los lugares referidos no están registrados en las cartas geográficas, las personas mencionan parajes o puntos del paisaje que forman parte de trayectos que realizan caminando a través de los cerros o en caravanas de burros de carga y sólo son conocidos por aquellos que comparten y eligen una travesía.

“... allí en el cerro hay un señor que viene a vender y él viene cada seis meses si, viene tres veces al año. Ahora quiere venir en este mes, pero no ha aparecido ya ha de caer por ahí, ya hasta mayo ya ha de tardar se llama JG y viene de Compuel, más allá de Hualfín, lejos, lejos... A lomo de mula en tres días llega aquí, trae lana, también hace tejidos igual que nosotros, también trae tejidos, trae peleros, también trae más hilos de llama, hilos de oveja, se los compro yo. Aaah, a veces trae hilo preparado ya, para lavar y tejer no más, para pulover también trae, de llama, de oveja. Esa gente tiene mucha llama, mucha llama, cualquier cantidad de llama, igual cualquier cantidad de oveja... Vive con su familia ahí, vive con su señora, sus hijos, creo que son seis, creo que son en total para atender toda esa hacienda, llamas, ovejas y cabras, bastantes, ovejas creo que son quinientas para arriba. Por eso cuando trae, trae mucha lana para trabajar así como es que está teniendo ella" (SCHG, 46 años, Hilandera y Tejedora, Tomuco)

\subsection{2- Unidades domésticas del cerro}

Las zonas de mayor altura conocidas como el cerro, el abra, las peñas son los lugares que suministran materias primas, las lanas, allí en diferentes haciendas o puestos se crían camélidos domesticados como las llamas (Lama glama) y también ovejas y cabras. 
Los siguientes parajes aparecen mencionados como productores de lana y de hilo hilado: Luracatao, Cuchiyacu, Antofagasta de la Sierra, Compuel, Hualfín, Aguadita, Brealito, Amaicha, Tacuil, Colomé.

En esta zona también habitan las vicuñas (Vicugna vicugna), camélidos silvestres cuya lana es altamente apreciada y valuada, pero su obtención implica la caza del animal. Los relatos de varias hilanderas describe cómo durante años se les traían los cueros de la vicuña para rasurarles la lana e iniciar todo el proceso de hilado. La prohibición sobre su captura es ley nacional en el país y la provincia de Salta ${ }^{70}$ desde hace casi 30 años.

En el cerro además se elaboran tres tipos de tejidos que se venden en los valles: peleros, hondas y $\operatorname{sogas}^{71}$. De una a tres veces al año bajan desde las zonas altas al valle para vender la lana, hilos y plantas medicinales. Recorren grandes distancias de hasta tres días con sus burros cargados.

"Los que se dedican a sacar la lana de llama bueno, son los mismos que tienen los criaderos.

No ellos ya viven ahí, en el cerro, son de también, de la finca del Luracatao pero ya viven en los cerros. Ellos ya traen en septiembre, octubre y noviembre... Cuando está lloviendo no, antes de la lluvia, porque aquí llueve siempre en diciembre, en enero recién llueve, de enero a marzo... Hay como 3 o 4 personas nomás que... no tienen mucho, mucho que vender... no es como la oveja, la oveja tiene cualquier persona, cualquier familiar tiene una oveja

\footnotetext{
70 Referencia a la prohibición de la caza de vicuña, Expediente № 1-2002-5351000485/05- 2 del registro de la Secretaría de Ambiente y Desarrollo Sustentable del Ministerio de Salud y Ambiente, la Ley No 22.421 de Protección y Conservación de la Fauna Silvestre, el Decreto No 666 del 18 de julio de 1997 y la Ley No 23.582 del 20 de julio de 1988, y sancionada en 2005 y que consta de antecedentes desde el año 1988, y Ley 5313 promulgada en 1978 en la provincia de Salta.

${ }^{71}$ Todos estos artefactos están hechos de fibras procesadas, y por lo tanto son artefactos textiles. Pero el textil, es un caso especial porque es cuadrangular y plano.
} 
Hay 300, 400 por ahí... (animales). Hay alguien que esquila 200 y otro año, otros 200, no? rotando. Pero ya viven distanciados, pongamos de aquí viven uno que traiga aquí, el otro está más lejos...

A la derecha hay un criadero... crían llamas y ahí hay otro... serán 20, 30 $\mathrm{Km}$. otro. No pero eso ya se venden solo, como son sus criaderos de ellos, no ellos venden ya... bajan a veces cargado en burro todo el animal para que vendan...

Ahí en esas casas vive una familia, será familia de 7, 6 así... tienen los animales, no, no se planta nada... ya viven de eso...

Ellos van y vienen seguido porque ellos bajan a comprar mercadería, sí... porque ahí no pueden comprar, no..." (JG, 40 años, Tejedor, Luracatao)

Durante mucho tiempo, cada criador de los puestos en los cerros bajaba al valle a vender toda la producción de lana, alternando, un criador un año y otro al siguiente. Ahora la situación cambió y a las tradicionales caravanas de altura se agregan la comercialización a través de los camiones que circulan por las rutas nacionales y provinciales, en un trayecto que se inicia en Catamarca y recorre las zonas altas comprando lana y cueros.

\subsection{3- Unidades domésticas del valle}

Las localidades ubicadas en el valle o quebrada de altura de Molinos son los espacios donde se tiñe la lana, se tejen las telas en los telares, se componen o terminan las piezas y se construyen las herramientas necesarias a su procesamiento. Los lugares citados son Humanao, Tomuco, el Pueblo de Molinos, Santa Rosa, Seclantás, Seclantás Adentro, La Banda Grande, El Churcal, El Colte.

Con relación a las tinturas, el uso de tintas industriales o anilinas y de las tinturas naturales nos remite a los comerciantes ambulantes bolivianos que proveen tintas particulares de colores especiales, el resto de las tinturas industriales se adquieren en la 
ciudad capital de Salta. Los productos para teñir de origen vegetal se obtienen por intercambio con parientes o caravaneros que vienen de diferentes parajes. Consisten fundamentalmente en partes del fruto, raíces, hojas de plantas que se recolectan en las zonas altas.

Los elementos en madera, que constituyen la tecnología asociada a la actividad: telares, puchicanas, palas y peines, son realizados en maderas del lugar: sauce (Salix Humboldtiana Wild), algarrobo (Prosopis nigra, Prosopis alba) , chañar (Geoffroea decorticans) y cardón (Cereus forbesii) por los miembros varones de dos generaciones de una familia de Molinos. Su oficio de carpinteros es reconocido por todos los expertos teleros de la zona.

Pero la condición más ventajosa y característica de las comunidades de este valle de altura es la proximidad a los caminos y ruta nacional 40, 68 y provincial 33 y 42, mediante los cuales se accede fácilmente y mediante transportes públicos, a ciudades más grandes como Cachi, Cafayate, Salta y a los parajes y pueblos intermedios, como Seclantás, El Carril, Payogasta y otros anteriormente citados. Consecuente los medios de comunicación vial convierten al valle en un espacio de conexión indispensable para la distribución y comercialización de hilos y tejidos, así como para la contratación de mano de obra en la confección de textiles. A la vez, estos sitios del valle se convierten en lugares de amplia circulación y consumo de textiles -en su condición de artesanías-, debido a la presencia creciente de turistas nacionales y extranjeros en la zona.

\subsection{4- Trayectorias de los tejedores en Molinos}

La identificación en la historia personal de sucesos de trabajo que se insertan en eventos colectivos -como la actividad textil- puede dar cuenta de las variables que intervienen en la continuidad y cambio de los patrones de organización en los Valles Calchaquíes. La trayectoria de los teleros más ancianos se inicia hace 50 años con el trabajo en las fincas. Desde las unidades domésticas ubicadas en los puestos de altura, hilan, tejen y bordan como parte de las actividades o servicio a los finqueros: 
“En La Aguadita, este..., nosotros hemos perdido el padre, hemos quedado con la mamá y así que hemos trabajado así en hilao, en flecos, tejido, muy pesado...

Y después ya, claro ahí era una Finca, una finca privada, el patrón no nos dejaba salir a ninguna parte, y traían, llevaban a la Finca a cuidar ovejas, trabajaban los peones, teníamos que ir a cocinar para darle de almorzar a los peones....

Aquí en Entre Ríos, ahí trabajábamos nosotros. Era de los C. Si vivía el finado LM, LM, el apellido creo es PC, C pero sí, porque nosotros trabajábamos ahí, eran ellos que venían...

Si, esos eran tenían que trabajar ahí no tenían que ir afuera, ahí no más y trabajar para la Finca, así era. En la Finca, hilábamos, trabajábamos 2 meses en cada lugar. Trabajábamos, por ejemplo, 2 meses ahí, te hacían trabajar, pastear ovejas, cocinar, lavar hilo, lavar lana y ahí sí, íbamos para la casa 2 meses y le daban hilo para hilar en la casa. Cumplíamos los 2 meses en la casa y ya lo que quedaban cuenta aquí iban de vuelta ellos a su casa y nosotros quedábamos de vuelta". (GTR, 69 años, Hilandera, El Refugio)

Además de hilar y tejer para los dueños de las fincas, muchos expertos relatan que en el pasado solían recibir pedidos de trabajos de parte de personas del pueblo, del cerro, y de afuera o de otras ciudades, que intermediaban para la comercialización. En general se hace referencia a estas situaciones como dar obra, dar a hilar, tejer y/o componer. En los relatos parece como una actividad situada en el pasado y a través de la cual se evoca a personas conocidas, pero ya desaparecidas, que formaban parte de un circuito más amplio de tejedores y a especialistas que iniciaban el textil y lo finalizaban entregando la pieza terminada.

“... hila también, hila o no, ya da mano de obra, también da a hilar la lana, ahí no, ahí no, los que tejen han muerto, en Humanao había que se llamaba, donde está la otra señora, doña E, le conocí que se llamaba LD, el sabía tejer 
y la señora se llamaba BD, ella sabía arreglar los ponchos, así como le digo, así arregladitos, hacía los mosquitos, tejer los flecos y su marido sabía tejer el campo del poncho, y ya no viven, ellos han muerto los dos, así que no hay ahí. Después había uno, SG, ese también sabía tejer y la hija sabía tejer los flecos, sabía arreglar los ponchos, ... sabía llevar para mí, yo sé tejer flecos y arreglar ponchos y ahí está MG ese también los sabía tejer y sabía llevar también para que le arregle los ponchos" (LCCH, 71 años, Hilandera y Tejedora, Pucará)

Hacia la década del setenta, muchos de estos tejedores obtienen mercaderías y comercializan sus productos a través del Mercado de Artesanías de Molinos. El docente a cargo de la escuela del pueblo -persona que goza de alto prestigio en estas comunidadeses quien dirige la actividad junto a treinta familias del pueblo.

A pesar de estos cambios, las unidades domésticas continúan siendo el espacio de producción:

"A Salta si, se vende un poco aquí también, así es. En una parte de Salta en el Mercado Artesanal de Salta hace mucho en el '70 pues, eeeh voy un día no? a ver cómo era eso y había un montón de ponchos industriales, cosas industriales, entonces justo viene un señor y me dice: "-que está mirando qué viene a comprar", "-no estoy mirando", le digo, y le digo: "-por qué venden aquí cosas industriales", "-pero no me diga eso" dice "-como voy ... cosas industriales" y ha sido el administrador, yo que sabía!... Y comencé a explicarle esto y esto, todo, todo... Después le dije, le dije, "-por qué no coloca, digo, un Anexo del Mercado en todos los pueblos del valle para que la gente vaya", y "-tiene razón"... Bueno y dieron a todos los Municipios, dieron a todos los Municipios, a mi me dieron directamente a mí y a otros les dieron todo al municipio 2 millones de pesos ... De los que yo tenía aquí de las ventas se movía no? y aparte eso lo que yo pasaba bueno y esta pieza era para colocar ahí ve? Todos cardones aquí así como estantes del cerro y puse los tapices todo y así rústico. Y resulta que después dieron la orden de 
allá de que levanten todos los anexos de todo el valle y levantaron todo, vinieron un día "-para qué?", "-venimos a llevarnos todo" "a bueno" le digo, así que tenía todas las cosas, los materiales y esas cosas, saqué la mercadería, les entregué todo a ellos. Eso daba ganancia, o sea tiene ganancia, no tiene gasto, ni un gasto, ni un gasto, así que ni gasto de alquiler de local nada. Claro, para ello levantaba, venía, vendía y listo. Eso fue en el año, cuándo fue que bajaron a Estela Perón? En el '75, ‘75, ‘74 por ahí, que teníamos aquí el Anexo". (LZ, 52 años, Tejedor, Molinos)

Otros tejedores recuerdan que sus productos, principalmente tapices y telas para confección de trajes, eran cambiados por mercaderías, principalmente alimentos y combustibles. Un recordado intermediario, capataz de finca, las vendía como costosas artesanías en un comercio de la ciudad de Salta. Esta situación se mantuvo por años y es la expresión misma de las transacciones desiguales entorno al trabajo de elaboración de los textiles y su comercialización:

"El va y siempre está engañando, yo creo... "yo soy el dueño", él toma por nada, él lleva cosas, mercadería cambia así... la plata la cambia con ropa así (se ríe) porque yo tengo, me acuerdo, cuando era más joven tenía ese grabador, me cambió por 60 metros de barracán (se ríe) que valía, va el trabajo mío valía mucho pero el grabador no valía nada. Hacer 60 metros lleva dos meses (se ríe).

Los que tejen para él son de un poco más (lejos), como el lugar de aquí son Refugios, después está La Puerta, hay un lugar que se llama Cabrería, la Sala de Luracatao... de ahí son...

Sí, después ya está Alumbres, toda esa parte ya ... pero no son muchos, son 15... después tiene una casa también en Salta le hizo un... Se llama Casa de Artesanías “El Luracatao”, dice." (JG, 40 años, Tejedor, Luracatao) 
En los últimos 20 años, parte de la producción y comercialización de la lana y los textiles se realiza a través de un nuevo emprendimiento, una asociación que nuclea a varios tejedores del valle y del cerro. La Asociación de Artesanos y Productores San Pedro Nolasco de los Molinos y el Criadero Coquena de vicuñas en semicautividad constituyen la alternativa actual que promueve la sustentabilidad de esta actividad tradicional:

“... hay 60 personas, 60 socios acá en... No todos son tejedores, aquí le he dicho que son 28 nada más, el resto bueno trabajan así en la tierra... Otros ponen cebolla, pimentón, otros siembran avena, alfalfa. Y otros son chofer de tractores, camioneros, por lo menos yo soy artesano y entonces... somos varios los que hacen de todo, de todo un poco.

Algunos son agricultores y artesanos también, hacen las dos cosas, porque en Luracatao son agricultores... ponen cebollas y en vez de tejer están trabajando en el campo. Depende de la época, sí, porque a veces que nosotros no podemos vender, a veces que no hay con qué pagar para poder trabajar (silencio) Y después no sé (se ríe) ya todo de artesanías.

Yo desde el '85 trabajando en la Asociación y todos los que vinieron también... Los que se asociaron también trabajaban para JD. Y sí... les conviene más (la Asociación de Productores y Artesanos), para pasarse la vida así (como en el pasado)..." (JG, 40 años, Tejedor, Luracatao)

\section{4.- Hacia un Modelo de la Actividad Textil}

El enfoque analítico hasta aquí desarrollado, ha servido para aproximarnos a una caracterización y modelización de la actividad textil. Haciendo hincapié en los aspectos centrales y distintivos del proceso de elaboración de los textiles, esta caracterización ha dado como resultado un conjunto de categorías articuladas que delimitan y dan significado a un dominio o campo conceptual, el de la actividad textil en Molinos. En este marco, la terminología para designar los aspectos técnicos y contextuales constituye un léxico 
amplio. Este "modo de decir" constituye un indicador que señala la necesidad y función de un "lenguaje" emergente de la práctica textil. La combinación de palabras en cacán, aymara y quechua vincula la actividad textil actual en Molinos a desarrollos regionales en los Valles Calchaquíes y al mismo tiempo, a un contexto más amplio, el de la tradición andina, proyectando así fuertes relaciones temporales y espaciales con los datos provenientes de las investigaciones arqueológicas y etnohistóricas sobre las comunidades de tejedores en Perú, Chile y Bolivia.

Asimismo, la vigencia de un léxico que surge de la práctica textil asociado a la complejidad de la tecnología y el diseño, la memoria numérica y la habilidad para el cálculo y la destreza manual que requiere el tejido, conduce a la comparación entre los modelos clasificatorios provenientes de los estudios académicos centrados en propuestas de análisis técnico y estilístico, y a los modelos inductivo-etnográficos, tendiente a su ajuste y al logro de futuras explicaciones no basadas en aspectos puramente técnicos.

La información específica acerca de un conjunto de elementos y procesos manuales que están involucrados en la actividad de tejer ha aportado a la construcción de un modelo de la actividad textil mediante la identificación de categorías descriptivas, funcionales y relacionales. A diferencia de otras caracterizaciones de la actividad textil, desde este enfoque es imposible presentar una estrategia analítica que considera categorías descriptivas como variables aisladas. Por una parte, fue necesario tomar en cuenta la asociación entre ellas como dependientes de la propia dinámica de la actividad textil y desde la valoración personal que le otorga cada experto. Por otra parte, la selección y combinación de algunas de ellas se evidencia como una estrategia analítica sumamente útil al momento de reconocer el modo de organización local de la actividad textil. Asimismo, satisface la necesidad de contar con indicadores que conduzcan a una evaluación del desarrollo de la actividad textil desde parámetros propios. 
El Estudio Etnográfico de la Actividad Textil como aporte a la Caracterización del Modo de Vida en el Pueblo de Molinos y zona de influencia (Provincia de Salta)

La siguiente tabla sintetiza la combinación de varias categorías-variables (Tabla 3.22)

\begin{tabular}{|c|c|c|c|}
\hline Componentes & $\begin{array}{l}\text { Relaciones } \\
\text { Sociales }\end{array}$ & $\begin{array}{l}\text { Relaciones } \\
\text { tecnológicas }\end{array}$ & Relaciones con los bienes \\
\hline $\begin{array}{c}\text { Agente } \\
\text { (actores+acciones) }\end{array}$ & $\begin{array}{c}\text { Interacción en } \\
\text { grupos de expertos }\end{array}$ & $\begin{array}{l}\text { Manejo de técnicas, } \\
\text { instrumentos }\end{array}$ & $\begin{array}{c}\text { Decisiones sobre } \\
\text { elaboración y } \\
\text { comercialización de textiles }\end{array}$ \\
\hline $\begin{array}{c}\text { Tecnología (técnicas e } \\
\text { instrumentos) }\end{array}$ & $\begin{array}{l}\text { Transferencia de } \\
\text { conocimientos y } \\
\text { habilidades }\end{array}$ & $\begin{array}{l}\text { Herencia e } \\
\text { Innovaciones }\end{array}$ & $\begin{array}{l}\text { Tipos, cantidad y calidad de } \\
\text { textiles }\end{array}$ \\
\hline $\begin{array}{l}\text { Productos (objetos } \\
\text { manufacturados) }\end{array}$ & $\begin{array}{c}\text { Organización de la } \\
\qquad A T\end{array}$ & $\begin{array}{c}\text { Transformaciones de la } \\
\text { materia prima }\end{array}$ & Circulación y consumo \\
\hline
\end{tabular}

\subsection{1 -Contextos: Paisaje y Trayectoria}

Las entrevistas realizadas a los actuales expertos en el hilado, tejido y armado de los textiles tradicionales andinos de Molinos nos permiten acceder a complejos relatos cargados de imágenes donde se fusionan las dimensiones espaciales y temporales del paisaje montañoso, los recursos propios de diversos ambientes ecológicos y el trabajo de la gente, dando significado e identidad cultural a la actividad y productos textiles calchaquíes en Argentina.

Los relatos de las trayectorias individuales centrados en la experiencia en un campo de trabajo, operan como contextos en que cada informante selecciona y combina aspectos particulares del entorno físico y sus componentes. La conjunción entre memoria y experiencia asigna a las actividades y al espacio en que ocurren, distintos significados a lo largo de sus trayectorias de vida personal.

De este modo el paisaje reconocido por los molinistos se va configurando y transformando articulado en una estrategia de vida particular, que se actualiza día tras día y se trasmite de generación en generación por la práctica cotidiana y los relatos. 
La posibilidad de recuperar, a través de un abordaje sistemático, estos modos de representación del espacio y las experiencias de trabajo a lo largo de la trayectoria personal harán posible valorar alternativas de generación y transmisión del conocimiento acerca del medio ambiente que garantizan la continuidad, flexibilidad y sustentabilidad de las estrategias de subsistencia locales.

Por último, el análisis de los relatos sobre la secuencia de la actividad textil, además, nos presentó una y otra vez diversas referencias al paisaje local y la trayectoria personal de los tejedores. Esto nos condujo a la posibilidad de trascender el dominio mismo de la actividad textil ampliando los límites de la propia secuencia, para situarnos en los bordes de otros posibles dominios a explorar. Claramente, el paisaje y la trayectoria de los tejedores son dos aspectos recurrentes en los relatos sobre la actividad textil y permiten introducir datos sobre otras actividades domésticas y cotidianas, proyectando la actividad textil hacia otros dominios conceptuales y de experiencia. Es decir, a través de esta estrategia de abordaje de la actividad textil podemos vislumbrar la posibilidad de reconocer y explorar nuevos campos semánticos y prácticas. 


\section{CAPÍTULO 4 \\ Redes Sociales en la Actividad Textil}

\section{1- El Dominio Relacional de la Actividad Textil}

Si inicialmente el discurso de los expertos nos permitió recomponer la actividad textil como una secuencia de operaciones que se suceden unas a otras en diferentes etapas, ahora tomaremos el mismo corpus de referencia para mostrar cómo la actividad textil puede ser abordada desde las relaciones entre los actores.

El tratamiento de los datos discursivos obtenidos en el contexto de las unidades domésticas $^{72}$ resultó, en una primera etapa de la investigación, en la delimitación inicial de la actividad, la definición de categorías para su descripción y el ordenamiento del campo conceptual de la actividad textil (AT en adelante) ${ }^{73}$. Las particularidades del relato de cada uno de los informantes elegidos derivaron en la elaboración de un modelo del dominio conceptual de la actividad que caracterizó el proceso completo de obtención de una pieza textil.

En esta segunda etapa de la investigación identificamos y extraemos del corpus inicial, la información sobre los aspectos relativos a la interacción entre individuos que participan en la AT. De esta manera, tendremos la posibilidad de señalar cómo las percepciones, actitudes y creencias de los tejedores Molinistos respecto de la AT están afectadas por las restricciones y oportunidades de las estructuras de vínculos, más que por motivos normativos internalizados y por ende preestipulados o considerados previos y esenciales para la acción (Wellman, 1988). Así por ejemplo, el acceso a recursos -como información, materias primas, instrumentos y/o fuerza de trabajo- es el resultado de la estructura que adquieren los vínculos en su propio "network environment" o "medio" de redes sociales (Borgatti y Foster, 2003)

\footnotetext{
72 El trabajo etnográfico situado en el ámbito de las unidades domésticas no sólo permitió relevar información de tipo discursivo, sino que se constituyó en un ámbito para la observación y el registro de las rutinas cotidiana.

${ }^{73}$ Ver Capítulo 3 de esta tesis.
} 
Más aún, la perspectiva que introduciremos en este estudio nos permitirá aproximarnos a una primera descripción de la dinámica de la AT. La visión de flujo y conectividad inherente a esta perspectiva pondrá el énfasis en las relaciones entre los eventos ${ }^{74}$ que acontecen al establecerse una situación de intercambio de recursos o de tareas compartidas en el marco de la AT. De esta manera, proponemos una alternativa a la visión habitual que considera el dominio de la textilería como la suma de cada uno de las etapas de la actividad al modo de agregados de componentes esenciales. En este sentido y para alcanzar este propósito introduciremos la noción de red social de modo que, en adelante, intentaremos una caracterización de la actividad textil desde la perspectiva de una serie de actores que mantienen vínculos o lazos, cuyo contenido es de crucial importancia para el estudio de la textilería en el contexto socio-cultural de los Valles Calchaquíes. La consideración al mismo tiempo de los actores y el contenido de sus relaciones, expresado en forma de redes, presenta una alternativa teórico-metodológica con implicancias en la descripción, el análisis y los resultados del estudio de la actividad.

En el capítulo anterior quedaron establecidas las asociaciones cognitivas entre las categorías que describen la actividad textil y los temas relevantes desde el punto de vista cultural, a través de su reconocimiento en el corpus de enunciados. En este capítulo proponemos considerar el carácter relacional de la AT en los datos, mediante la identificación de las acciones que realizan las personas que participan de la AT. Esta alternativa de análisis está inspirada en las hipótesis provenientes de la perspectiva del ARS.

Podemos sostener entonces que entre el capítulo anterior y el presente existirá una complementariedad de enfoques basados en el análisis del conocimiento local, por un lado, y en las interacciones de la gente, por otro. En el análisis de conocimiento local hemos utilizado procedimientos para el manejo de datos no estructurados y cualitativos anclados en las categorías discursivas o lo que la "gente dice" acerca de la actividad. De esta manera, queda delimitado un campo de actividad sobre el cual se construyó un

74 En el ARS se considera que una relación, vínculo y lazo pueden representar un evento da en una red social. (Wasserman y Faust, 1999) En nuestro caso, las etapas de la AT serán consideradas como eventos que relacionan o vinculan a los tejedores, hilanderas, y otros actores que participan de la AT. 
modelo de carácter cognitivo de la textilería. El análisis de redes sociales nos permitirá dar cuenta de las interacciones involucradas en el modo de hacer y en la concreción de la actividad textil prefigurando un modelo basado en las interacciones. Como resultado de este análisis, si en la primera etapa desnudábamos la estructura cognitiva para conocer el campo de la AT, ahora los actores no se presentarán solos con un guión o libreto, sino que se comportarán configurando un espacio en el escenario social, puesto al descubierto por la topología ${ }^{75}$ y conectividad ${ }^{76}$ relacional.

En los párrafos anteriores hemos enfatizado sobre algunas implicancias sustantivas que presenta el ARS como alternativa de valor para el estudio de la AT. En los párrafos siguientes incorporaremos otros aportes de carácter teórico y metodológico. En referencia a esto, podemos observar cómo la recolección de datos de tipo cualitativo obtenidos de las entrevistas en profundidad a un grupo de informantes resultó en una descripción pormenorizada de la secuencia de la actividad textil, mientras que asociada a esta información fue posible reconocer datos acerca de la percepción de los actores de sus propios vínculos o lazos. Este cuerpo de datos relativos a las relaciones sociales y al intercambio entre los actores requirió ser sistematizado y formalizado por su valor en la investigación. En esta instancia, el ARS se presentó como una metodología que considera los vínculos sociales como unidades analíticas y que ofrece un mecanismo para cuantificar y medir propiedades de las relaciones entre los actores.

Asimismo el ARS aparece como una estrategia que, basada en la descripción y en la inducción, permite contextualizar al actor y sus acciones en el espacio social - patrón relacional o "estructura"-, conduciendo a la elaboración de un modelo complementario del trabajo etnográfico inicial.

\footnotetext{
75 Topología de redes: análisis de la estructura o configuración de lazos en una red. Enfoque que presta mayor atención a los patrones de interconexión que al contenido de los lazos. (Harary, 1969:1; Paenza, 2006:171-189)

${ }^{76}$ Conectividad: la noción de red social contiene no solo un enfoque estructural sino también de flujos de recursos y por ende de la dinámica propia de estas estructuras. (Wasserman y Faust, 1999:115)
} 
"Como método de contextualización de la conducta, el análisis de redes puede dramáticamente mejorar la investigación cualitativa. A la inversa, es imposible diseñar un estudio de redes, o interpretar los resultados provistos por este tipo de análisis, sin tener previamente realizado una cuidadosa etnografía del escenario utilizando aproximaciones y cuestiones clásicas. En el sentido contrario, usar exclusivamente el análisis de redes es un ejercicio puramente formal..." (Lazega, 1997:120)

La idea de que la contextualización de la conducta de un actor $y$, en particular, las acciones o las interacciones de un grupo de actores, pueden observarse y entenderse en base a las posibilidades y restricciones de una estructura, considera también que esta contextualización opera a múltiples niveles. Por un lado, contempla la diferencia de las posiciones de cada individuo en la estructura de la red y por otro, toma en cuenta la combinación de múltiples relaciones dadas por su pertenencia simultánea a dos o más redes diferentes. Mientras en la teoría sociológica clásica (Parsons, 1976), el nexo entre la acción y la estructura social está dado por la noción de rol (Linton, 1964 en Bohannan, 1993), aquí consideraremos como significativa la posición de cada individuo en la red y focalizaremos sobre la complejidad de sus vínculos entendiendo su contenido como el resultado del solapamiento de distintos tipos de lazos que definen múltiples redes sociales.

Por último, cabe agregar que la perspectiva del ARS muestra su poder analítico como alternativa de investigación aplicada o de agencia ${ }^{77}$. La visión de un grupo de actores que toman decisiones en el contexto de una red de relaciones sin más restricciones y oportunidades que las que se conjugan por la acción, incorporando y extrayendo recursos de la red misma, instala la información a escala de los sucesos mismos posibilitando la descripción y representación de los intercambios efectivos y las condiciones socio estructurales que los hacen posibles. En este sentido, el análisis constituye una poderosa herramienta para el diagnóstico y resolución de problemas de interés socio-económico para las comunidades en la actualidad. Así, el punto central de esta investigación aporta a la definición de parámetros a considerar en los programas actuales de promoción

77 Agencia: Habilidad de un actor para organizar situaciones futuras y distribuir recursos. (Kadushin 2004:28) 
comunitaria en la zona del NOA. Al final del capítulo esperamos mostrar cómo los procesos de transmisión de la información, la circulación de materias primas y herramientas, y el trabajo en la AT facilitan la cohesión social y con ello la disponibilidad, expansión y "acumulación" de capital humano. Es decir, suponemos que dada la presencia de ciertos componentes humanos y establecida la forma de interacción entre ellos, podremos delinear una trama relacional a escala de la población de Molinos reconociendo un modelo social y económico que se muestra estratégico y sustentable para las comunidades.

\section{2- Condiciones sustantivas y fundamentos metodológicos para un análisis de redes sociales}

El análisis de redes sociales es, a la vez, una perspectiva teórica y un conjunto de métodos. En términos de teoría, el ARS extiende y complementa los enfoques tradicionales de las ciencias sociales centrándose en las causas y las consecuencias de las relaciones entre los actores y grupos de actores más que sobre las características de los individuos y grupos aislados. En términos de método, el ARS establece mediciones y mapea las relaciones entre los actores y grupos. Para cuantificar las relaciones, el analista de redes puede aplicar modelos y técnicas que son comúnmente utilizadas por otras ciencias sociales y naturales. (Borgatti, 2009; Freeman, L. 2004).

La investigación en redes sociales propone un conjunto de conceptos y mecanismos analíticos que originalmente emergieron del planteo de temas relacionales estimulados por el trabajo empírico a microescala, como los trabajos sobre sociedades tribales en África y pequeñas comunidades rurales en Inglaterra; sobre factorías y comunidades en USA, y sobre estudios de casos en laboratorio. Es así que las investigaciones resultantes se desarrollaron paralelamente en varios campos disciplinarios como el de la antropología social, la sociología y la psicología social desde el año 1930, continuando hasta la actualidad. Diez años más tarde y con los aportes de la matemática, los estudios de redes sociales comienzan a disponer de un soporte analítico capaz de abordar la complejidad 
de este nuevo objeto ${ }^{78}$. Actualmente, las contribuciones de la estadística y la informática convierten al ARS, en una potente herramienta metodológica. Estos desarrollos han dado forma y operatividad al tradicional concepto de red social y estructura social que planteara Radcliffe Brown, uno de los primeros que postuló la metáfora de "social fabric" (tejido social), "network" de relaciones o "webs"(red de conexiones) para explicar la vida social de los "pueblos primitivos" (Radcliffe Brown, 1969:217; Scott 2000:10,28).

El análisis de redes requiere de varias condiciones preliminares, la primera es la justificación de la delimitación del escenario social bajo examen, la segunda, la selección de las relaciones a considerar para conformar la red social (Marsden, 1990). En lo concerniente a los límites, los intentos de explicar las interacciones individuales exclusivamente en términos de la pertenencia a grupos corporativos, en función de la cultura o de los sistemas de valores, han resultado ser muy poco satisfactorios (Requena Santos, 2003). En cambio, la flexibilidad del análisis de redes ofrece maneras de definir y redefinir el alcance de una investigación de un modo exploratorio y analítico. Usualmente, los sistemas sociales no tienen contornos claros, entonces el ARS permite a los investigadores definir provisoriamente esos límites. Esto ocurre después que se ha hecho una exploración de los procesos que conducen la definición de los límites de la perspectiva de los miembros de la propia red (Lazega, 1997).

En lo concerniente al campo de relaciones, los datos reticulares se obtienen a través de los procedimientos habituales de recolección de información etnográfica, que en esta investigación proviene fundamentalmente de entrevistas y también de situaciones de observaciones en el contexto de las actividades que desarrollan los expertos. Estos datos reticulares no son en sí mismos un conjunto de interacciones sociales sobre la AT, sino que constituyen una objetivación de cada interacción que se establece entre los individuos y que se registra como un hecho almacenado en el stock de la memoria de los entrevistados (Lozares Colina, 2005).

\footnotetext{
78 En la matemática constituye un campo particular en cuyo desarrollo convergen la teoría de grafos, la teoría de conjuntos, la teoría de matrices, el análisis numérico y probabilístico, topología y combinatoria. Son reconocidas sus aplicaciones en áreas como la física, química, genética, psicología, antropología y lingüística, ciencias de la comunicación, tecnología informática, ingeniería civil y eléctrica, arquitectura.
} 
Las relaciones sociales, tomadas como unidades de análisis serán definidas en esta etapa de la investigación en tres sentidos. En primer término, el "recíproco" o su carácter de conductas interactivas; en segundo término, el aspecto "normativo" o el que considera la conexión de cada interacción a una estructura ideacional. Por último, el "constitutivo" que alude a cómo las relaciones constituyen la vida social en tanto cada persona es consciente de que su trayectoria está entrelazada con la de otras personas y las trayectorias de estas con la suya (Ingold, 1991). En este capítulo sólo analizaremos las relaciones o vínculos sociales por su contenido interactivo, es decir, aquel que empíricamente se reconoce en las disposiciones cooperativas entre los actores, en lo concerniente al intercambio de conocimientos, la experiencia para aplicarlos, la circulación de herramientas y de recursos naturales (Teves, Crivos y Lamarche, 2005).

Planteamos además, la necesidad de describir los patrones de interacción que se generan al visualizar los modos particulares en que los vínculos entre las personas se configuran y reconfiguran en este estudio. Tomando diferentes técnicas del ARS y orientados por los objetivos de esta investigación, es posible caracterizar un modelo de organización que estructura a la AT. La estrategia metodológica se basa principalmente en la operacionalización de las nociones relacionales involucradas en conceptos tan amplios como el de unidad doméstica; grupos de expertos y especialidades; intercambio en relaciones simétricas o asimétricas, y flujos en relaciones orientadas y/o balanceadas de información, recursos y trabajo; alcance socio- espacial y articulación entre actividad y zonas ecológicas.

Otra de las condiciones que justifican la aplicación de la metodología de ARS, focaliza sobre el espacio y la dinámica definidos por las relaciones y los individuos. A través de esta herramienta podemos observar conjuntos de interacciones en estados, fases o etapas sincrónicas y también abordarlas desde una perspectiva temporal, lo que permite diferenciar por un lado, entornos situacionales y por otro, el proceso de desarrollo de las redes sociales. En el caso del análisis relacional en esta tesis, las condiciones o situación de interacción están definidas por la actividad textil por todas las personas involucradas en ella y mencionados en estos entornos. Esta estrategia confiere un referente relativamente homogéneo para el estudio de las interacciones en la AT y deja 
El Estudio Etnográfico de la Actividad Textil como aporte a la Caracterización del Modo de Vida en el Pueblo de Molinos y zona de influencia (Provincia de Salta)

Laura Teves

explícito un supuesto clave acerca de los contextos situacionales complejos en los que se circunscriben las interacciones abordadas en un análisis de redes sociales de las actividades (Lozares Colina, 2005).

\subsection{1- Nociones básicas}

Hasta el momento hemos mostrado las condiciones para llevar adelante el análisis de los datos reticulares. Pero cabe además, retomar el camino por el cual generamos una serie de "textos" que se elaboraron a partir de las entrevistas en profundidad y las observaciones en el campo. Es decir, primeramente dispusimos de datos sobre la AT, que luego de ser codificados como "palabras", fueron procesados para emprender un análisis cualitativo basado en la búsqueda de asociaciones discursivas. Ahora, en esta instancia, necesitamos que esa transformación del texto proceda en una codificación de "números" identificar patrones de vínculos basada en un análisis cuantitativo ${ }^{80}$.

Los procedimientos analíticos, aplicados al material de entrevistas en profundidad y observaciones, procederán en una fase formal nominal, a la caracterización de la AT mediante la búsqueda de los atributos o propiedades de los actores y los eventos. Mientras que en la fase formal ordinal que desarrollaremos aquí, nos abocaremos a las propiedades de los vínculos o relaciones involucrados en la AT. Cabe aclarar que el ARS toma y redimensiona la información sobre los aspectos nominales de la AT como condición necesaria para el estudio de las redes sociales poniendo la caracterización de los actores y eventos en función de las relaciones entre ellos. De esta manera concluiremos acerca de

\footnotetext{
79 "In any event, you have to talk about the text and this means you have to produce labels for themes and labels for articulations between themes. All this gets you away from the text, just as surely as numerical coding does. Quantitative analysis involves reducing people (as observed directly or through their texts) to numbers, while qualitative analysis involves reducing people to words -- and your words, at that." (Bernard, R. 1986:11)

80 "When it comes right down to it, qualitative data (text) and quantitative data (numbers) can be analyzed by quantitative and qualitative methods. In fact, in the phrases 'qualitative data analysis' and 'quantitative data analysis', it is impossible to tell if the adjectives 'qualitative' and 'quantitative' modify the simple noun 'data' or the compound noun 'data analysis'." (Bernard, R. 1986:10)
} 
la conveniencia de una aproximación, convergencia y complementariedad de estos dos enfoques metodológicos de investigación.

La delimitación de los aspectos relacionales en el campo de la actividad textil requiere de un conjunto de conceptos que articule los supuestos centrales del modelo de redes sociales con las observaciones en terreno. Para esto definiremos una serie de conceptos cuyo valor es operacional y se basa en los criterios instrumentales o procedimientos por los cuales se establecen nexos entre el nivel conceptual -términos teóricos y observacionales- con algún tipo de proceso, objeto o evento -es decir, los hechos bajo estudio. Consecuentemente, los conceptos claves en el análisis de redes nos permitirán definir entidades, problemas y niveles de análisis relacional en el campo de la AT. Estas nociones fundamentales son las de actor, lazo o vínculo, díada ${ }^{81}$, tríada ${ }^{82}$, subgrupo, grupo ${ }^{83}$, relación y red social.

El ARS se ocupa de las entidades sociales y vínculos entre esas entidades. Las entidades sociales son los actores 0 agentes y refieren a un individuo $o$ a colectivos sociales tales como las organizaciones, comunidades $u$ otro tipo de agrupamiento de personas. En esta investigación definiremos como actores al mismo tipo de entidades individuales, es decir, trabajaremos con una selección de actores, los expertos en la textilería, representados por tejedores, hilanderas y componedoras, y no por grupos de personas. Sus atributos más relevantes describen sus roles en tanto especialistas, edad y género, lugar de pertenencia, lugares por los que se desplazan y los recursos de que disponen para la AT. Respecto a la red de circulación o desplazamientos de personas, tomaremos como puntos de relación a las localidades donde habitan los expertos y su factibilidad de disponer de recursos naturales y ofrecerlos como materias primas.

En cuanto a los vínculos, lazos, conexiones o relaciones, son considerados como los conectores de un par de actores, completando la unidad de análisis de las redes sociales. Una amplia variedad de conductas involucran tipos diferentes de lazos. En esta investigación definiremos los lazos basados en relaciones de parentesco, trabajo,

\footnotetext{
81 Díada es una relación entre dos actores o nodos

82 Los vínculos entre tres actores o nodos definen una tríada

83 Subgrupos y Grupos son conjuntos de actores o nodos en una red
} 
transacción y comercio, transferencia de recursos materiales y no materiales, y vínculos espaciales por circulación y viaje.

Una vez definidos los actores y las relaciones, podremos presentar la noción de red social, que consiste en un conjunto finito de personas y vínculos definidos entre ellas. La red social que describiremos aquí se compone de actores y lazos que emergen de la actividad textil. La configuración de la red de actividad podrá describir patrones de vínculos y predecir las implicancias que ellos tienen sobre los actores en la organización social de la comunidad Molinos.

\subsection{2- Sistematización y formalización de los datos relacionales}

El desarrollo del ARS depende de la disponibilidad de un tipo de datos, los relacionales, es decir, aquellos que refieren a conexiones sustantivas específicas. Tal como las hemos definido en este estudio incluye: transacciones de recursos materiales y no materiales, interacciones, movimientos espaciales y relaciones de parentesco, amistad y entre vecinos o conocidos. Junto al tipo y contenido de los vínculos, el enfoque provee de datos que informan acerca de las características de los actores. Las variables atributivas de los actores son inseparables de las variables atributivas vinculares. Desde el punto de vista etnográfico el condicionamiento de una variable hacia la otra es central y su valor se aprecia en la fase de delimitación del contenido de una relación por referencia a las versiones alternativas de los actores sobre una relación tipificada. Posteriormente, la consideración de los atributos de los actores y los vínculos entre ellos es central en la fase de interpretación de los resultados emergentes del análisis y en la contextualización de las redes sociales. En este apartado nos ocuparemos de mostrar el modo en que es preciso dar forma y ordenar tanto los atributos que caracterizan a los actores como a las relaciones.

Mientras, por una parte, hemos introducido un conjunto de conceptos que se convierten en instrumento para la operacionalización en el campo de la AT, de una serie de hipótesis acerca de las relaciones sociales; por otro lado, veremos cómo los datos así delimitados 
serán formalizados y codificados en una expresión numérica que hará posible la aplicación de cálculos y mediciones.

Los pasos a seguir para la sistematización de los datos del ARS que se presentan en esta sección describen los mecanismos que proceden en una serie de etapas: selección, ordenamiento, almacenado y manejo de los datos relacionales.

La selección de datos relacionales implica pensar en las relaciones sociales como "constructos sociales". En este sentido, por un lado, nos enfrentamos a las concepciones que los propios actores tienen sobre las relaciones que refieren, las diferencias que se observan entre cada uno de ellos. Al mismo tiempo cabe preguntarse sobre, ¿cuáles son los límites que definen una relación? En cualquier caso, dada la ambigüedad y vaguedad inherente a las expresiones del lenguaje natural utilizado tanto por el informante como por el investigador, se impone clarificar y definir las unidades de análisis. Esto justifica nuestra decisión de aplicar los conceptos operativos y procedimientos que conducen a la elaboración y construcción de los modelos propios del ARS.

Dicho lo anterior, se presenta inmediatamente la cuestión sobre ¿cómo elegir o seleccionar la población o los individuos en una investigación relacional? Las posibilidades son al menos, tres. La primera, adoptar el enfoque posicional, centrado en las conexiones estructurales en poblaciones, grupos y eventos. Como segunda opción, focalizar en los individuos y sus interacciones. La tercera alternativa, se basa en la consideración de las interacciones en un ámbito o espacio. Esto se convierte en la clave para elegir personas y vínculos relevantes a una actividad o evento social. Lo fundamental es la elección de las actividades y eventos en los cuales la gente está involucrada, independientemente de cualquier asignación a priori de posición, función o pertenencia a un nivel de organización social particular (Scott, 2000:58-60). Este criterio es diferente al que opera en contextos de investigación donde la pertenencia a grupos étnicos, instituciones o el desempeño en cargos tales como "jefe" "doctor", "padre", "maestro"..., determina la visión sobre la cantidad, calidad y alcance de las relaciones sociales. 
Para un ordenamiento de los datos de una investigación relacional podemos utilizar una matriz de datos. Una matriz de datos habitualmente pude considerase como un marco, recuadro o soporte en el cual organizamos de modo más o menos eficiente la información. Puede tener un diseño tan simple como la figura de una tabla o de un patrón de filas y columnas. Estas matrices almacenan información sobre el valor o la medición de un atributo en un caso estudiado -informantes- en relación a una variable -edad, género, grupo étnico, ocupaciones, escolaridad- (Scott, 2000: 39).

En el caso de las matrices para datos relacionales, se considera a la sociomatriz como la matriz primaria. Esta tendrá una disposición de filas y columnas y en el cruce entre ellas queda circunscrito un espacio llamado celda (Figura 1). Por lo general en cada celda se coloca un número que indica la presencia o ausencia de relación entre los actores; es decir, si existe la relación se coloca uno (1), si no existe se coloca cero $(0)^{84}$.

Los datos acerca de los lazos entre personas o entre personas y eventos pueden expresarse no solo en forma de matriz sino también por un esquema gráfico llamado sociograma (Figura 2). El sociograma es uno de los aportes más novedosos originados desde el estudio de las interacciones personales, creado en 1936 por el psicólogo Jacob Moreno. Consiste en un diagrama que presenta las propiedades formales de una red social, mostrando una imagen de las "configuraciones sociales" implícitas en los vínculos personales de un informante. Su interés principal consiste en carácter innovador y analítico de su representación de la metáfora de "red de relaciones", "trama social" y "tejido de conexiones". En el gráfico vemos como los mismos datos están dispuestos en la matriz y en un sociograma. En este último, los actores son representados por puntos y las líneas que los unen simbolizan cada relación presente entre ellos.

\footnotetext{
${ }^{84}$ Utilizaremos dígitos binarios, 0 y 1, para indicar la presencia o ausencia de una relación entre actores.
} 
El Estudio Etnográfico de la Actividad Textil como aporte a la Caracterización del Modo de Vida en el Pueblo de Molinos y zona de influencia (Provincia de Salta)

C O L U M N A S

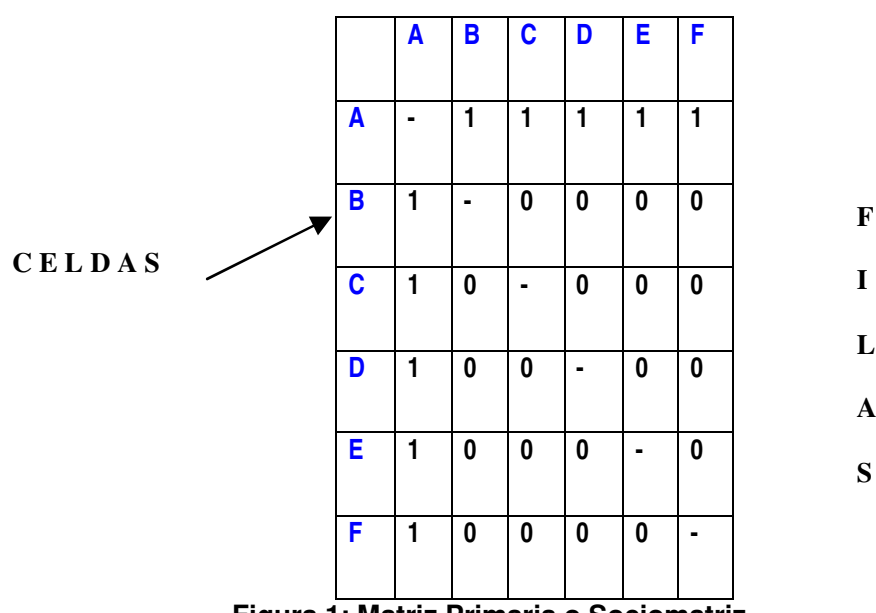

Figura 1: Matriz Primaria o Sociomatriz

F

I

$\mathbf{L}$

A

S

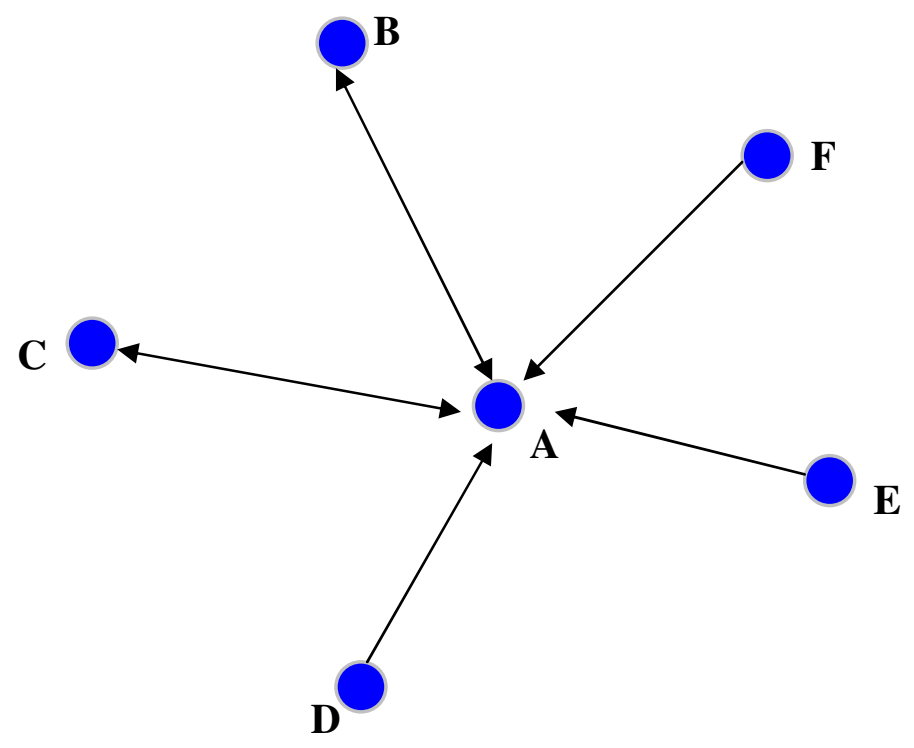

Figura 2: Sociograma de la matriz tipo

Las matrices pueden ser de dos tipos, rectangulares o de incidencia y cuadradas 0 de adyacencia. Las primeras, son matrices con agentes en las filas y eventos en las columnas, cada celda señala la relación existente entre una persona y su inclusión en un 
tipo de acontecimiento o tarea. Las segundas, son matrices donde en un caso, las filas y las columnas corresponden a las mismas personas y en otro caso, las matrices tienen los mismos eventos en filas y columnas. En ellas se representan a los agentes/actores y las celdas muestran si los pares de personas están vinculados por el mismo evento. 0 podemos observar la opción, en la que filas y columnas estén ocupadas por los eventos y las celdas indiquen pares de sucesos que están conectados por personas en común. En el ejemplo que sigue, podemos suponer que un grupo de tejedores interviene en cinco contextos diferentes de realización de la $A T\left(E_{1}\right.$ a $\left.E_{5}\right)$. Lo representaremos en una matriz de incidencia (a) y a partir de ella derivaremos dos matrices de adyacencia ${ }^{85}$. En la matriz de adyacencia (b) podremos observar la relación entre los tejedores por referencia a su participación en los eventos de la AT, si tomamos al actor A y su relación con el actor B vemos que participan juntos en 3 eventos. En la matriz de adyacencia (c) el cruce entre el evento $\mathbf{E}_{3}$ y $\mathbf{E}_{5}$ indica que 2 actores están involucrados en ellos (Figura 3 y Figura 4).

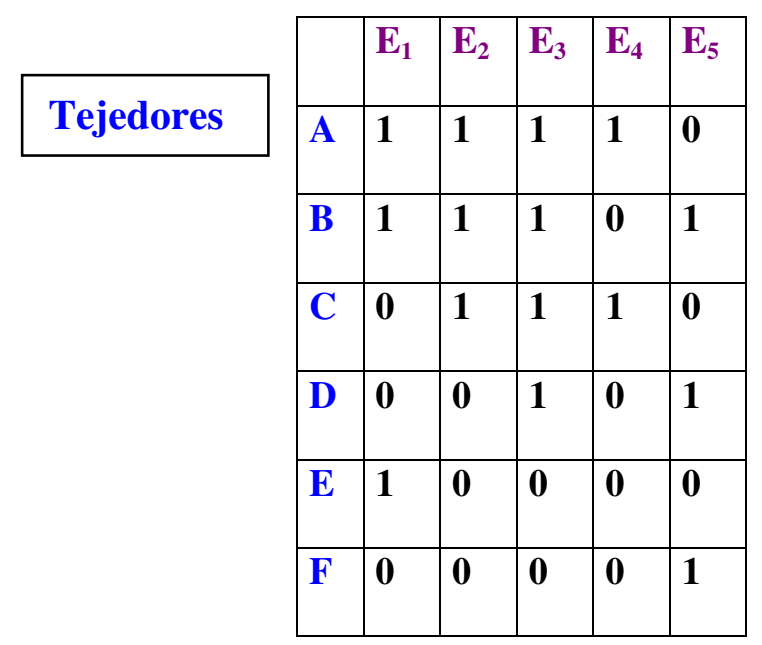

\section{Actividades}

Figura 3: Matriz de INCIDENCIA (a) Actores $x$ eventos

${ }^{85}$ La operación de multiplicación de una matriz de incidencia por sí misma resulta en dos matrices de adyacencia. 


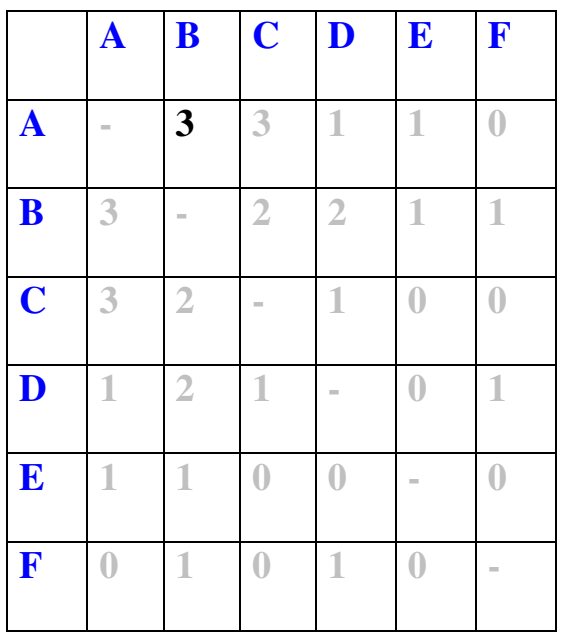

Eventos x Eventos

Figura 4: Matriz de ADYACENCIA (b)

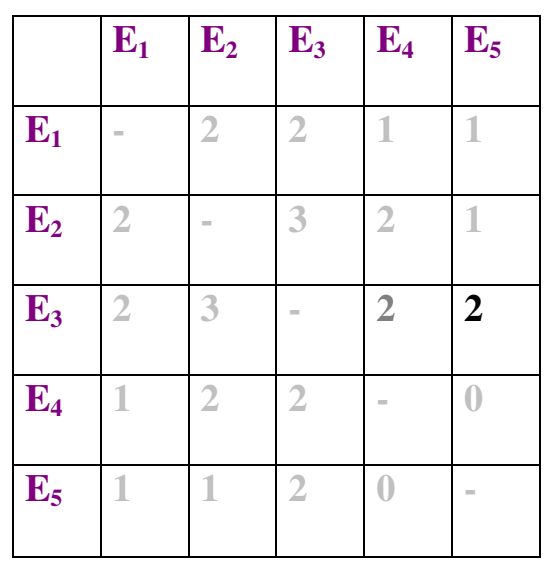

Actores x Actores

Matriz de ADYACENCIA (c)

Otra convención a tener en cuenta es la orientación de los datos en la matriz, su disposición indica el modo de lectura y comprensión de los datos presentados. El ordenamiento de datos nos ubica respecto a cómo debemos entender el sentido de las relaciones que hemos colectado. Así en las filas van los actores desde los que se inicia la relación y en las columnas, se lista a los actores o eventos que son receptores de ella. La celda que surge de la intersección de fila y columna contiene el valor de la relación. De este modo la relación se lee de izquierda a derecha, en el ejemplo de la figura 3 se indica que el actor $D$ participa en el evento $E_{5}$, o que el actor $A$ no se relaciona con el actor $F$ (Figura 4). La consideración sobre el sentido de las relaciones conduce a definir la direccionalidad de las relaciones, es decir, realizamos la codificación de los datos de modo que, si el actor A dice que elige para trabajar a B, entonces podemos suponer que $B$ prefiere al actor $A$ (relación no dirigida). Pero si $A$ dice que elige a $E$, pero este no lo acepta, en definitiva, no lo menciona o no reconoce que tiene un vínculo con $A$, entonces la relación estará orientada en el sentido de A hacia $E$ y no a la inversa (relación dirigida). Tómese como ejemplo el diseño de la Figura 5. 


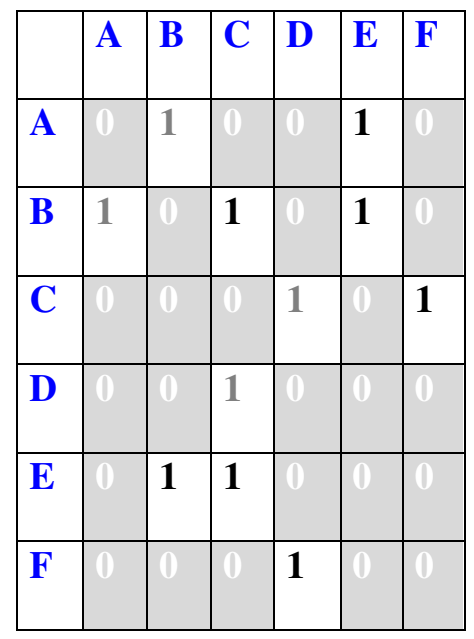

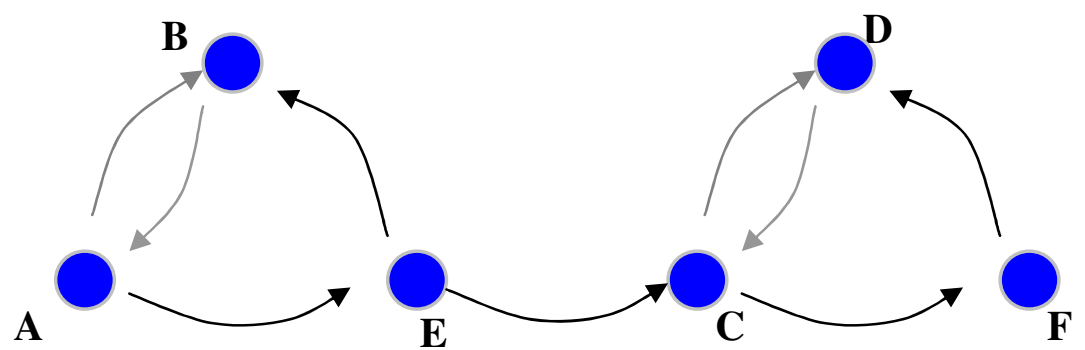

Figura 5: Grafo dirigido y su matriz

Es interesante señalar que el ordenamiento mismo de los datos en la matriz ya arroja información sobre las relaciones que de otra manera no podría ser advertida en el estado de los datos aislados. El contenido de una matriz puede mostrar, si la relación entre dos actores es fuerte, por ejemplo más eventos compartidos. Por lo tanto, vamos advirtiendo algunas propiedades de las redes como la centralidad de los actores en una red y las conexiones más laxas que indican cuáles son los sectores periféricos de esa misma red. Siguiendo con la observación del contenido de una matriz, no podemos dejar de lado la diagonal de una matriz. En el caso de las matrices simétricas con relaciones no dirigidas pueden dividirse por su diagonal en dos mitades, la mitad superior es idéntica a la mitad inferior y la información redundante, cada mitad es la imagen en espejo de la otra. En las matrices de adyacencia que contienen datos dirigidos la diagonal debe ser considerada porque no es lo mismo el par de actores $(A, C)$ que indica la presencia de una relación, que el par de actores (C,A) en el cual la relación está ausente (ver Figura 6). En este sentido, la propiedad de direccionalidad genera y diferencia dos tipos de matrices, la simétrica con vínculos no dirigidos, recíprocos o reflexivos ${ }^{86}$ y la asimétrica, cuyos vínculos son dirigidos.

\footnotetext{
${ }^{86}$ También llamados loops e indica el vínculo del nodo con sí mismo, por ejemplo, A con A, B con B.
} 
El Estudio Etnográfico de la Actividad Textil como aporte a la Caracterización del Modo de Vida en el Pueblo de Molinos y zona de influencia (Provincia de Salta)

Laura Teves
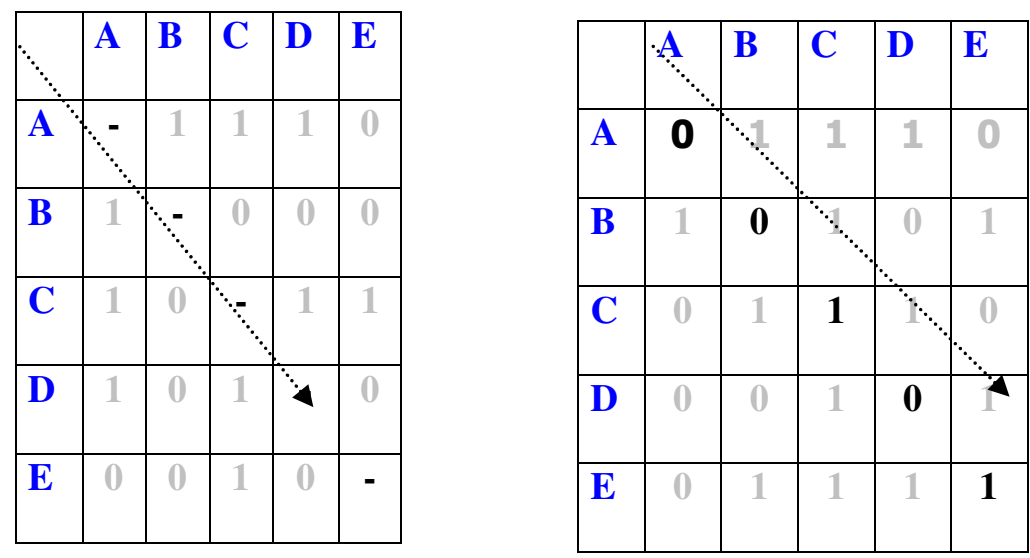

Figura 6: Diagonal de una matriz simétrica y asimétrica

El almacenamiento de los datos requiere del uso de computadoras y programas que se ajusten al manejo eficiente de los datos relacionales. La lógica de los datos en una matriz puede ser traducida en un archivo de computadora y su manipulación en ese entorno se vuelve imprescindible cuando las matrices cuentan con más de 5 o 6 filas y columnas. Los listados de nombres de actores que luego se colocarán en filas y columnas pueden guardarse y editarse en procesadores de texto y bases de datos (Ver Figura 7).

\begin{tabular}{|l|l|l|l|l|l|l|}
\hline & $\mathbf{A}$ & $\mathbf{B}$ & $\mathbf{C}$ & $\mathbf{D}$ & $\mathbf{E}$ & $\mathbf{F}$ \\
\hline A & & $\mathbf{1}$ & & & $\mathbf{1}$ & \\
\hline B & $\mathbf{1}$ & & $\mathbf{1}$ & & $\mathbf{1}$ & \\
\hline C & & & & $\mathbf{1}$ & & $\mathbf{1}$ \\
\hline D & & & $\mathbf{1}$ & & & \\
\hline E & & $\mathbf{1}$ & $\mathbf{1}$ & & & \\
\hline F & & & & $\mathbf{1}$ & & \\
\hline
\end{tabular}
A $\mid$ B E
B A C E
C D F
D C
E B C
F D

\begin{tabular}{|lll}
\hline $\mathrm{AB}$ & $\mathrm{AE}$ & \\
$\mathrm{BA}$ & $\mathrm{BC}$ & $\mathrm{BE}$ \\
$\mathrm{CD}$ & $\mathrm{CF}$ & \\
$\mathrm{DC}$ & \\
$\mathrm{EB}$ & $\mathrm{EC}$ \\
$\mathrm{FD}$ & \\
\hline
\end{tabular}

Figura 7: De la matriz al listado de actores y relaciones 
El Estudio Etnográfico de la Actividad Textil como aporte a la Caracterización del Modo de Vida en el Pueblo de Molinos y zona de influencia (Provincia de Salta)

Sin embargo, la mayor utilidad y compatibilidad para la clasificación y ordenamiento de los datos en matrices se obtiene mediante una hoja de cálculo que luego se exporta para continuar el análisis con las herramientas específicas del ARS. Los programas para computadoras facilitan los cálculos con los datos ya ordenados en forma de matrices y permiten almacenar conjuntamente los datos relacionales numéricos con aquellos que señalan atributos o nombres, de este modo no se pierde el nexo entre las relaciones y las características de los actores (Tabla 1).

\begin{tabular}{|c|c|}
\hline DL $n=5$ & DL $n=33$ \\
\hline \begin{tabular}{|l|} 
format=edgelist1 \\
\end{tabular} & format=edgelist1 \\
\hline \begin{tabular}{|l|} 
labels: \\
\end{tabular} & labels: \\
\hline 1 & "1" 1 \\
\hline 2 & "7" 1 \\
\hline 7 & "12" 1 \\
\hline 8 & "14" 1 \\
\hline 688 & \\
\hline 10002 & \\
\hline \begin{tabular}{|l|} 
labels embedded \\
\end{tabular} & \\
\hline data: & \\
\hline 7 & \\
\hline $\mathbf{1}$ & \\
\hline $\begin{array}{|ll|}1 & 10002 \\
\end{array}$ & \\
\hline 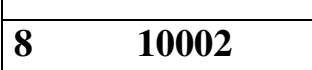 & \\
\hline \begin{tabular}{|l|}
1 \\
1
\end{tabular} & \\
\hline $\begin{array}{|ll|}1 & 688 \\
\end{array}$ & \\
\hline \begin{tabular}{|ll}
688 & 2
\end{tabular} & \\
\hline
\end{tabular}

Tabla 1: Listado de datos relacionales y atributivos codificados y ordenados para procesar 


\subsection{3- Algoritmos y Mediciones}

Mientras que el sociograma ha mantenido su valor como un modo de analizar y visualizar una red, su carácter explicativo se amplió con la presencia de un lenguaje formal originado en el campo de la matemática y que se denomina teoría de grafos. Un grafo es un conjunto de líneas conectadas por puntos. Los puntos, vértices o nodos, representan a los actores y las líneas, arcos o lazos representan las relaciones entre los actores. La teoría de grafos consiste en un cuerpo de axiomas matemáticos y reglas ${ }^{87}$ que describen las propiedades de los patrones formados por las líneas. Aún cuando los diagramas en teoría de grafos son muy importantes, más lo es la posibilidad de aproximar los datos de una matriz en las cualidades de una red social. Para esto exploraremos conceptos y procedimientos de la teoría de grafos que luego aplicaremos en la descripción de la red de la actividad textil en Molinos.

De las matrices adyacentes ${ }^{88}$ con lazos dirigidos desde un actor a otro, obtenemos grafos dirigidos o dígrafos, la presencia y dirección de la relación queda indicada por una línea con una flecha en el diagrama del grafo (ver la Figura 2 y la Figura 5). La importancia o intensidad de una relación puede ser representada por un valor numérico, la medida de intensidad más conocida es la multiplicidad de una línea. Ésta puede ser relevada mediante el registro de la cantidad de contactos, es decir, la frecuencia de interacciones en un mismo tipo de relación, así como la pluralidad de contenidos de un vínculo.

Otro concepto que utilizaremos es el de densidad, el cual describe el nivel general de vinculación entre los nodos de un grafo. La densidad se calcula estimando el número y la proporción de líneas al considerar el grafo como un todo. Esta medida es de gran utilidad para diferenciar dos niveles de ARS, el de las redes personales o egocentradas y el nivel de las redes totales o sociocéntricas. En el primer caso, el interés se focaliza en un nodo o actor particular aislado de la red total y un subgrupo de vínculos muy próximos que lo

\footnotetext{
${ }^{87}$ Un conjunto finito de instrucciones o pasos que sirven para ejecutar una tarea y/o resolver un problema se conoce como algoritmo. (Hanneman, 2000:17-19)

${ }^{88}$ El sociograma es una matriz de adyacencia porque las entradas en la matriz indican si dos nodos son vecinos y están conectados por un lazo, o no lo están. (Wasserman y Faust, 1999:11-12)
} 
rodean. En las redes totales, la densidad describe el patrón de conexiones en base a todas las relaciones de todos los actores. Esto es central para identificar cómo la red ejerce un poder condicionante sobre sus miembros y esto ocurre no sólo por los lazos directos que llegan a un actor, como puede inferirse del caso anterior en las egoredes, sino por los lazos indirectos y sus propiedades emergentes e independientes de los actores mismos.

Una de las propiedades más destacadas de un grafo es la conectividad, es decir, la existencia de nexos que comunican todos los pares de nodos de ese grafo. Los nodos en un grafo desconectado pueden formar dos o más subgrafos (ver en la Figura 8 los nodos y lazos encerrados en un círculo). Los subgrafos en un grafo conectado se llaman componentes. Estas definiciones tienen implícita la idea de que un grupo de nodos/actores junto con las líneas/relaciones/ resultan críticos a la hora de mantener conectado un grafo/red social. La prueba de conectividad se basa en observar si el grafo persiste como un todo a pesar de quitarle nodos y líneas.

En los grafos dirigidos la noción de camino indica la secuencia de lazos entre dos nodos no adyacentes (ver en la Fig. 8, las líneas entre los nodos $A \longrightarrow B \longrightarrow C \longrightarrow$ B). Paso es el camino donde cada nodo y cada lazo del recorrido son diferentes (en la Figura 8, por ejemplo las líneas entre los nodos A $\quad \begin{array}{ll}B & \text { D). La longitud de un paso consiste en la }\end{array}$ medición de los lazos que a modo de "pisadas" integran un paso (en el ejemplo anterior de la figura 8 desde el nodo $A$ al nodo $D$, hay 2 pasos). Por último, distancia mide la longitud del paso más corto o geodésico entre dos puntos del grafo (en la Figura 8, desde el nodo $A$ para llegar al nodo $C$ el camino más corto es $A-\complement$ ). Las dimensiones de los grafos hasta aquí definidas describen propiedades basadas en un "criterio de alcance" aplicado a actores y relaciones. Esto se visualiza claramente en las ilustraciones o diagramas de los grafos o redes, pero las técnicas de formalización gráfica no conducen a una asociación directa entre las distancias relacionales y las distancias del mundo físico. Los diseños de los sociogramas o grafos son el producto de ordenamientos arbitrarios de puntos y líneas basados en las propiedades de las redes, constituyendo verdaderos mapas relacionales que representan las configuraciones estructurales de un grupo ${ }^{89}$.

89 Esto no impide la comparación por solapamiento con mapas geográficos. Varios trabajos combinan ARS y GIS (Molina, J. L, Ruiz, A. y L. Teves 2005; de la Rosa; 2005). 


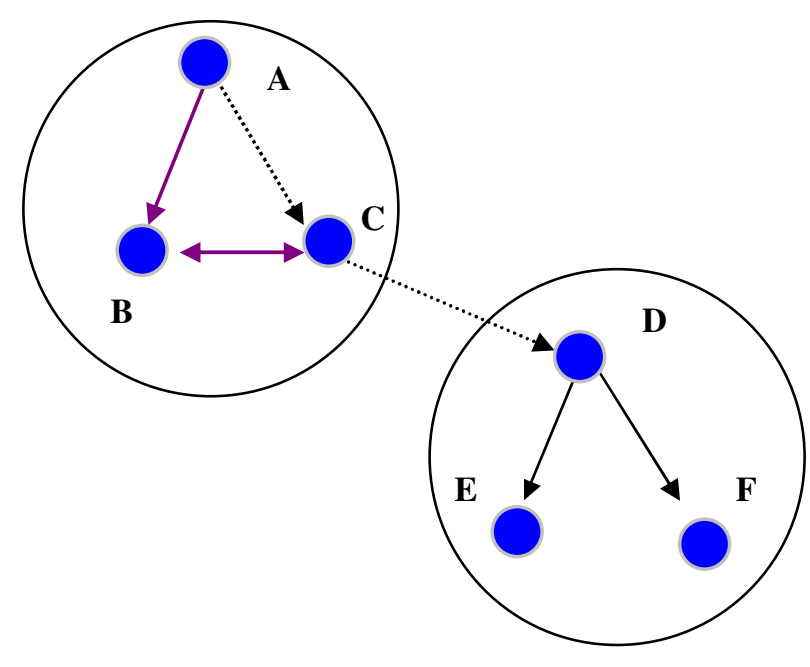

Figura 8. Grafo dirigido o dígrafo: sub-grato, camino y paso (...)

\section{3- Hipótesis y Datos para un análisis de las redes sociales en Molinos}

4.3.1- Formulación de hipótesis relacionales en la actividad textil

El enfoque y la información etnográfica presentada precedentemente condujeron a la delimitación y planteo de tres hipótesis que en adelante, guiarán la investigación en el sentido del ARS. Quedan de este modo enunciadas:

1- Las prácticas cotidianas en las unidades domésticas remiten a entornos sociales y espaciales más amplios que pueden delimitarse a través de la red social de un Ego.

2- La toma de decisiones individuales es relativa a la racionalidad de los patrones de organización intragrupal en la AT.

3- Las prácticas cotidianas de subsistencia manifiestan la persistencia de la complementariedad entre los microambientes andinos.

El planteo de estos supuestos permite establecer una correspondencia con los objetivos de la investigación, con los datos relacionales utilizados para el análisis y las redes descriptas, 
El Estudio Etnográfico de la Actividad Textil como aporte a la Caracterización del Modo de Vida en el Pueblo de Molinos y zona de influencia (Provincia de Salta)

Laura Teves

así como derivar los resultados de sus propiedades y las consecuencias de estos resultados en las explicaciones de los fenómenos abordados (ver la Tabla 2).

Tabla 2- Articulación de las diferentes etapas de la investigación y su adecuación con un encuadre relacional.

\begin{tabular}{|l|l|l|l|}
\hline Objetivos & Corpus de Datos & Descripción Red & Resultados \\
\hline $\begin{array}{l}\text { Delimitación de la red social involucrada } \\
\text { en las actividades económicas }\end{array}$ & $\begin{array}{l}\text { Relaciones personales de } \\
\text { ego }\end{array}$ & $\begin{array}{l}\text { Transacciones para la } \\
\text { subsistencia }\end{array}$ & $\begin{array}{l}\text { Correlación de los } \\
\text { atributos relacionales en } \\
\text { las redes personales }\end{array}$ \\
\hline $\begin{array}{l}\text { Caracterización del patrón organizativo } \\
\text { implicado en la AT }\end{array}$ & $\begin{array}{l}\text { Relaciones entre expertos } \\
\text { en la AT }\end{array}$ & $\begin{array}{l}\text { Especialidades y } \\
\text { actividades adicionales } \\
\text { vinculadas a la AT }\end{array}$ & $\begin{array}{l}\text { Composición de los } \\
\text { grupos de práctica90 }\end{array}$ \\
\hline $\begin{array}{l}\text { Reconstrucción del circuito de } \\
\text { producción y comercialización de los } \\
\text { textiles en la región (tradicional y actual) }\end{array}$ & $\begin{array}{l}\text { Relaciones entre } \\
\text { localidades por actividades } \\
\text { de intercambio en la AT }\end{array}$ & $\begin{array}{l}\text { Circulación de recursos, } \\
\text { información y trabajo }\end{array}$ & $\begin{array}{l}\text { Topología de la red de } \\
\text { transacciones }\end{array}$ \\
\hline
\end{tabular}

\subsection{2- Datos para un análisis de redes sociales en la actividad textil}

Inicialmente, tomamos el material de entrevistas semi- estructuradas realizadas a 15 informantes. Estas personas fueron elegidas por su reconocida condición de "experto" en la realización de los característicos textiles del valle calchaquí salteño. Este material nos aportó información cualitativa acerca de los actores involucrados en la AT y actividades económicas relacionadas como una secuencia de operaciones en la cadena productiva del textil. Posteriormente, tomamos el mismo corpus para mostrar cómo las mismas actividades pueden ser abordadas desde las relaciones entre los actores involucrados.

Como señalamos al comienzo de este capítulo, el tratamiento de los datos discursivos y observacionales resultó, en la primera etapa de la investigación, en la delimitación del dominio de la actividad textil, la definición de categorías para su descripción y el ordenamiento del campo conceptual implicado. A partir del dominio conceptual de la

${ }^{90}$ Grupos de Prácticas o Comunidad de Práctica refiere a mucho más que el conocimiento técnico o las habilidades asociadas con las tareas. Los miembros están relacionados a través del tiempo y las comunidades se manifiestan alrededor de las cosas que les suceden. El hecho de que ellos estén organizados de un modo particular en un área de conocimento y actividades les otorga iniciativa e identidad. (Lave y Wenger, 1991) 
actividad reconstruido teniendo en cuenta las particularidades del relato de cada uno de los informantes seleccionados, se elaboró un modelo que caracteriza el proceso completo de obtención de productos textiles (Teves, 2005:4).

En una segunda instancia de la investigación, identificamos y extraemos del corpus inicial, la información relativa a la interacción entre los individuos tanto en el ámbito doméstico, como en diversos espacios significativos para la prosecución de la actividad textil. En este momento del desarrollo de la investigación los "vínculos reales" concentran nuestro especial interés y se abandonan las relaciones establecidas entre categorías que refieren a la actividad y emergen del análisis del corpus discursivo. Ahora nos concentraremos en el aspecto ontológico relacional de estos datos como una re-lectura del mismo corpus e inspirada en las hipótesis provenientes de la perspectiva del ARS. De este modo, el estudio desde la dimensión cognitiva de la AT será complementada con la del estudio sobre la dimensión social y organizacional.

Los datos relacionales nos permitirán describir las actividades como expresión de todos y cada uno de los episodios que acontecen al establecerse una relación de intercambio de recursos o de realización de tareas comunes en lo que ya hemos descrito como dominio de la actividad. Para lograr este propósito introduciremos la noción de red social, de modo que en adelante, intentaremos una caracterización de la actividad textil desde la perspectiva de una serie de actores que mantienen vínculos o lazos en ese contexto sociocultural de una región de los Valles Calchaquíes. La consideración de los actores y el contenido de sus relaciones, expresadas en forma de redes, presentan una clara alternativa metodológica con implicancias en la descripción e interpretación de la actividad. 
El Estudio Etnográfico de la Actividad Textil como aporte a la Caracterización del Modo de Vida en el Pueblo de Molinos y zona de influencia (Provincia de Salta)

Tabla 3- Textilería y otras actividades de subsistencia asociadas en términos de los datos para el ARS.

\begin{tabular}{|c|c|c|c|c|c|}
\hline Contextos & Nodos & $\begin{array}{l}\text { Atributos de los } \\
\text { actores }\end{array}$ & Tipos de relaciones & Tipo de red & $\begin{array}{l}\text { Alcance de la } \\
\text { red }\end{array}$ \\
\hline $\begin{array}{l}\text { Actividades en la unidad } \\
\text { doméstica }\end{array}$ & $\begin{array}{l}\text { Informante } \\
\text { "experto" }\end{array}$ & $\begin{array}{l}\text { Sexo, edad } \\
\text { División del } \\
\text { trabajo }\end{array}$ & $\begin{array}{l}\text { Lazos parentales y lazos no } \\
\text { parentales }\end{array}$ & Red de ego & Local \\
\hline $\begin{array}{l}\text { Actividades fuera de la } \\
\text { UD } \\
\text { Fincas } \\
\text { Mercados } \\
\text { Asociación }{ }^{91}\end{array}$ & $\begin{array}{l}\text { Tejedores, } \\
\text { troperos, } \\
\text { criadores, } \\
\text { asociados } \quad \text { y } \\
\text { otros. }\end{array}$ & \begin{tabular}{lr|} 
Tipo & de \\
especialidad & $y$ \\
tareas & \\
\end{tabular} & $\begin{array}{l}\text { Lazos de intercambio y } \\
\text { laborales }\end{array}$ & Red de especialistas & Regional \\
\hline $\begin{array}{l}\text { Actividades en zonas } \\
\text { ecológicas } \\
\text { Específicas }\end{array}$ & $\begin{array}{ll}\text { Pueblos } \quad y \\
\text { parajes }\end{array}$ & $\begin{array}{ll}\text { Tipos } & \text { de } \\
\text { ambientes } & \end{array}$ & $\begin{array}{lr}\text { Relaciones } & \text { de } \\
\text { complementariedad entre } \\
\text { zonas }\end{array}$ & Red geográfica & Tras regional \\
\hline
\end{tabular}

\section{4- Estrategias analíticas: egoredes, socioredes y su topología}

\subsection{1- Las relaciones personales en las actividades domésticas}

El ego-experto ${ }^{92}$ seleccionado en esta instancia del análisis es una mujer de 45 años que vive con su familia en una vivienda típica del valle en la localidad de Tomuco. Menciona 34 personas -hombres, mujeres y niños-, con las que se relaciona a través de varias

${ }^{91}$ Asociación Productores y Artesanos San Pedro Nolasco de los Molinos (APASPNM).

92 Ego-informante es la persona que constituirá el nodo o referente a partir del cual se iniciará la construcción de una red personal o ego red. Las relaciones sociales mencionadas por Ego pueden cubrir un amplio campo de vínculos afectivos, cognitivos, parentales y no parentales, basados en roles o acciones. 
actividades, entre ellas la textilería, la agricultura, la recolección, la cría de ganado y el trabajo asalariado. Las actividades mencionadas generan, entre ego y los alteri referidos, intercambios diádicos de bienes o mercancías $^{93}$ y de trabajo que resultan en 52 transacciones.

La residencia de las personas vinculadas remite a sitios distribuidos a lo largo del valle o localizados en diferentes altitudes del valle y cerros. Entre las mencionadas, pueden distinguirse cuatro categorías de personas, entre parientes y no parientes. Entre estos últimos se identifican a vecinos, amigos y "gente conocidd". Los lazos o relaciones que se entablan a través de la textilería y otras actividades asociadas, refieren al menos a cinco modos de transferencia o transacciones. Estos cubren los campos del intercambio desigual, reciproco, directo e indirecto de materias primas o recursos (Intercambio Tipo I); bienes o mercancías (Intercambio Tipo II); trabajo o servicios (Intercambio Tipo III) y áreas de comercialización (Intercambio Tipo IV). Estas últimas tienen lugar en los mercados locales donde bienes y trabajo son transferidos por su equivalente en moneda corriente. Las designaciones locales: "al partir", "multiplico", compra-venta, "dar obrd" y "sociedad", identifican algunas de estas relaciones.

Cada par de nodos y su correspondiente lazo, cuyo contenido refiere a un objeto, transacción o servicio, encuentra un lugar en la matriz de adyacencia. Los lazos dirigidos que indican la orientación de un vínculo entre Ego y sus Alteri ${ }^{94}$, permite seguir la dirección de las interacciones. Pero, en algunos casos se observa la falta de reciprocidad en las interacciones entre el informante y los alteri mencionados. Consideramos que esto puede ocurrir porque los datos acerca de las interacciones fueron aportados espontáneamente en las entrevistas cuyo tema principal era "cómo se hace un textil". La entrevistada muy hábilmente introdujo su conocimiento sobre los intercambios vinculados a estas tareas lo cual me posibilitó entender los mecanismos que articulan las etapas de realización de un textil. Finalmente, múltiples motivos que pueden haber mediado en el recuerdo de algunos intercambios y la no especificación o mención de otros.

\footnotetext{
${ }^{93}$ Mercancías o flujo de bienes en una red (Hage y Harary, 1991).

${ }^{94}$ Alteri: conjunto de personas mencionadas por un Ego-informante. Alteri es la versión latina de Alters para los angloparlantes.
} 
El Estudio Etnográfico de la Actividad Textil como aporte a la Caracterización del Modo de Vida en el Pueblo de Molinos y zona de influencia (Provincia de Salta)

Laura Teves

En la tabla 4 se observa la disposición de los datos codificados que han sido utilizados para construir la red personal de la experta y establecer las correlaciones según las variables relacionales de transacciones, parentesco y espacio de las actividades de valor económico. 
El Estudio Etnográfico de la Actividad Textil como aporte a la Caracterización del Modo de Vida en el Pueblo de Molinos y zona de influencia (Provincia de Salta)

Tabla 4- Ordenamiento de las relaciones económicas, sociales y espaciales de un ego y sus alteri para la construcción de su red personal.

\begin{tabular}{|c|c|c|c|c|}
\hline \multirow[t]{5}{*}{$\begin{array}{l}\text { Informante (I) } \\
\text { I-SCHG }^{95}\end{array}$} & Alter (II) & $\begin{array}{l}\text { Tipos de transacciones } \\
\text { Cantidad de transacciones }\end{array}$ & $\begin{array}{l}\text { Parientes }^{96} \\
\text { No parientes }\end{array}$ & Lugares $^{97}$ \\
\hline & II-AG & $\begin{array}{l}\text { Intercambio I } \\
\text { Intercambio III } \\
\text { Intercambio II I }\end{array}$ & NP: Amigas & Tomuco \\
\hline & \begin{tabular}{|l|} 
II-CH \\
\end{tabular} & Intercambio IV & $\begin{array}{r}\text { NP: Conocidos } \\
0\end{array}$ & $\begin{array}{l}\text { Pueblo de Molinos } \\
\text { 0 }\end{array}$ \\
\hline & \begin{tabular}{|l|} 
II-SC \\
\end{tabular} & $\begin{array}{l}\text { Intercambio I } \\
\text { Intercambio III }\end{array}$ & P: primo & $\begin{array}{l}\text { Las Ramadas } \\
\text { Humanao }\end{array}$ \\
\hline & III-S1 & $\begin{array}{l}\text { Intercambio I } \\
\text { Intercambio II } \\
\text { Intercambio I }\end{array}$ & P: prima & Colomé \\
\hline
\end{tabular}

${ }^{95}$ Código que identifica al Ego_experto sobre el que se construye la red.

96 En la Tabla, $\mathbf{P}$ indica relaciones entre Ego y un pariente y en la matriz se carga como el valor (1); mientras que NP, indica la relaciones entre Ego y sus conocidos no parientes; y vale (0).

${ }_{97}$ Se indicará con (1) el lugar de residencia del informante y con (0) otros lugares donde se sitúan las relaciones de Ego con sus alteri. 


\subsection{2- Los grupos y subgrupos en las redes de actividad}

Las relaciones que se entablan entre los actores son extraídas o construidas por la descripción que surge de los propios informantes al referir a los actores que intervienen y desempeñan funciones específicas en la actividad textil. Los vínculos entre los actores quedan señalados mediante líneas que unen los puntos de cada grafo. Pero esas relaciones no son equiparables, es decir, cada miembro de la red integra un grupo, cuyos miembros se caracterizan por un tipo de atributos, algunos saben hilar, tejero componer, ó son productores de materias primas ó comercializan los textiles. La elección de los miembros de cada grupo conforma una red diferente de otras para llevar adelante las distintas tareas vinculadas a la AT.

Observamos que los informantes identifican al menos tres tipos de integrantes en sus propias redes: (1) los especialistas en la elaboración de las piezas de tejido: tejedores, hilanderas, componedoras, (2) agentes en la compra-venta: Coordinador de la Asociación, empresarios, promotores culturales, funcionarios municipales, finqueros, contratistas que "dan obra" y (3) abastecedores de materia prima: "caravaneros", "ambulantes", transportistas, criadores.

Los datos sistematizados y utilizados para comparar las Ego_redes se presentan en la tabla 5 donde se ordenan en base a las tareas específicas que desempeñan los actores y los vínculos en la red de la actividad textil. 
El Estudio Etnográfico de la Actividad Textil como aporte a la Caracterización del Modo de Vida en el Pueblo de Molinos y zona de influencia (Provincia de Salta)

Laura Teves

Tabla 5- Codificación y ordenamiento de los actores y los vínculos en la red de la actividad textil.

\begin{tabular}{|c|c|c|c|}
\hline \multicolumn{3}{|c|}{ Notación para la Sociomatriz } & \multirow[b]{2}{*}{ Actividad } \\
\hline ID & Código o Acrónimo del Nombre del Actor & $\begin{array}{l}\text { Código de la } \\
\text { actividad }\end{array}$ & \\
\hline 1 & TG & 1 & Tejedor \\
\hline 5 & $\mathbf{A G}$ & 1 & Hilandera - Tejedora \\
\hline 9 & Ach & 3 & Carpintero \\
\hline 15 & Afa & 1 & Tejedora pulloveres de la APASPNM \\
\hline 16 & Aro & 1 & Modista de la APASPNM \\
\hline 22 & Boli & 2 & Vendedor tintura \\
\hline 26 & Cata & 2 & Intermediario lanas y cueros \\
\hline 29 & Yapu & 1 & Componedora \\
\hline 30 & Comprador1-LCCH & 2 & Comprador de hilo \\
\hline 33 & Comprador1-SR & 2 & Vendedor de lanas \\
\hline 36 & Comprador2-SR & 2 & Proveedor de plantas medicinales \\
\hline 38 & Comprador3-SR & 2 & Comprador de lana \\
\hline 40 & Criador1-SR & 2 & Vendedor de lana de llama y oveja \\
\hline 41 & Criadores1-JG & 2 & Productor de lana llama \\
\hline 45 & DiFaLo & 2 & Hilandera - Componedora \\
\hline 47 & EG & 1 & Tejedor \\
\hline 48 & Guay & 1 & Tejedor- Agricultor \\
\hline 52 & Finquero-RV & 2 & Finquera \\
\hline 57 & Choco & 3 & Carpintero \\
\hline 67 & GeGó & 1 & Tejedor \\
\hline 69 & GraBa & 2 & $\begin{array}{l}\text { Promotor de eventos culturales y comerciales } \\
\text { (mercado de artesanías) }\end{array}$ \\
\hline 70 & GTR & $1-3$ & Tejedora- Criadora de ovejas \\
\hline 78 & Ha.Gu & 3 & Tropero de caravanas \\
\hline 79 & Herrero-MF & 3 & Herrero \\
\hline 81 & Ha.LCCH & 3 & Proveedor tinturas industriales \\
\hline 84 & JuQui & 3 & Agricultor- Criador \\
\hline 88 & MeBull & 2 & $\begin{array}{l}\text { Organizador de eventos comerciales y } \\
\text { culturales (mercado de artesanías) }\end{array}$ \\
\hline 94 & Meló & 2 & Coordinador de la AAPSPNM \\
\hline 99 & ResponsableMercadoArtesanal & 2 & Funcionario provincial \\
\hline 103 & BertoFa & 2 & Funcionario local \\
\hline 109 & SR & 3 & Tropero de caravanas \\
\hline 111 & Sr. Fa & 3 & Criador y productor de lana \\
\hline 115 & Sr. Ló & $1-3$ & Criador- Tejedor \\
\hline 123 & Sr. Torteros-SCHG & 3 & Ceramista (torteros) \\
\hline 134 & Sr.darobra1-EG & 2 & Empleador \\
\hline 137 & Sra. Gó & 3 & Proveedor de tinturas industriales \\
\hline 147 & Sra. Ló & $1-3$ & Criadora. Hilandera \\
\hline 151 & Sr2-SR & 3 & Proveedor de mercaderías \\
\hline 158 & Yuyero1-JG & 3 & Proveedor de vegetales para teñir \\
\hline
\end{tabular}




\subsection{3- Las relaciones sociales en el espacio}

Los 15 informantes entrevistados proveyeron un listado de personas con las que participan juntos en la actividad textil. Mediante las respuestas obtenidas se localizó a estas personas en diferentes puntos geográficamente referenciados en los valles interserranos, zonas próximas a las localidades y parajes en otras provincias limítrofes y en puntos más distantes de la región del NOA.

La lista sin repeticiones alcanza a 175 personas, las que entran en relación con los informantes a partir de las transacciones llevadas a cabo en el marco de la obtención de recursos naturales, la disponibilidad de tecnología, la contratación de mano de obra y la comercialización de productos en el mercado.

La red de relaciones sociales encuentra un correlato geográfico en el territorio delimitado por el Departamento de Molinos y otras localidades de la región. Se consideran 38 localidades que remiten a 68 pares de tramos distribuidos en 3 trayectos. Estas atraviesan a lo largo de valles, abras y cerros, de norte a sur todos los espacios del Departamento de Molinos, y de este a oeste se proyectan hacia las ciudades de Antofagasta y Santa María de la provincia de Catamarca, así como a las provincias de Córdoba y Buenos Aires. Al norte la circulación llega hasta Salta capital y más allá de las fronteras con Bolivia.

Las tablas 6 y 7 muestran la disposición de los datos utilizados para establecer y medir el grado de conexión entre las redes personales, la obtención de recursos provenientes de los microambientes y la circulación de productos por las rutas a escala de la región. 
El Estudio Etnográfico de la Actividad Textil como aporte a la Caracterización del Modo de Vida en el Pueblo de Molinos y zona de influencia (Provincia de Salta)

Tabla 6- Disposición de los datos sobre recursos y lugares en la red de actividad económicas.

\begin{tabular}{|c|c|c|c|}
\hline \multirow{2}{*}{$\begin{array}{l}\text { Código } \\
\text { Localidad }\end{array}$} & \multirow[t]{2}{*}{ Localidades } & \multicolumn{2}{|c|}{ Elementos del circuito de transacciones } \\
\hline & & $\begin{array}{l}\text { Actividades, bienes y productos } \\
\text { directamente relacionados con el } \\
\text { Proceso de Producción Textil }\end{array}$ & $\begin{array}{l}\text { Actividades, bienes y productos } \\
\text { indirectamente relacionados con el } \\
\text { Proceso de Producción Textil }\end{array}$ \\
\hline L1 & Tomuco-Molinos & $\begin{array}{l}\text { Hilados } \\
\text { Tejidos }\end{array}$ & $\begin{array}{l}\text { Cultivos } \\
\text { Cría de animales } \\
\text { Agricultura } \\
\text { Abono }\end{array}$ \\
\hline L2 & Molinos-Pueblo & $\begin{array}{c}\text { Hilos } \\
\text { Tejidos } \\
\text { Utensilios }\end{array}$ & $\begin{array}{c}\text { Turismo } \\
\text { Provisiones } \\
\text { Comercialización }\end{array}$ \\
\hline L3 & Santa María-Catamarca & Hilos & Cueros \\
\hline L5 & Tacuil-Molinos & $\begin{array}{l}\text { Nogal para teñir } \\
\text { Utensilios- Sogas }\end{array}$ & $\begin{array}{l}\text { Cría de animales } \\
\text { Semillas de maíz }\end{array}$ \\
\hline L7 & Salta-Capital & Tinturas industriales & $\begin{array}{c}\text { Artesanías } \\
\text { Comercialización } \\
\end{array}$ \\
\hline L8 & Compuel-Salta & $\begin{array}{c}\text { Vellón de lana } \\
\text { Hilos de llama y oveja }\end{array}$ & Plantas Medicinales \\
\hline L9 & Colomé-Salta & Hilados & $\begin{array}{c}\text { Cultivos } \\
\text { Cría de animales }\end{array}$ \\
\hline L10 & Humanao-Molinos & Tejidos & Agricultura \\
\hline L11 & Entre Ríos-Molinos & $\begin{array}{l}\text { Hilos } \\
\text { Peines } \\
\text { Tejidos }\end{array}$ & $\begin{array}{c}\text { Agricultura } \\
\text { Cría vicuñas en semicautividad } \\
\text { Comercialización }\end{array}$ \\
\hline L12 & Santa Rosa_Molinos & Tejidos & \\
\hline L13 & Barranca-Molinos & Lanas & Cría de animales \\
\hline L14 & Hualfin-Molinos & $\begin{array}{l}\text { Utensilios } \\
\text { Lanas }\end{array}$ & Cría de animales \\
\hline L15 & Luracatao-Molinos & Lanas- Hilos & Cría de animales \\
\hline L23 & Buenos Aires-Capital & $\begin{array}{l}\text { Tinturas } \\
\text { Telares }\end{array}$ & Comercialización \\
\hline L24 & Mayuco-Tacuil & Lanas & Cría de animales \\
\hline L26 & La Esquina-Molinos & Tejidos & \\
\hline L27 & $\begin{array}{l}\text { Antofagasta de la } \\
\text { Sierra- Catamarca }\end{array}$ & Lanas & Cría de animales \\
\hline L29 & Cafayate-Salta & Utensilios & Comercialización \\
\hline L31 & Córdoba & Tejidos & Comercialización \\
\hline L33 & Huerta Grande_Salta & Tejidos & Agricultura \\
\hline L34 & Cabrería- Luracatao & Lanas & Cría de animales \\
\hline L35 & Alumbre- Luracatao & Lanas & Cría de animales \\
\hline L36 & Compuel_Salta & $\begin{array}{c}\text { Lanas, hilos de llama y oveja } \\
\text { Peleros }\end{array}$ & $\begin{array}{c}\text { Cría de ovejas, llamas cabras } \\
\text { Recolección de plantas medicinales }\end{array}$ \\
\hline
\end{tabular}


El Estudio Etnográfico de la Actividad Textil como aporte a la Caracterización del Modo de Vida en el Pueblo de Molinos y zona de influencia (Provincia de Salta)

Tabla 7- Listado de pares de localidades referentes a los trayectos en las rutas de circulación de materias primas, mano de obra y comercialización de textiles.

\begin{tabular}{|l|l|}
\hline 1. Alumbre/Luracatao- Entre Ríos & 2. Luracatao- Tomuco \\
\hline 3. Amaicha- Tacuil & 4. Molinos- Amaicha \\
\hline 5. Banda Grande - Entre Ríos & 6. Molinos- Banda Grande \\
\hline 7. Banda Grande- Salta & 8. Molinos- Buenos Aires \\
\hline 9. Banda Grande- Molinos & 10. Molinos- Córdoba \\
\hline 11. Barranca/Tacuil- Molinos & 12. Molinos- El Colte \\
\hline 13. Bolivia- Molinos & 14. Molinos- Huerta Grande \\
\hline 15. Bolivia- Tomuco & 16. Molinos- Humanao \\
\hline 17. Brealito- Tomuco & 18. Molinos- Luracatao \\
\hline 19. Buenos Aires- Entre Ríos & 20. Molinos- Salta \\
\hline 21. Cabrería- Entre Ríos & 22. Molinos- Santa Rosa \\
\hline 23. Cachi Adentro-Tomuco & 24. Molinos- Tomuco \\
\hline 25. Cafayate- Molinos & 26. Patos- Molinos \\
\hline 27. Cafayate- Tomuco & 28. Patos- Tomuco \\
\hline 29. Catamarca- Molinos & 30. Salta - Tomuco \\
\hline 31. Colomé- Molinos & 32. Salta- Entre Ríos \\
\hline 33. Colomé- Tomuco & 34. Salta- Luracatao \\
\hline 35. Compuel- Tomuco & 36. Salta- Molinos \\
\hline 37. El Puente- Banda Grande & 38. Santa María/Catamarca- Entre Ríos \\
\hline 39. El Puente- El Churcal & 40. Santa Rosa- Entre Ríos \\
\hline 41. El Puente- Entre Ríos & 42. SantaMarí/Catamarca- Tomuco \\
\hline 43. El Refugio/Luracatao- Entre Ríos & 44. Seclantás Adentro- Tomuco \\
\hline 45. Entre Ríos - Molinos & 46. Tacuil- Entre Ríos \\
\hline 47. Entre Ríos- Buenos Aires & 48. Tacuil- Molinos \\
\hline 49. Entre Ríos- Cachi & 50. Tacuil- Tomuco \\
\hline 51. Entre Ríos- Luracatao & 52. Tacuil-Patos \\
\hline 53. Entre Ríos- Salta & 54. Tomuco- Amaicha \\
\hline 55. Entre Ríos- Tomuco & 56. Tomuco- Entre Ríos \\
\hline 57. Hualfín - Tomuco & 58. Tomuco- La Esquina \\
\hline 59. Hualfin- Molinos & 60. Tomuco- Luracatao \\
\hline 61. La Puerta/Luracatao- Entre Ríos & 62. Tomuco- Molinos \\
\hline 63. Luracatao- Entre Ríos & 64. Tomuco- Salta \\
\hline 65. Luracatao- Molinos & 66. Tomuco- Santa Rosa \\
\hline 67. Luracatao- Seclantás & 68. Tomuco- Tiopampa \\
\hline
\end{tabular}




\section{5- Testeo de los supuestos sobre los aspectos relacionales de las AT en Molinos}

\subsection{1- Las unidades domésticas y la red social de Ego}

La elección de los modelos de ARS se adecua a los objetivos propuestos para este estudio, por esto, hemos optado por establecer tres instancias analíticas acordes a las hipótesis planteadas y que al mismo tiempo proveen un dominio conceptual formalizado $y$ operativo, así como procedimientos para contrastar los supuestos de partida (Tabla 8)

\section{Tabla 8- Selección de los cálculos para la resolución de los problemas planteados.}

\begin{tabular}{|c|c|c|}
\hline Conceptos operativos & Modelos de ARS & Operaciones provistas por UCINET6 \\
\hline $\begin{array}{l}\text { Ego-red: variables dependientes e independientes, } \\
\text { lazos } \\
\text { Correlación estadística: red observada, red } \\
\text { estructurada. }\end{array}$ & Correlación de Matrices & $\begin{array}{l}\text { TOOLS > STATISTICS > } \\
\text { MATRIX (QAP) > QAP-CORRELATION }\end{array}$ \\
\hline Densidad: tamaño, lazos, pares, componentes. & Densidad & $\begin{array}{l}\text { NETWORK > } \\
\text { EGO NETWORKS > DENSITY }\end{array}$ \\
\hline $\begin{array}{l}\text { Conectividad: caminos, punto de corte, distancia, } \\
\text { alcance. }\end{array}$ & Cohesión & $\begin{array}{l}\text { NETWORK > } \\
\text { COHESION > DISTANCE NETWORK > COHESION }> \\
\text { REACHABILITY }\end{array}$ \\
\hline
\end{tabular}

5.1- La hipótesis 1, enunciada del siguiente modo,

Las actividades en las unidades domésticas remiten a entornos sociales y espaciales más amplios que pueden observarse a partir de las redes personales de los actores,

La misma será testeada a través del análisis de correlación o QAPCorrelation. Este procedimiento estadístico permite comparar redes y expresar el grado de correspondencia 
entre ellas. De este modo, una de las redes se constituye en una red observada mientras que la otra es la red modelo o estándar.

Los datos relacionales extraídos de las entrevistas a un informante permitieron obtener 3 redes personales. Las redes están construidas sobre la base de relaciones de intercambio -variable dependiente- y de relaciones de parentesco y localización - variables independientes-.

El cálculo en UCINET6 procede a partir de 3 matrices originadas de los pares ordenados seleccionados de acuerdo a las variables. Dos de las matrices -denominadas modelopermitirán crear redes que servirán para correlacionar con una sola matriz que tomaremos como la observada. Entonces corre el algoritmo denominado $Q A P$, de Correlación de Matrices o Procedimiento de Asignación Cuadrática. Este mecanismo consiste en el cálculo del índice de Pearsons cuyo valor es significativo si es $<0.05$ y no hay correlación entre la redes si el valor es mayor.

En nuestro caso, los valores obtenidos como resultados de la correlación indican que entre la matriz observada "transacción" y la matriz "lugar", la correlación de Pearson es 0.534 , es decir, mucho mayor que 0.05: En el caso de la correlación entre la matriz observada "transacción" y la matriz estructura "parentesco" el índice de Pearson es 0.511 . Por lo tanto, concluimos que no existe asociación entre la red de transacción de un ego y sus redes parentales y espaciales. 
El Estudio Etnográfico de la Actividad Textil como aporte a la Caracterización del Modo de Vida en el Pueblo de Molinos y zona de influencia (Provincia de Salta)

Laura Teves

Figura I- Visualización de la Ego_red en base a las variables medidas

Transacciones Totales de un Ego en la muestra de Frecuencia de intercambio en las actividades Informantes: circulación de objetos y trabajo en la económicas cotidianas de Ego actividad textil y otras actividades cotidianas.
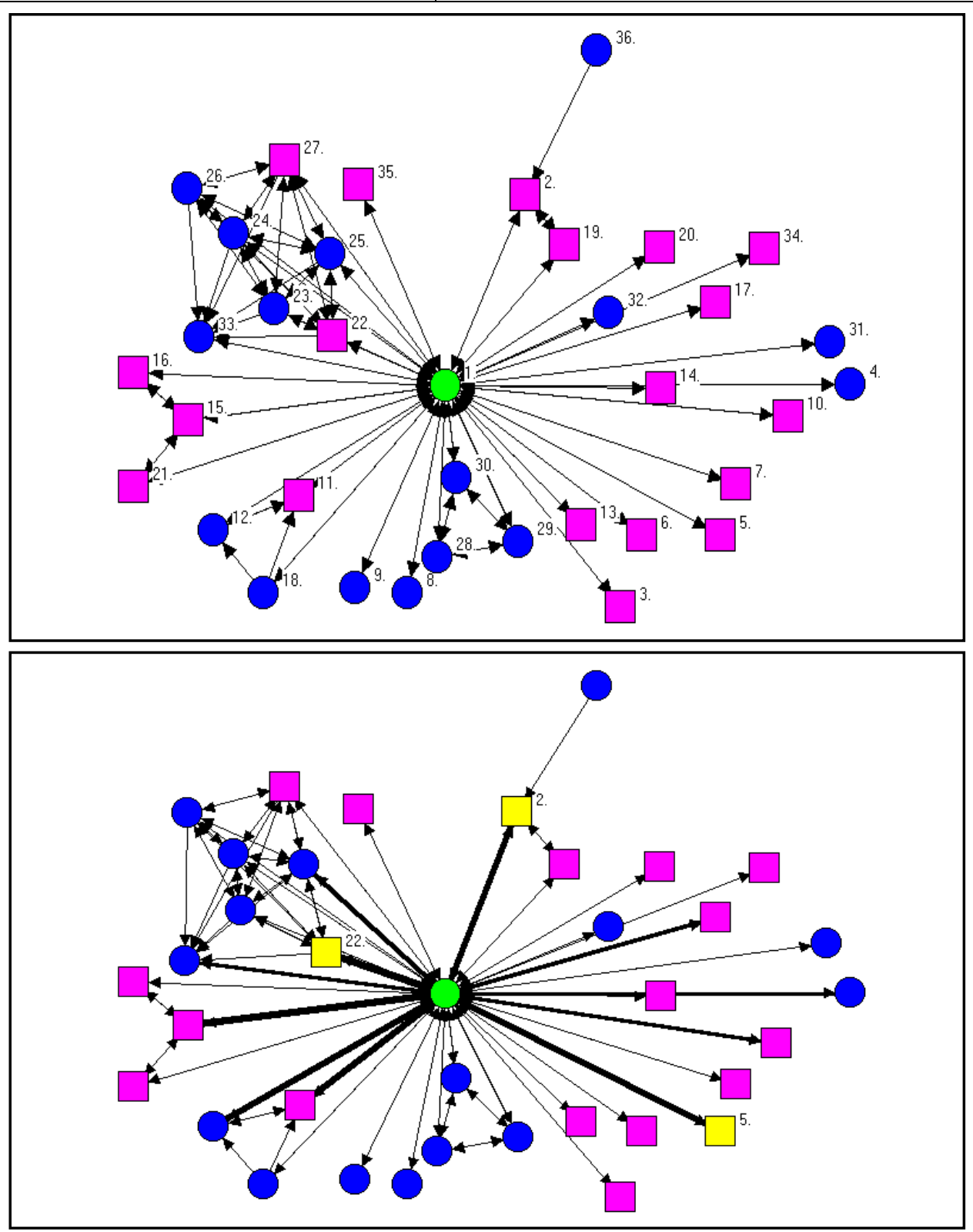

REFERENCIAS

EGO (en verde)

Personas vinculadas sólo por la actividad agrícola, la ganadería y servicios (azul)

Personas vinculadas sólo por la actividad textil (fucsia) Personas vinculadas por la actividad textil, agricultura, recolección y ganadería (amarillo) Grosor de los lazos: indica mayor frecuencia de interacción 
El Estudio Etnográfico de la Actividad Textil como aporte a la Caracterización del Modo de Vida en el Pueblo de Molinos y zona de influencia (Provincia de Salta)

Laura Teves

Transacciones entre Ego y sus alteri parientes y no parientes
Transacciones que relacionan personas mediante parámetros de localidad de residencia de Ego y otras localidades de la región.
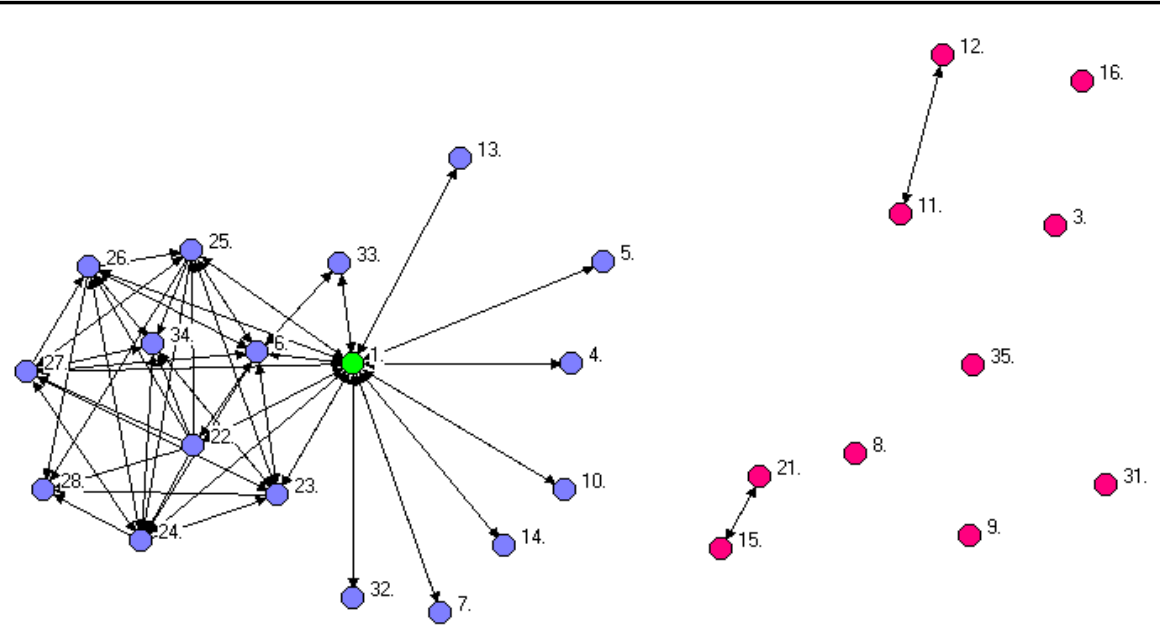

$0^{18}$

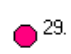

$0^{30}$

917
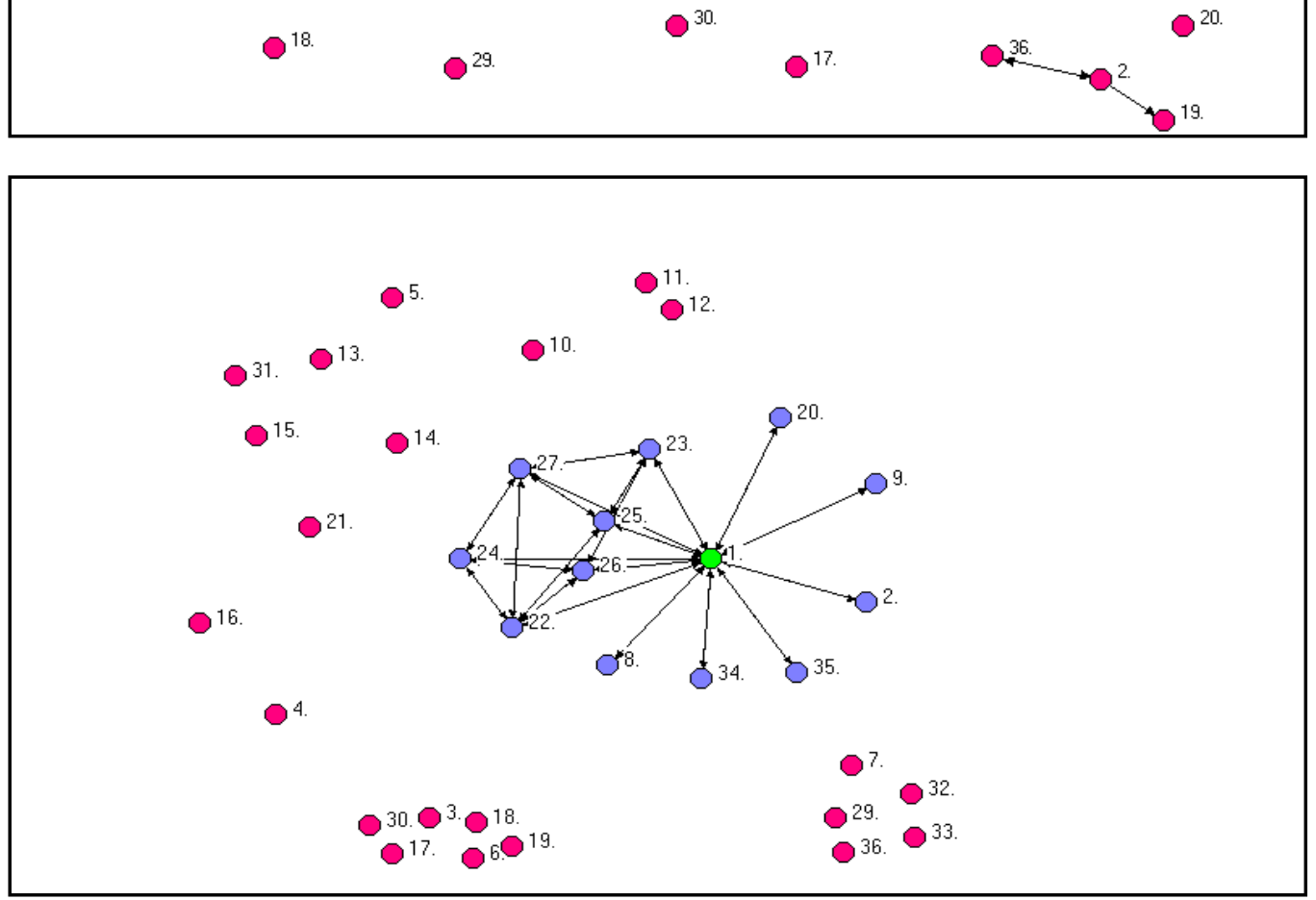

REFERENCIAS

EGO (en verde)

Relaciones recíprocas entre los Alteri Parientes (azul)

Alteri No parientes (rosado)

Alteri que viven en la Localidad de EGO (azul)

Alteri en diferentes localidades del Valle (rosado) 


\subsection{2- La toma de decisiones y los patrones de organización intragrupal}

La hipótesis 2, enuncia que

La toma de decisiones individuales es relativa a la racionalidad de los patrones de organización intragrupal.

Sostendremos este supuesto sobre la base del análisis de densidad o density, el cual introduce una rutina que construye la red de un ego o red personal, para cualquier actor elegido dentro de la red total y calcula un conjunto de propiedades para la ego_red. Considera juntos o separados, los datos dirigidos dentro y fuera de las redes personales y calcula 14 medidas propias de las ego_redes.

Con los datos de las 15 personas que conforman la muestra total de informantes y sus alteri mencionados se construyó una matriz de actor $\mathrm{x}$ actor, $* 15 \mathrm{x} * 157$. La matriz contiene las relaciones que establecen los 15 informantes a lo largo de la secuencia de etapas que conforman la actividad textil, la cual introduce 157 alteri con 202 relaciones entre ellos. De esta manera se obtiene un digrafo o grafo con vínculos orientados y dicotómicos.

La exploración mediante el cálculo de densidad en ego_networks en UCINET6 nos permite explorar las configuraciones de tales relaciones considerando díadas y triadas, actores y la red total. A partir de allí, es posible elaborar conjeturas acerca de las características de cada configuración y sus modos de articulación con otras. De este modo, calculamos el tamaño de nodos en la red, es decir, el número de alteri a los que ego está directamente conectado; la cantidad de lazos potenciales y efectivamente posibles, vinculados directamente a ego o no. A la vez, podemos distinguir las relaciones personales o de cada actor, en la red total de las actividades para esa muestra de actores. En cuanto a la medida de densidad, expresa una proporción de las relaciones efectivas dentro de una red personal con respecto a las relaciones posibles en la red total. 
El Estudio Etnográfico de la Actividad Textil como aporte a la Caracterización del Modo de Vida en el Pueblo de Molinos y zona de influencia (Provincia de Salta)

Laura Teves

Tabla 9- Medidas de densidad para la red de cada Ego $^{98}$

\begin{tabular}{|c|c|c|c|c|c|c|c|}
\hline \multicolumn{2}{|c|}{ Tipos de Miembros } & \multicolumn{3}{|c|}{ Entre grupo de Informantes } & \multicolumn{3}{|c|}{ Entre Miembros de la Red Total } \\
\hline Ego & Alter & Tamaño & Lazos & Pares & Tamaño & Lazos & Pares \\
\hline $\mathrm{LCCH}$ & 31 & 8 & 30 & 56 & 26 & 324 & 650 \\
\hline JG & 28 & 7 & 32 & 42 & 63 & 1058 & 3906 \\
\hline ML & 20 & 10 & 54 & 90 & 41 & 894 & 1640 \\
\hline SCHG & 18 & 6 & 20 & 30 & 3 & 6 & 6 \\
\hline $\mathrm{VL}$ & 18 & 5 & 12 & 20 & 55 & 1324 & 2970 \\
\hline SR & 17 & 6 & 22 & 30 & 35 & 528 & 1190 \\
\hline MF & 15 & 5 & 14 & 20 & 46 & 1114 & 2070 \\
\hline RV & 13 & 9 & 42 & 72 & 30 & 870 & 870 \\
\hline LZ & 10 & 6 & 22 & 30 & 32 & 876 & 992 \\
\hline GTR & 9 & 9 & 40 & 72 & 8 & 56 & 56 \\
\hline $\mathrm{MCl}$ & 6 & 6 & 26 & 30 & 17 & 272 & 272 \\
\hline FV & 6 & 8 & 40 & 56 & 77 & 2012 & 5852 \\
\hline $\mathbf{A G}$ & 4 & 3 & 6 & 6 & 40 & 596 & 1560 \\
\hline MAR & 4 & 0 & 0 & 0 & 9 & 72 & 72 \\
\hline ETG & 3 & 0 & 0 & 0 & 9 & 72 & 72 \\
\hline
\end{tabular}

Referencias

Muestra: 15 informantes, 202 alteri, 157 alteri sin repeticiones, 30 repetidos.

Tamaño: El número de alteri a los que ego está directamente conectado.

Lazos: El número total de lazos en la red de ego, sin lazos que involucran a ego Pares: El número total de pares de alteri en la red de ego, incluidos lazos potenciales.

${ }^{98}$ Tomamos la opción de colorear algunos valores en gris para destacar los valores en color negro, los que coinciden con los aspectos que deseamos destacar en este análisis de las ego_redes. 
Se observa en la Tabla 9 que el informante $F V$ tiene una red personal de tamaño 6, es decir, menciona seis alteri formando parte de su red personal. $F V$, es el informante con menor cantidad de relaciones aportadas y reconocidas por él mismo. Pero en el conjunto de los informantes considerados en esta investigación, su red alcanza a 8 personas y un total de 40 vínculos entre esos actores. Cuando se observa el nodo de $F V$ en la muestra completa, su red personal presenta un tamaño de 77 individuos, con 5.852 pares de alteri que potencialmente pueden ser alcanzados a través de su propia red. Es decir, que $F V$ es una persona conocida por la mayoría de los involucrados en la actividad textil.

En cuanto a la propiedad de densidad de las redes personales, la mayoría alcanza entre el $50 \%$ y el $100 \%$ de lazos esperados sobre los lazos posibles en la red total. Con respecto a la conformación interna de cada ego-red se observa que hay una distribución uniforme del tipo de relaciones. Cada ego-red está integrada por especialistas en la elaboración de las piezas de tejido, por agentes en la compra-venta y por abastecedores de recursos naturales. Asimismo, se observa que los vínculos no son redundantes, los actores son casi exclusivos de la red de cada informante. Esto nos permite proponer que la actividad textil se desarrolla en pequeños grupos con miembros que pertenecen solamente a un grupo y se eligen para conformarlo. 
El Estudio Etnográfico de la Actividad Textil como aporte a la Caracterización del Modo de Vida en el Pueblo de Molinos y zona de influencia (Provincia de Salta)

Figura 9. Visualización de la red completa de la AT mostrando a los actores diferenciados por sus especialidades.

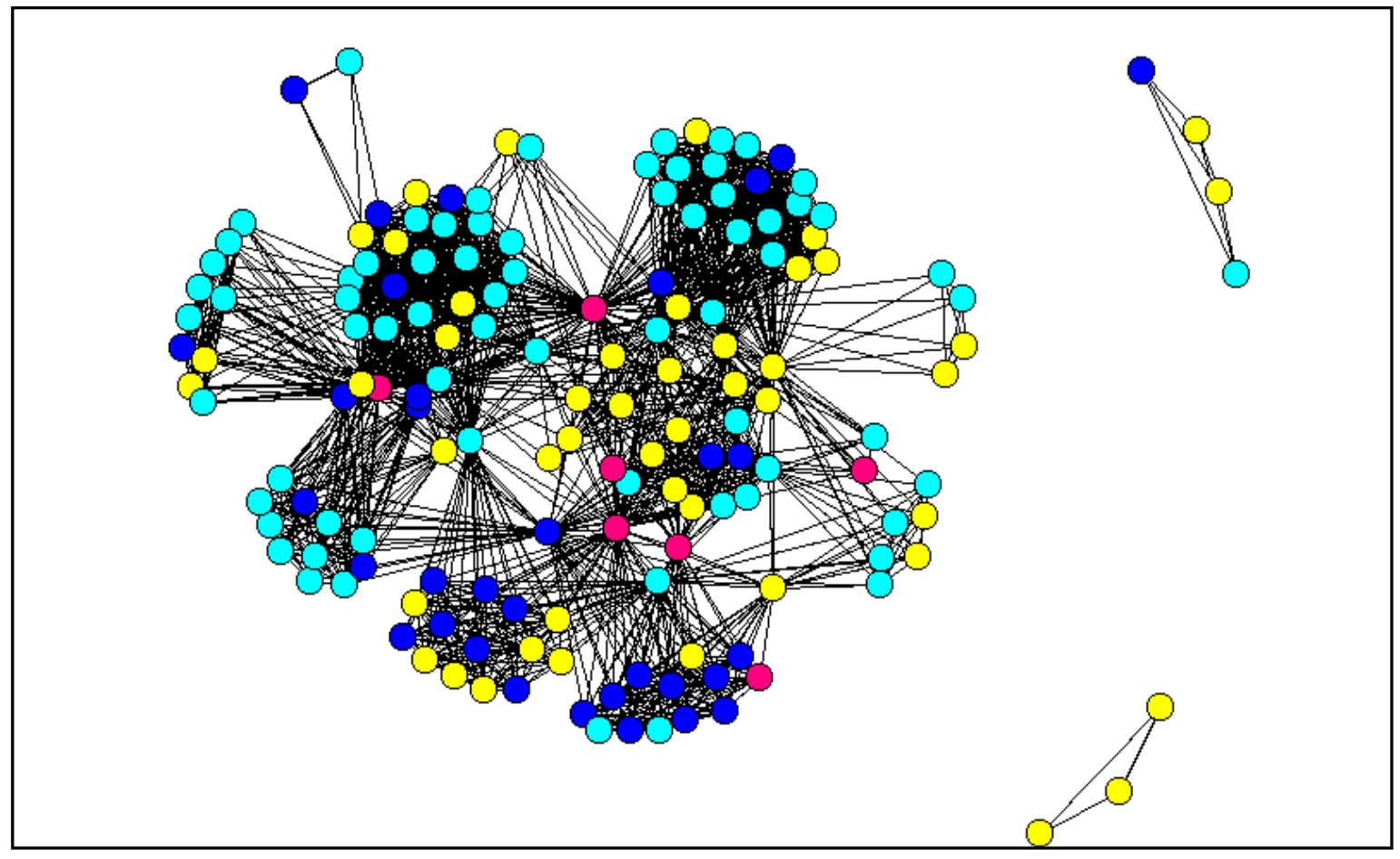

Referencias:

Productor textil (nodo amarillo) Productor de materias primas (nodo azul) Agente de compra y venta (nodo celeste) Actor con alta densidad en la red (nodos fucsia)

\subsection{3- Las prácticas cotidianas y la complementariedad ecológica}

Para el testeo de esta hipótesis 3,

Las prácticas cotidianas son expresivas de la persistencia del principio de complementariedad ecológica entre los microambientes andinos

Partiremos del análisis de conectividad o connectedness de una red, es decir, tomaremos un conjunto de nodos y de lazos que conectan pares de nodos, de los cuales 
se dice que son adyacentes. Un camino en la red es una secuencia de nodos adyacentes, en la que cada uno aparece una sola vez, junto con los lazos definidos por los pares de nodos adyacentes en la secuencia. Una red tiene conectividad $k$ si entre cada par de nodos hay por lo menos $k$ caminos independientes. El concepto de conectividad refleja aspectos importantes de la organización social en tanto da cuenta de estructuras parecidas a un árbol, donde la supresión de algunos nodos o lazos puede desconectar la estructura de la red. La conectividad proporciona una medida de la cohesión social.

En nuestro caso, los nodos que en la red total eran tomados como equivalentes a las personas, aquí los hemos reemplazado por nodos que representan a las localidades y a los espacios donde se concentran los recursos. En esta nueva representación de la red, las relaciones entre los nodos refieren a las rutas o caminos entre las localidades por donde circulan los productos y mercancías.

Los cálculos en UCINET6 se realizaron tomando como base de datos una matriz de adyacencia, (Tabla 10) sobre la que se construye una matriz de distancia o distancia generalizada entre todos los pares de nodos de un grafo. El recorrido o la extensión de un "camino" marca el número de líneas que este contiene. El cálculo mide el tamaño del camino más corto entre dos nodos (Borgatti, Everett y Freeman, 2002). De este modo, para cada par de nodos, el algoritmo encuentra las líneas-edges buscando el camino más corto entre ellos. Se observa en las celdas de la matriz un número que indica el valor de ese camino entre los nodos (Tabla 11). Finalmente, se obtiene el valor de cohesión basado en la distancia, que en nuestro caso, es de 0.313 -en un rango de 0 a 1 y sabiendo que el valor más alto indica mayor cohesividad.

Sobre la base de la primera matriz de adyacencia, se puede establecer el cálculo de alcance, utilizando el algoritmo alcance o reachability en UCINET6. De este modo, se construye una matriz de alcance o dirección que evalúa cada par de nodos y para cada uno, establece el valor de un camino óptimo. Entonces el algoritmo encuentra si existe un camino de cualquier tamaño que los conecte. 
El Estudio Etnográfico de la Actividad Textil como aporte a la Caracterización del Modo de Vida en el Pueblo de Molinos y zona de influencia (Provincia de Salta)

Tabla 10- Matriz Adyacente

\begin{tabular}{|l|l|l|l|l|l|l|l|l|l|l|l|l|}
\hline & Alu & Ama & Ca & ER & LP & Lur & Mol & Pat & Ref & Sal & Sec & Tac \\
\hline Alu & & & & & & 1 & & & & & & \\
\hline Ama & & & & & & & & & & & & 1 \\
\hline Ca & & & & & & & & & 1 & & & \\
\hline ER & 1 & & 1 & & 1 & 1 & 1 & & 1 & 1 & & \\
\hline LP & & & 1 & & & & & & & & & \\
\hline Lur & & & & 1 & 1 & & & & & & 1 & \\
\hline Mol & & & & & & & & & & & & \\
\hline Pat & & & & & & & & & & & & \\
\hline Ref & & & & 1 & & & & & & & & \\
\hline Sal & & & & & & 1 & & & & & & \\
\hline Sec & & & & & & & & & & & & \\
\hline Tac & & & & & & & & 1 & & & & \\
\hline Tom & & 1 & & & & 1 & 1 & & & & & \\
\hline
\end{tabular}

Tabla 11- Matriz de Distancia

\begin{tabular}{|l|c|c|c|c|c|c|c|c|c|c|c|c|c|}
\hline & Alu & Ama & Ca & ER & LP & Lur & Mol & Pat & Ref & Sal & Sec & Tac & Tom \\
\hline Alu & 0 & 4 & 3 & 2 & 2 & 1 & 3 & 6 & 3 & 3 & 2 & 5 & 3 \\
\hline Ama & & 0 & & & & & 2 & 2 & & & & $\mathbf{1}$ & \\
\hline Ca & 3 & 4 & 0 & 2 & 3 & 3 & 3 & 6 & 1 & 3 & 4 & 5 & 3 \\
\hline ER & 1 & & 1 & 0 & 1 & 1 & 1 & 4 & 1 & 1 & 2 & 3 & 1 \\
\hline LP & 4 & 5 & 1 & 3 & 0 & 4 & 4 & $\mathbf{7}$ & 2 & 4 & 5 & 6 & 4 \\
\hline Lur & 2 & 3 & 2 & 1 & 1 & 0 & 2 & 5 & 2 & 2 & 1 & 4 & 2 \\
\hline Mol & & & & & & & 0 & & & & & & \\
\hline Pat & & & & & & & & 0 & & & & & \\
\hline Ref & 2 & 3 & 2 & 1 & 2 & 2 & 2 & 5 & 0 & 2 & 3 & 4 & 2 \\
\hline Sal & 3 & 4 & 3 & 2 & 2 & 1 & 3 & $\mathbf{6}$ & 3 & 0 & 2 & 5 & $\mathbf{3}$ \\
\hline Sec & & & & & $\mathbf{4}$ & & & 0 & & & 0 & & \\
\hline Tac & & & & & & & & 1 & & & & 0 & \\
\hline Tom & 3 & 1 & 3 & $\mathbf{2}$ & 2 & 1 & 1 & 3 & 3 & 3 & 2 & 2 & 0 \\
\hline
\end{tabular}

Cantidad de "pasos" en el "camino" entre dos localidades, Tomuco (Tom) y Entre Ríos (ER).

De este modo resulta que los circuitos en la porción del Valle Calchaquí a la que corresponde el Departamento de Molinos se pueden diferenciar mediante el recorrido de las siguientes rutas: 
1- "la ruta del cerro", denominamos así a los trayectos seguidos a través de las huellas y caminos por donde los troperos o caravaneros transportan la materia prima y otros objetos para el intercambio y venta. Los dos recorridos más habituales tal como los reconoce la gente de Molinos son el camino al Luracatao y el camino a Tacuily a Compuel. Extensos trayectos bordeados por picos de casi 6.000 m.s.n.m, establecen conexión entre 12 localidades a través de cientos de kilómetros. Los puntos más importantes de estos recorridos son identificados en el análisis como aquellos sitios que removidos de la red, logran desconectarla (puntos en azul en la Figura II). Estos lugares coinciden con los espacios que concentran mayor cantidad de recursos naturales necesarios para la actividad.

Figura II- Visualización de la red de caminos o "la ruta del cerro" con puntos de corte (cutpoint).
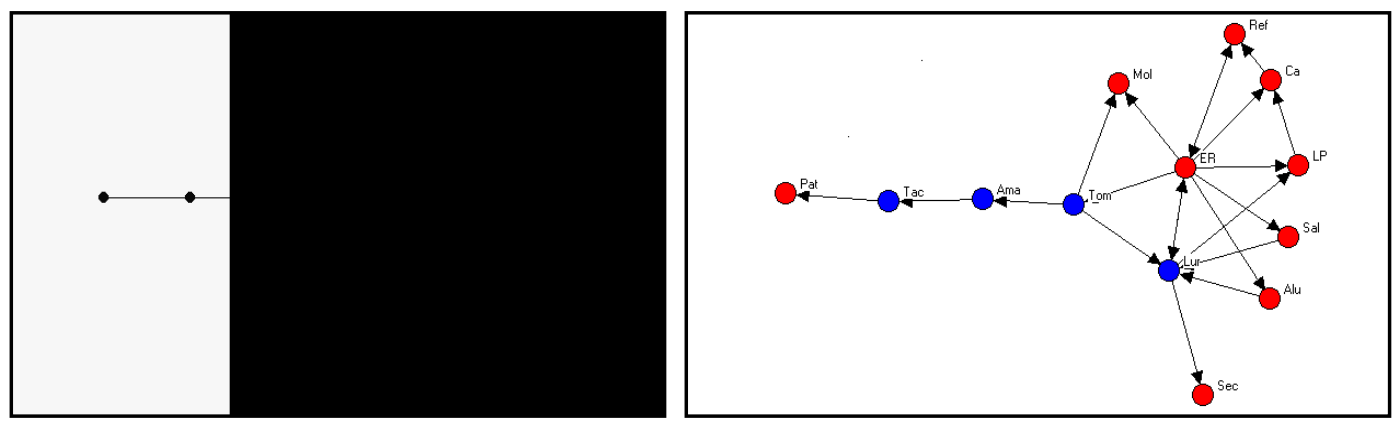

2- "ruta del valle" o la circulación de productos, recursos y trabajo entre el pueblo de Molinos y otros 13 parajes localizados a lo largo del valle. Coincide con la contratación de mano de obra para la confección de los textiles entre los expertos en la actividad textil.

3- "la ruta del mercado", señalada por los caminos de salida del valle y del cerro hacia 10 de las grandes ciudades de provincia donde se comercializan los productos de todas las localidades. Esta red integra a las demás rutas en un circuito regional cuyo recorrido llega a las demás provincias del área del noroeste argentino y con alcance transnacional a localidades de Chile y Bolivia. 
El Estudio Etnográfico de la Actividad Textil como aporte a la Caracterización del Modo de Vida en el Pueblo de Molinos y zona de influencia (Provincia de Salta)

Figura III- Visualización de la red total de localidades y rutas de circulación de materias primas, mano de obra y comercialización de textiles.

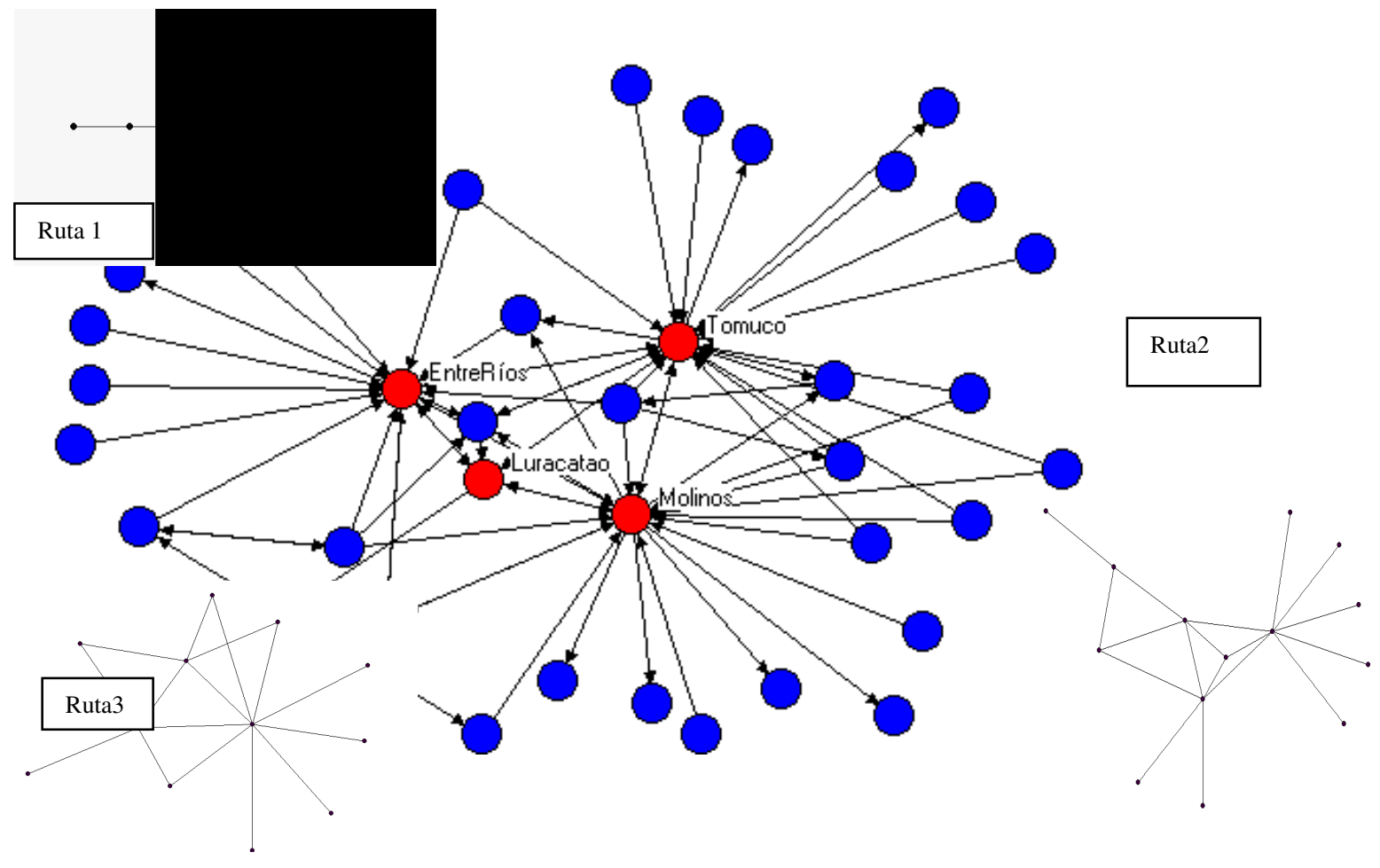

Referencias

Nodos Rojos: Localidades de los Informantes

Nodos Azules: Localidades referenciadas

Ruta 1: Trayecto específico de la ruta de montaña

Ruta 2: Trayecto específico del camino del valle

Ruta 3: Trayecto específico de la ruta comercial 


\section{6- La Actividad Textil desde los vínculos y patrones}

En base a los resultados obtenidos podemos arribar a algunas conclusiones, las que serán planteadas de acuerdo a su alcance en el marco de esta investigación.

Con respecto a la primera hipótesis, decimos que las interacciones a propósito del intercambio de un informante-experto en la esfera de subsistencia, muestran que las relaciones sociales observadas en el contexto de la actividades cotidianas y en el ámbito de la unidad doméstica, involucran relaciones de parentesco y de no parentesco, siendo estás últimas más numerosas y frecuentes. Aún cuando tradicionalmente estas comunidades han fundado los vínculos de subsistencia en el parentesco y situado el intercambio en la unidad doméstica, notamos en la ego_red de transacciones, la amplitud y diversidad de localizaciones que conectan a cada experto con otras unidades domésticas de personas que no son parientes.

En cuanto a las consecuencias teórico-metodológicas de esta misma hipótesis, vemos que las nociones de experto y de unidad doméstica deben ser redefinidas como unidades analíticas para el estudio etnográfico de las actividades de subsistencia. Estos resultados conducen inevitablemente a una discusión de la adecuación de las nociones básicas de la etnografía -cultura, grupo étnico- para dar cuenta de estas configuraciones. El alcance de las relaciones de valor económico entre los individuos en las comunidades en estudio trasciende los mundos autocontenidos y autónomos de los abordajes funcionalistas clásicos, y la noción de las redes sociales puede dar cuenta de ellas.

Desde la perspectiva de la eventual transferencia de los resultados sobre el análisis de las redes egocentradas y su incidencia a nivel de las comunidades andinas del NOA, creemos que la identificación del experto coincide con la visualización de personas con capacidad para la organización de emprendimientos de valor económico, creando y sosteniendo relaciones que a priori, no encuentran limitaciones étnicas, territoriales, sociales o institucionales. Las prácticas vinculadas a las actividades domésticas son la clave para la observación y descripción de las interacciones sociales individuales y grupales. A su vez, constituyen contextos privilegiados para el abordaje de los aspectos constitutivos, 
motivacionales y normativos de las relaciones, permitiendo la adecuada aplicación de la información etnográfica a la resolución de problemas vinculados al manejo de recursos, la producción y comercialización de los textiles y otros bienes.

Con respecto a la segunda hipótesis, concluimos que en el plano empírico, los atributos y los lazos de los actores están dados por las propiedades de la red en el caso de cada actividad considerada. Los vínculos -dirigidos u orientados- en el contexto de la red total destacan a los individuos más importantes en la actividad textil. De este modo, los actores más relevantes no son aquellos que las teorías sociológicas nos anticipan en relación a la conducta esperada por su carácter o pertenencia a los "típicos hombres campesinos de las etnias locales de tradición Koya o Diaguito-Calchaquí". En este sentido, la combinación de la etnografía y el ARS da la posibilidad de descubrir el alcance y modos de organización que resultan de las interacciones en diferentes contextos.

Por otra parte, los estudios antropológicos que se ocupan del tema de las actividades utilizan modelos centrados en la caracterización de la actividad como secuencia de etapas. Muchos de ellos no consideran que la dinámica de las acciones y la toma de decisiones personales puedan estar condicionadas por la posición de personas especializadas; las elecciones, en un espectro de alternativas, de otras personas intervinientes en la actividad; y por la combinación de personas y relaciones que son, en su mayoría, ocasionales.

Los resultados de nuestro análisis -a partir del referente empírico considerado- nos acerca a la trama de relaciones sociales en las comunidades andinas de Molinos, señalando a los individuos que operan desde las prácticas cotidianas en entornos de grupos étnicos y en sectores rurales, en un escenario complejo de asociaciones a través de la pertenencia a unidades institucionales - unidad doméstica, fincas, asociación de productores y artesanosintegradas a su modo de vida. En este sentido hemos dado cuenta de la variabilidad de las estrategias individuales que configuran ese modo de vida, en oposición a la visión de homogeneidad que subyace a los proyectos gubernamentales o no gubernamentales que diseñan y ejecutan planes con el voluntarioso objetivo de promover el "desarrollo sostenible" de estas comunidades. 
Por último y en referencia a los aportes derivados de la tercera hipótesis sostenida en esta investigación, decimos que es posible reconocer y destacar tres rutas principales de circulación de recursos que posibilitan una actualización permanente del flujo de relaciones sociales. Las actividades se desarrollan a escala local y regional, y la condición para la conexión de la red está dada por la vinculación e integración de nodos que remiten a los característicos ambientes de valle y puna.

De este modo, es claro que el enfoque teórico-metodológico basado en los datos relacionales emergentes de las actividades conduce a la necesidad de considerar a los fenómenos más allá de los contextos etnográficos iniciales anclados en la observación a micro-escala del ámbito doméstico. En este sentido, se introduce el carácter topológico propio del análisis de redes sociales en su proyección ontológica espacial.

Finalmente, la red de las actividades de subsistencia funciona sólo cuando las relaciones sociales alcanzan a todos los espacios ecológicos andinos. Es de notar asimismo que a través de estos espacios se articulan al menos tres modalidades de intercambio, que van desde las más tradicionales -documentadas por los estudios etnohistóricos y arqueológicos- como el trueque con las caravanas trashumantes de burros, el servicio en las fincas, hasta las formas contemporáneas de comercialización en los mercados nacionales e internacionales. Mediante la red de rutas que hemos presentado no cabe duda que los caminos de circulación de bienes o mercancías muestran una relación de complementariedad entre las zonas de altura o puna y las zonas de los fondos de valles, conectando un territorio de cientos de kilómetros cuadrados. Pero no sólo esto es evidente desde la visualización de las redes al superponerse sobre los mapas geológicos y geográfico-políticos, sino que el análisis de ARS indica los puntos centrales de conectividad en las rutas de intercambio, cuya remoción de la red de circulación implicaría la desarticulación de las relaciones entabladas entre los espacios ecológicos de abastecimiento de los recursos naturales, de producción de mercancías y de transacción. De este modo el ARS constituye un instrumento para el diagnóstico del grado de cohesión ecológico-social en el área. 


\section{CONCLUSIONES}

\section{La actividad textil como aporte a una etnografía de los valles calchaquíes}

En un primer acápite sintetizaremos los fundamentos de la perspectiva empírica, teóricometodológica y de transferencia desarrollada en la investigación de tesis.

1. El trabajo desarrollado en esta tesis es un primer paso en el abordaje sistemático de la actividad textil en la zona de Molinos. Al momento de iniciar la investigación contábamos con antecedentes de estudios previos basados en el análisis de los textiles por su valor arqueológico. Pero nuestra propuesta, si bien focaliza sobre la cultura material, se desarrolla desde la perspectiva de una etnografía de la actividad textil actual, en pequeñas comunidades del Departamento de Molinos, en Salta. La investigación obtuvo un perfil propio definido sobre la base de tres supuestos.

Primero, consideramos que los tejedores y los textiles en las regiones andinas históricamente han ocupado una posición especial, siendo sustento y expresión del poder político, reforzando los lazos económicos y facilitando la apertura de vías de intercambio a través de la circulación de bienes. En definitiva, los textiles pueden considerarse como indicadores para la consideración de la subsistencia y la economía andina.

Segundo, asumimos que los grupos locales rurales desarrollan sus estrategias de subsistencia en el contexto de espacios limitados a ambientes ecológicos específicos y a su explotación optimizada. Esto se pone en práctica a través de los ciclos de intercambio y comercio así como el mercadeo de materias primas, productos agrícolas y mano de obra. Tercero, en conjunción con los supuestos anteriores, se plantea la necesidad de estudios etnográficos que adoptan una perspectiva a micro escala y focalizan sobre el modo en que los recursos son utilizados en la esfera doméstica. La investigación de las actividades y rutinas cotidianas, que tienen lugar en estos enclaves, permite un acceso directo a las más complejas configuraciones de conocimientos y prácticas. De este modo, nuestro estudio se concentra en el microanálisis de las actividades de subsistencia realizadas en las unidades domésticas, en una región geográfica claramente definida. 
2. El trabajo más afanoso e intenso de esta tesis ha consistido en la exploración metodológica para tratar el problema planteado, caracterizar la actividad textil. La adecuación y potencial de las herramientas utilizadas permitieron alcanzar la meta propuesta a través de los objetivos. No obstante, reconocemos dificultades y limitaciones que se han presentado durante el desarrollo del trabajo y que hoy podemos evaluar a la luz del resultado de su aplicación.

La metodología de análisis de datos no numéricos o cualitativos y no estructurados (Nud*ist) funcionó como un organizador y modelizador de las actividades sobre la base del discurso y observación, además permitió la formalización de los datos que a futuro posibilitará lo que hoy podría considerarse una restricción de este trabajo. Me refiero a que un mayor sondeo sobre una muestra más amplia aportaría más categorías o diferentes, así como permitiría avanzar en el sentido de conectar nuevos dominios, más allá de los campos que hemos descripto: aquellos vinculados al ambiente y a la trayectoria vital de los tejedores. (Sy, 2008)

Respecto al uso de las herramientas para análisis de las relaciones sociales (ARS), su poder de análisis la convierte en una estrategia de la cual pueden obtenerse resultados no previstos en la investigación. Esta no es una cuestión menor en los trabajos antropológicos si tomamos en cuenta que algunos estudios en el área sociocultural se ven envueltos en mecanismos tautológicos y experiencias circulares.

No obstante, cabe un comentario sobre las críticas que el ARS genera respecto a la reducción de información etnográfica implicada en la delimitación de los datos relacionales. Desde nuestro punto de vista y como ya lo sostuvimos en el capítulo 4, el ARS se constituiría en una estrategia muy limitada si no contara con un estudio cualitativo de referencia. Esto es particularmente insoslayable en las investigaciones antropológicas en las cuales es imprescindible considerar la información etnográfica como instancia descriptiva previa a todo análisis. La condición generalista del ARS como técnica que se aplica en diferentes disciplinas bajo la condición de la delimitación y manejo de un tipo específico de datos cuantificables, no puede dejar de lado la condición contextualista inherente a los estudios antropológicos socioculturales. (Miceli, 2008) 
3. Esta investigación se propuso alcanzar y aportar algunas reflexiones acerca de dos objetivos pragmáticos. En este sentido, a través de esta tesis nos hemos propuesto, por un lado, aportar a la evaluación del proceso de producción textil tradicional en relación con la problemática de la economía regional y la identidad étnica. Y por otro, contribuir al desarrollo sostenible de la actividad textil por su valor potencial en el mercado.

En el capítulo 1 hemos revisado de modo minucioso informes socio-económicos que desde diversos organismos oficiales y privados se interesan por la situación de las comunidades de Valles Calchaquíes. En este sentido, podemos señalar que existen diferencias de enfoque que conducen a conclusiones que pueden ser complementadas, entre otros por el trabajo antropológico. Los estudios integrados requieren atención en factores tales como la creciente participación política de las comunidades indígenas; el sentido de pertenencia a la cultura andina, particularmente su lengua y territorios; el desafío de los estados nacionales multiétnicos; la capacidad de agencia y de cambio de los individuos de las comunidades en los mismos escenarios donde antes se los percibía como grupos homogéneos.

Desde nuestro enfoque no vemos a las comunidades rurales como entidades socioeconómicamente aisladas. Cada una de ellas tiene sus propias modalidades de vínculos con la sociedad nacional, con los movimientos transnacionales, migraciones y actualmente se platean nuevas demandas vinculadas al consumo. Muchos de sus miembros re-evaluan sus orígenes autóctonos comunes y utilizan activamente los medios de comunicación electrónica, lo cual, además de ser valorado como un modo de intercambio de información, ofrece la posibilidad de crear comunidades con extensiones en el ciberespacio. En el escenario nacional, los grupos locales rurales representados por sus líderes y organizaciones están requiriendo cada vez más de espacios políticos y posiciones de poder.

Actualmente, el interés en los estudios antropológicos concernientes a las estrategias ecológicas focaliza sobre la eficiencia adaptativa y la gran variedad de perspectivas individuales y colectivas para percibir, preservar y explorar medio-ambientes específicos.

Adicionalmente, las dinámicas de los procesos de transformación social en los contextos de los estados-nación y los procesos de producción globalizados conducen a considerar 
otros tópicos importantes. Esto incluye procesos a micro-escala involucrados en la realización de las actividades de subsistencia. Este insight en el conocimiento tradicional basado en las prácticas podría formar una parte integrada de todos los futuros esfuerzos que aspiran a la racionalidad y consecuentemente a promover el desarrollo sustentable en el contexto rural regional. En el ámbito científico, la profundización de nuestro conocimiento acerca de los grupos locales conduce a cuestiones complejas que requieren articulaciones a nivel de investigaciones macro analíticas.

A continuación presentaremos los aportes y discusiones respecto a los principales tópicos vinculados al tema de la actividad textil en Molinos.

La actividad textil (AT) puede modelizarse a partir del análisis de las historias personales de los expertos o especialistas locales -teleros, hilanderas y componedoras-. La actividad textil observada desde cada trayectoria mucho más que como un conjunto de conductas especializadas y desarrolladas por cada individuo, se presenta como un conjunto de conocimientos y acciones inseparables de múltiples relaciones entre los actores. Es entonces, que surge la necesidad de situar la AT en un contexto que le otorgue la misma relevancia a estos dos niveles del análisis.

La actividad textil y su descripción inicial en el ámbito doméstico permitió un acceso a las rutinas y prácticas cotidianas. Como resultado de este abordaje, se establece la simultaneidad y complejidad de las acciones que están implicadas conjuntamente en la actividad textil y otras actividades de subsistencia. Las referencias a la división de tareas y sub- especialidades, por género y edad en la actividad textil se ven redimensionada por la destacada y reiterada mención a algunos actores. Esto permite trabajar conjuntamente las descripciones sobre los atributos propios de los expertos con la exploración de las características de los individuos por su localización o posición relativa dentro de una red de relaciones grupales. A priori se podrían establecer jerarquías entre los expertos, sobre la base de una serie de categorías sociológicas no pertinentes a este contexto. La influencia y estructuración de la secuencia de la actividad textil puede visualizarse en su dinámica desde uno o varios niveles de "localización" de los actores. 
El manejo de la diversidad de recursos naturales, cuya influencia se percibe en el acceso a una variedad de calidades de materias primas y de tecnologías, ha sido observado a través de las alternativas que permiten decidir en cada momento que pasos seguir en la actividad textil. Pero esto no es azaroso, ni depende solamente de la elección correcta y racional de un solo actor, sino que puede ser estudiado como consecuencia de la influencia y la intervención del conjunto de actores que participan en la actividad textil.

En base a los datos empíricos analizados en esta investigación la actividad textil en Molinos puede caracterizarse como una secuencia lineal o cadena operativa de tareas que conduce a la concreción de un objetivo, la elaboración de la pieza de textil. En este sentido coincidimos con Lemonnier, Rolandi, Séiller Baldinger, Gisbert. Pero con la particularidad de que la actividad textil en Molinos no está conformada por una secuencia regular, repetitiva ni única de acciones tendientes a la elaboración de una pieza. En cambio, la actividad textil está atravesada por un número de alternativas u opciones que ofrecen la posibilidad de tomar decisiones en relación a las distintas instancias de su desarrollo. Así por ejemplo, en la ejecución de la actividad textil aparece el uso complementario de tecnologías tradicionales y tecnologías actuales para la elaboración de las piezas de tejido. En cuanto a los especialistas, estos son entrenados en el espacio de la unidad doméstica y su trabajo organizado de acuerdo al género, edad y familia de tejedores.

La organización de la actividad textil se halla en estrecha relación con la de otras actividades de subsistencia como la agricultura y la cría de ganado de altura. El desarrollo de tales actividades requiere de una organización flexible y adaptativa como resulta serlo la unidad doméstica en el área en estudio. Los lazos parentales, de amistad y de padrinazgo en y entre los miembros de las unidades domésticas son los constituyentes primarios en la organización de las actividades. Las diferencias de status o liderazgo que argumentan a favor de una jerarquización social, en y entre los miembros de las unidades domésticas, se justifican por referencia al emprendimiento exitoso de actividades de valor económico.

La vigencia y continuidad de la actividad textil es posible por referencia a su adecuación a un medio ambiente particular. Los productos de valor económico de esta actividad 
El Estudio Etnográfico de la Actividad Textil como aporte a la Caracterización del Modo de Vida en el Pueblo de Molinos y zona de influencia (Provincia de Salta)

Laura Teves

involucran recursos naturales de diferentes ambientes ecológicos locales y adquieren valor para la subsistencia cuando se integran en un circuito que incluye tanto instituciones tradicionales -modalidades de intercambio como el trueque, "al partir", y las caravanascomo las alternativas del mercado capitalista. De este modo, las estrategias de subsistencia de los pobladores del Valle configuran redes sociales que articulan diferentes modos y niveles de interacción a nivel local, regional y global. 


\section{REFERENCIAS BIBLIOGRÁFICAS}

Administración de Parques Nacionales (APN). 2007. "Proyecto: Componente de Desarrollo de Capacidades Nacionales para el Fortalecimiento del Sistema Nacional de Áreas Protegidas". Informe de Consultoría. Evaluación Social. Programa Pobladores y Comunidades. Dirección de Conservación y Manejo. Dirección Nacional de Conservación de Áreas Protegidas. Octubre de 2007. pp. 1- 121.

Ambrosetti, J. B. 1896. "Costumbres y supersticiones en los valles calchaquíes (Provincia de Salta). Contribución al estudio del Folklore calchaquí". En: Anales de la Sociedad Científica Argentina, tomo XLI, pp 41-85. Buenos Aires.

Ambrosetti, J.B. 1902. "Antigüedades calchaquíes. Datos arqueológicos sobre la provincia de Jujuy (República Argentina)". Anales de la Sociedad Científica Argentina.

Ambrosetti, J.B. 1904. "Apuntes sobre la arqueología de la Puna de Atacama". Revista del Museo de La Plata XIII: 1-30. La Plata, Argentina.

Ambrosetti, J.B. 1907. "Exploraciones arqueológicas en la ciudad prehistórica de La Paya (valle Calchaquí, provincia de Salta)". Publicaciones de la Facultad de Filosofía y Letras 3, Buenos Aires.

Andermann, J y A. Fernández Bravo. 2003. "Objetos entre tiempos: Coleccionismo, soberanía y saberes del margen en el Museo de La Plata y el Museo Etnográfico." Márgenes-Margens vol 4 pp 28-37. Belo Horizonte, Buenos Aires, Mar del Plata, Salvador.

Andrada, L. 2002. "Escenarios Provinciales en la Coyuntura: Panorama de las principales actividades económicas. Provincia de Salta." Consejo Federal de Inversiones (CFI), Argentina.

Anello, A. 2002. "Familia indígena y sociedad en el curato de Londres (Catamarca) terminando el siglo XVII". En: Los pueblos de Indios del Tucumán colonial: pervivencia y desestructuración. Farberman, Judith y Raquel Gil Montero (comp). 2002. EdiUnju. Universidad Nacional de Quilmes Ediciones.

Apffel Marglin, F. 2003. El Espíritu de las Aguas: Su Olvido y Su Recuerdo. Edición: Antonio Rengifo Balarezo. Lima, Perú. 
Arenas, P. 1991. Antropología en la Argentina. El aporte de los científicos de habla alemana. Instituto Cultural Argentino-Germana. Museo Etnográfico "J.B. Ambrossetti", Facultad de Filosofía y letras de la UBA. Buenos Aires, Argentina.

Atlas Argentino. 2004. PAN. Programa de acción nacional de lucha contra la desertificación. Dirección de Conservación de Suelos. Secretaría de Ambiente y Desarrollo Sustentable de la Nación (SAyDS), INTA, GTZ. Cooperación Técnica Argentino - Alemana. Buenos Aires.

Atlas Sociolingüístico de Pueblos Indígenas de América Latina. 2009. Tomo 2. Fondo de las Naciones Unidas para la Infancia, UNICEF y Agencia Española para la Cooperación Internacional al Desarrollo, AECI. UNICEF-FUNPROEIB Andes. Cochabamba, Bolivia.

Atlas Total de la República Argentina. 2008. Salta, Tomo 22. Editorial Argentino. Argentina.

Baldini, L. y V. Villamayor. 2007. "Espacios productivos en la Cuenca del Río Molinos (Valle Calchaquí, Salta)". Cuadernos de la Facultad de Humanidades y Ciencias Sociales, Julio Nro. 32. Univ. Nac. de Jujuy, S.S. de Jujuy, Argentina. Pp. 35-51.

Barth, $\mathrm{F}$ (comp.). 1976. Los grupos étnicos y sus fronteras. Fondo de Cultura Económica. México.

Benedetti, A. 2005. "Incorporación de nuevas tierras durante el periodo de conformación del agro moderno en la argentina: El territorio de Los Andes, primeras décadas del siglo XX .Mundo Agrario." Revista de Estudios Rurales. Año/Vol. 6, número 011 Universidad Nacional de La Plata. La Plata, Argentina.

Russell Bernard, H; Pertti J. Pelto; Oswald Werner; James Boster; A. Kimball Romney; Allen Johnson; Carol R. Ember and Alice Kasakoff. 1986. "The Construction of Primary Data in Cultural Anthropology". En: Current Anthropology, vol. 27, No 4, August-October 1986, pp. 382-396.

Bernard, H. R. 1996. "Qualitative data, quantitative analysis". Cultural Anthropology Methods Journa/Vol.8(1)Pp 9-11.

Bernard, H. R. 2006. Research methods in anthropology. Qualitative and quantitative approaches. Altamira Press. United States of America 
Bird, J. 1951. "Recent Developments in the Treatment of Archaelogical Textil. Anthropological Papers". Museum of Anthropology, University of Michigan Nro.8 Essays on Archaeology Methods.

Blau, P. 1977. "Teoría macrosociológica de la estructura social." En: Análisis de redes sociales Origenes, teorías y aplicaciones. Requena Santos (comp). Centro de Investigaciones Sociológicas. "Monografías" N¹98. Siglo XXI de España, España.

Boas, F. 1909. "The Kuwakiutl of Vancour Island". Memoirs of the American Museum of Natural History New York. Vol V. Part II. Jusep North Pacific Expedition. E.J. Brill Printers abd Publishers, Leiden, Holland, G. E. Stechert, New York, USA. pp. $307-515$

Boas, F. 1920. "Los métodos de la etnología". En: Bohannan, Paul. 1973. Antropología Lecturas. Madrid, McGrawn-Hill. Pp. 93-100.

Bohannan, P. y M. Glazer.1993. Antropología Lecturas. McGraw-Hill. España.

Boixadós, R. 2002. "Los pueblos de la Rioja colonial. Tierra, trabajo y tributo en el siglo XVII." En: Los pueblos de Indios del Tucumán colonial: pervivencia y desestructuración. Farberman, Judith y Raquel Gil Montero (compiladoras). 2002. EdiUnju. Universidad Nacional de Quilmes Ediciones.

Boman, E. 1908. Antiquites de la Région Andine de la République Argentine et du Désert D'Atacama. 2 vol. París.

Borgatti, S. A. Mehra; D. Brass, G. Labianca. 2009. "Network Analysis in the Social Science." Science 323, 892.

Borgatti, S. P. 1994. "Cultural domain analysis". Journal of Quantitative Anthropology, Vol 4 pp. 261-278.

Borgatti, S.P., M.G. Everett, and L.C. Freeman. 2002. UCINET 6 for Windows: Software for Social Network Analysis. Harvard: Analytic Technologies.

Borgatti, S. P. and Pacey C. Foster. 2003. "The Network Paradigm in Organizational Research: A Review and Typology." Journal of Management 2003 29(6) 991-1013. 
El Estudio Etnográfico de la Actividad Textil como aporte a la Caracterización del Modo de Vida en el Pueblo de Molinos y zona de influencia (Provincia de Salta)

Borgatti, S. y Foster,P. 2003. "The Network paradigm in organizational research: A review and typology". Journal of management. 29 (6) Pp 991-1013

Bunge, M. 1981. La investigación científica. Su estrategia y su filosofía. Editorial Ariel. 8.a Edición. Barcelona, España.

Cabrera, A. 1971. Fitogeografía de la República Argentina. Boletín de la Sociedad Argentina de Botánica, Vol XIV, Nro.12, Buenos Aires, Argentina.

Cáceres, D. M. 2007. Catálogo de tecnologías para pequeños productores agropecuarios 2. En: Proyecto de Desarrollo de Pequeños Productores Agropecuarios- PROINDER. Serie Estudios e Investigaciones No 13. Daniel M. Cáceres; Gustavo Soto; Mario Barrientos; ilustrado por Diana Abal Solís; Laura Ribulgo; Beatriz Comba. - $1^{\text {a }}$ ed. Buenos Aires: Secretaría Agricultura, Ganadería, Pesca y Alimentación, 2007. CD $<$ http://www.proinder.gov.ar/Productos/Hipermedia/contenidos/ta2/Archivos/institucional/ catalogo.htm>

Caggiano, M y M. C. Sempé. 1994. América. Prehistoria y Geopolítica. Tea Tipográfica Editora Argentina. Buenos Aires.

Camisa, N. A. 1990. "Experiencias y producción de aceites escenciales en la región del noroste del país." Sugerencias. V Congreso Internacional de Recursos Naturales Aromáticos y Medicinales. Salta, Argentina. Anales de SAyPA, № 11 pp 145-150.

Cannon, J. and M. Cannon. 1994. Dye Plants and dyeing. Timber Press and Royal Botanic Gardens, Kew. Portland, Oregon. USA. Ex Libris LEBA

Cardarelli, S. 2006. El sector Artesanías en las Provincias del Noroeste de Argentina. Catamarca, Jujuy, Salta y Tucumán. FLACSO, PRODERNOA, FIDA. Ciudad Autónoma de Buenos Aires, Argentina.

Cardich, A. 1981. "Puscanturpa. Un posible recuerdo mítico sobre las fluctuaciones de los límites superiores del cultivo en los Andes Centrales". Scientia et praxis. Revista de la Universidad de Lima. Nro. 15, Lima Perú.

Cardich, A. 1988. Civilización Andina: Su formación. Consejo Nacional de Ciencia y Tecnología. Lima, Perú. 
Cardich, A. 2000. "Dos divinidades del Antiguo Panteón Centro-Andino: Yana Raman o Libiac Cancharco y Rayguana." Revista Investigaciones Sociales Año IV, Nro 5 Instituto de Investigaciones Sociales, Facultad de Ciencias Sociales. Universidad Nacional de San Marcos. Lima, Perú.

Caro Figueroa, G. 2008. "La Patria de Güemes. Escenario de las luchas por la Emancipación". En: Atlas Total de la República Argentina. Salta, Tomo 22. Editorial Argentino. Argentina

Carr, C. and J. E. Neitzel (Editors). 1995. Style, Society, and Person. Archaeological and Ethnological Perspectives. Plenum Press. new York and London. Interdisciplinary Contributions to Archaeology.

Censabella, M. 2000. Las lenguas indígenas de la Argentina. Una mirada actual. Eudeba. Buenos Aires, Argentina.

Centro de Investigaciones y Estudios Económicos de Salta (CEE). 1999. Diagnóstico socioeconómico: Provincia de Salta. Año 1997-1998. Fundación Salta. Salta, Argentina.

Chertudi, S. y R. Nardi. 1960. "El tejido en Santiago del Estero". Cuadernos del Instituto Nacional de Investigaciones Folklóricas, Buenos Aires: 1960 Nro.1, pp. 53-82.

Cigliano, E. M. 1973. "Las ruinas arqueológicas". En: Tastil una ciudad Preincaica Argentina. Ediciones Cabargon. Buenos Aires.

Colby, B., J. Fernández. y D. Kronenlfed. 1981. "Hacia la convergencia de la antropología cognitiva y simbólica". American Ethnologist, vol. 8, N03, August. Traducción propia.

Comunidades Unidas de Molinos (CUM) <http://lacum.blogspot.com/>

Conklin, W. y B. Mallon Conklin. 1997. "Un Textil Aguada en Contexto Atacameño". Cuadernos 17, INAPL. Traducción propia

Convenio Nro. 169. (1991) 2007. Sobre Pueblos Indígenas y Tribales en Países Independientes. Organización Internacional del Trabajo, OIT. 
Cook, K. 1990. "La vinculación de actores y estructuras desde la perspectiva de las redes de intercambio". En: Requena Santos, Félix (Comp.). 2003. Análisis de redes sociales. Orígenes, teorías y aplicaciones. Colección Monográfica Nro. 198. CIS. Centro de Investigaciones Sociológicas. Madrid, España.

Corcuera, R. 1987. Herencia Textil Andina. Ed. Ducilo, Buenos Aires.

Corcuera, R. 1989. "El tejido andino y sus reservorios culturales". Revista Ciencia e Investigación. Tomo 43.Nro 2.

Cresswell, R. 1976. Avant-propos. Techniques et culture. 1;5-6.

Cresswell, R. y M. Godelier. 1981. Útiles de encuesta y de análisis antropológico. Editorial Fundamentos. España.

Crivos, M. 1978. "Algunos aspectos de la medicina popular en Molinos (provincia de Salta)". En: Revista Sapiens del Museo Arqueológico Doctor Osvaldo F. A. Menghin, Casa de la Cultura, Municipalidad de Chivilcoy, Chivilcoy, № 2, pgs. 15 a 27.

Crivos, M. 1981. "Dos estudios antropológicos sobre medicina tradicional de los Valles Calchaquíes, Argentina" (co-autora). En: Revista Folklore Americano, Instituto Pamericano de Geografía e Historia, OEA, No 31, 1981.

Crivos, M. 1995. "Metodología etnográfica y Juegos de lenguaje". Revista del Museo de La Plata (NS), Tomo IX, Antropología No 75, 1995, pgs. 239 a 263. La Plata. Argentina.

Crivos, M. 1996. "Las estrategias frente a la enfermedad en Molinos (Salta, Argentina). Una propuesta para el relevamiento de información empírica en el dominio de la etnobiología" (co-autora). En: Contribuciones a la Antropología Física Latinoamericana (Memoria del IV Simposio de Antropología Física "Luis Montané"). Instituto de Investigaciones Antropológicas - UNAM/ Museo Antropológico Montané, Universidad de La Habana, pg. 99 a 104.

Crivos, M. 1997. La aproximación etnográfica al estudio de la medicina tradicional. Una experiencia en los Valles Calchaquíes Salteños (Argentina) (co-autora). Ponencia al 49 Congreso Internacional de Americanistas, Quito, Ecuador, julio 1997. (A publicarse en Actas) 
Crivos, M. 2003. Contribución al estudio antropológico de la medicina tradicional de los Valles Calchaquíes (Provincia de Salta). Tesis de doctorado publicada. Facultad de Ciencias Naturales y Museo. Universidad Nacional de La Plata. <http://sedici.unlp.edu.ar?id=argunlp-tpg-0000000083>

Crivos, M. y M. R. Martínez. 1989. "El enfoque antropológico: Consolidación o ruptura de la dicotomía rural-urbano." Ponencia presentada en II Congreso Argentino y Latinoamericano de Antropología Rural. Salta, Agosto de 1989.

Crivos, M. y M. R. Martínez. 1996 Obituario Dr. Prof. Armando Vivante. Inédito

Crivos, M. y M. R. Martínez. 1996. "Acerca de la percepción de algunos fenómenos meteorológicos y naturales entre los pobladores de Molinos (Salta, Argentina)." En: Goloubinoff, M., E. Katz, A. Lammel (Eds.). Hombre y Clima en el mundo hispanoamericano. Abya-Yala, Ecuador.

Crivos; M. y M. R. Martínez. 1996. Estudio etnográfico de los Mbya-guaraní. Relación hombre- medio. Aristóbulo del Valle, Provincia de Misiones. Informe presentado a la Facultad de Ciencias Naturales y Museo de la Universidad Nacional de La Plata. Argentina.

Crivos, M. y M.R. Martínez. 2000. Anthropological Characterization of Lifestyles: Theoretical- Empirical Implications of the Strategies of Ethnographic Research. En: Theoretical Anthropology Electronic Journal.

D'Andrade, R. 1995. The Development of Cognitive Anthropology. Cambridge University Press.

Dávalos, Jhonny, Verónica Cereceda y Gabriel Martínez. 1992. Textiles Tarabuco. Proyecto Norte Chuquisaca. CORDECH, ASUR, Fondo Internacional de Desarrollo Agrícola, Cooperación Andina de Fomento, IICA Biblioteca Venezuela. La Madona, Sucre, Bolivia.

De Hoyos, M. 1999. Los Indios de Calchaqui y los recursos vegetales. En Etnohistoria. Publicación digital NAyA Noticias de Antropología y Arqueología. <http://www.etnohistoria.com.ar/>

De la Rosa Troyano, F. F.; R. Martínez Gasca; L. González Abril; F. Velasco Morente. 2005. Análisis de Redes Sociales mediante Diagramas Estratégicos y Diagramas Estructurales, Revista Hispana para el Análisis de Redes sociales, vol 8 \#1, Julio. <http://revistaredes.rediris.es> 
Desrosiers, S. 1992. Las técnicas de tejido ¿tienen un sentido? Un apropuesta de lectura de los tejidos andinos. Revista Andina Vol 19 (1):7-46. Cuzco.

Diagnóstico socioeconómico: Provincia de Salta. Año 1997-1998". Centro de Investigaciones y Estudios Económicos de Salta de la Fundación Salta. Fundación Salta. Salta, marzo de 1999.

Druc, I.C.1996. "De la Etnografía hacia la Arqueología: Aportes de entrevistas con ceramistas de Ancash (Perú) para la caracterización de la cerámica prehispánica". En Bull. Inst. Fr. Études andines 25(1): 17-41. Lima, Perú.

Elechosa, M. A y Juárez M. A. 2002 Las plantas aromáticas y sus aceites escenciales.pp 60-68 IDIA XXI Centro de Recursos Naturales IRB, ICyA. INTA Castelar, Buenos Aires.

Emery, I. (1966) 1980. The Primary Structure of Fabrics. The Textil Museum, Washington, D.C.

Emery, I. and P. Fishke. (eds). 1976. Ethnographic Textiles of the Western Hemisphere. Irene Emery Roundtable on Museum Textiles 1976 Proceedings the Textile Museum, Washington, D.C.

Esteva, G. 2000. Desarrollo. En: Viola, A. Antropología del Desarrollo. Teorías y estudios etnográficos en América Latina. Barcelona, Paidós.

Evans Pritchard, E. 1977. Los Nuer. Ed. Anagrama, Barcelona.

Failde de Calvo, V.; Ramilo, D. y Red Valles de Altura. 2004. El agua como disparador del desarrollo sustentable en los Valles áridos de Salta, Noroeste de Argentina. IV Jornadas Iberoamericanas sobre Enfoques integrados de la problemática del Agua, Cartagena de Indias, 26 al 30 de julio Colombia. Publicado en El agua en Iberoamerica CYTED. Argentina: volumen 10, pp. 119-126.

Farberman, J. 2002. "Feudarios y tributarios a fines del sigo XVII. Tierra, tributo y servicio personal en la Visita de Luján de Vargas a Santiago del Estero (1693)". En: Los pueblos de Indios del Tucumán colonial: pervivencia y desestructuración. Farberman, Judith y Raquel Gil Montero (compiladoras). 2002. EdiUnju. Universidad Nacional de Quilmes Ediciones. 
Fisher, Eva. 2003. "Prácticas manuales y elementos estructurales de los textiles andinos. De la estructura a la técnica: La confección textil visto como un proceso cognitivo." Ponencia al 51 Congreso Internacional de Americanistas. Santiago de Chile.

Fischer, E. 2008. Urdiendo el tejido social. Sociedad y producción textil en los Andes Bolivianos. Ethnologie. Band 24.Lit Verlag.

Flores Ochoa, J. (comp.). 1975. "Pastores de Alpaca". Allpanchis Vol. VIII. Revista del Instituto de Pastoral Andina. Cuzco, Perú.

Flores Ochoa, J. A. (comp.). 1977. Pastores de la Puna. Uywamichiq punarunakuna. Instituto de Estudios Peruanos. Lima, Perú.

Foster, G. 1965. "Peasant society and image of limited good". En American Anthropologist. Vol 67. Pp.93- 315.

Freeman, L. 2004. The development of Social Network Analysis. A study in the Sociology of Science. Empirical Press. Vancouver, B. C. Canadá.

Fung, R. 2002. "Clasificación y terminología en español de tejidos precolombinos". Actas de la II Jornadas Internacionales sobre textiles precolombinos. Institut Català de Cooperació Iberoamericana. Universitat Autònoma de Barcelona. España.

Gahan H. and M. Hannibal. 1999. Doing Qualitative Reserch Using QSR NUD. IST. Sage Publications. UK.

Gálvez, L. 1999. Molinos e Indalecio Gómez. Del valle Calchaquí a la Saénz Peña. Editado por el Centro de Estudios Históricos Dr. Indalecio Gómez, Salta, Argentina.

Garavaglia, J. C. 2002. "El poncho: una historia multiétnica". Capítulo VIII. pp. 185-200 en Boccara, Guillaume. Colonización, resistencia y mestizaje en las Américas (siglos XVI-XX). Abya Yala.

García Canclini, N. 1984. "Artesanía y Marginalidad: Cuestión Rural o Cuestión Urbana?" Trabajo presentado al Simposio de Antropología Urbana organizado por la Facultad Latinoamericana de Ciencias Sociales (FLACSO), Buenos Aires. 
García Canclini, N. 1992. Culturas Híbridas. Estrategias para entrar y salir de la modernidad. Editorial Sudaméricana. Historia y Cultura.

García, S. 1998. "Señalada en Antofagasta de la Sierra". Coordenadas. Revista de Educación, Buenos Aires.

García, S. y D. Rolandi. 1999. "Viajes comerciales, intercambio y relaciones sociales en la población de Antofagasta de la Sierra, Puna meridional argentina". Carlos E. Berbeglia (coordinador) Propuestas para una Antropología Argentina, V: 201-217. Buenos Aires, Biblos.

García S. y D. Rolandi. 2000. "La Preservación del recurso silvestre en relatos contemporáneos de la Puna argentina". Actas del XI Conferencia Internacional de Historia Oral. Volumen 1. pp 267-270. Estambul, Turquía.

García, S. y D. Rolandi. 2000. "Relatos y ritual referidos a la Pachamama en Antofagasta de la Sierra, Puna meridional argentina". Relaciones de la Sociedad de Antropología. Tomo XXV (2000): 7-25; Buenos Aires.

García, S., D. Rolandi, M. López y P. Valeri. 2002. "Viajes comerciales de intercambio en el departamento de Antofagasta de la Sierra, Puna meridional argentina: pasado y presente." Redes Revista hispana para el análisis de redes sociales. Vol.2,\#5, mayo 2002. <http://revista-redes.rediris.es>

Garreta, M. J. y Sola, M. E. 1992. "Fincas rurales en el Norte del Valle Calchaquí: Procesos de Conformación cambios y relaciones sociales". Cuadernos del INA 14 1992-93, pp 41-58.

Gil Mendieta, J. y S. Smith. Editores. 2002. Análisis de Redes. Aplicaciones en Ciencias Sociales. Instituto de Investigaciones en Matemáticas Aplicadas y Sistemas. Universidad Nacional Autónoma de México, México.

Gisbert, T.; Arze, S.; Cajías, M. 1987. Arte Textil y Mercado Andino. Ed. Gisbert y Cía. Bolivia.

Göbel, B. 1988. "Risk, Uncertainty, and Economic Exchange in a Pastoral Community of the Andean Highlands (Huancar, N.O. Argentina)". En: Kinship, Networks, and Exchange. Editado por Thomas Schweizer y Douglas R. White. Cambridge University Press. UK. 
Göbel, B. 1998. "Salir de viaje". Producción Pastoril e intercambio económico en el noroeste argentino. Separata Estudios Americanista de Bonn. Verlag. Anton Saurwein.

Göbel, B. 2001. "El ciclo anual de la producción pastoril en Huancar (Jujuy, Argentina)" en Mengoni Goñalons, G., D. Olivera y H. Yacobaccio (editores). El uso de los camélidos a través del tiempo. Ediciones del Tridente. Bs. As. Argentina.

González Navarro, C. 2002. "Los pueblos indígenas de la sierra y los pueblos indígenas de la Ilanura Córdoba (1573-1650)". En: Los pueblos de Indios del Tucumán colonial: pervivencia y desestructuración. Farberman, Judith y Raquel Gil Montero (comp). 2002. EdiUnju. Universidad Nacional de Quilmes Ediciones.

Graebner, F. 1940. Metodología Etnológica. Colección Teoría. Universidad Nacional de La Plata, República Argentina.

Granovetter, M. 1982. "La fuerza de los lazos débiles. Revisión de la Teoría Reticular". En Félix Requena Santos. 2003. Análisis de redes sociales. Orígenes, teorías y aplicaciones. Centro de Investigaciones Sociológicas. Madrid.

Guzmán, F. y otros. 1998. Registro de voces kechuwas vigentes en el discurso coloquial norteño. Unidad de Investigación en Lingüística y literatura (UILL) Universidad Nacional de Jujuy, Argentina.

Hage, P. and F. Harary. 1991. Exchange in Oceania. A Graph Theoretic Analysis. Clarendon Press Oxford. New York, United State.

Hammersley, M.y P. Atkinson. 1994. Etnografía. Métodos de investigación. Paidós básica. Barcelona. España.

Hanneman, R. A. 2000. Introducción a los métodos del análisis de redes sociales. Departamento de Sociología de la Universidad de California Riverside. En: < $\underline{\text { http://revistaredes.rediris.es/webredes/textos/Introduc.pdf> }}$

Harary, F. 1969. Graph Theory. Reading Mass: Adison Wesley.

Heider, F. 1946. "Actitudes y organización cognitiva". En Félix Requena Santos (comp) (2003) Análisis de Redes Sociales, CIS- Siglo XXI. 
Hoces de la Guardia Ch., S y A. M. Rojas Z. 2003. Textiles atacameños: Investigación, registro y diagnóstico de las artesanías textiles del Loa y el Salar de Atacama. Fundación Minera Escandida. Chile.

Howard, A. 1963. "Land, activity systems and decision-making models in Rotuma". Ethnology II (4).

Imbelloni, J. 1953. Epítome de culturología. Editorial Nova, Buenos Aires.

Ingold, T. 1991. Evolución y vida social. Grijalbo. México.

Institute for Human and Machine Cognition (IHMC). - Concept Map Sofware. Concept Map Tools. University of West Florida. Versión 2.9.1. <http://cmap.coginst.uwf.edu/>

Instituto Geográfico Militar (IGM). Carta Topográfica Hoja 2566-III- IGM-Argentina. Argentina.

Instituto Nacional de Estadísticas y Censos (INDEC). 1988. Censo Nacional Agropecuario $(C N A)$. $<$ http://www.indec.gov.ar/agropecuario/ $>$

Instituto Nacional de Estadísticas y Censos (INDEC). 1993. Censo Nacional Agropecuario (CNA). <http://www.indec.gov.ar/agropecuario/>

Instituto Nacional de Estadísticas y Censos (INDEC). 1997. Los Municipios de la Provincia de Salta. Estadísticas Básicas. Buenos Aires. República Argentina.

Instituto Nacional de Estadísticas y Censos (INDEC). 1999. Censo Nacional Agropecuario (CNA). <http://www.indec.gov.ar/agropecuario/>

Instituto Nacional de Estadísticas y Censo (INDEC). 2001. Censo Nacional de Población, Hogares y Viviendas 2001. Provincia de Salta. Buenos Aires. Argentina. www.indec.gov.ar

Instituto Nacional de Estadísticas y Censo (INDEC). 2005. Encuesta Complementaria de Pueblos Indígenas (ECPI), 2004-2005. (Complementaria del Censo 2001). Primeros resultados provisionales, Provincia de Salta. Pp. 1-5. Buenos Aires. Argentina. $<$ www.indec.gov.ar $>$ 
Instituto Nacional de Tecnología Agropecuaria (INTA). Programa Pro-Huerta $<$ http://www.inta.gov.ar/extension/prohuerta/> y Programa de la Pequeña Agricultura Familiar <http://www.inta.gov.ar/cipaf/>

Korn, F. y M. de Asúa. 2004. Investigación Social. Errores eruditos y otras consideraciones. Instituto de Investigaciones sociales. Academia Nacional de Ciencias Sociales de Buenos Aires. Argentina.

Kroeber, A. L. 1952. "El concepto de cultura en ciencia". En: Bohannan, Paul. 1973. Antropología Lecturas. Madrid, McGrawn-Hill. Pp. 104-122.

Laumonier, I., M.M.Rocca y E. M. Smolensky. 1983. Presencia de la tradición andina en Buenos Aires. Editorial de Belgrano. Buenos Aires, Argentina.

Lave J. and E. Wenger. 1991. Situated Learning. Legitimate peripheral participation, Cambridge: University of Cambridge Press.

Lave, J. 1995. Cognition in Practice. Cambridge University Press.

Lazega, E. 1997. "Network Analysis and Qualitative Research: a Method of Contextualización". Pp. 119-137. In: Context and Method in Qualitative Research. Edited by Gale Miller and Robert Dingwall. Sage Publications, London.

Leff, E. 1994. Ecología y capital. Racionalidad ambiental, democracia participativa y desarrollo sustentable. Siglo XXI Editores. México, 1994.

Lehmann Nitsche, R. 1902. "Catálogo de las antigüedades de la provincia de Jujuy". Revista del Museo de La Plata. Tomo XI. Pp 75-120.

Lehmann Nitsche, R. 2007. Legados Individuales. En: <http://www.iai.spk-berlin.de/> Ibero-Amerikanisches Institut Preussischer Kulturbesitz.

Lemonnier, P. 1992. Elements for an Anthropology of Technology. Anthropological Papers Museum of Anthropology University of Michigan No. 88. Ann Arbor, Michigan.

Lévi-Strauss, C. 1961. Estructuras elementales del parentesco. Obras del pensamiento Maestro. Nro. 16 y 17. Planeta Agostini. Vol I y II. Barcelona. 
LEY No 7304 Promulgada por Decreto No 1668 del 21/07/04. Sancionada el 01/07/04. Convenio Pcia. de Salta y firma Campo Rosario S.C.A. Regularización de ocupación de tierras - venta, cesión, transferencia de inmueble. Fincas Luracatao y Entre Ríos, Dpto. Molinos. B.O. No 16.945. Expte. No 91-13.575/04 y Proyecto de Declaración S-1742/04, República Argentina.

Linton, R. (1936) 1964. "Status y rol". En: Bohannan, Paul. 1973. Antropología Lecturas. Madrid, McGrawn-Hill. Pp. 91-204.

López J., W. Flores y C. Letourneux. 1993. LAYMI Salta Programa de Autodesarrollo Campesino PAC. Potosí \& Ruralter Editores. La Paz, Bolivia

Lopez, S (s.f). 1985. Tecnología Tradicional de Artesanía Textil: El caso de Morrope. Trabajo presentado en: Symposium "Algodón del País y Artesanía Textil", Museo del Banco Central de Reserva, Lima, Perú.

Lorandi, A. M. 2002. "Introducción". En: Los pueblos de Indios del Tucumán colonial: pervivencia y desestructuración. Farberman, Judith y Raquel Gil Montero (comp). 2002. EdiUnju. Universidad Nacional de Quilmes Ediciones.

Lowie, R. H. 19661. "Los determinantes de la cultura". En: Bohannan, Paul. 1973. Antropología Lecturas. Madrid, McGrawn-Hill. Pp. 126-138.

Lozares, C. 2005. "Bases metodológicas para el análisis de redes sociales, ARS". EMPIRIA. Revista metodológica de ciencias sociales UNED. 2005 vol 10 pp. 9-35.

Lumbreras, L. 1999. "Andean Urbanism and Statecraft". In: Salomon and Schwarz (editors) 1999. The Cambridge History of the Native Peolples of the Americas. Vol III. South America. Parte 1. Cambridge Univertsity Press. USA.

Malinowski, B. 1922. Los Argonautas del Pacífico Occidental. Obras Maestras del Pensamiento Contemporáneo, Nro. 67 y 68. Planeta Agostini Barcelona, España.

Malinowski, B. (1923) 1964. El problema del significado en las lenguas primitivas. En: C.K.Ogden y L.A.Richards: El significado del Significado. Una investigación acerca de la influencia del lenguaje sobre el pensamiento y de la ciencia simbólica. Paidós Básica, Buenos Aires. 
Marsden, P. V. 1990. "Network data and measurement". Annual Review of Sociology, Volume 16, pp. 435-463.

Martínez, M. R., A. Eguia. 1983. "Plantas de uso terapéutico en el pueblo de Molinos y zona de influencia. Prov. de Salta, Argentina". Primer Simposio Argentino y Latinoamericano de Farmacobotánica y Bromatología. Buenos Aires. Diciembre 1983.

Martínez, M. R., et al. 1984. "Algunas enfermedades en los valles calchaquíes salteños y los elementos utilizados en su terapia". II Congreso Internacional de Medicina Tradicional y Folklórica. Universidad Autónoma de Morelos, Cuernavaca, Méjico.

Martínez, M. R., A. Eguia. 1986. "Elementos de uso terapéutico en el pueblo de Molinos y zona de influencia, Prov. de Salta". Cuadernos 10. Instituto Nacional de Antropología. Secretaría de Cultura de la Nación, Bs. As.:63-82.

Martínez, M. R., et al. 1992. "Elementos terapéuticos relacionados con el ciclo sexual en una población del valle calchaquí, Salta, Argentina". En: Actas del Congreso de Etnobotanica'92. Córdoba. España. (En Prensa).

Martínez, M. R., et al. 1996. "La narrativa oral de los "médicos campesinos" como fuente para el estudio del cambio y continuidad en las concepciones y vivencias acerca de la enfermedad en Molinos (Salta, Argentina)". Publicado en las Actas de la IX International Oral History Conference. Gotemborg, Sweden. Junio de 1996.

Martínez, M. R., M. L. Pochetino. 1989. "La farmacia casera como fuente de información de elementos terapéuticos vegetales. Un estudio en los valles calchaquíes salteños". Academia de Farmacia y Bioquímica. Buenos Aires.

Martínez, M. R. y M. L. Pochettino. 2004. "Microambientes y recursos vegetales terapéuticos: Conocimiento Local en Molinos, Salta, Argentina". Zonas Áridas Nro. 8 20032004, Perú.

Marzocca, A. 1959. Historia de plantas tintóreas y curtientes. Instituto de Tecnología Agropecuaria. Secretaría de Estado de Agricultura y Ganadería de la Nación. Colección Agropecuaria del INTA. Buenos Aires. Ex Libris LEBA-FCNyM_UNLP.

Masuda, S. (editor). 1986. Etnografía e Historia del Mundo Andino. Continuidad y Cambio. Universidad de Tokio, Japón. 
El Estudio Etnográfico de la Actividad Textil como aporte a la Caracterización del Modo de Vida en el Pueblo de Molinos y zona de influencia (Provincia de Salta)

Masuda, S. (editor). 1988. Recursos Naturales Andinos. Universidad de Tokio, Japón.

Mata, S. (2000) 2006. Tierra y poder en Salta. El Noroeste argentino en vísperas de la Independencia. Segunda edición, CEPHIA-Universidad Nacional de Salta.

Mauss, M. (1954) 1979. Sociología y Antropología. Editorial Tecnos. Madrid.

Mauss, M. 1974. Introducción a la etnografía. Ediciones Istmo. España.

Meisch, L. 1984. "Symbolism in Textiles Tarabuco, Bolivia." Paper for presentation at the first meeting of the Indiana University Andean Studies Group. Bloomington, Indiana.

Mengoni Goñalons, G., D. Olivera, H. Yacobaccio (editores) 2001. El uso de los camélidos a través del tiempo. Ediciones Del Tridente. Buenos Aires.

Merlino, R. y M. Rabey. 1983. Pastores del Altiplano andino meridional: religiosidad, territorio y equilibrio ecológico. Allpanchis 21: 149.171.

Merlino, R., M. Sánchez Proaño y M. Ozcoidi. 1988. Persistencia y transformación del modo de vida andino en el extremo sur de los Andes Centrales. En Recursos Naturales Andinos, Shozo Masuda Editor, Tokio, Japón.

Merlino, R. y M. Sánchez Proaño. 1995. Identidad ambiental y cultural andina a través de sus expresiones orales y rituales. Revista de Investigaciones folklóricas 10:28.

Merlino, R. y M. Sánchez Proaño. 1996-1997. El sol llega, la sombra pasa. Representación verbal del hábitat en la Puna. Cuadernos del Instituto Nacional de Antropología y Pensamiento Latinoamericano 17. Buenos Aires. Argentina.

Miceli, J. 2008. Los problemas de validez en el análisis de redes sociales: algunas reflexiones integradoras. Revista Redes, Vol 14, \#1. ISSN 1579-0185. España. $<$ http://revista-redes.rediris.es>

Millán de Palavecino, M. D. 1981. Arte del tejido en la Argentina. Ediciones Culturales Argentinas. Subsecretaría de Cultura Ministerio de Cultura y Educación. Buenos Aires. 
Ministerio de Ciencia y Tecnología (MinCyT). 2010. Consejo Federal de Ciencia y Tecnología Proyectos Federales de Innovación Productiva (CFECyT). Eslabonamientos Productivos (PFIP-ESPRO) <www.cofecyt.mincyt.gov.ar >

Ministerio de Producción. Secretaría de Agricultura, Ganadería, Pesca y Alimentos. Proyecto de Desarrollo Rural del NOA, PRODERNOA. República Argentina. <http://www.sagpya.mecon.gov.ar/prodernoa/> y <http://www.sagpya.mecon.gov.ar>

Mitchell, C. (1966) 1999. "Orientaciones teóricas de los estudios urbanos en África". En Wolf y Banton (comp). Antropología Social de las Sociedades Complejas. Alianza Editorial.

Molina, J L., A. Ruiz y L. Teves. 2005. "Localizando geográficamente las redes personales". Revista Redes < http://revista-redes.rediris.es/html-vol8/vol8 5.htm>

Monné, M., G. Soria y Ruiz, M. 2003. "Eric Boman". Pacarina. Revista de Arqueología y Etnografía Americana. Año 3 Nro. 3. Octubre de 2003. Universidad Nacional de Jujuy.

Murra, J. V. 1972. El "control vertical" de un máximo de pisos ecológicos en la economía de las sociedades andinas. Ensayo publicado en el Tomo II de la Visita de la Provincia de León de Huanuco (1562) Iñigo Ortiz de Zuñiga, visitador. Universidad Hermilio Valdizan, Huanuco, Perú.

Murra, J. V. 1975. Formaciones económicas y políticas del mundo andino. Lima, Perú.

Muscio, H. 2006. "Una aproximación evolutiva a la complejidad y al orden social durante el periodo temprano a través del estudio de representaciones rupestres. El caso de la Quebrada de Matancillas, Puna Argentina". Estudios Atacameños vol 31.

Nardi, R. L. J. 1979. "El Kakán, Lengua de los Diaguitas". SAPIENS N03. Museo Arqueológico "Dr. Osvaldo F. A. Menghin", Chivilcoy. Buenos Aires.

Nielsen, A. E. 1997-1998. "Tráfico de caravanas en el sur de Bolivia: Observaciones etnográficas e implicancias arqueológicas". Relaciones de la Sociedad Argentina de Antropología, Tomo XXII-XXIII. Buenos Aires.

Noceti, M. B. 2007. Estudio etnográfico en instituciones destinadas a la atención de niños en riesgo social. Tesis de doctorado no publicada. Universidad Nacional de La Plata. 
El Estudio Etnográfico de la Actividad Textil como aporte a la Caracterización del Modo de Vida en el Pueblo de Molinos y zona de influencia (Provincia de Salta)

Ortiz Malmierca, M. 1995. Production and Society. Pre-Columbian textile production Northwest Argentina. Thesis for master's degree. University of Stockholm.

Ottonello, M. M. y A. M. Lorandi. 1987. Introducción a la Arqueología y Etnología. Diez mil años de Historia Argentina. Editorial Universitaria de Buenos Aires, Argentina.

Paenza, A. 2006. Matemáticas ... ¿estás ahí? Episodio 2. Universidad Nacional de Quilmes. Siglo XXI. Argentina.

Palma, N. H. 1973. Cap. 1. La población actual. En Cigliano, E. 1973. Tastil una ciudad Preincaica Argentina. Ediciones Cabargon. Buenos Aires.

Parsons, T. 1976. El Sistema Social. Madrid, Rev. de Occidente, 1976.

Paul, A. 1990. Paracas Ritual Attire. Symbols of Authority in Ancien Perú. University of Oklahoma Press. Norman and London, USA.

Podestá, M.M., D. Rolandi \& M. Sánchez Proaño. 2005. El Arte Rupestre de Argentina Indígena. Noroeste. Academia Nacional de Historia \& Union Academique International. Buenos Aires: GAC.

Podgorny. I. 2000. "Vitrinas y administración. Los criterios de organización de las colecciones antropológicas del Museo de La Plata entre 1897 y 1930". Relics \& Selves: Articles Iconographies of the Nacional in Argentina, Brazil and Chile. <http://www.bbk.ac.uk/ibamuseum/texts/Podgorny01.htm>

Popp, J. y M. A. Gasperini. 1999. "El Mercado de tierras en dos provincias argentinas: La Rioja y Salta". CEPAL- Serie Desarrollo Productivo 66. Naciones Unidas, Santiago de Chile.

Popp, J. y M. A. Gasperini. 2003. "Políticas para promover los mercados de tierras rurales en Argentina". Capítulo VII, Segunda Parte: Búsqueda de soluciones. Estudios de caso sobre Argentina, Brasil, Colombia, Guatemala, Paraguay, Perú y República Dominicana. pp. 241 a 268. En: Tejo, Pedro (Compilador). 2003. Mercados de tierras agrícolas en América Latina y el Caribe: una realidad incompleta. Comisión Económica para América Latina y el Caribe (CEPAL), Naciones Unidas (ONU), Santiago de Chile.

Pulo, M. (coord.). 1996-99. Proyecto Nro. - Título 010/95- Conservación de vicuñas en el Departamento Molinos. Asociación de Productores de San Pedro Nolasco de los Molinos, 
Salta. Ministerio de Desarrollo Social y Medio Ambiente de la Nación. Fondo para el Desarrollo de las Américas. Argentina.

Quiroga, A. 1903. "Cómo vestían los calchaquíes. Sus prendas y adornos. Tocado y peinado. Vestido y tejido", en Estudios, Tomo 6, pp 7-61. Buenos Aires.

Quiroga, A. (1929) 2005. El folklore Calchaquí. Editorial Sarquís, Catamarca.

Rabey, M. 1986. "Creatividad tecnológica entre los campesinos del Sur de los Andes Centrales". II Congreso Argentino de Antropología Social. Buenos Aires. Publicado en Revista de Antropología, 8. Santa Fe, 1987. Area de Programación y Evaluación del Centro Regional y Desarrollo de Santa Fé -CERIDE. Consejo Nacional de Investigaciones Científicas y Técnicas (CONICET), Pag. 98 -119.

Rabey, M. 1994. "Conocimiento popular, recursos naturales y desarrollo: El caso de los Andes argentinos". En M. A. Rabey, ed., 1994. El uso de los recursos naturales en las montañas: Tradición y transformación. Montevideo: NESCO/IUBs: 201-212.

Rabey, M. 1999. "Construcción de conocimientos y cuidado de la biodiversidad: El caso de los pastores altoandinos". En D. Matteucci, O. Sobrig, G. Hallfter y J. Morello, eds., Biodiversidad en América Latina. Buenos Aires: EUDEBA.

Radcliffe-Brown, A. R. (1969) 1986. Estructura y función en la sociedad primitiva. Obras Maestras del Pensamiento Contemporáneo. Nro. 63, Planeta Agostini Barcelona, España.

Raffino, R. 1975. "Potencial económico y modelos ecológicos en el NOA". En Relaciones de la Sociedad Argentina de Antropología IX:21-46. Buenos Aires.

Raffino, R. 1983. Los Inkas del Kollasuyu. Origen, naturaleza y transfiguración de la ocupación Inka en los Andes Meridionales. 2da. Edición. Ramos Americana Editora. La Plata, Argentina.

Raffino, R. 1984. "Excavaciones en el Churcal. Valle Calchaquí, República Argentina". Revista del Museo de La Plata; Secc. Antrop.; (NS); T. VIII, Nro. 59. La Plata.

Raffino, R. 1988. Poblaciones Indígenas en Argentina. Tea. Buenos Aires. 
Remorini, C. 2008. Aporte a la caracterización etnográfica de los procesos de saludenfermedad en las primeras etapas del ciclo vital, en comunidades Mbya-Guarani de Misiones, República Argentina. Tesis de doctorado publicada. Universidad Nacional de La Plata.

Requena Santos, F. (Comp.). 2003. Análisis de redes sociales. Orígenes, teorías y aplicaciones. Colección Monográfica Nro. 198. CIS. Centro de Investigaciones Sociológicas. Madrid, España.

Richards, L. 2005. Handling Qualitative Data, A Practical Guide, London Sage Publications.

Roberts, F. S. 1993. Graph Theory and Its Applications to Problems of Society. Society for Industrial and applied Mathematics. Philadelphia, Pensylvania, USA.

Rolandi de Perrot, D. 1972. Estudio sobre textiles del yacimiento arqueológico de Santa Rosa de Tastil, Provincia de Salta. Tesis Doctoral N0308. Facultad de Ciencias Naturales Museo, Universidad Nacional de La Plata. Inédita.

Rolandi de Perrot, D. 1973. "Ikat en Tastil, Provincia de Salta". En Relaciones de la Sociedad Argentina de Antropología. Argentina. Tomo VII, n.s., pp 183-185.

Rolandi de Perrot, D. 1973. "Los textiles Tastileños". En Cigliano, E. Tastil una ciudad Preincaica Argentina. Ediciones Cabargon. Buenos Aires.

Rolandi de Perrot, D. 1978. 1.000 años de Tejido en la Argentina. Catálogo de textiles Precolombinos. Ministerio de Cultura y Educación, Instituto Nacional de Antropología.

Rolandi, D. 1975. Cuestionario- guía para el relevamiento de datos sobre artesanía textil y artesanos. (Inédito)

Rolandi, D. y D. Jiménez de Pupareli. 1983- 1985. "La tejeduría tradicional de la puna Argentino- Boliviana". Cuadernos del Instituto Nacional de Antropología. 10. Buenos Aires, Argentina.

Rolandi, D. 1984. Elaboración del anteproyecto de Ley de creación del "Programa Nacional de Artesanías Tradicionales". (Co-autora) 
El Estudio Etnográfico de la Actividad Textil como aporte a la Caracterización del Modo de Vida en el Pueblo de Molinos y zona de influencia (Provincia de Salta)

Rolandi, D. 1991. Análisis económico-financiero del Mercado Nacional de Artesanías Tradicionales Argentinas (MATRA). Trabajo inédito.

Rolandi, D. y S. García. 1997. "Del Tejido Hemos Vivido", en Visión Americanista de la Artesanía. Instituto Andino de Artes Populares, Quito, Ecuador.

Rowe, A. 1984. Costumbres \& Featherwork of the Lord of Chimor. The Textiles Museum, Washington, D.C.

Sánchez Parga, J. 1995. Textos Textiles en la Tradición Cultural AndinaInstituto Andino de Artes Populares (IADAP) - CAB, 1995, 87 p. Quito, Ecuador.

Santoni, M. y G. Torres. 1995-96. "Antiguos productos como base alimentaria de los campesinos actuales. Un problema cultural." Revista Andes 7. CEPIHA. Facultad de Humanidades - Universidad Nacional de Salta. Salta.

Sapir, E. 1929. "El estatus de la lingüística como ciencia". En: Bohannan, Paul. 1973. Antropología Lecturas. Madrid, McGrawn-Hill. Pp. 142-147.

Schweizer, T. 1997. "Embeddedness of Ethnographic Cases. A Social Networks Perspective". Current Anthropology Vol 38 (5): pp. 739-760.

Schweizer, T. y D. White (ed). 1998. Kinship, Networks, and Exchange. Cambridge University Press.

Scott, J. 2000. Social Network Analysis. A Handbook. Sage Publication Ltd, London.

Seeland, K. (Edited). 1997. Nature is Culture. Indigenous knowledge and socio-cultural aspects of trees and Forests in non European Cultures. Intermediate Technology Publications. UK.

Seiler- Baldinger, A. 1996. A Classification of Techniques. Smithsonian Institution Press.

Senado de la Nación. Proyecto de Declaración Manifestando Beneplácito por la firma del Convenio entre la Provincia de Salta y los propietarios de la Finca Luracatao S-1742/04. Dra. Sonia Escudero. Senadora de la Nación, República Argentina. 10 de Junio de /2004. 
Shiffrin, R. M. and K. Börner. 2004. "Mapping knowledge domains". Proceedings of the National Academy of Sciences of the United States of America, April 6, 2004 vol. 101 suppl. 1, http://www.pnas.org/content/vol101/suppl 1/

Sichra, I. 2009. "Argentina Andina". En: Cap. VII: Andes, Atlas Sociolingüístico de Pueblos Indígenas de América Latina. 2009. Tomo 2. pp. 535-545. UNICEF, AECI y FUNPROEIB Andes. Cochabamba, Bolivia.

Sillar B. 1996. 1996. "The Dead and the Drying. Techniques for Transforming People and things in the Ande"s. En Journal of Material Culture, vol. 1 (3), november 1996. pp.259291. Sage Publications. London.

Software for Qualitative Data Analysis. 1997. QSR NUD.IST 4.0 (License Number: WP40E). Qualitative Solutions \& Research Pty Ltd, Melbourne Victoria, Australia.

Solá, J. V. (1949) 1975. Diccionario de Regionalismo de Salta, República Argentina. Editorial Plus Ultra. Buenos Aires.

Solanilla, V. 2002. "La colección de textiles del Museo Barbier-Mueller de Barcelona". Actas de la II Jornadas Internacionales sobre textiles precolombinos. Institut Català de Cooperació Iberoamericana. Universitat Autònoma de Barcelona. España.

Soprano, G. 2007. "Configuración de liderazgos y grupos académicos en la investigación antropológica argentina. Análisis histórico centrado en la Facultad de Ciencias Naturales y Museo de la Universidad Nacional de La Plata. 1930-1990". Primer Congreso Argentino de estudios Sociales de la Ciencia y la Tecnología. Universidad Nacional de Quilmes, Bernal, Pcia. Buenos Aires, Argentina.

Spradley, J. 1979. The Ethnographic interview. United States, Wadsworth Group/Thomas Learning.

Sweeney, E. S. y A. A. Domínguez Benavides. 1998. Robustiano Patrón Costas. Una leyenda argentina. Emecé Editores. Argentina.

Sy, A. 2008. Estrategias frente a la enfermedad en dos comunidades Mbya Guaraní (Ka'aguy Poty e Ivy Pytã Provincia de Misiones). Aporte del estudios de casos a la investigación etnográfica de los procesos de salud-enfermedad. Tesis de doctorado sin publicar. Facultad de Ciencias Naturales y Museo. Universidad Nacional de La Plata. 
El Estudio Etnográfico de la Actividad Textil como aporte a la Caracterización del Modo de Vida en el Pueblo de Molinos y zona de influencia (Provincia de Salta)

Taullard, A. 1949. Tejidos y Ponchos Indígenas de Sudamérica. Editorial Guillermo Kraft Limitada. Buenos Aires.

Tejo, P. (Comp.). 2003. Mercados de tierras agrícolas en América Latina y el Caribe: una realidad incompleta. Comisión Económica para América Latina y el Caribe (CEPAL), Naciones Unidas (ONU), Santiago de Chile.

Teseira, M E. y M. F. Sola. 2001. "Artesanías. Caracterización General e Historia Cultural. Regiones de la Puna, Prepuna y Valles Calchaquíes". Consejo Federal de Inversiones, Argentina.

Teves, L. 2002. "Trazas de paisajes en Molinos, un pueblo del Valle Calchaquí, Salta, Argentina". En: The Power of Oral History: Memory, Healing and Development, Philippe Denis y James Worthington (ed). Pietermaritzburg, Sudáfrica, International Oral History Association y University of Natal, 2002, 4 vols. Vol. 1, p. 145. ISBN 0-620-29161-3.

Teves, L; Crivos M; Martínez, M.R. y Sáenz, C. 2002. "Una aplicación de la metodología de redes sociales a la investigación etnográfica". Redes. Revista hispana para el análisis de redes sociales, Vol 2, \#6. ISSN 1579-0185. España. <http://revista-redes.rediris.es>

Teves, L. 2004. "Red de actores que intervienen en al secuencia terapéutica de casos de gripe y susto en una población del Departamento de Molinos, Salta (Argentina). Anexo 26." En: Crivos, Marta, 2004. "Contribución al estudio antropológico de la medicina tradicional de los Valles Calchaquíes (Provincia de Salta)". Tesis de Doctorado. FCNyM. UNLP.

Teves, L. 2005. "Análisis de Redes sociales y actividades económicas en las comunidades de Molinos". Redes. Revista hispana para el análisis de redes sociales. Vol.9\#2, Dic. 2005, $<$ http://revista-redes.rediris.es>

Teves, L.; M. Crivos y A. Lamarche. 2005. "Vida Doméstica y Redes Sociales". Actas del Io Congreso Latinoamericano de Antropología. Universidad Nacional de Rosario, Argentina.

Universidad Nacional de Salta. (1997). Informe sobre desarrollo humano de la Provincia de Salta.1997. Honorable Senado de la Nación.

V.V.A.A. 1977. El País de los Argentinos. Atlas Total de la República Argentina. Publicaciones del Centro Editor de América Latina. v. 21, v. 23 y v. 28. Buenos Aires. 
V.V.A.A. 1999. Descripción del Sistema Microfinanciero. Asociación de Mujeres Warmi Sayajsunqo. Responsable Rosario Andrada de Quispe - Bustamante 165, Abra Pampa, Jujuy (4660) - ARGENTINA. Experiencias con Organismos no Gubernamentales. Proyecto Desarrollo Sustentable de las Zonas Áridas y Semiáridas en Argentina. Convenio SAyDSINTA-GTZ. Diciembre de 2006. Edición digital www.webvillanueva.com.ar septiembre 2007.

V.V.A.A. 1999. Fondo Rotatorio Autogestivo de Productos Veterinarios en Comunidades Rurales del Valle Calchaquí, Salta. Instituto Nacional de Tecnología Agropecuaria (INTA). Agencia de Extensión Rural INTA Seclantás - Red Valles de Altura. Responsable: Ing. Diego N. Ramilo - Seclantás - Prov. de Salta - ARGENTINA. Experiencias con Organismos Gubernamentales. Proyecto Desarrollo Sustentable de las Zonas Áridas y Semiáridas en Argentina. Convenio SAyDS-INTA-GTZ. Diciembre de 2006. Edición digital www.webvillanueva.com.ar septiembre 2007.

V.V.A.A. 2008. Atlas Total de la República Argentina. Editorial Argentino S.A. v.22.

Varela, R. A. 2001. Estudio y Relevamiento en Salta. Resumen Ejecutivo. Consejo Federal de Inversiones. Argentina.

Vega, C. 1960. La Ciencia del Folklore. Editorial Nova. Buenos Aires.

Video Film Documentary Educational Resources. "Franz Boas (1858-1942)". 1980. The Odyssey series by T.W. Timreck, Executive Producer, Michael Ambrosino, color, 59 min. $<$ www.der.org/films/franz-boas.html $>$

Vitry, C. 2004. "Camino de los Diaguitas y del Inga en Escoipe. Intersecciones entre la historia y la arqueología". Revista Escuela de Historia. Año 3, Vol. 1, No 3, 2004. Salta, Argentina.

Vitry, C. 2008. El nevado de Cachi. Palloni Ediciones. 3ra edición. Salta, Argentina.

Vivante, A., M. Crivos y A. Eguía. 1979. "Contribución al estudio de la infraestructura antropológica de la medicina argentina". Ponencia presentada al Primer Congreso Mundial de Medicina Folklórica. En: Actas del Primer Congreso Mundial de Medicina Folklórica. Lima, Iquitos, Cuzco, octubre/noviembre 1979. 
Von Tshudi, J. J. 1966. "Viaje por las Cordilleras de los Andes de Sudamérica, de Córdoba a Cobija, en al año 1858". Boletín de la Academia Nacional de Ciencias. Tomo XLV. Córdona, Rep. Argentina. Pp 324-405.

Vreeland, J. 1986. "Una perspectiva antropológica de la paleotecnología en el desarrollo agrario del norte de Perú". América Indígena Vol. XLVI Nro. 2. Abril-Julio de 1986.

VVAA. (1990) "Tejidos Precolombinos. Terminología Textil en español". Documento de Trabajo. Encuentro Regional de Expertos sobre Conservación de Textiles Precolombinos. Arica, Chile.

Washburn D. K. y D. W. Crowe. 1992. Symmtries of Culture. Theory an Practice of Pattern Analysis. University of Washington Press. Seattle and London. 2da, edición.

Wasserman, S. and K. Faust. 1999. Social network analysis: methods and applications. Cambridge University Press. United States of America

Weller, S. C. y A. K. Romney. 1988. "Systematic Data Collection". Qualitative research methods series. 10. Newbury Park: Sage Publications, pp. 77.

Wellman, B. 1988. "Structural analysis: from method and metaphor to theory and substance". In Wellman, Barry \& S. D. Berkowitz, eds. 1988. Social Structures. A Network Approach. Cambridge: Cambridge University Press.

White, D. R. and M. Houseman. 2002. "The Navigability of Strong Ties: Small Worlds, Tie Strength and Network Topology". Complexity 8 (1): 72-81.

Wissler, C. (1917) 1950. The American Indian: An Introduction to the Anthropology of the New World. New York, Peter Smith.

Wissler, C. 1910. "Material Culture of the Blackfoot Indians". Anthropological Papers of the American Museum of Natural History. Volume V, Part I. New York. Published by Order of the Trustees.

Wolfe, A. W. 1961. In the Ngombe Tradition: Continuity and Change in the Congo. Evanston: Northwestern University Press. 
El Estudio Etnográfico de la Actividad Textil como aporte a la Caracterización del Modo de Vida en el Pueblo de Molinos y zona de influencia (Provincia de Salta)

Laura Teves

Wolfe, A. W. 1963. "The African Mineral Industry: Evolution of a Supranational Level of Integration". Social Problems 11(2):153-64.

Wolfe, A. 1978. "The Rise of Network Thinking in Anthropology". Social Networks, 1 (1978) 53-64. @Elsevier Sequoia S.A., Lausanne -Printed in the Netherlands.

Wolfe, A. 1996. "Contributions of Anthropology to Conflict Resolution". From: Anthropological Contributions to Conflict Resolution. Edited by Alvin W Wolfe and Honggang Yang. Southern Anthropological Society Proceedings, No.29, 1996 Pp. 1-10. Michael V. Angrosino, Series Editor. The University of Georgia Press Athens and London. 


\section{BIBIBLIOGRAFIA CONSULTADA}

Appadurai, Arjun (ed.). 1991. La vida social de las cosas. Perspectiva cultural de las mercancías. Grijalbo, México.

Arnold, Denise Y. 1994. Hacer al Hombre a Imagen de Ella: Aspectos de género en los textiles de Qaqachaka. Revista Chungara Vol. 26, Nro.1. pp. 79-115. Universidad de Tarapacá. Arica, Chile.

Arnold, Denise Y. 2000. "Convertirse en persona" el tejido: la terminología aymara de un cuerpo textil. Actas de la I Jornada Internacional sobre Textiles Precolombinos. Victòria Solanillas Demestre- (ed.) pp. 9-28. Departament d'Art de la Universitat Autònoma de Barcelona, Bellaterra, Barcelona, España.

Balfet, Hèléne, Sophie Desrosiers, Yves Delaporte, y otros. 1991. Observer L'Action Technique. Des chaînes opératoires pour quoi faire? Éditions du Centre National de la Recherche Scientifique, París.

Carrington, Peter J. John Scott and Stanley Wasserman. (eds.) 2005. Models and Methods in Social Network Analysis. Cambridge, Cambridge University Press.

Cereceda, Verónica. 1978. Sémiologie des tissus andins: Les Talegas d'Isluga. Annales. Économies, Sociétés, Civilisations, Volume 33, Numéro 5-6, pp. 1017-1035. Armand Colin. Paris.

Cereceda, V. 1987. Aproximaciones a una estética andina: de la belleza al tinku. En: Tres reflexiones sobre el pensamiento andino de Bouysse-Cassagne, Thérèse, Harris Olivia, Platt, Tristan y Cereceda, Verónica. Colección Biblioteca Andina, 1. La Paz: Instituto de historia social boliviana. HISBOL, Bolivia.

Cereceda, Verónica. 1990. A partir de los colores de un pájaro. Boletín Museo Chileno de Arte Precolombino, Volumen 4, pp. 57 a 104, Santiago de Chile.

Cereceda, Verónica, Jhonny Davalos y Jaime Mejia. 1993. Una diferencia, un sentido: Ios diseños de los textiles Tarabuco y Jalqáa. Sucre: ASUR. 
Cereceda, Verónica. 1993 - "Cette étendue entre l'altiplano et la mer... Un mythe chipaya hors texte." En: Aurore Becquelin et Antoinette Molinié (eds), pp. 227-284. Mémoire de la tradition. Société d'Ethnologie, Nanterre, París.

Cereceda, Verónica. 1996 - Renacimiento de un arte indígena. Los textiles jalq'a y tarabuco del centro sur de Bolivia. ASUR, Sucre.

Delaporte, Yves. 1984. Perspectives Methodologiques et Théoriques dans L'Étude du Vêtement. L'Ethnographie 1984. Vêtement et Sociétés 2. Tome LXXX Neméro Spécial 9293-94 de I'Ethnographie.

Emery Irene. 1979. Indonesian textile. Roundtable on Museum Textiles. Proceedings The Textile Museum. Washinton, D.C.

Femenías, Blenda. 2005. Gender and the Boundaries of Dress in Contemporary Peru. Austin: University of Texas Press.

Ferreiro, Juan Pablo. 2004. Parentesco y estructuras familiares en Jujuy, siglos XVII y XVIII, Cristina López de Albornoz (comp.) Familia, Parentesco y redes Sociales. Red de Est. Históricos, Poblacionales y Socioculturales-Instituto de Estudios. Geograficos, F.F.yL.UNT, Pp. 65/101. Tucumán, Argentina.

Ferreiro, Juan Pablo y Federico Fernández. 2008. Apuntes etnográficos y Análisis de Redes Sociales en la localidad de Santa Ana (Provincia de Jujuy). Ponencia presentada en el IX Congreso Argentino de Antropología Social, Posadas, Misiones, Argentina.

Fisher, Eva. 2000. Los usos del tiempo en América: Comunida Andina y uso del tiempo- el caso de Upinhuaya. Conferencia en el 50 Congreso Internacional de Americanistas, Varsavia, Polonia. 10 al 14 de Julio.

Fischer, Eva. 2002. Las categorías del tiempo y el concepto de temporalidad: el caso de Upinhuaya. Revista Andina Nro. 35, pp. 167-190. Centro de Estudios Regionales Andinos Bartolomé de Las Casas. Cuzco, Perú.

Fischer, Eva. 2002. Textiles, Historia y Antropología Cognitiva - Ejemplos Andinos de Tradición y Cambio. Actas de las II Jornadas Internacionales sobre Textiles Precolombinos. pp. 161-175. Victoria Solanila Demestre (ed.) UAB - Institut Català de Cooperació Iberoamericana. España. 
Foccaro, Rosa. 1986. Arte Textil Argentino Hoy, publicado por Beutelspacher SRL. Buenos Aires. Imprimió Gaglianone.

Franquemont, Edward, Christine Franquemont and Billie Jean Isbell. 1992. Awaq ñawin: El ojo del tejedor. La práctica de la cultura en el tejido. Revista Andina 20 (1): 47-80.

García, S., D. Rolandi, M. López y P. Valeri. 2003. "Para el gasto":Vigencia de redes de intercambio en un área rural del Noroeste argentino. Ponencia Presentada en Sunbelt XXIII. International Social Network Conference. Cancún, Quintana Roo, México. Febrero $12-16$

Göbel, Barbara. 1997. "You Have to Exploit Luck": Pastoral Household Economy and the Cultural Handling of Risk and Uncertainty in the Andean Highlands. Nomadic People International Union of Anthropological and Ethnological Sciences, pp. 37-53, Volume 1 ISSUE 1, Germany and United Kingdom.

Göbel, Barbara. 1999. Why Herd Animals Die. Environmental Perception and Cultural Risk Management in the Andes. In: Coping with Changing Environments. Social dimensions of endangered ecosystems in the developing world. Lohnert Beate and Helmut Geist. Ashgate Pp. 205-229. England/USA.

Godelier, Maurice. 1974. La 'moneda de sal' y la circulación de mercancías en los Baruya de Nueva Guinea. Cap IX, pp. 267 a 298. En Economía, fetichismo y Religión en las Sociedades Primitivas. Siglo XXI.

Guía de Exposición. 1995. Diseño en la textiñería del Norte de Chile. Univerdidad de Antofagasta. Chile.

Guía Museo Luigi Pigorini. 1982. Simbolo e tecnica nei tessuti dell'antico Perù. De Luca Editore. Roma.

Harris, Olivia. 1985. Roles y Valores de la Mujer Andina. Allpanchis, Nro. 25 Año XV, Vol XXI pp. 17-42. Instituto de Pastoral Andina, Cusco. Perú.

Hermitte, Esther y Carlos Herrán. 1970 ¿Patronazgo o cooperativismo? Obstáculos a la modificación del sistema de interacción social en una comunidad del noroeste argentino. la Revista de Sociología 70/2. Pp. 293-317. 
Hermitte, Esther y Carlos Herrán. 1977. Sistema productivo, instituciones intersticiales y formas de articulación social en una comunidad del noroeste argentino. En Procesos de articulación social. Esther Hermitte y Leopoldo Bartolomé. Compiladores. Consejo Latinoamericano de Ciencias Sociales (CLACSO)

Hermitte, Esther y Herbert Klein. 1971. Crecimiento y estructura de una comunidad provinciana de tejedores de ponchos: Belén 1678-1869. Documento de Trabajo. Centro de Investigaciones Sociales del Instituto Torcuato Di Tella. Buenos Aires, Argentina.

Hermitte, Esther. 1968. Movilidad social en una comunidad bicultural. Revista Latinoamericana de Sociología. Centro de Investigaciones Sociales del Instituto Torcuato Di Tella. 68-1. Pp. 6-37.

Humphrey, Caroline y Stephen Hugh-Jones (compiladores). 1998. Trueque, intercambio y valor. Aproximaciones Antropológicas. Biblioteca Abya-Yala. Quito, Ecuador.

Iriarte, Isabel. 1987. Análisis técnico de Gasas Prehispánicas. En Ruth Corcuera. Gasas prehispánicas. Fundación para la Educación, la Ciencia y la Cultura. Instituto para la Cultura e Historia Hispanoamericanas. Pp. 103. Consejo Editorial REDTEXTILIA, Argentina.

Johnson, Grace and Douglas Sharon (Editors) 1994. Cloth \& Curing. Continuity and Change in Oxaca. San Diego Museum Papers Nro. 32. Museum of Man, USA.

Karasik, Gabriela. 1984. "Intercambio tradicional en la puna jujeña" Revista Runa: archivo para las ciencias del hombre, Buenos Aires, 1984, 14 p. 51-91: bibliogr. p. 89-91.

Lalonger, Louise. 1994. La transition des colorants naturesles aux colaronts synthétiques et ses répercussions. Material History Review 40 (Fall 1994)/ Reveu d'histoire de la culture matérielle 40. p. 1928.

Lozares Colina, Carlos, Laura Teves y Dafne Muntanyola. 2006. Del atomismo al relacionismo. La red socio-cognitiva como paradigma del cambio operado en la concepción de lo social y de la cognición. Redes. Revista hispana para el análisis de redes sociales. Vol.10 \#1, Junio 2006, <http://revista-redes.rediris.es>

Merlino, Rodolfo y Mario Ravey. 1981. Antropología Aplicada a la Investigación y Desarrollo de Tecnología Aplicada. Publicaciones del Instituto de Antropología. Nueva Epoca XXXVI, p.7-21. Universidad Nacional de Córdoba. 
National Reserch Council. 2003. Dynamic Social Network Modeling and Analysis. Worshop Summary and Papers, Ronald Breiger, Kathleen Carley and Philippa Pattison. Committee on Human Factors. Borad on Behavioral, Cognitive, and Sensoty Sciences, Division of Behavioral and Social Sciences and Education.Washington, DC: The National Academies Press.

Ortiz Malmierca, Martha. 1994. Deshaciendo la madeja. Ediciones de Saltomortal Estocolmo, Suecia.

Plattner, Stuart. 1991. Antropología Económica. Alianza Editorial. México D.F.

Price, Steven. 1995. The 19th Textile Museum Rug Convention: What is a Tribal Rug? Oriental Rug Review No. 124, Vol. 16, No. 1, October/November, 1995, 56 pages. Textil Museum, Washintog D.C.

Quiroga, Adán. 189. Calchaquí y la Epopeya de las Cumbres. Revista Museo de La Plata 49, p. 185-224. La Plata, Argentina.

Reborati, Carlos (Comp.) 1997. De Hombres y Tierras Una Historia Ambiental del Noroeste Argentino. Proyecto Desarrollo Agroforestal en Comunidades Rurales del Noroeste Argentino, (Sociedad Alemana de Cooperación Técnica (GTZ). Salta, Argentina.

Requena Santos, Félix. 1989. El concepto de red social, Revista Española de Investigaciones Sociológicas, 48, p. 137-152.

Requena Santos, Félix. 1991. Redes sociales y mercado de trabajo. Elementos para una teoría del capital relacional. Col. Monografías (119), Madrid: Centro de Investigaciones Sociológicas.

Rolandi, Diana y Silvia García. "Me amanecí tejiendo". El valor económico del tejido en una comunidad de la Puna Argentina. En: Estudios sociales del NOA , año 5, nº 5, 2002:55-81.

Rotman, Mónica B. 1996. Consumo Cultural: Prácticas y representaciones de consumo artesanal. Cuadernos de Antropología Social Nro. 9 pp. 173-187.

Rowe, Ann P. (editor). 1998. Costume and identity in highland Ecuador. University of Washington Press, USA. 
El Estudio Etnográfico de la Actividad Textil como aporte a la Caracterización del Modo de Vida en el Pueblo de Molinos y zona de influencia (Provincia de Salta)

Sawyer, Alan. 1963. Tahuanaco Tapestry Design. Textile Museum Journal. Vol 1 Nro. 2 pp. 27-38. University of California. Berkley, California.

Shozo Masuda (Editor). 1988. Recursos Naturales Andinos. Universidad de Tokio, Japón.

Stenborg, Per and Adriana Muñoz. 1999. Masked Histories. A Re-examination of de Rodolfo Schreiter Collection from North-western Argentina. Etnologiska Studier 43. Göteborg, Suecia.

Teves, Laura. 2009. Redes sociales, economía y ambiente en Molinos. I Reunión Latinoamericana de Análisis de Redes Sociales. Agencia de Promoción Científica y Tecnológica, Municipalidad de La Plata y Facultad de Ciencias Naturales y Museo. Universidad Nacional de La Plata. ISBN 978-950-34-0513-0.

Torres, Garciela F. y Mirta Elsa Santoni. 1997. Los efectos de la conquista: modificaciones de los patrones alimentarios de la región del NOA, siglos XVI al VIII. Serie Antropológica Ediciones del Sol. Pp 61- 98. Buenos Aires.

Trinchero Hugo (editor). 1995. Producción doméstica y capital. Estudios desde la antropología económica. Editorial Biblos.

Veber, Hanne. 1996. External Inducement and Non- Westernalization in the Uses of the Ashéninka Cushma. En Journal de Material Culture. Volume 1 July 1996.

Villagra, Marisa. 1995. Ronda de Voces. Edición comentada de relatos orales documentados en Amaicha del Valle, NOA. Stocholms Universitet, Estocolmo.

Winterhalder, Bruce y Bram Tacker. 1998. Risk and Diversification in a Mixed Foraging and Agropastoral Market Economy in Southwestern Madagascar. Social, Behavioral, and Eonomic Research. http://www.nsf.gov/sbe/sber/anthro/samples/wintprop.htm

Zorn, Elayne and Juan Quispe. 2004. The Cultural Significance of Andean Cloth and Implications of Its Decline. In: B.L. Farmer, A. Maretzki, y L. Semali (eds) Proceedings of the Conference on 'Indigenous Knowledges': Transforming the Academy. Inter-institutional Consortium of Indigenous Knowledges (ICIK), University Park, The Pennsylvania State University http://www.ed.psu.edu/icik/2004proceedings/section5-zorn-quispe-withpics.pdf 
El Estudio Etnográfico de la Actividad Textil como aporte a la Caracterización del Modo de Vida en el Pueblo de Molinos y zona de influencia (Provincia de Salta)

Laura Teves

Zorn, Elayne y Linda Clare Farthing. 2007. Communitarian Tourism. Hosts and Mediators in Peru. Annals of Tourism Research, Vol. 34, No. 3, pp. 673-689, 2007. Printed in Great Britain. 
El Estudio Etnográfico de la Actividad Textil como aporte a la Caracterización del Modo de Vida en el Pueblo de Molinos y zona de influencia (Provincia de Salta) 
El Estudio Etnográfico de la Actividad Textil como aporte a la Caracterización del Modo de Vida en el Pueblo de Molinos y zona de influencia (Provincia de Salta)

ANEXO 3.1

\section{LISTADO de INFORMANTES}

\begin{tabular}{|c|c|c|c|c|c|}
\hline Expertos Entrevistados & Actividad & Lugar & Edad & Procedencia & Otras actividades \\
\hline Experto_1 & $\begin{array}{c}\text { Hilandera } \\
\text { Componedora }\end{array}$ & Pueblo & 71 & $\begin{array}{c}\text { Puesto } \\
\text { Finca de Pucará }\end{array}$ & $\begin{array}{l}\text { Ama de casa } \\
\text { Médica } \\
\text { campesina }\end{array}$ \\
\hline Experto_2 & $\begin{array}{c}\text { Hilandera } \\
\text { Tejedora }\end{array}$ & Tomuco & 46 & Tomuco & $\begin{array}{l}\text { Ama de casa } \\
\text { Agricultora } \\
\text { Vende pan }\end{array}$ \\
\hline Experto_3 & $\begin{array}{c}\text { Hilandera } \\
\text { Tejedora }\end{array}$ & Tomuco & 53 & Tomuco & $\begin{array}{c}\text { Ama de casa } \\
\text { Médica campesina } \\
\text { Vende pan }\end{array}$ \\
\hline Experto_4 & Hilandera & Tomuco & 69 & $\begin{array}{c}\text { El Refugio } \\
\text { Finca Luracatao }\end{array}$ & $\begin{array}{l}\text { Ama de casa } \\
\text { Agricultora }\end{array}$ \\
\hline Experto_5 & Tejedor & Pueblo & & Pueblo & $\begin{array}{l}\text { Agricultor } \\
\text { Jubilado }\end{array}$ \\
\hline Experto_6 & Hilandera & Pueblo & Más 70 & Finca Colomé & Ama de casa \\
\hline Experto_7 & Tejedor & Entre Ríos & 40 & Luracatao & Empleado \\
\hline Experto_8 & Tejedora & Pueblo & 50 & Finca Colomé & $\begin{array}{l}\text { Ama de casa } \\
\text { Comerciante }\end{array}$ \\
\hline Experto_9 & Hilandera & $\begin{array}{l}\text { Banda } \\
\text { Grande }\end{array}$ & 70 & Finca Pucará & $\begin{array}{c}\text { Ama de casa } \\
\text { Pastora } \\
\text { Mediera }\end{array}$ \\
\hline Experto_10 & Tejedor & Pueblo & 50 & Pueblo & $\begin{array}{l}\text { Empleado } \\
\text { municipal }\end{array}$ \\
\hline Experto_11 & Hilandera & Tomuco & 30 & Tacuil & Ama de casa \\
\hline Experto_12 & Tejedor & El Puente & 40 & Pueblo & Empleado \\
\hline Experto_13 & Tejedor & Tomuco & 30 & Tacuil & Albañil \\
\hline Experto_14 & Tejedor & Tomuco & 52 & Tomuco & $\begin{array}{l}\text { Criador } \\
\text { Agricultor } \\
\text { Ceramista }\end{array}$ \\
\hline Experto_15 & Tropero & Tomuco & 60 & & Criador \\
\hline Experto_16 & Tropero & Pueblo & 74 & Tomuco & $\begin{array}{c}\text { Agricultura } \\
\text { Vende leña } \\
\text { Jubilado } \\
\end{array}$ \\
\hline
\end{tabular}


El Estudio Etnográfico de la Actividad Textil como aporte a la Caracterización del Modo de Vida en el Pueblo de Molinos y zona de influencia (Provincia de Salta)

Laura Teves

\begin{tabular}{|c|c|c|c|c|c|}
\hline Experto_17 & $\begin{array}{c}\text { Hilandera } \\
\text { Tejedora }\end{array}$ & Entre Ríos & 30 & Luracatao & Ama de casa \\
\hline Experto_18 & Tejedor & Santa Rosa & 40 & Pueblo & Agricultor \\
\hline Experto_19 & Carpintero & Pueblo & 40 & Tomuco & Agricultor \\
\hline Experto_20 & Componedora & Pueblo & 40 & Molinos & Empleada \\
\hline
\end{tabular}


El Estudio Etnográfico de la Actividad Textil como aporte a la Caracterización del Modo de Vida en el Pueblo de Molinos y zona de influencia (Provincia de Salta)

Laura Teves

\section{ANEXO 3.2}

\section{Cuestionario-guía para Entrevistas Abiertas y Semiestructuradas. Relevamiento de la tejeduría tradicional en el área de Molinos- Valles Calchaquíes, Salta, Argentina}

\begin{tabular}{|l|}
\hline Items a relevar \\
\hline Item 1- OBTENCION DE HILOS \\
\hline Materia prima \\
\hline Preparación del hilo \\
\hline Utensilios para hilar \\
\hline Tipos de Hilos \\
\hline Entrenamiento y Aprendizaje \\
\hline \multicolumn{1}{|c|}{ Preguntas que efectivamente se hicieron en el trabajo de campo } \\
\hline Q1: ¿Usted sabe hilar? \\
\hline Q1: Recuerda ¿quién le enseñó a hilar? \\
\hline Q1: ¿A qué edad comenzó a hilar con la puchicana? \\
\hline Q1: Actualmente ¿dónde obtiene la lana? \\
\hline Q1: Para Usted ¿cuál es la mejor lana para hilar? \\
\hline Q1: ¿Qué tipo de lana esta hilando ahora? \\
\hline Q1: ¿Cómo reconoce cuáles son las lanas de mejor calidad? \\
\hline Q1: ¿Prefiere los torteros de madera o de piedra? \\
\hline Q1: ¿Quién fabrica los torteros? \\
\hline Q1: ¿Cuánto tiempo le lleva hilar para una frazada? \\
\hline Q1: ¿Cómo se hace para torcer el hilo? \\
\hline Q1: ¿Usted le ha enseñado a alguien a hilar? \\
\hline Item 2- EL TEÑIDO \\
\hline Tinturas naturales y anilinas comerciales \\
\hline Mordientes \\
\hline Utensilios para teñir \\
\hline Colores \\
\hline Lanas \\
\hline Entrenamiento y Aprendizaje \\
\hline Q2: ¿Usted sabe teñir la lana? \\
\hline Q2: Desde su experiencia ¿con qué elemento se tiñe mejor? \\
\hline
\end{tabular}


El Estudio Etnográfico de la Actividad Textil como aporte a la Caracterización del Modo de Vida en el Pueblo de Molinos y zona de influencia (Provincia de Salta)

Laura Teves

\begin{tabular}{|l|}
\hline Q2: Cómo obtienen los yuyos para teñir \\
\hline Q2: ¿Utiliza hilos teñidos a de color natural? \\
\hline $\begin{array}{l}\text { Q2: ¿Usted opina que los colores logrados con “tinta" (anilinas comerciales) son más } \\
\text { firmes o duraderos? }\end{array}$ \\
\hline Q2: ¿Utiliza siempre el mismo mordiente? \\
\hline Q2: ¿Qué tipo y color de lana prefiere para teñir? \\
\hline Q2: ¿Quién le enseñó a teñir lanas? \\
\hline Q2: ¿Desde cuándo lo hace? \\
\hline Q2: ¿En qué momento prefiere teñir? \\
\hline Q2: ¿Alguna persona se ha interesado en aprender a teñir? \\
\hline Item 3- LOS TEJIDOS \\
\hline Piezas de textil \\
\hline Utensilios para tejer \\
\hline Técnicas para tejer \\
\hline Terminación de las piezas \\
\hline Entrenamiento y Aprendizaje \\
\hline Q3: A Usted, ¿quién le enseñó a tejer? \\
\hline Q3: ¿Recuerda desde cuándo teje? \\
\hline Q3: ¿Usted teje todo el año? \\
\hline Q3: ¿El telar de qué madera es? \\
\hline Q3: ¿Dónde obtuvo la pala y el peine? \\
\hline Q3: ¿Cuánto tiempo le lleva tejer una frazada por ejemplo? \\
\hline Q3: ¿Teje durante todo el año? \\
\hline Q3: Usted ¿qué momento del día prefiere para tejer? \\
\hline Q3: Para comenzar el tejido ¿por dónde se empieza, por la derecha o por la izquierda? \\
\hline Q3: A los hilos de abajo del tejido ¿Usted, cómo les llama usted? \\
\hline $\begin{array}{l}\text { Q3: Para una frazada ¿cuántos hilos de urdimbre considera que son necesarios pasar } \\
\text { por el peine? }\end{array}$ \\
\hline Q3: ¿los hilos de la urdimbre de qué lanas son? \\
\hline Q3: ¿De qué material son los lisos? \\
\hline Q3: ¿Para quién tejió esta frazada/poncho? \\
\hline Q3: ¿Cuántos días le lleva terminarlo? \\
\hline $\begin{array}{l}\text { Q3: Desde su punto de vista, para que el tejido salga bien, ¿cuáles son las cosas que } \\
\text { hay que tener en cuenta? }\end{array}$ \\
\hline
\end{tabular}


El Estudio Etnográfico de la Actividad Textil como aporte a la Caracterización del Modo de Vida en el Pueblo de Molinos y zona de influencia (Provincia de Salta)

Laura Teves

Q3:¿Qué variedades de tejidos diferentes sabe hacer?

Q3: Qué tipo de instrumentos utiliza para cada tipo de tejido?

Q3: ¿Cómo se arman o terminan las piezas de tejido?

Q3: ¿Usted considera que los más jóvenes están interesados en trabajar con el tejido?

Item 4- PRODUCCION Y COMERCIALIZACIÓN

Obtención de materias primas

Proceso de elaboración de los textiles

Regalo, Intercambio, compra-venta

Q4: ¿Hace tareas de hilado para Usted mismo o por encargo?

Q4: ¿Usted teje para los miembros de su casa o para otros?

Q4: ¿Realiza Usted mismo todas las tareas para la confección de una pieza textil?

Q4:¿Usted le ha regalado a alguien las piezas de tejido?

Q4: ¿Le han pagado por hilar, tejer 0 arreglar una pieza?

Q4: ¿Si no tiene dinero como obtiene la materia prima? 


\section{ANEXO 3.3}

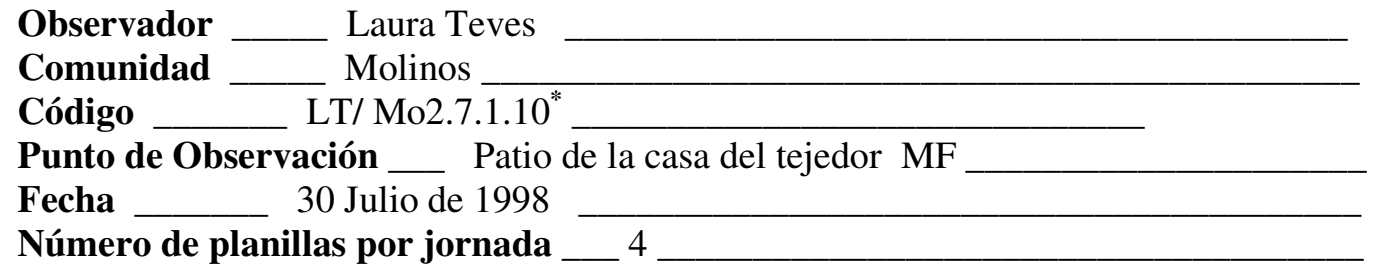

\section{PLANILLAS DE OBSERVACION}

\begin{tabular}{|c|c|c|}
\hline $\begin{array}{c}\text { HOR } \\
\text { A }\end{array}$ & ACTIVIDAD & CONTEXTO \\
\hline $10: 15$ & $\begin{array}{l}\text { MF agrega } 6 \text { hilos a la urdimbre que había } \\
\text { armado ayer. Le pidió más hilo a VL ya que } \\
\text { MF está tejiendo por encargo de VL. }\end{array}$ & $\begin{array}{l}\text { Estoy observando en el patio } \\
\text { de la casa de MF. El telar está } \\
\text { ubicado debajo de la galería } \\
\text { semicubierta. Visto de frente } \\
\text { sobre el extremo final derecho. }\end{array}$ \\
\hline $10: 30$ & $\begin{array}{l}\text { Coloca todos los hilos de urdimbre en el peine, } \\
\text { corta y ata. Para poner los hilos entre los } 2 \\
\text { fierritos del peine y deja un espacio entre } \\
\text { medio, es decir, los hilos de la urdimbre van } \\
\text { alternados entre los "dientes" del peine. } \\
\text { Me explica que el peine es de un largo } \\
\text { adecuado para realizar una manta de } 1 \text { plaza, } \\
\text { que valen aproximadamente } \$ 180 \text { pesos y que } \\
\text { lo hacen unos herreros de Cafayate. }\end{array}$ & $\begin{array}{l}\text { Para trabajar está sentado en un } \\
\text { banco de frente a mi en un } \\
\text { espacio entre os palos del telar }\end{array}$ \\
\hline 11:00 & Sigue cortando y atando la urdimbre. & $\begin{array}{l}\text { Seguimos charlando y me } \\
\text { cuenta sobre el lugar dónde } \\
\text { vivía, Mayuco, en Tacuil. }\end{array}$ \\
\hline $11: 10$ & $\begin{array}{l}\text { Terminó de atar el último hilo de urdimbre y } \\
\text { comenzó a colocarla sobre el peine de hierro }\end{array}$ & \\
\hline $11: 14$ & Terminó de colocar la urdimbre en el peine & \\
\hline $11: 16$ & $\begin{array}{l}\text { Tomó el peine de fierro y lo fijo con unas } \\
\text { sogas de lana a los palos del telar. }\end{array}$ & \\
\hline $11: 30$ & $\begin{array}{l}\text { Se para y uno hilos que están más lejos } \\
\text { Comienza con la tarea de enlisar, es decir, } \\
\text { coloca un conjunto de hilos llamados lisos que }\end{array}$ & $\begin{array}{l}\text { Me explica que esta pieza se } \\
\text { trabaja con } 4 \text { tipos de lisos. }\end{array}$ \\
\hline
\end{tabular}

\footnotetext{
* Referencias sobre el Código: Iniciales del Observador/ Iniciales de la Comunidad. $\mathrm{N}^{\circ}$ de Viaje. № del Tipo de registro (código 7 = Planilla). $\mathrm{N}^{\circ}$ Planilla. $\mathrm{N}^{\circ}$ de Hoja
} 


\begin{tabular}{|l|l|l|} 
11:39 & $\begin{array}{l}\text { permiten relacionan la urdimbre que ya está en } \\
\text { el peine con los planos o niveles por donde se } \\
\text { pasaránn los hilos de la trama. }\end{array}$ & $\begin{array}{l}\text { Acaba de llegar una mujer con } \\
\text { varios niños, es la prima de IF, } \\
\text { la esposa de MF, viene desde } \\
\text { Tacuil y trae a los niños a la } \\
\text { escuela de Molinos } \\
\text { IF ya tiene el almuerzo } \\
\text { preparado porque MF come y a } \\
\text { l1:45 13:30 se va a trabajar a la } \\
\text { construcción. Vuelve a la } \\
\text { tardecita. }\end{array}$ \\
$\begin{array}{l}\text { Pone el 2do. Liso } \\
\text { Terminó de enlisar por el día de hoy. }\end{array}$ & $\begin{array}{l}\text { Guardó la urdimbre con el peine, la ató con } \\
\text { una soga sobre el lado de los lisos y la tapó } \\
\text { con una lona. }\end{array}$ & \multicolumn{2}{|l}{} \\
\hline
\end{tabular}

ANEXO 3.4

NUD*IST 4 - Formato Tipo para el Encabezamiento de los Documentos

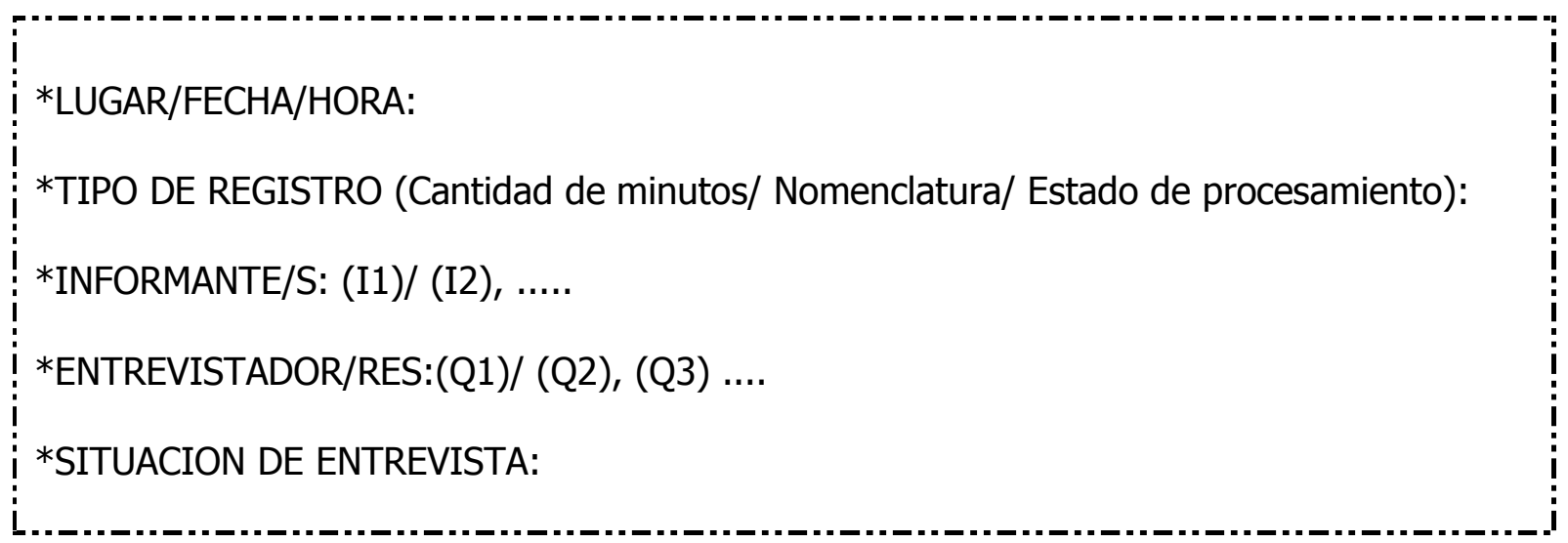

\section{Entrevista con encabezado y codificación}


El Estudio Etnográfico de la Actividad Textil como aporte a la Caracterización del Modo de Vida en el Pueblo de Molinos y zona de influencia (Provincia de Salta)

Laura Teves

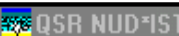

File Edit Project Documents IndexSystem Windows Help

漨D Document Browser: 'Experto 1.4':17-17

IN-LINE DOCUMENT: Experto_1.4

Salta - Molinos- Viaje 1- Domingo $2 \overline{0}$ de Abril de 1997-18:00hs

*Cinta TDK D 60: LT- Mo1.2.

Lado A completo.

Lado B- V000 a V

Informante: LCCH (11), sus nietos y amiga RV (12)

Entrevistador: Laura Teves (Q1)

tSituación de Entrevista: por la tarde alrededor de las 18 hs. en el

patrodala casa del Pueblo de Molinos.

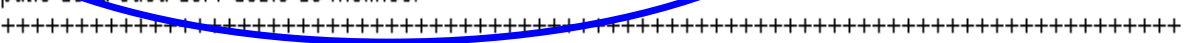

[Experto_1.4: 1 - 522 ]

RV es la dueña de la casa pero actualmente vive en la Finca La Banda

Grande frente al Churcal.

LADO A-V

12: ¿Es la primera vez, quiere decir que anda usted?

Q1: sí, es la primera vez

2: (NO SE ENTIENDE) a Lidia (SE RIE)

11: nos conociamo' antes

12: ah..

11: (SE RIE)

Q1: porque yo vine con otras dos personas, otras dos profesoras.

Una de ellas hace que viene desde el año 82 , que ya la conocía a Lidia.

Entonces ellas me presentaron a Lidia.

11: sí, hace mucho que viene... la otra, ¿cómo se llama la gorda?

Q1: Q3, le dicen Q3.

11: ah $Q 3$

Q1: Clelia se llama

11: ah, ¿Lelia se llama?

Q1: y le dicen $Q 3$, sí..

11: Ah...(NO SE ENTIENDE) Conociendo mucho tiempo

12: y la ha encontrao aquí o en Humanao? 
El Estudio Etnográfico de la Actividad Textil como aporte a la Caracterización del Modo de Vida en el Pueblo de Molinos y zona de influencia (Provincia de Salta) 
El Estudio Etnográfico de la Actividad Textil como aporte a la Caracterización del Modo de Vida en el Pueblo de Molinos y zona de influencia (Provincia de Salta)

Laura Teves

\section{ANEXO 3.5}

\section{Anexo NUD*IST 4- Unidades Textuales codificadas al NODO 56251-URDIMBRE}

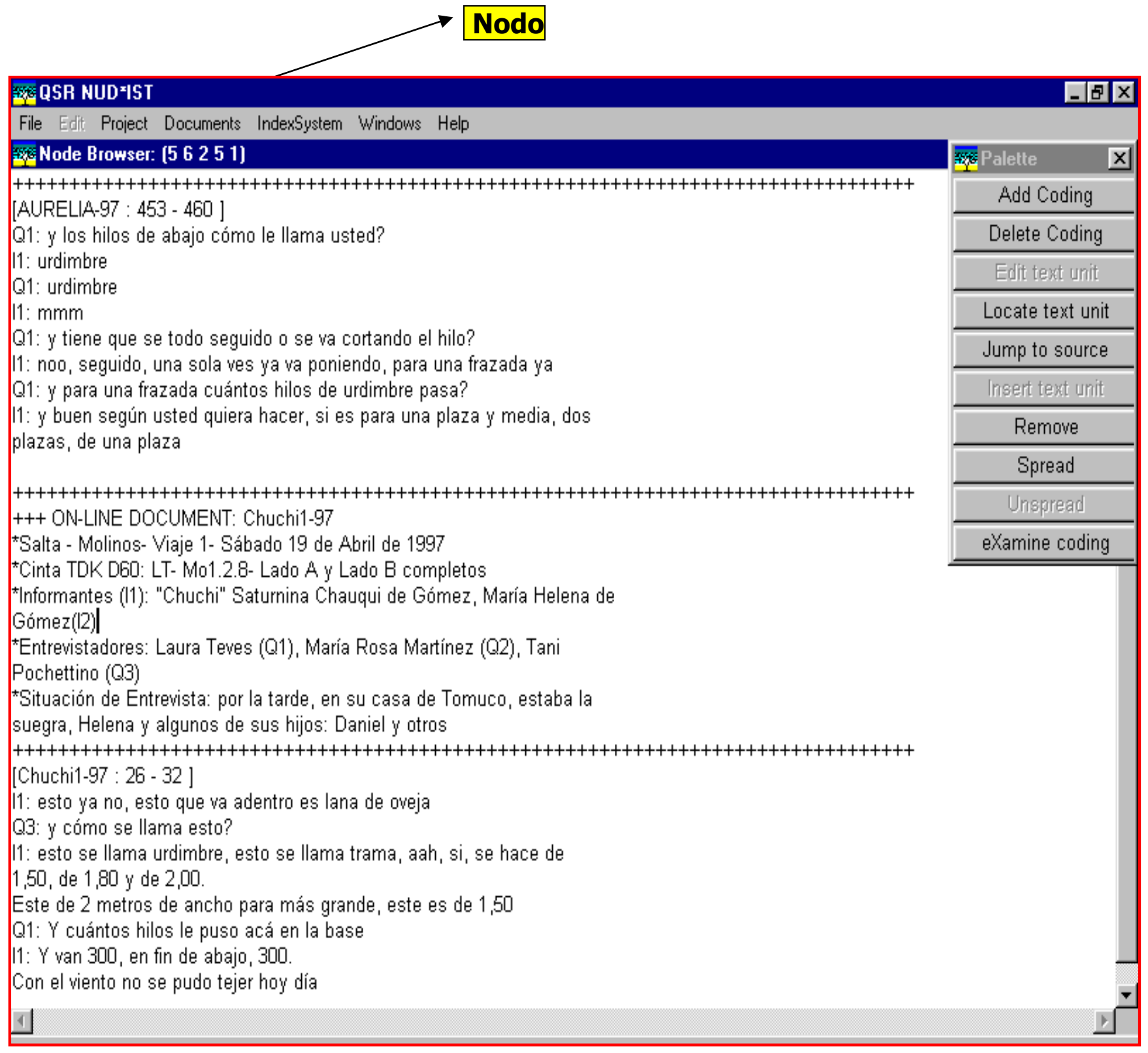


El Estudio Etnográfico de la Actividad Textil como aporte a la Caracterización del Modo de Vida en el Pueblo de Molinos y zona de influencia (Provincia de Salta)

Laura Teves

ANEXO 3.6

Anexo NUD*IST 4 - Búsqueda de Categorías en un Documento

Q.S.R. NUD.IST Power version, revision 4.0 .

PROJECT: MOLINOS - User Laura Teves - 2007

$++++++++++++++++++++++++++++++++++++++++++++++++++++++++++++++++++++++$

Búsqueda por palabra

Text search for 'tejer'

+++ Searching document Experto_3

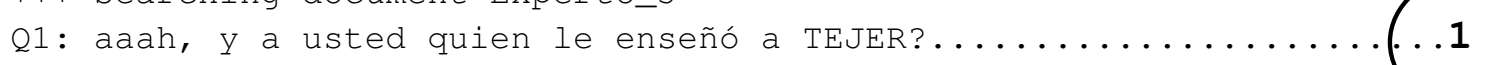

+++1 text unit out of $491,=0.20 \%$

Unidad textual

+++ Searching document Experto-2.1

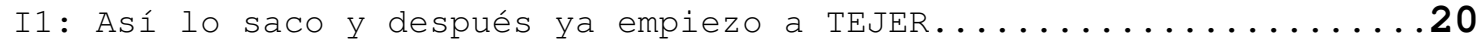

+++1 text unit out of $948,=0.11 \%$

+++ Searching document Experto_4

Nos sentamos y me hizo hilar, luego me regaló una puchinana y un vellón

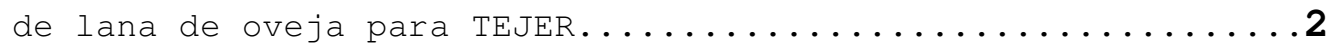

+++ Searching document Experto_1.3

+++ Searching document Experto_1.4

I2: pa' TEJER no pa' hilar........................110

1 text unit out of $527=0.19 \%$

+++ Searching document Experto_5

Porcentaje de unidades de
texto por documento para
la búsqueda de re la
categoría "tejer"

Lo hacíamos primero a mano, después lo hacíamos con la devanadora que usan para TEJER, la máquina de tejer, más rápido porque sino para ovillar, un, un kilo de hilo se necesitaba casi un día, mientras que con devanadora en una hora, en una hora se ovilla todo, entonces cada ves hay que

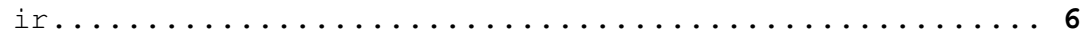

+++1 text unit out of $693,=0.14 \%$

Results of text search for 'tejer':

Total number of text units found $=14$

Finds in 14 documents out of 19 online documents, $=74 \%$ 
El Estudio Etnográfico de la Actividad Textil como aporte a la Caracterización del Modo de Vida en el Pueblo de Molinos y zona de influencia (Provincia de Salta)

Laura Teves

The online documents with finds have a total of 8633 text units, so text units found in these documents $=0.16 \%$.

The selected online documents have a total of 10139 text units, so text units

found in these documents $=0.14 \%$. 
El Estudio Etnográfico de la Actividad Textil como aporte a la Caracterización del Modo de Vida en el Pueblo de Molinos y zona de influencia (Provincia de Salta)

ANEXO 3.7

Anexo NUD*IST 4 - Índice de Documentos

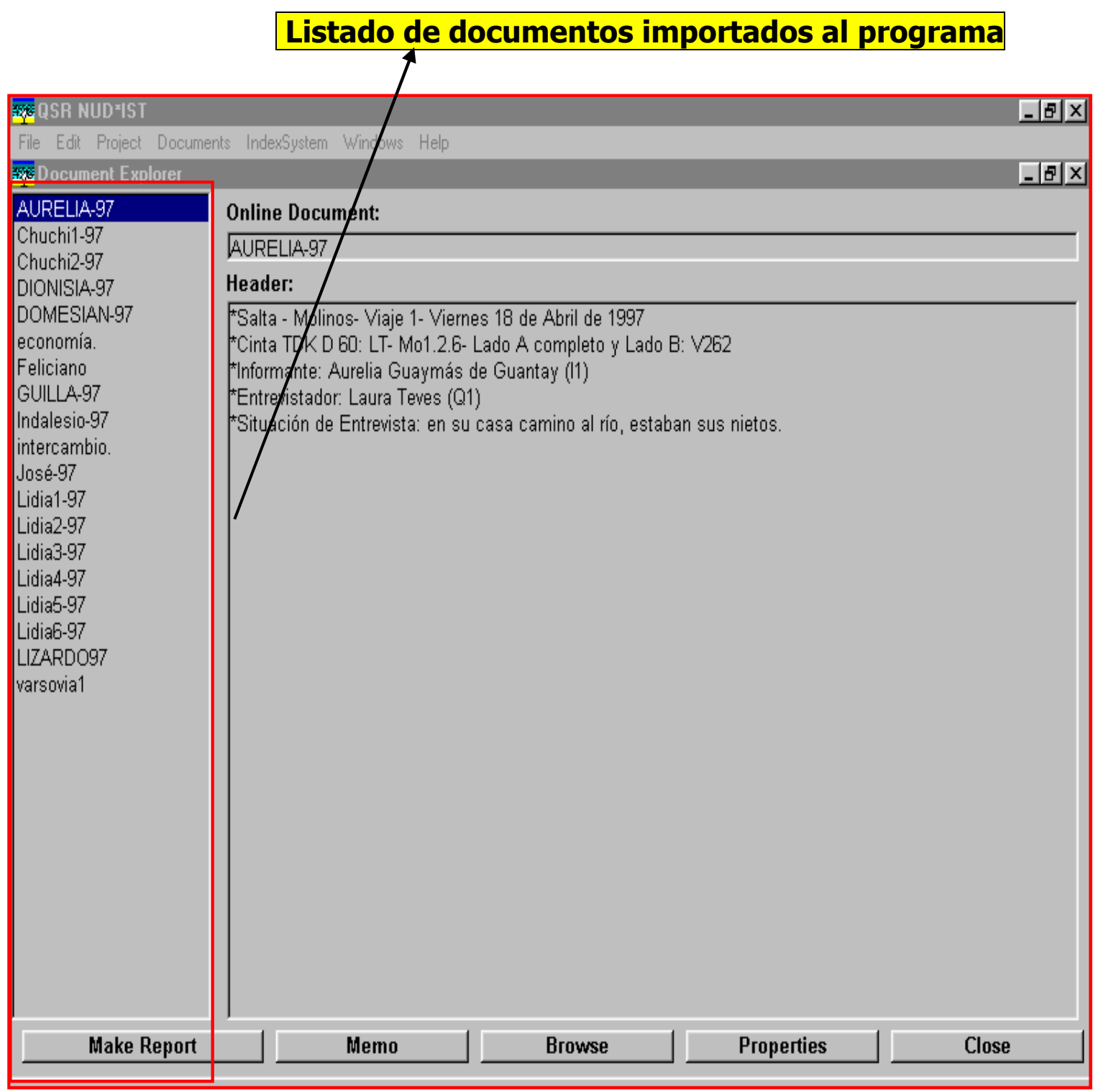


El Estudio Etnográfico de la Actividad Textil como aporte a la Caracterización del Modo de Vida en el Pueblo de Molinos y zona de influencia (Provincia de Salta)

ANEXO 3.8

\section{Anexo NUD*IST 4 - Sistema Índice o Árbol de Nodos}

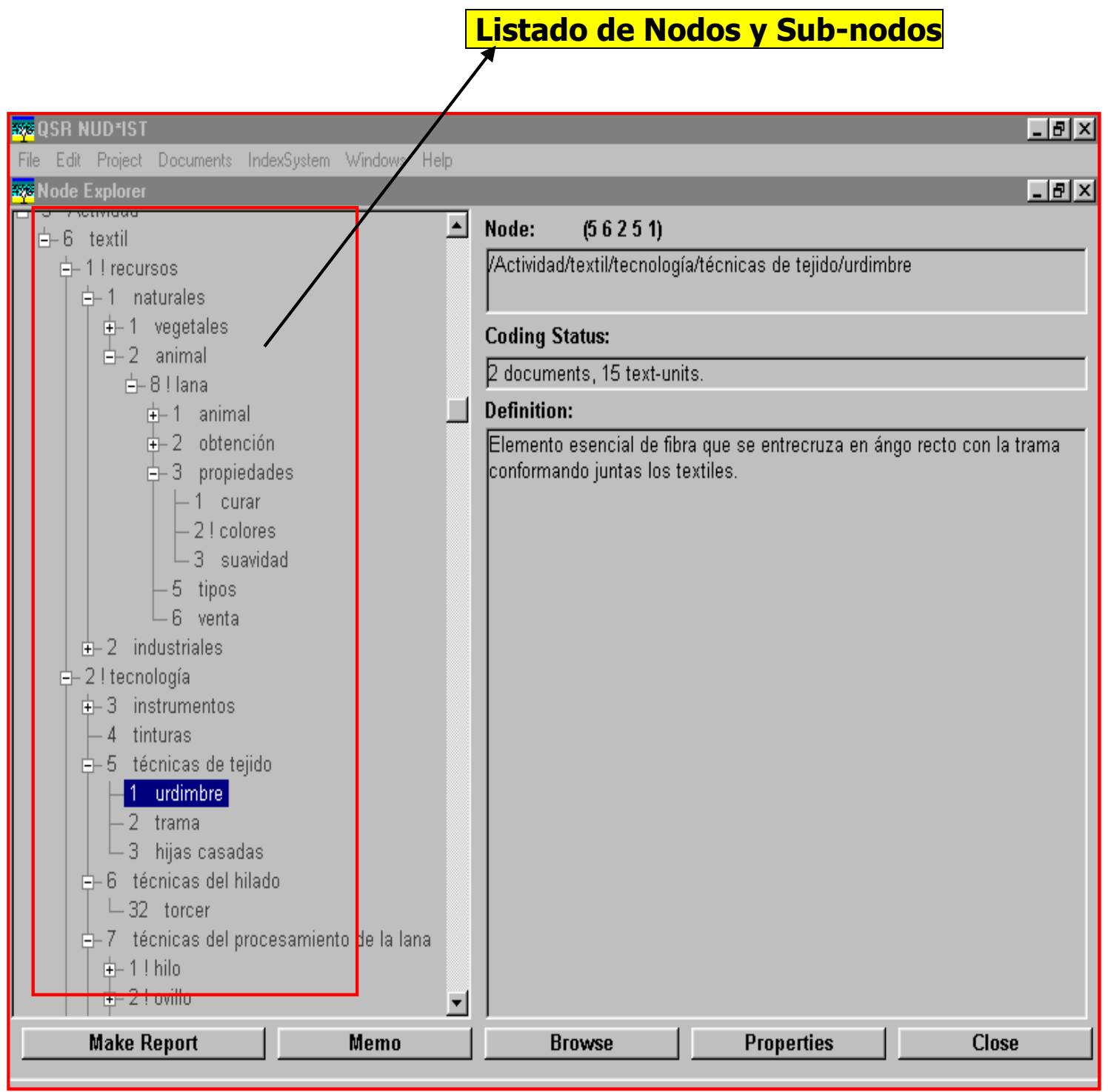


El Estudio Etnográfico de la Actividad Textil como aporte a la Caracterización del Modo de Vida en el Pueblo de Molinos y zona de influencia (Provincia de Salta)

\section{ANEXO 3.9}

Anexo NUD*IST 4 - DIAGRAMA DE ÁRBOL

Árbol Desplegado mostrando el Nodo 6 y sub-nodos asociados

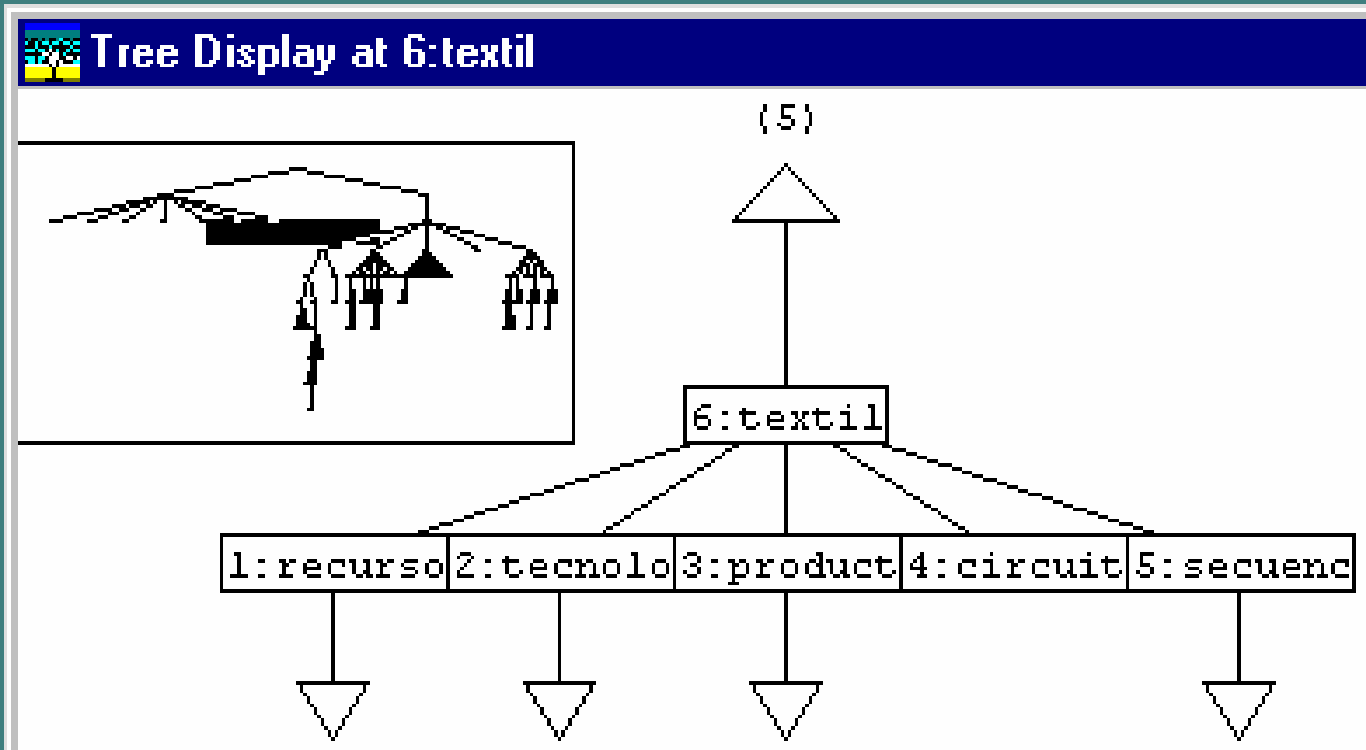




\section{Anexo Técnico 4.1: Correlación de variables relacionales y redes personales.}

La secuencia de trabajo para la obtención de las relaciones utilizadas en el análisis sería:

1- datos de entrevistas y observaciones sobre actividades

2- identificación de pares de relaciones mencionadas por un informante

3- codificación de las relaciones entre personas y armado de las 3 matrices: la red a este nivel es la de una informante con las personas que ella menciona porque establecen transacciones con ella, siendo parientes o conocidos y en un espacio. Por este motivo tenemos una red de transacciones, una de parentesco y una de localización, donde las mismas relaciones son reemplazadas de acuerdo a las variables atributivas de las personas.

4- Procesamiento en UCINET (QUAP correlation)

5- Representación gráfica con Net-draw

Redes personal de I-SCHG: Ego_red de un Informante con los alters mencionados, tipos de relaciones entabladas y frecuencias, contextos espaciales de las interacciones.

\begin{tabular}{|c|c|c|c|c|c|}
\hline $\begin{array}{l}\text { Informant } \\
\text { e (1) } \\
\text { 1- I-SCHG }\end{array}$ & Alter (2) & $\begin{array}{c}\text { Contenido de las } \\
\text { Transacciones entre } 1 \text { y } 2 \\
\text { Da----------- } \rightarrow \text { Recibe } \\
\text { Recibe }<-------- \text { Da }\end{array}$ & $\begin{array}{l}\text { Tipos de } \\
\text { transacciones } \\
\text { Cantidad de } \\
\text { transacciones }\end{array}$ & \begin{tabular}{|l} 
Relaciones \\
Parentales y \\
No \\
parentales
\end{tabular} & \begin{tabular}{|l} 
Relacione \\
s \\
espaciale \\
s
\end{tabular} \\
\hline
\end{tabular}




\begin{tabular}{|c|c|c|c|c|c|}
\hline $\begin{array}{l}1 . \\
\text { AG }\end{array}$ & $\begin{array}{l}\text { Zapallo, } \\
\text { maíz } \\
\text { Ayuda con } \\
\text { el tejido } \\
\text { Buscar } \\
\text { leña }\end{array}$ & $\begin{array}{l}\text { Semillas que le } \\
\text { traen de Salta } \\
\text { Teje } \\
\text { Ayuda a buscar } \\
\text { leña }\end{array}$ & $\begin{array}{l}\text { Intercambio } \\
\text { Cooperación } \\
\text { Cooperación } \\
3\end{array}$ & NP: Amigas & Tomuco \\
\hline \begin{tabular}{|l|} 
Herrero \\
\end{tabular} & Dinero & Peine par telar & $\begin{array}{l}\begin{array}{l}\text { Compra- } \\
\text { venta }\end{array} \\
1\end{array}$ & $\begin{array}{l}\text { NP: } \\
\text { Conocidos } \\
0\end{array}$ & $\begin{array}{l}\text { Pueblo de } \\
\text { Molinos } \\
0\end{array}$ \\
\hline $\begin{array}{l}3 . \\
\text { Señor1 }\end{array}$ & $\begin{array}{l}\text { Abono } \\
\text { para la } \\
\text { tierra } \\
\text { Chacra }\end{array}$ & $\begin{array}{l}\text { Cebolla, } \\
\text { pimiento, uvas, } \\
\text { zapallo } \\
\text { Cultivo (7ha) }\end{array}$ & $\begin{array}{l}\text { Intercambio } \\
\text { "sociedad" } \\
2\end{array}$ & \begin{tabular}{|l|}
$\begin{array}{l}\text { Pariente } \\
\text { (primo) }\end{array}$ \\
\end{tabular} & \begin{tabular}{|l} 
Las \\
Ramadas \\
Humanao \\
\\
0
\end{tabular} \\
\hline $\begin{array}{l}4 . \\
\text { Señora } 1\end{array}$ & $\begin{array}{l}\text { Cabritos } \\
\text { Queso }\end{array}$ & $\begin{array}{l}\text { Cría: agua y } \\
\text { pastaje } \\
\text { Leche } \\
\text { Nogal para } \\
\text { teñir }\end{array}$ & $\begin{array}{l}\text { Intercambio } \\
\text { "al partir" } \\
\text { "multiplico" } \\
\text { "vende al } \\
\text { gancho" } \\
\text { Encargue } \\
3\end{array}$ & \begin{tabular}{|l|}
$\begin{array}{l}\text { Pariente } \\
\text { (prima) }\end{array}$ \\
\end{tabular} & Colomé \\
\hline $\begin{array}{l}5 . \\
\text { HG }\end{array}$ & Teje & $\begin{array}{l}\text { Ayuda con el } \\
\text { hilado }\end{array}$ & $\begin{array}{l}\text { Subsistencia } \\
\text { Doméstica } \\
1\end{array}$ & \begin{tabular}{|l} 
Pariente \\
(suegra) \\
1
\end{tabular} & $\begin{array}{l}\text { Pueblo de } \\
\text { Molinos } \\
0\end{array}$ \\
\hline $\begin{array}{l}6 . \\
\text { Cuñada }\end{array}$ & $\begin{array}{l}\text { Trabajo de } \\
\text { teñido de } \\
\text { prendas }\end{array}$ & \begin{tabular}{|l|} 
Tinturas \\
industriales
\end{tabular} & $\begin{array}{l}\text { Intercambio } \\
1\end{array}$ & \begin{tabular}{|l} 
Pariente \\
1
\end{tabular} & $\begin{array}{l}\text { Salta } \\
0\end{array}$ \\
\hline \begin{tabular}{|l}
7. \\
Vecino 3
\end{tabular} & Carne & Burros & $\begin{array}{l}\text { Intercambio } \\
1\end{array}$ & $\begin{array}{l}\text { NP: Vecinos } \\
0\end{array}$ & \begin{tabular}{|l} 
Tomuco \\
1
\end{tabular} \\
\hline
\end{tabular}


El Estudio Etnográfico de la Actividad Textil como aporte a la Caracterización del Modo de Vida en el Pueblo de Molinos y zona de influencia (Provincia de Salta)

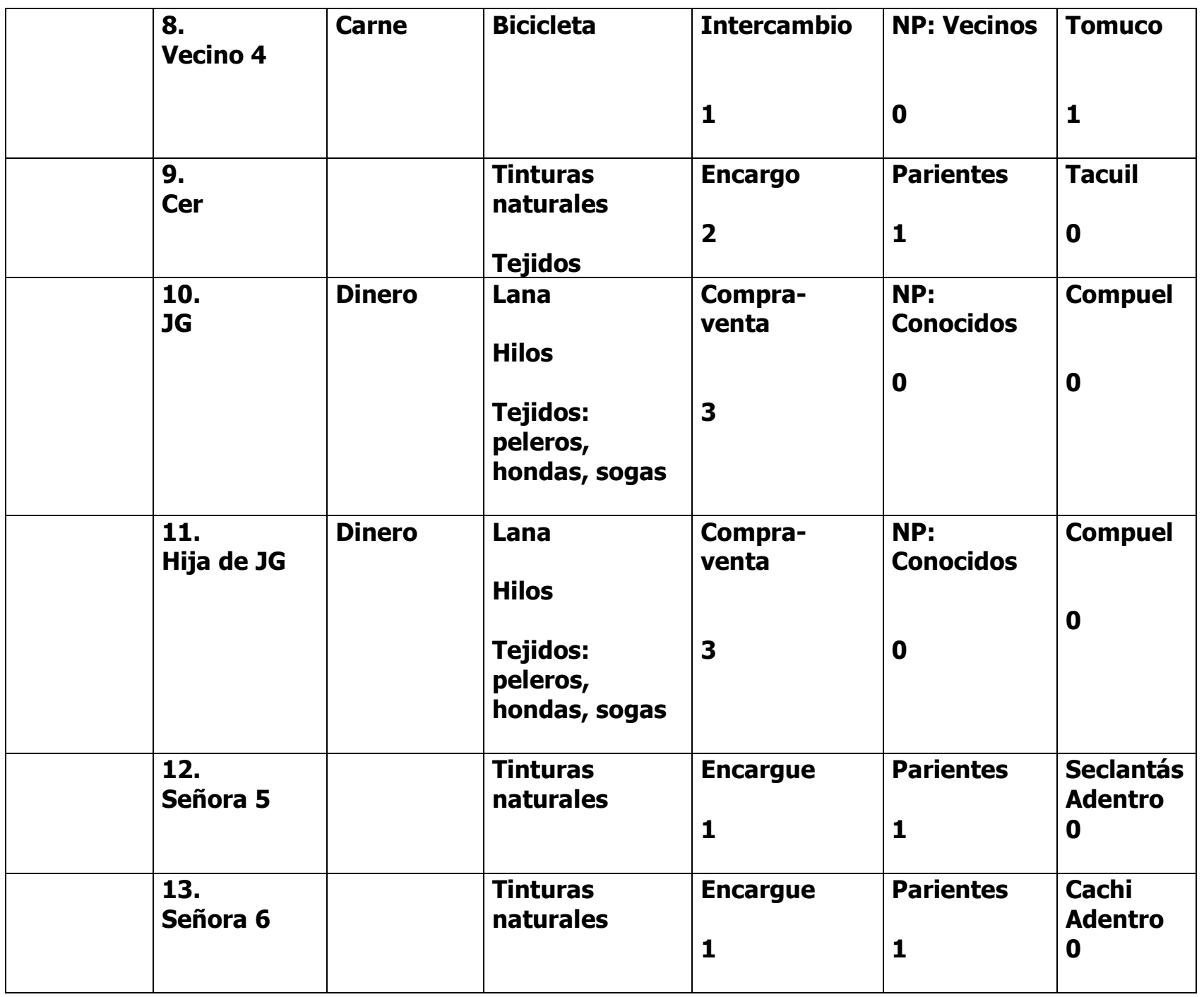




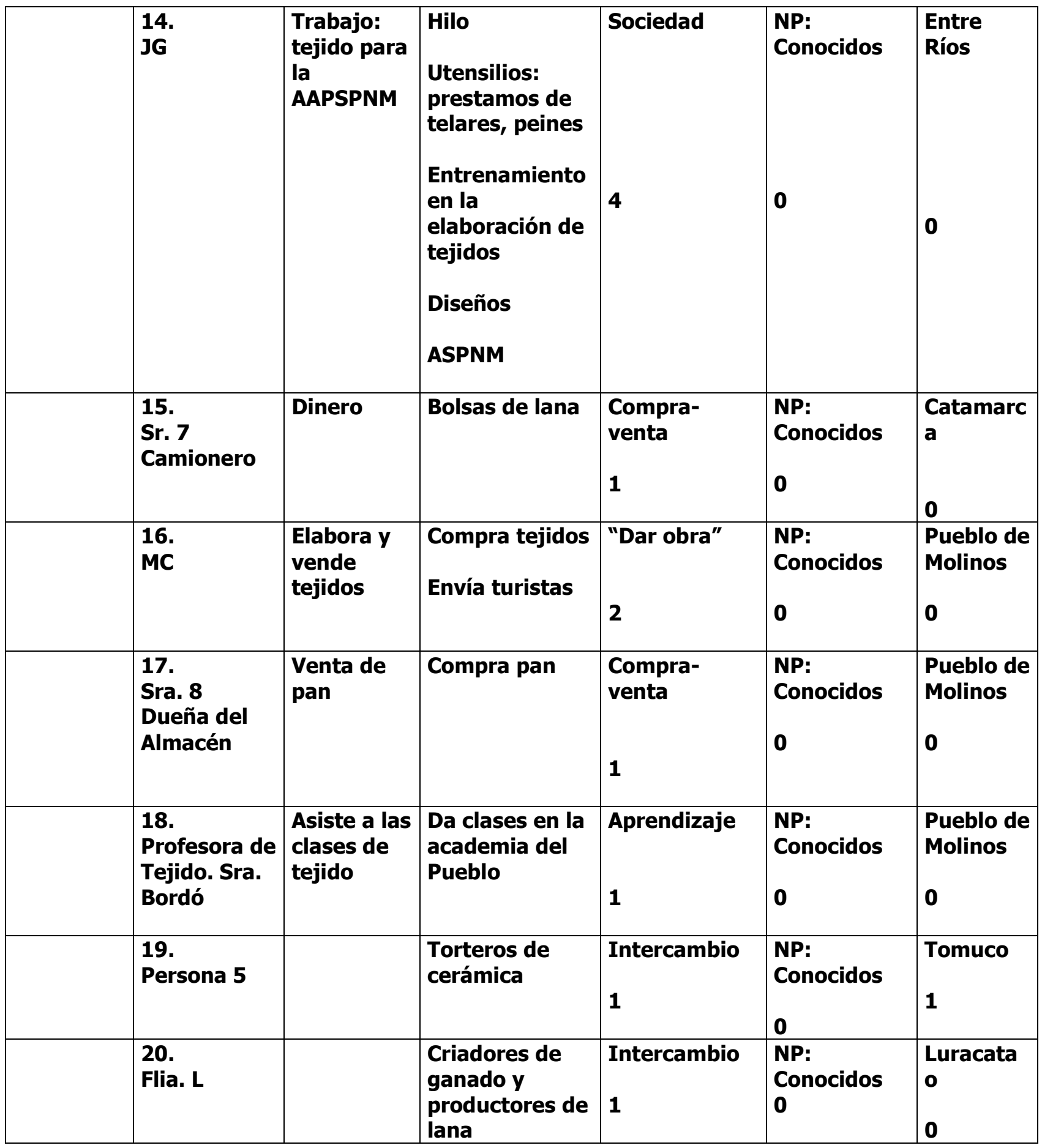




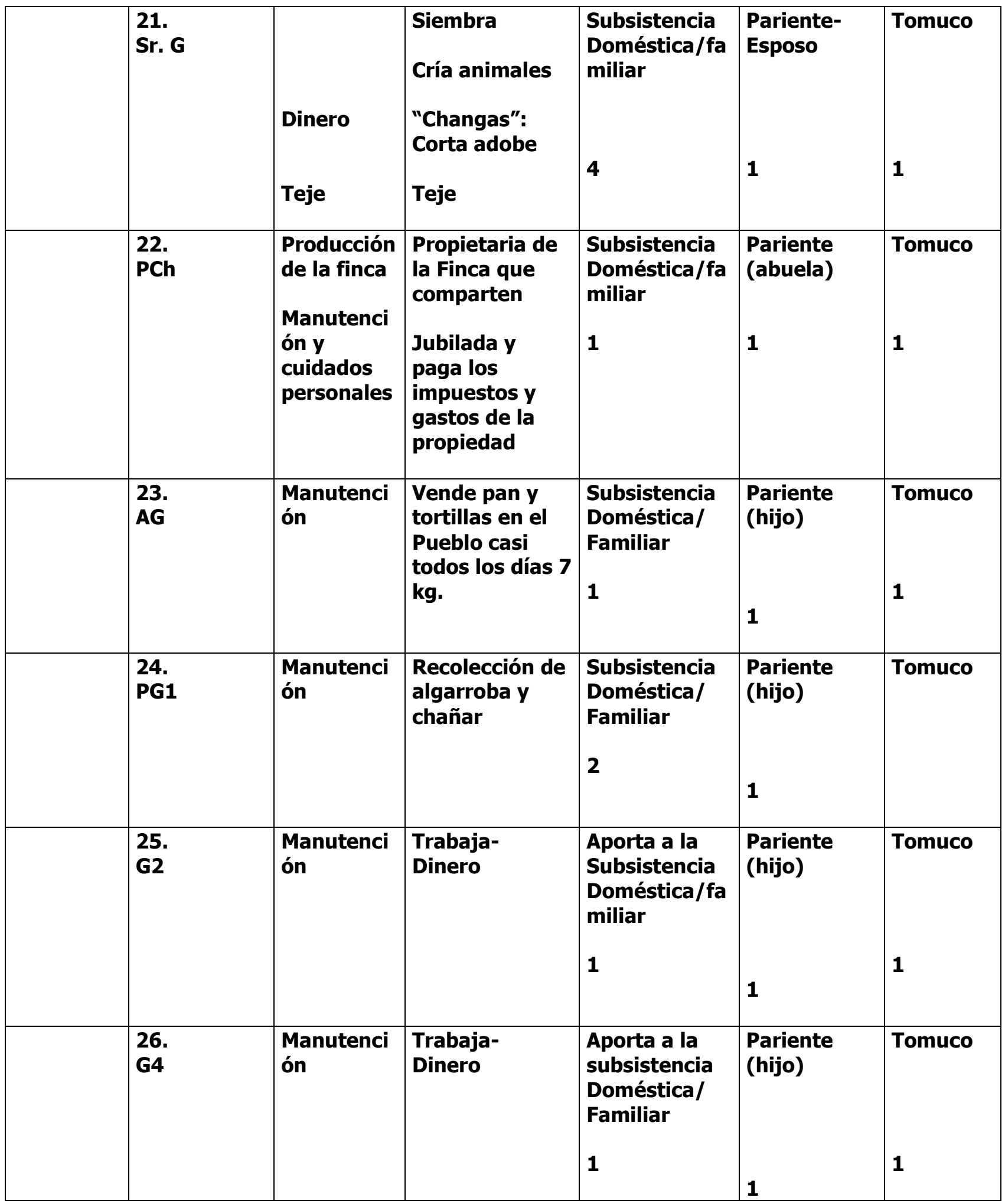


El Estudio Etnográfico de la Actividad Textil como aporte a la Caracterización del Modo de Vida en el

\begin{tabular}{|c|c|c|c|c|c|}
\hline \begin{tabular}{|l|}
26. \\
Ingeniero
\end{tabular} & & $\begin{array}{l}\text { Instalación de } \\
\text { una cisterna de } \\
\text { agua para } \\
\text { riego }\end{array}$ & 1 & $\begin{array}{l}\text { No Pariente } \\
0\end{array}$ & $\begin{array}{l}\text { Salta } \\
0\end{array}$ \\
\hline $\begin{array}{l}27 . \\
\text { Personal de } \\
\text { Salud } \\
\text { Pública }\end{array}$ & & $\begin{array}{l}\text { Instalación de } \\
\text { una cisterna de } \\
\text { agua para } \\
\text { riego }\end{array}$ & 1 & $\begin{array}{l}\text { No Pariente } \\
0\end{array}$ & $\begin{array}{l}\text { Salta } \\
0\end{array}$ \\
\hline $\begin{array}{l}28 . \\
\text { Doctor }\end{array}$ & & $\begin{array}{l}\text { Control de la } \\
\text { instalación de } \\
\text { agua }\end{array}$ & 1 & $\begin{array}{l}\text { No Pariente } \\
0\end{array}$ & $\begin{array}{l}\text { Molinos } \\
0\end{array}$ \\
\hline $\begin{array}{l}29 . \\
\text { Chica } \\
\text { empleada }\end{array}$ & & \begin{tabular}{|l|}
$\begin{array}{l}\text { Tareas } \\
\text { domésticas }\end{array}$ \\
Cuidado de \\
animales
\end{tabular} & 1 & $\begin{array}{l}\text { No Pariente } \\
0\end{array}$ & $\begin{array}{l}\text { Seclantás } \\
0\end{array}$ \\
\hline \begin{tabular}{|l|}
30. \\
Hermana
\end{tabular} & \begin{tabular}{|l|} 
Plumas de \\
suri
\end{tabular} & & 1 & $\begin{array}{l}\text { Pariente } \\
\text { (Hna.) } \\
1\end{array}$ & $\begin{array}{l}\text { Salta } \\
0\end{array}$ \\
\hline $\begin{array}{l}31 . \\
\text { CG5 }\end{array}$ & & \begin{tabular}{|l|} 
Cuidados \\
personales \\
Visitas \\
regulares
\end{tabular} & 2 & $\begin{array}{l}\text { Pariente } \\
\text { (Hija) } \\
1\end{array}$ & $\begin{array}{l}\text { Salta } \\
0\end{array}$ \\
\hline $\begin{array}{l}32 . \\
\text { PV }\end{array}$ & $\begin{array}{l}\text { Socia de la } \\
\text { AAPSPNM }\end{array}$ & $\begin{array}{l}\text { Tejedor, socio } \\
\text { de la } \\
\text { AAPSPNMr }\end{array}$ & 1 & $\begin{array}{l}\text { No Pariente: } \\
\text { Vecino } \\
0\end{array}$ & \begin{tabular}{|l} 
Tomuco \\
1
\end{tabular} \\
\hline $\begin{array}{l}33 . \\
\text { Sra. Ch }\end{array}$ & & $\begin{array}{l}\text { Le abastece de } \\
\text { plantas } \\
\text { medicinales }\end{array}$ & 1 & $\begin{array}{l}\text { NP: } \\
\text { Conocida } \\
0\end{array}$ & $\begin{array}{l}\text { Tomuco } \\
1\end{array}$ \\
\hline
\end{tabular}


El Estudio Etnográfico de la Actividad Textil como aporte a la Caracterización del Modo de Vida en el Pueblo de Molinos y zona de influencia (Provincia de Salta)

MATRIZ transacciones 35 x 35

\begin{tabular}{|c|c|c|c|c|c|c|c|c|c|c|c|c|c|c|c|c|c|c|c|c|c|c|c|c|c|c|c|c|c|c|c|c|c|c|c|c|}
\hline & 1 & 2 & 36 & 3 & 4 & 5 & 6 & 7 & 8 & 9 & 10 & 11 & 12 & 13 & 14 & 15 & 16 & 17 & 18 & 19 & 20 & 21 & 22 & 23 & 24 & 25 & 26 & 27 & 28 & 29 & 30 & 31 & 32 & 33 & 34 & 35 \\
\hline 1 & & 3 & & 1 & 2 & 3 & 1 & 1 & 1 & 1 & & 1 & 3 & & & 4 & 1 & 2 & 1 & 1 & & & 4 & 1 & 1 & 2 & 1 & 1 & & & & 1 & 1 & & & \\
\hline 2 & 3 & & & & & & & & & & & & & & & & & & & 1 & & & & & & & & & & & & & & & & \\
\hline 36 & & 1 & & & & & & & & & & & & & & & & & & & & & & & & & & & & & & & & & & \\
\hline 3 & 1 & & & & & & & & & & & & & & & & & & & & & & & & & & & & & & & & & & & \\
\hline 4 & 2 & & & & & & & & & & & & & & & & & & & & & & & & & & & & & & & & & & & \\
\hline 5 & 3 & & & & & & & & & & & & & & & & & & & & & & & & & & & & & & & & & & & \\
\hline 6 & 1 & & & & & & & & & & & & & & & & & & & & & & & & & & & & & & & & & & & \\
\hline 7 & 1 & & & & & & & & & & & & & & & & & & & & & & & & & & & & & & & & & & & \\
\hline 8 & 1 & & & & & & & & & & & & & & & & & & & & & & & & & & & & & & & & & & & \\
\hline 9 & 1 & & & & & & & & & & & & & & & & & & & & & & & & & & & & & & & & & & & \\
\hline 10 & 2 & & & & & & & & & & & & & & & & & & & & & & & & & & & & & & & & & & & \\
\hline 11 & 3 & & & & & & & & & & & & 1 & & & & & & & & & & & & & & & & & & & & & & & \\
\hline 12 & 3 & & & & & & & & & & & 1 & & & & & & & & & & & & & & & & & & & & & & & & \\
\hline 13 & 1 & & & & & & & & & & & & & & & & & & & & & & & & & & & & & & & & & & & \\
\hline 14 & 1 & & & & & & & & & & & & & & & & & & & & & & & & & & & & & & & & & & & \\
\hline 15 & 4 & & & & & & & & & & & & & & & & 1 & & & & & 1 & & & & & & & & & & & & & & \\
\hline 16 & 1 & & & & & & & & & & & & & & & 1 & & & & & & & & & & & & & & & & & & & & \\
\hline 17 & 2 & & & & & & & & & & & & & & & & & & & & & & & & & & & & & & & & & & & \\
\hline 18 & 1 & & & & & & & & & & & 1 & 1 & & & & & & & & & & & & & & & & & & & & & & & \\
\hline 19 & 1 & 1 & & & & & & & & & & & & & & & & & & & & & & & & & & & & & & & & & & \\
\hline 20 & 1 & & & & & & & & & & & & & & & & & & & & & & & & & & & & & & & & & & & \\
\hline 21 & 1 & & & & & & & & & & & & & & & 1 & & & & & & & & & & & & & & & & & & & & \\
\hline 22 & 4 & & & & & & & & & & & & & & & & & & & & & & & 1 & 1 & 1 & 1 & 1 & & & & & & 1 & & \\
\hline 23 & 1 & & & & & & & & & & & & & & & & & & & & & & 1 & & 1 & 1 & 1 & 1 & & & & & & 1 & & \\
\hline 24 & 1 & & & & & & & & & & & & & & & & & & & & & & 1 & 1 & & 1 & 1 & 1 & & & & & & 1 & & \\
\hline 25 & 2 & & & & & & & & & & & & & & & & & & & & & & 1 & 1 & 1 & & 1 & 1 & & & & & & 1 & & \\
\hline 26 & 1 & & & & & & & & & & & & & & & & & & & & & & 1 & 1 & 1 & 1 & & 1 & & & & & & 1 & & \\
\hline 27 & 1 & & & & & & & & & & & & & & & & & & & & & & 1 & 1 & 1 & 1 & 1 & & & & & & & 1 & & \\
\hline 28 & 1 & & & & & & & & & & & & & & & & & & & & & & & & & & & & & 1 & 1 & & & & & \\
\hline 29 & 1 & & & & & & & & & & & & & & & & & & & & & & & & & & & & 1 & & 1 & & & & & \\
\hline 30 & 1 & & & & & & & & & & & & & & & & & & & & & & & & & & & & 1 & 1 & & & & & & \\
\hline 31 & 1 & & & & & & & & & & & & & & & & & & & & & & & & & & & & & & & & & & & \\
\hline 32 & 1 & & & & & & & & & & & & & & & & & & & & & & & & & & & & & & & & & & & \\
\hline 33 & 2 & & & & & & & & & & & & & & & & & & & & & & & & & & & & & & & & & & & \\
\hline 34 & 1 & & & & & & & & & & & & & & & & & & & & & & & & & & & & & & & & & & & \\
\hline 35 & 1 & & & & & & & & & & & & & & & & & & & & & & & & & & & & & & & & & & & 0 \\
\hline
\end{tabular}


El Estudio Etnográfico de la Actividad Textil como aporte a la Caracterización del Modo de Vida en el Pueblo de Molinos y zona de influencia (Provincia de Salta)

Matriz parientes $35 \times 35$

\begin{tabular}{|c|c|c|c|c|c|c|c|c|c|c|c|c|c|c|c|c|c|c|c|c|c|c|c|c|c|c|c|c|c|c|c|c|c|c|c|c|}
\hline & 1 & 2 & 36 & 3 & \begin{tabular}{|l|}
4 \\
\end{tabular} & 5 & 6 & 7 & \begin{tabular}{|l|}
8 \\
\end{tabular} & \begin{tabular}{|l|}
9 \\
\end{tabular} & \begin{tabular}{|l|}
10 \\
\end{tabular} & \begin{tabular}{|l|}
11 \\
\end{tabular} & 12 & \begin{tabular}{|l|}
13 \\
\end{tabular} & \begin{tabular}{|l|}
14 \\
\end{tabular} & 15 & 16 & 17 & \begin{tabular}{l|l}
18 \\
\end{tabular} & \begin{tabular}{|l|}
19 \\
\end{tabular} & 20 & 21 & 22 & 23 & 24 & 25 & 26 & 27 & 28 & 29 & 30 & 31 & 32 & 33 & 34 & 35 \\
\hline 1 & & & & & \begin{tabular}{|l|}
1 \\
\end{tabular} & \begin{tabular}{|l|}
1 \\
\end{tabular} & 1 & 1 & & & 1 & & & 1 & 1 & & & & & & & & 1 & 1 & 1 & 1 & 1 & \begin{tabular}{|l|}
1 \\
\end{tabular} & & & & & \begin{tabular}{|l|}
1 \\
\end{tabular} & 1 & & \\
\hline 2 & & & \begin{tabular}{l|}
1 \\
\end{tabular} & & & & & & & & & & & & & & & & & 1 & & & & & & & & & & & & & & & & \\
\hline 36 & & \begin{tabular}{|l|}
1 \\
\end{tabular} & & & & & & & & & & & & & & & & & & & & & & & & & & & & & & & & & & \\
\hline 3 & & & & & & & & & & & & & & & & & & & & & & & & & & & & & & & & & & & & \\
\hline 4 & 1 & & & & & & & & & & & & & & & & & & & & & & & & & & & & & & & & & & & \\
\hline 5 & 1 & & & & & & & & & & & & & & & & & & & & & & & & & & & & & & & & & & & \\
\hline 6 & 1 & & & & & & & & & & & & & & & & & & & & & & 1 & 1 & 1 & 1 & 1 & 1 & & & & & & 1 & & \\
\hline 7 & 1 & & & & & & & & & & & & & & & & & & & & & & & & & & & & & & & & & & & \\
\hline 8 & & & & & & & & & & & & & & & & & & & & & & & & . & . & . & . & & & & & & & & & \\
\hline 9 & & & & & & & & & & & & & & & & & & & & & & & & & & & & & & & & & & & & \\
\hline 10 & 1 & & & & & & & & & & & & & & & & & & & & & & & & & & & & & & & & & & & \\
\hline 11 & & & & & & & & & & & & & \begin{tabular}{|l|}
1 \\
\end{tabular} & & & & & & & & & & & & & & & & & & & & & & & \\
\hline 12 & & & & & & & & & & & & $\begin{array}{ll}1 \\
\end{array}$ & & & & & & & & & & & & & & & & & & & & & & & & \\
\hline 13 & 1 & & & & & & & & & & & & & & & & & & & & & & & & & & & & & & & & & & & \\
\hline 14 & 1 & & & & & & & & & & & & & & & & & & & & & & & & & & & & & & & & & & & \\
\hline 15 & & & & & & & & & & & & & & & & & & & & & & 1 & & & & & . & 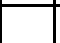 & & & & & & & & \\
\hline 16 & & & & & & & & & & & & & & & & & & & & & & & & & & & & & & & & & & & & \\
\hline \begin{tabular}{|l|}
17 \\
\end{tabular} & & & & & & & & & & & & & & & & & & & & & & & & & & & & & & & & & & & & \\
\hline 18 & & & & & & & & & & & & & & & & & & & & & & & & & & & & & & & & & & & & \\
\hline 19 & & & & & & & & & & & & & & & & & & & & & & & & & & & & & & & & & & & & \\
\hline 20 & & & & & & & & & & & & & & & & & & & & & & & & & & & & & & & & & & & & \\
\hline 21 & & & & & & & & & & & & & & & & \begin{tabular}{|l|}
1 \\
\end{tabular} & & & & & & & & & . & . & . & & & & & & & & & \\
\hline 22 & 1 & & & & & & 1 & & & & & & & & & & & & & & & & & . & \begin{tabular}{|l|}
1 \\
\end{tabular} & 1 & 1 & 1 & 1 & & & & & & \begin{tabular}{|l|}
1 \\
\end{tabular} & \\
\hline 23 & 1 & & & & & & 1 & & & & & & & & & & & & & & & & & 1 & & 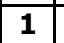 & 1 & 1 & 1 & & & & & & \begin{tabular}{|l|}
1 \\
\end{tabular} & \\
\hline 24 & 1 & & & & & & 1 & & & & & & & & & & & & & & & & & 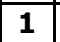 & \begin{tabular}{|l|}
1 \\
\end{tabular} & & 1 & 1 & 1 & & & & & & \begin{tabular}{|l|}
1 \\
\end{tabular} & \\
\hline 25 & 1 & & & & & & 1 & & & & & & & & & & & & & & & & & \begin{tabular}{|l|l}
1 \\
\end{tabular} & \begin{tabular}{l|}
1 \\
\end{tabular} & \begin{tabular}{|l|l}
1 \\
\end{tabular} & & 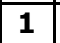 & 1 & & & & & & \begin{tabular}{|l|}
1 \\
\end{tabular} & \\
\hline 26 & 1 & & & & & & 1 & & & & & & & & & & & & & & & & & \begin{tabular}{|l|}
1 \\
\end{tabular} & 1 & \begin{tabular}{|l}
1 \\
\end{tabular} & 1 & . & 1 & & & & & & 1 & \\
\hline 27 & 1 & & & & & & 1 & & & & & & & & & & & & & & & & & \begin{tabular}{|l|}
1 \\
\end{tabular} & 1 & 1 & 1 & $1 \mathbf{1}$ & & & & & & & \begin{tabular}{|l|}
1 \\
\end{tabular} & \\
\hline 28 & & & & & & & & & & & & & & & & & & & & & & & & & & & & & & & & & & & & \\
\hline 29 & & & & & & & & & & & & & & & & & & & & & & & & & & & & & & & & & & & & \\
\hline 30 & & & & & & & & & & & & & & & & & & & & & & & & & & & & & & & & & & & & \\
\hline 31 & & & & & & & & & & & & & & & & & & & & & & & & & & & & & & & & & & & & \\
\hline 32 & 1 & & & & & & & & & & & & & & & & & & & & & & & & & & & & & & & & & & & \\
\hline 33 & 1 & & & & & & 1 & & & & & & & & & & & & & & & & & & & & & & & & & & & & & \\
\hline 34 & & & & & & & & & & & & & & & & & & & & & & & & & & & & & & & & & & & & \\
\hline 35 & & & & & & & & & & & & & & & & & & & & & & & & & & & & & & & & & & & & 0 \\
\hline
\end{tabular}


El Estudio Etnográfico de la Actividad Textil como aporte a la Caracterización del Modo de Vida en el Pueblo de Molinos y zona de influencia (Provincia de Salta)

Matriz lugares 35 x 35

\begin{tabular}{|c|c|c|c|c|c|c|c|c|c|c|c|c|c|c|c|c|c|c|c|c|c|c|c|c|c|c|c|c|c|c|c|c|c|c|c|c|}
\hline & 1 & 2 & 36 & 3 & \begin{tabular}{|l|}
4 \\
\end{tabular} & 5 & 6 & 7 & 8 & 9 & 10 & \begin{tabular}{|l|}
11 \\
\end{tabular} & 12 & 13 & \begin{tabular}{|l|}
14 \\
\end{tabular} & 15 & 16 & \begin{tabular}{|l|}
17 \\
\end{tabular} & \begin{tabular}{|l|}
18 \\
\end{tabular} & 19 & 20 & \begin{tabular}{|l|}
21 \\
\end{tabular} & 22 & 23 & 24 & 25 & 26 & 27 & 28 & 29 & \begin{tabular}{l|l}
30 & 3 \\
\end{tabular} & \begin{tabular}{l|l}
31 & 3 \\
\end{tabular} & \begin{tabular}{l|l}
32 & 3 \\
\end{tabular} & \begin{tabular}{|l|l}
33 & 3 \\
\end{tabular} & \begin{tabular}{l|l}
34 & 3 \\
\end{tabular} & 35 \\
\hline 1 & & 1 & & & & & & & 1 & 1 & & & & & & & & & & & 1 & & 1 & \begin{tabular}{|l|}
1 \\
\end{tabular} & \begin{tabular}{|l|}
1 \\
\end{tabular} & 1 & 1 & 1 & & & & & & & \begin{tabular}{l|l}
1 & 1
\end{tabular} & 1 \\
\hline 2 & 1 & & & & & & & & & & & & & & & & & & & & & & & & & & & & & & & & & & & \\
\hline 36 & & & & & & & & & & & & & & & & & & & & & & & & & . & . & . & & & & & & & & & \\
\hline 3 & & & & & & & & & & & & & & & & & & & & & & & & & & & & & & & & & & & & \\
\hline 4 & & & & & & & & & & & & & & & & & & & & & & & & & & & & & & & & & & & & \\
\hline 5 & & & & & & & & & & & & & & & & & & & & & & & & & & & & & & & & & & & & \\
\hline 6 & & & & & & & & & & & & & & & & & & & & & & & & & & & & & & & & & & & & \\
\hline 7 & & & & & & & & & & & & & & & & & & & & & & & & & & & & & & & & & & & & \\
\hline 8 & 1 & & & & & & & & & & & & & & & & & & & & & & & & & & & & & & & & & & & \\
\hline 9 & 1 & & & & & & & & & & & & & & & & & & & & & & & & & & & & & & & & & & & \\
\hline 10 & & & & & & & & & & & & & & & & & & & & & & & & & & & & & & & & & & & & \\
\hline 11 & & & & & & & & & & & & & & & & & & & & & & & & & & & & & & & & & & & & \\
\hline 12 & & & & & & & & & & & & & & & & & & & & & & & & & & & & & & & & & & & & \\
\hline 13 & & & & & & & & & & & & & & & & & & & & & & & & & & & & & & & & & & & & \\
\hline 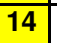 & & & & & & & & & & & & & & & & & & & & & & & & & & & & & & & & & & & & \\
\hline 15 & & & & & & & & & & & & & & & & & & & & & & & & & & & & & & & & & & & & \\
\hline 16 & & & & & & & & & & & & & & & & & & & & & & & & & & & & & & & & & & & & \\
\hline 17 & & & & & & & & & & & & & & & & & & & & & & & & & & & & & & & & & & & & \\
\hline 18 & & & & & & & & & & & & & & & & & & & & & & & & & & & & & & & & & & & & \\
\hline 19 & & & & & & & & & & & & & & & & & & & & & & & & & & & & & & & & & & & & \\
\hline 20 & 1 & & & & & & & & & & & & & & & & & & & & & & & & & & & & & & & & & & & \\
\hline 21 & & & & & & & & & & & & & & & & & & & & & & & & & & & . & & & & & & & & & \\
\hline 22 & 1 & & & & & & & & & & & & & & & & & & & & & & & . & 1 & 1 & 1 & 1 & 1 & & & & & & & \\
\hline 23 & 1 & & & & & & & & & & & & & & & & & & & & & & & 1 & & 1 & 1 & 1 & 1 & & & & & & & \\
\hline 24 & 1 & & & & & & & & & & & & & & & & & & & & & & & 1 & 1 & . & 1 & 1 & 1 & & & & & & & \\
\hline 25 & 1 & & & & & & & & & & & & & & & & & & & & & & & 1 & 1 & 1 & & 1 & 1 & & & & & & & \\
\hline 26 & \begin{tabular}{l|l}
1 \\
\end{tabular} & & & & & & & & & & & & & & & & & & & & & & & 1 & 1 & 1 & 1 & . & 1 & & & & & & & \\
\hline 27 & 1 & & & & & & & & & & & & & & & & & & & & & & & 1 & 1 & 1 & 1 & 1 & & & & & & & & \\
\hline 28 & & & & & & & & & & & & & & & & & & & & & & & & & & & & & & & & & & & & \\
\hline 29 & & & & & & & & & & & & & & & & & & & & & & & & & & & & & & & & & & & & \\
\hline 30 & & & & & & & & & & & & & & & & & & & & & & & & & & & & & & & & & & & & \\
\hline 31 & & & & & & & & & & & & & & & & & & & & & & & & & & & & & & & & & & & & \\
\hline 32 & & & & & & & & & & & & & & & & & & & & & & & & & & & & & & & & & & & & \\
\hline 33 & & & & & & & & & & & & & & & & & & & & & & & & & & & & & & & & & & & & \\
\hline 34 & 1 & & & & & & & & & & & & & & & & & & & & & & & & & & & & & & & & & & & \\
\hline 35 & 1 & & & & & & & & & & & & & & & & & & & & & & & & & & & & & & & & & & & 0 \\
\hline
\end{tabular}


En las filas de cada matriz van los nombres codificados de los Alters (II-SI; II_CH; II-SG....) y en las columnas de la matriz van los datos sobre las transacciones.

En otra matriz van los datos sobre el parentesco $(1=$ presencia de relación parental, $0=$ ausencia de relación parental).

La tercer matriz se construye para las localidades, en la filas van los códigos de los Alters y en las columnas los lugares donde se hacen las transacciones ( $1=$ Tomuco, lugar donde vive la informante y $0=$ todos los demás lugares mencionados).

Luego, existe un mecanismo que se llama de QAP que permite superponer estas matrices, es decir, el programa hace correr los datos y los compara para buscar correlaciones. El procedimiento viene bien en este caso porque a mi me interesa saber si dónde hay transacciones hay parientes y si todas las transacciones se hacen en Tomuco, es decir en el lugar de residencia de EGO. Finalmente, mostraremos que el cálculo dice que no hay correlación entre transacción, parientes y lugar de residencia. Podemos decir entonces que se confirma que la red de transacciones no se restringe solamente al entorno de las relaciones que se dan en la unidad doméstica (en el sentido que la hemos definido). 
El Estudio Etnográfico de la Actividad Textil como aporte a la Caracterización del Modo de Vida en el Pueblo de Molinos y zona de influencia (Provincia de Salta)

Laura Teves

\section{Análisis en UCINET6}

TOOLS > STATISTICS > MATRIX (QAP) > QAP-CORRELATION

Se correlacionan la Matriz de transacciones (transa2-dicotm) con la Matriz de espacios (lugar1). El valor que resulta de la Correlación de Pearson de 0.534. Como el nivel típico es 0.05 , entonces esta correlación no es considerada significativa ya que $0.534>0.05$.

En segundo lugar se correlacionan la Matriz de transacciones (transa2-dicotm) con la Matriz de parentesco (pariente1) obteniéndose un valor de la Correlación de Pearson de 0.511. Este valor es > 0.05, lo que indica que no hay correlación entre la matrices.

\section{QAP MATRIX CORRELATION}

$\begin{array}{ll}\text { Observed matrix: } & \text { transa2-dicotom } \\ \text { Structure matrix: } & \text { lugar1 } \\ \text { \# of Permutations: } & 2500 \\ \text { Random seed: } & 151\end{array}$

Univariate statistics

$\begin{array}{rrrr} & & 1 & 2 \\ & & \text { transa2- } & \text { lugar1 } \\ & & ------ & ------- \\ 1 & \text { Mean } & 0.087 & 0.039 \\ 2 & \text { Std Dev } & 0.282 & 0.193 \\ 3 & \text { Sum } & 110.000 & 49.000 \\ 4 & \text { Variance } & 0.080 & 0.037 \\ 5 & \text { SSQ } & 110.000 & 49.000 \\ 6 & \text { MCSSQ } & 100.397 & 47.094 \\ 7 & \text { Euc Norm } & 10.488 & 7.000 \\ 8 & \text { Minimum } & 0.000 & 0.000 \\ 9 & \text { Maximum } & 1.000 & 1.000 \\ 10 & \text { N of Obs } & 1260.000 & 1260.000\end{array}$

Hubert's gamma: 41.000

Bivariate Statistics

\begin{tabular}{|c|c|c|c|c|c|c|}
\hline & 1 & 2 & 3 & 4 & 5 & 6 \\
\hline NPorm & Value & Signif & Avg & SD & P (Large) & $\mathrm{P}(\mathrm{Small})$ \\
\hline & & & & & & \\
\hline $\begin{array}{l}1 \text { Pearson Correlation: } \\
2500.000\end{array}$ & 0.534 & 0.000 & -0.000 & 0.065 & 0.000 & 1.000 \\
\hline $\begin{array}{c}2 \\
2500.000\end{array}$ Simple Matching: & 0.939 & 0.000 & 0.880 & 0.019 & 0.000 & 1.000 \\
\hline $\begin{array}{l}3 \text { Jaccard Coefficient: } \\
2500.000\end{array}$ & 0.347 & 0.000 & 0.029 & 0.031 & 0.000 & 1.000 \\
\hline $\begin{array}{l}4 \text { Goodman-Kruskal Gamma: } \\
2500.000\end{array}$ & 0.977 & 0.000 & -0.215 & 0.524 & 0.000 & 1.000 \\
\hline
\end{tabular}


El Estudio Etnográfico de la Actividad Textil como aporte a la Caracterización del Modo de Vida en el Pueblo de Molinos y zona de influencia (Provincia de Salta)

Laura Teves

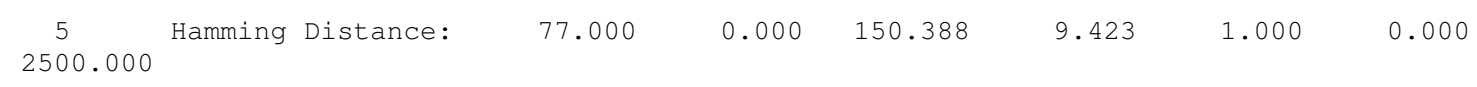

Running time: 00:00:01

Output generated: 24 Jun $1014: 48: 34$

Copyright (c) 1999-2004 Analytic Technologies

QAP MATRIX CORRELATION

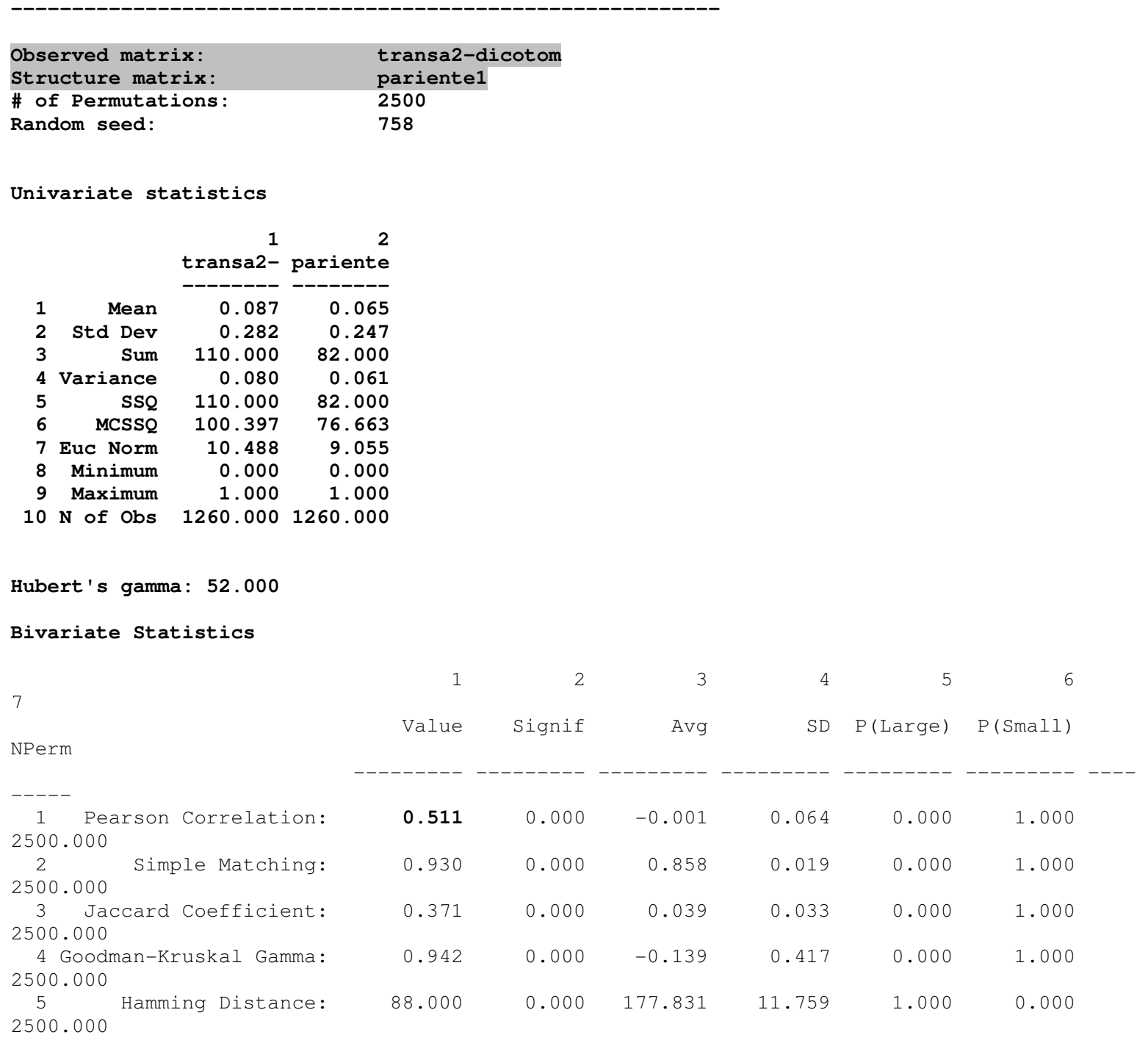

Running time: 00:00:01

Output generated: 24 Jun $1014: 47: 25$

Copyright (c) 1999-2004 Analytic Technologies 
El Estudio Etnográfico de la Actividad Textil como aporte a la Caracterización del Modo de Vida en el Pueblo de Molinos y zona de influencia (Provincia de Salta)

Laura Teves

\section{Correlación QAP}

\section{TOOLS > STATISTICS > MATRIX (QAP) > QAP-CORRELATION}

PROPósito Computa la correlación y otras medidas similares entre las entradas de 2 matrices cuadradas, y accede a la frecuencia de medidas a azar tan amplias como las actuales observadas.

DESCRIPCIÓN El procedimiento es principalmente utilizado para testear la asociación entre redes. Con frecuencia, una red es la red observada y la otra es una red modelo o red standard.

El algoritmo procede en dos pasos. En el primer paso, computa el coeficiente de correlación de Pearson (matching más simple, Jaccard, Goodman Kruskal Gamma and Hamming distance) entre células correspondientes a las dos matrices de datos. En el segundo paso, permuta al azar filas y columnas (sincrónicamente) de una matriz (la matriz observada, si la distinción es relevante) y vuelve a computar la correlación y otras medidas.

El segundo paso es corrido cientos de veces en orden a computar la proporción de veces que una medida al azar es tan amplia o igual a la medida observada y calculada en el paso 1. Una proporción baja (<0.05)sugiere una fuerte relación entre las matrices que parecen tener ocurra probablemente.

\section{PARAMETROS}

Matriz de datos: Nombre de la base de datos conteniendo la primer matriz (la observada o matriz dependiente, si tales distinciones son significativas. Tipo de datos: Matriz cuadrada.

\section{Matriz Estructura:}

Nombre de la base datos conteniendo la matriz independiente, modelo o standard (si tales distinciones son signmificativas). Tipo de datos: Matriz Cuadrada.

Número de permutaciones al azar: (Defecto = 500)

Número de correlaciones to compute between the data matrix and the randomly permuted structure matrix. The larger the number of permutations, the better the estimates of 
El Estudio Etnográfico de la Actividad Textil como aporte a la Caracterización del Modo de Vida en el Pueblo de Molinos y zona de influencia (Provincia de Salta)

Laura Teves

standard error and "significance", but the longer the computation time.

Treat diagonals as valid? (Default = NO)

If YES, the values along the main diagonals of each matrix are included in the computation of correlation.

Otherwise, they are treated as missing.

Random number seed: The random number seed sets off the random permutations. UCINET generates a different random number as default each time it is run. This number should be changed if the user wishes to repeat an analysis. The range is 1 to 32000 .

LOG FILE El outpt consiste en una síntesis estadística de algunas estadísticas de cada matriz seguida de sus resultados. El siguiente ejemplo de output es generado:

Pearson Correlation: Simple Matching:

Jaccard Coefficient: Goodman-Kruskal Gamma: Hamming Distance:

\begin{tabular}{|c|c|c|c|c|c|c|}
\hline Value & Sign & Avg & $\mathrm{SD}$ & P (Large) & $\mathrm{P}(\mathrm{Small})$ & NPerm \\
\hline 0.120 & 0.101 & -0.002 & 0.086 & 0.101 & 0.943 & 2500.000 \\
\hline 0.667 & 0.101 & 0.625 & 0.032 & 0.101 & 0.943 & 2500.000 \\
\hline 0.176 & 0.101 & 0.120 & 0.039 & 0.101 & 0.943 & 2500.000 \\
\hline 0.319 & 0.101 & -0.021 & 0.249 & 0.101 & 0.943 & 2500.000 \\
\hline 70.000 & 0.101 & 78.738 & 6.348 & 0.943 & 0.101 & 2500.000 \\
\hline
\end{tabular}

La columna Valor indica que el valor observado entre las dos redes, en este caso es 0.120 para la correlación y 0.176 para Jaccard. The average random correlation was almost zero with a standard error of 0.086 . The percentage of random correlations that were as large as 0.120 was 0.101 that is $10.01 \%$. Hence of the 2,500 random permutations just over 250 produced a correlation of 0.120 or higher. At a typical 0.05 level, this correlation would not be considered significant since 0.101> 0.05. The table gives the P(Large) as well as $\mathrm{P}$ (Small) note that for the Hamming distance it is P(Small) that needs to be considered as smaller values imply more similarity. The column headed significance attempts to identify the correct value from P(Small) and P(Large), however when the observed value is close to zero it can get this wrong since this selection is based upon whether the observed value is positive or negative. In this instance the user should consider the measure used and the type of data. TIMING $O\left(\mathrm{~N}^{\wedge} 2\right)$ per permutation.

REFERENCIAS: Borgatti, S.P., Everett, M.G. and Freeman, L.C. 2002. Ucinet 6 for Windows. Harvard: Analytic Technologies. 


\section{Anexo Técnico 4.2: Análisis de centralidad y redes totales}

\section{La toma de decisiones individuales está vinculada con los patrones de organización intra grupal}

La matriz actor $x$ actor, cuya notación es * $15 x$ *157, se construye con los datos de 15 informantes y vínculos con alters. La matriz contiene las relaciones entabladas por estos 15 expertos a lo largo de las diferentes etapas de la secuencia de la actividad e introduce 157 alters quiénes comparten 202 relaciones. De esta manera se obtiene un grafo orientado con lazos dicotómicos.

Una matiz es como una grilla o enrejado, en las filas pondremos las 15 personas 0 informantes y en las columnas, las 157 personas mencionadas por las 15 personas tomadas como referentes. Este ordenamiento es así porque representa al par ordenado análogo a dónde se inicia la relación (filas a la izquierda) y la relación va dirigida a las columnas de la derecha. En nuestro caso el informante=Ego 1 dice que tiene relación con la persona= Alter 78 y 157.

\begin{tabular}{|l|l|l|l|l|l|l|l|l|l|l|l|l|l|l|}
\hline & 1 & --- & ---- & --- & --- & --- & -- & --- & 78 & --- & 87 & 99 & --- & 157 \\
\hline 1 & & & & & & & & & 1 & & & & & 1 \\
\hline-- & 0 & & & & & 1 & & & & & 1 & & & 1 \\
\hline-- & 0 & 1 & & 1 & & & & & & & & 1 & & \\
\hline-- & 0 & & & & 1 & & & & & & & & & \\
\hline 15 & 0 & & 1 & & & & & 1 & & 1 & & & & \\
\hline
\end{tabular}

Informante

Las 202 relaciones son las que aparecen con un 1 es decir presencia de interacción. La ausencia de relaciones entre los nodos es $=0$. 
La Tabla muestra las mediciones de densidad de las redes personales de cada Ego

\begin{tabular}{|c|c|c|c|c|c|c|c|}
\hline \multicolumn{2}{|l|}{ Kind of member } & \multicolumn{3}{c|}{$\begin{array}{r}\text { Between groups of } \\
\text { informants }\end{array}$} & \multicolumn{2}{c|}{$\begin{array}{r}\text { Between the members of } \\
\text { the total network }\end{array}$} \\
\hline Ego & Alter & Size & Links & Pares & Size & Links & Pares \\
\hline LCCH & 31 & $\mathbf{8}$ & 30 & 56 & 26 & 324 & 650 \\
\hline JG & 28 & 7 & 32 & 42 & $\mathbf{6 3}$ & 1058 & 3906 \\
\hline ML & $\mathbf{2 0}$ & $\mathbf{1 0}$ & $\mathbf{5 4}$ & $\mathbf{9 0}$ & 41 & 894 & 1640 \\
\hline SCHG & 18 & 6 & 20 & 30 & 3 & 6 & 6 \\
\hline VL & 18 & 5 & 12 & 20 & $\mathbf{5 5}$ & 1324 & 2970 \\
\hline SR & 17 & 6 & 22 & 30 & 35 & 528 & 1190 \\
\hline MF & 15 & 5 & 14 & 20 & 46 & 1114 & 2070 \\
\hline RV & 13 & $\mathbf{9}$ & 42 & 72 & 30 & 870 & 870 \\
\hline LZ & 10 & 6 & 22 & 30 & 32 & 876 & 992 \\
\hline GTR & 9 & $\mathbf{9}$ & 40 & 72 & 8 & 56 & 56 \\
\hline MCI & 6 & 6 & 26 & 30 & 17 & 272 & 272 \\
\hline FV & $\mathbf{6}$ & $\mathbf{8}$ & 40 & 56 & $\mathbf{7 7}$ & $\mathbf{2 0 1 2}$ & $\mathbf{5 8 5 2}$ \\
\hline AG & 4 & 3 & 6 & 6 & 40 & 596 & 1560 \\
\hline MAR & 4 & 0 & 0 & 0 & 9 & 72 & 72 \\
\hline ETG & 3 & 0 & 0 & 0 & 9 & 72 & 72 \\
\hline
\end{tabular}

Patron: 15 informants, 202 alters, 157 alters without repetitions, 30 repetitions Size: The number of actors (alters) to whom Ego is directly linked

Links: Total number of links in ego's network (does not contain the links including ego)

Pares: Total number of alter-pares in ego's network - i.e. potential links

Los datos provienen del análisis en UCINET6 de 1 matriz de *15x157 que luego se transfoma en dos matrices de affiliación, una de *15x15 y otra de *157x157. Sobre cada una de ellas aplico el algoritmo de Ego Networks. 
El Estudio Etnográfico de la Actividad Textil como aporte a la Caracterización del Modo de Vida en el Pueblo de Molinos y zona de influencia (Provincia de Salta)

Laura Teves

El cuadro se compone por una parte de la información proveniente de los resultados que figuran en los Anexos (abajo). 
El Estudio Etnográfico de la Actividad Textil como aporte a la Caracterización del Modo de Vida en el Pueblo de Molinos y zona de influencia (Provincia de Salta)

Laura Teves

\section{EGO NETWORKS}

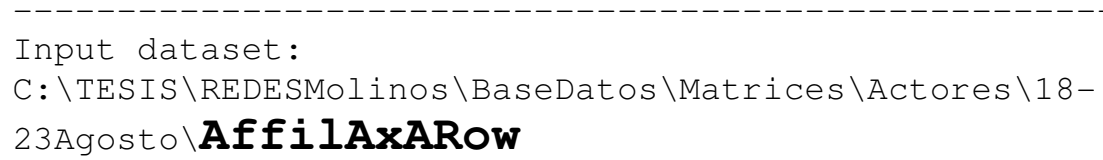

WARNING: Data matrix was dichotomized.

Density Measures

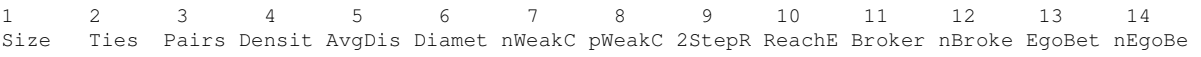

\begin{tabular}{|c|c|c|c|c|c|c|c|c|c|c|c|c|c|c|c|}
\hline 1 & $\mathrm{LCCH}$ & 8.00 & 30.00 & 56.00 & 53.57 & 1.50 & 3.00 & 1.00 & 12.50 & 85.71 & 19.35 & 13.00 & 0.23 & 5.50 & 19.64 \\
\hline 2 & $\mathrm{SCHG}$ & 6.00 & 20.00 & 30.00 & 66.67 & 1.33 & 2.00 & 1.00 & 16.67 & 78.57 & 22.00 & 5.00 & 0.17 & 2.25 & 15.00 \\
\hline 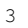 & JG & 7.00 & 32.00 & 42.00 & 76.19 & 1.24 & 2.00 & 1.00 & 14.29 & 85.71 & 19.05 & 5.00 & 0.12 & 1.50 & 7.14 \\
\hline 4 & $\mathrm{MCI}$ & 6.00 & 26.00 & 30.00 & 86.67 & 1.13 & 2.00 & 1.00 & 16.67 & 85.71 & 21.82 & 2.00 & 0.07 & 0.50 & 3.33 \\
\hline 5 & LZ & 6.00 & 22.00 & 30.00 & 73.33 & 1.27 & 2.00 & 1.00 & 16.67 & 71.43 & 20.41 & 4.00 & 0.13 & 1.33 & 8.89 \\
\hline 6 & $\mathrm{AG}$ & .00 & 6.00 & 6.00 & 100.00 & 1.00 & 1.00 & 1.00 & 33.33 & 71.43 & 40.00 & 0.00 & 0.00 & 0.00 & 0.00 \\
\hline 7 & GTR & 9.00 & 40.00 & 72.00 & 55.56 & 1.50 & 3.00 & 1.00 & 11.11 & 85.71 & 17.14 & 16.00 & 0.22 & 7.33 & 20.37 \\
\hline 8 & MAR & 0.00 & 0.00 & 0 & 0 & 0.00 & 0.00 & 0.00 & .00 & 0.00 & 0 & 0.00 & 0.00 & 0.00 & 0.00 \\
\hline 9 & EG & 0.00 & 0.00 & 0.00 & 0.00 & 0.00 & 0.00 & 0.00 & 0.00 & 0.00 & 0.00 & 0.00 & 0.00 & 0.00 & 0.00 \\
\hline 10 & FV & 8.00 & & & & 1.29 & & 1.00 & 50 & & & 8.00 & 0.14 & 2.08 & 7.44 \\
\hline 11 & $\mathrm{MF}$ & 5.00 & 14.00 & 20.00 & 70.00 & 1.30 & 2.00 & 1.00 & 20.00 & 78.57 & 28.21 & 3.00 & 0.15 & 1.00 & 10.00 \\
\hline 12 & VL & 5.00 & 12.00 & 20.00 & 60.00 & 1.50 & 3.00 & 1.00 & 20.00 & 85.71 & 27.91 & 4.00 & 0.20 & 2.33 & 23.33 \\
\hline 13 & $\mathrm{SR}$ & 6.00 & 22.00 & 30.00 & 73.33 & 1.27 & 2.00 & 1.00 & 16.67 & 85.71 & 22.64 & 4.00 & 0.13 & 1.42 & 9.44 \\
\hline 14 & RV & 9.00 & 42.00 & 72.00 & 58.33 & 1.44 & 3.00 & 1.00 & 11.11 & 85.71 & 16.22 & 15.00 & 0.21 & 5.78 & 16.06 \\
\hline 15 & ML & 10.00 & 54.00 & 90.00 & 60.00 & 1.40 & 2.00 & 1.00 & 10.00 & 85.71 & 15.00 & 18.00 & 0.20 & 5.15 & 11.44 \\
\hline
\end{tabular}

1. Size. Size of ego network.

2. Ties. Number of directed ties.

3. Pairs. Number of ordered pairs.

4. Density. Ties divided by Pairs.

5. AvgDist. Average geodesic distance.

6. Diameter. Longest distance in egonet.

7. nWeakComp. Number of weak components.

8. pWeakComp. NWeakComp divided by Size.

9. 2StepReach. \# of nodes within 2 links of ego.

10. ReachEffic. 2StepReach divided Size.

11. Broker. \# of pairs not directly connected.

12. Normalized Broker. Broker divided by number of pairs.

13. Ego Betweenness. Betweenness of ego in own network.

14. Normalized Ego Betweenness. Betweenness of ego in own network. 
El Estudio Etnográfico de la Actividad Textil como aporte a la Caracterización del Modo de Vida en el Pueblo de Molinos y zona de influencia (Provincia de Salta)

Laura Teves

\section{EGO NETWORKS}

Input dataset: C: $\backslash$ TESIS $\backslash$ REDESMolinos $\backslash$ BaseDatos $\backslash$ Matrices $\backslash$ Actores $\backslash 18-$

23Agosto $\backslash$ AffilAxACodCol

WARNING: Data matrix was dichotomized.

Density Measures

\begin{tabular}{|c|c|c|c|c|c|c|c|c|c|c|c|c|c|c|c|}
\hline & & 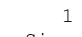 & 2 & 3 & 4 & 5 & 6 & 7 & 8 & D & 10 & 11 & 12 & 13 & D \\
\hline & & Size & Ties & Pairs & Densit & AvgDis & Diamet & & pWeakC 2 & $2 \mathrm{StepR}$ & ReachE & Broker $\mathrm{r}$ & nBroke $\mathrm{E}$ & EgoBet & $\mathrm{nEg} g \mathrm{Be}$ \\
\hline 1 & 1.1 & 5.00 & 20.00 & 20.00 & 100.00 & 1.00 & 1.00 & 1.00 & 20.00 & 45.51 & 56.35 & 0.00 & 0.00 & 0.00 & 0.0 \\
\hline 2 & 2.1 & 40.00 & 596.00 & 1560.00 & 38.21 & 1.73 & 3.00 & 1.00 & 2.50 & 86.54 & 16.00 & 482.00 & 0.31 & 273.70 & 35.09 \\
\hline 3 & 3.3 & 44.00 & 1146.00 & 1892.00 & 60.57 & 1.39 & 2.00 & 1.00 & 2.27 & 87.82 & 9.77 & 7373.00 & 0.20 & 85.63 & 9.05 \\
\hline 4 & 4.1 & 27.00 & 702.00 & 702.00 & 100.00 & 1.00 & 1.00 & 1.00 & 3.70 & 63.46 & 10.73 & 0.00 & 0.00 & 0.00 & 0.00 \\
\hline 5 & 5.1 & 19.00 & 342.00 & 342.00 & 100.00 & 1.00 & 1.00 & 1.00 & 5.26 & 87.82 & 21.27 & 0.00 & 0.00 & 0.00 & 0.00 \\
\hline 6 & 6.1 & 27.00 & 702.00 & 702.00 & 100.00 & 1.00 & 1.00 & 1.00 & 3.70 & 63.46 & 10.73 & 0.00 & 0.00 & 0.00 & 0.00 \\
\hline 7 & 7.1 & 30.00 & 870.00 & 870.00 & 100.00 & 1.00 & 1.00 & 1.00 & 3.33 & 78.85 & 11.13 & 0.00 & 0.00 & 0.00 & 0.00 \\
\hline 8 & 8.1 & 30.00 & 870.00 & 870.00 & 100.00 & 1.00 & 1.00 & 1.00 & 3.33 & 78.85 & $5 \quad 11.13$ & 0.00 & 0.00 & 0.00 & 0.00 \\
\hline 9 & 9.1 & 19.00 & 342.00 & 342.00 & 100.00 & 1.00 & 1.00 & 1.00 & 5.26 & 87.82 & 21.27 & 0.00 & 0.00 & 0.00 & 0.00 \\
\hline 10 & 10.2 & 24.00 & 350.00 & 552.00 & 63.41 & 1.37 & 2.00 & 1.00 & 4.17 & 82.69 & 16.88 & 3 101.00 & 0.18 & 32.55 & 11.79 \\
\hline 11 & 11.2 & 25.00 & 356.00 & 600.00 & 59.33 & 1.41 & 2.00 & 1.00 & 4.00 & 71.15 & $5 \quad 19.34$ & 4122.00 & 0.20 & 48.70 & 16.23 \\
\hline 12 & 12.1 & 30.00 & 870.00 & 870.00 & 100.00 & 1.00 & 1.00 & 1.00 & 3.33 & 78.85 & 11.13 & 0.00 & 0.00 & 0.00 & 0.00 \\
\hline 13 & 13.2 & 30.00 & 870.00 & 870.00 & 100.00 & 1.00 & 1.00 & 1.00 & 3.33 & 78.85 & 11.13 & 0.00 & 0.00 & 0.00 & 0.00 \\
\hline 14 & 4.1 .2 & 55.00 & 1324.00 & 2970.00 & 44.58 & 1.55 & 2.00 & 1.00 & 1.82 & 87.82 & 8.74 & 4823.00 & 0.28 & 28.96 & 15.42 \\
\hline 15 & 15.3 & 17.00 & 272.00 & 272.00 & 100.00 & 1.00 & 1.00 & 1.00 & 5.88 & 55.13 & 19.82 & 0.00 & 0.00 & 0.00 & 0.00 \\
\hline 16 & 16.1 & 27.00 & 702.00 & 702.00 & 100.00 & 1.00 & 1.00 & 1.00 & 3.70 & 63.46 & 10.73 & 0.00 & 0.00 & 0.00 & 0.00 \\
\hline 17 & 7.1 .3 & 17.00 & 272.00 & 272.00 & 100.00 & 1.00 & 1.00 & 1.00 & 5.88 & 55.13 & 19.82 & 0.00 & 0.00 & & 0.00 \\
\hline 18 & 18.3 & 27.00 & 702.00 & 702.00 & 100.00 & 1.00 & 1.00 & 1.00 & 3.70 & 63.46 & 10.73 & 0.00 & 0.00 & 0.00 & 0.00 \\
\hline 19 & 19.1 & 14.00 & 182.00 & 182.00 & 100.00 & 1.00 & 1.00 & 1.00 & 7.14 & 46.15 & 19.94 & 0.00 & 0.00 & & 0.00 \\
\hline 20 & 20.1 & 27.00 & 702.00 & 702.00 & 100.00 & 1.00 & 1.00 & 1.00 & 3.70 & 63.46 & 10.73 & 0.00 & 0.00 & & 0.00 \\
\hline 21 & 21.2 & 30.00 & 870.00 & 870.00 & 100.00 & 1.00 & 1.00 & 1.00 & 3.33 & 78.85 & 11.13 & 0.00 & 0.00 & 0.00 & 0.00 \\
\hline 22 & 22.2 & 16.00 & 240.00 & 240.00 & 100.00 & 1.00 & 1.00 & 1.00 & 6.25 & 62.18 & 26.01 & 0.00 & 0.00 & & 0.00 \\
\hline 23 & 2.2 & 16.00 & 240.00 & 240.00 & 100.00 & 1.00 & 1.00 & 1.00 & 6.25 & 62.18 & 26.01 & 0.00 & 0.00 & 0.00 & 0.00 \\
\hline 24 & 24.2 & 16.00 & 240.00 & 240.00 & 100.00 & 1.00 & 1.00 & 1.00 & 6.25 & 62.18 & 26.01 & 0.00 & 0.00 & & 0.00 \\
\hline 25 & 25.2 & 16.00 & 240.00 & 240.00 & 100.00 & 1.00 & 1.00 & 1.00 & 6.25 & 62.18 & 26.01 & 0. & 0.00 & & 0.00 \\
\hline 26 & 26.2 & 16.00 & 240.00 & 240.00 & 100.00 & 1.00 & 1.00 & 1.00 & 6.25 & 62.18 & 26.01 & 0.00 & 0.00 & 0.00 & 0.00 \\
\hline 27 & 27.2 & 45.00 & 1080.00 & 980.00 & 54.55 & 1.45 & 2.00 & 1.00 & 2.22 & 87.82 & 10.10 & 450.00 & 0.23 & 100.00 & 10.10 \\
\hline 28 & 28.2 & 9.00 & 72.00 & 72.00 & 100.00 & 1.00 & 1.00 & 1.00 & 11.11 & 54.49 & 41.46 & & 0.00 & & 0.00 \\
\hline 29 & 29.2 & 16.00 & 240.00 & 240.00 & 100.00 & 1.00 & 1.00 & 1.00 & 6.25 & 62.18 & 26.01 & 0.00 & 0.00 & & 0.00 \\
\hline 30 & 30.2 & 27.00 & 702.00 & 702.00 & 100.00 & 1.00 & 1.00 & 1.00 & 3.70 & 63.46 & 73 & 0.00 & 0.00 & & 0.00 \\
\hline 31 & 31.2 & 27.00 & 702.00 & 702.00 & 100.00 & 1.00 & 1.00 & 1.00 & 3.70 & 63.46 & 10.73 & 0.00 & 0.00 & 0. & 0.00 \\
\hline 32 & 32.2 & 27.00 & 702.00 & 702.00 & 100.00 & 1.00 & 1.00 & 1.00 & 3.70 & 63.46 & 10.73 & 0.00 & 0.00 & & 0.00 \\
\hline 33 & 33.2 & 27.00 & 702.00 & 702.00 & 00.00 & 1.0 & 1.00 & 1.00 & 3.70 & 63.46 & 10.73 & 0 . & 0.00 & & 0.00 \\
\hline 34 & 34.2 & 14.00 & 182.00 & 182.00 & 100.00 & 1.00 & 1.00 & 1.00 & 7.14 & 46.15 & 19.94 & 0.00 & 0.00 & 0.00 & 0.00 \\
\hline 35 & 35.1 & 3.00 & 6.00 & 6.00 & 100.00 & 1.00 & 1.00 & 1.00 & 33.33 & 1.92 & 25.00 & 0. & 0.00 & & 0.00 \\
\hline 36 & 36.1 & 9.00 & 72.00 & 72.00 & 00.00 & 1.00 & 1.00 & 1.00 & 1.11 & 54.49 & 41.46 & 0.00 & 0.00 & 0. & 0.00 \\
\hline 37 & 37.1 & 9.00 & 72.00 & 72.00 & 100.00 & D & 1.00 & 0 & 11.11 & 49 & & & & & 0.00 \\
\hline 38 & 38.1 & 17.00 & 272.00 & 272.00 & 100.00 & 1.00 & 1.00 & 1.00 & 5.88 & 58.33 & 18.38 & 0.00 & 0.00 & 0.00 & 0.00 \\
\hline 39 & 39.1 & 30.00 & 870.00 & 870.00 & 100.00 & 1.00 & 1.00 & 1.00 & 3.33 & 78.85 & 11.13 & 0.00 & 0.00 & 0.00 & 0.00 \\
\hline 40 & 40.1 & 42.00 & 1020.00 & 1722.00 & 59.23 & 3 & 3.00 & 0 & 2.38 & .67 & 10.16 & 5351. & 0.20 & 241.43 & 28.04 \\
\hline 41 & 41.1 & 30.00 & 870.00 & 870.00 & 00.00 & .0 & 1.00 & 1.00 & 3.33 & .85 & 11.13 & 0. & 0.00 & 0. & 0.00 \\
\hline 42 & 42. & 30.00 & 870.00 & 0.00 & 100.00 & 1 & 1.00 & ) & 3.33 & .85 & & & & & 0.00 \\
\hline 43 & 43.2 & 12.00 & .00 & .00 & 0.00 & 1.00 & 1.00 & .00 & 8.33 & 3.33 & 37.79 & 0. & 0.00 & & 0.00 \\
\hline 44 & 44.2 & 12.00 & 132.00 & 132.00 & 100.00 & .00 & 1.00 & 1.00 & 8.33 & 3.33 & 37.79 & 0. & 0.00 & 0. & 0.00 \\
\hline 45 & & .00 & 2.00 & 132.00 & .00 & D & 1.00 & 0 & 8.33 & 33 & & & 0 & & 0.00 \\
\hline 46 & 46.2 & 12.00 & 132.00 & 132.00 & 100.00 & .0 & 1.00 & .00 & 8.33 & 3.33 & 37.79 & 0.00 & 0.00 & 0.00 & 0.00 \\
\hline 47 & 47.2 & 16.00 & 240.00 & 240.00 & 100.00 & 1.00 & 1.00 & 1.00 & 6.25 & 2.18 & 26.01 & 0.00 & 0.00 & 0.00 & 0.00 \\
\hline 48 & 4 & 12.00 & .00 & .00 & 1 & D & 00 & 0 & .33 & 33 & 79 & 0 & 0 & 0 & 0.00 \\
\hline 49 & 49.2 & 12.00 & .00 & 2.00 & 100.00 & 1.0 & 1.00 & 1.00 & 8.33 & .33 & 37.79 & 0.00 & 0.00 & 0.00 & 0.00 \\
\hline 50 & & 0 & .00 & .00 & 1 & & 1 . & ) & 8.33 & & & & & & 0.00 \\
\hline 51 & 51.2 & 30.00 & 870.00 & 870.00 & 100.00 & D & 1.00 & 0 & 3.33 & 78.85 & 11.13 & 0.00 & 0.00 & 0.00 & 0.00 \\
\hline 52 & 52.1 .3 & 77.00 & 2012.00 & 852.00 & 4.38 & .98 & .00 & 1.00 & 1.30 & 5.51 & 6.101 & 1920.00 & 0.331 & 1236.98 & 42.28 \\
\hline 53 & 53.3 & 44.00 & 46.00 & 92.00 & 7 & 7 & 0 & 0 & 2.27 & .82 & 9.77 & 7373.00 & 0.20 & 85.63 & 9.05 \\
\hline 54 & 54.1 & 17.00 & .00 & 272.00 & 100.00 & D & 1.00 & 1.00 & 5.88 & 3.33 & 18.38 & 0.00 & 0.00 & 0.00 & 0.00 \\
\hline 55 & & & & & & & & & & & & & & & 0.00 \\
\hline 56 & 6.1 .3 & & 00 & .00 & 1 & D & 1 & ) & 0 & 46 & 4 & 0 & 0 & 0 & 0.00 \\
\hline 57 & 57.3 & 17.00 & 272.00 & 272.00 & 100.00 & 1.00 & 1.00 & 1.00 & 5.88 & 55.13 & 19.82 & 0.00 & 0.00 & 0.00 & 0.00 \\
\hline 5 & & & & & & & & & 7.14 & & & & & & 0.00 \\
\hline 59 & 59 & 00 & .00 & .00 & 1 & D & 1. & ) & 3.33 & .85 & 11.13 & 0 . & 0.00 & 0 & 0.00 \\
\hline 60 & 60.1 & .00 & .00 & .00 & 0.00 & 00 & 1.00 & 00 & 3.33 & 85 & 11.13 & 0.00 & 0.00 & 0. & 0.00 \\
\hline 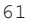 & & .00 & .00 & .00 & .00 & & & ) & 5.88 & & & 0 & 0.00 & & 0.00 \\
\hline 62 & 62.1 & .00 & .00 & 2.00 & .00 & & 1 & ) & 5.88 & 33 & 18.38 & 0.00 & 0.00 & 0. & 0.00 \\
\hline 63 & & & & & & & & & & & & & & & 0.00 \\
\hline 64 & 64 & 00 & .00 & .00 & 1 & D & 7 & ) & 38 & 33 & 38 & 0. & 0.00 & 0. & 0.00 \\
\hline 65 & 65.3 & 23.00 & 396.00 & 506.00 & 78.26 & 22 & 0 & 00 & 4.35 & 87.82 & 18.22 & 55.00 & 0.11 & 9.04 & 3.57 \\
\hline 66 & & & .00 & .00 & 100.00 & & & & 5.26 & & 21.27 & & & 0.00 & 0.00 \\
\hline 67 & 67.1 & 0 & 2.00 & 2.00 & 10 & & & & 7.14 & 15 & 19.94 & 0.00 & 0.00 & 0.00 & 0.00 \\
\hline 68 & .1 .2 .3 & 63.00 & 1058.00 & 3906.00 & 27.09 & & & & & .23 & 9.821 & 21424.00 & 0.36 & 959.00 & 49.10 \\
\hline 69 & & & & & & & & & 1.82 & & 9.26 & & 0.31 & 461.23 & 1.06 \\
\hline 70 & 70.3 & 51.00 & 912.00 & 2550.00 & 35.76 & 2.11 & 4.00 & 1.00 & 1.96 & 94.23 & 10.70 & 819.00 & 0.32 & 558.10 & 43.77 \\
\hline 71 & 71.3 & 37.00 & 842.00 & 1332.00 & 63.21 & & & & 2.70 & & 11.95 & 245.00 & 0.18 & 72.45 & 10.88 \\
\hline 72 & 72 & 2 & .00 & 702.00 & 100.00 & & & & 3.70 & 16 & 10.73 & 0. & 0.00 & 0.00 & 0.00 \\
\hline 73 & 73.1 & 27.00 & 702.00 & 702.00 & 100.00 & 1. & & 1.00 & 3.70 & 63.46 & 10.73 & 0.00 & 0.00 & 0.00 & 0.00 \\
\hline 74 & 4.1 & & .00 & & 100. & & & & 11.11 & & & 0.00 & 0.00 & 0.00 & \\
\hline 75 & 75. & 26.00 & 4.00 & 650.00 & 49.85 & 1.81 & & 1.00 & 3.85 & 91.67 & 21.06 & $5 \quad 163.00$ & 0.25 & 124.87 & 38.42 \\
\hline 76 & 76.1 & 14.00 & 182.00 & 182.00 & 100.00 & 1.0 & & 1.00 & 7.14 & 46.15 & 19.94 & 0.00 & 0.00 & 0.00 & 0.00 \\
\hline 77 & 77. & & & & & & & & 33.33 & & & & & & 0.00 \\
\hline 78 & 78.2 & 19.00 & 342.00 & 342.00 & 100.00 & 1.00 & 1.00 & 1.00 & 5.26 & 87.82 & 21.27 & 0.00 & 0.00 & 0.00 & 0.00 \\
\hline
\end{tabular}


El Estudio Etnográfico de la Actividad Textil como aporte a la Caracterización del Modo de Vida en el Pueblo de Molinos y zona de influencia (Provincia de Salta)

Laura Teves

\begin{tabular}{|c|c|c|c|c|c|c|c|c|c|c|c|c|c|c|c|}
\hline 79 & 79.2 & 5.00 & 410.00 & 600.00 & 68.33 & 1.32 & 2.00 & 1.00 & 4.00 & 95.51 & 18.17 & 95.00 & 0.16 & 24.33 & 8.11 \\
\hline 80 & 80.2 & 32.00 & 876.00 & 992.00 & 88.31 & 1.12 & 2.00 & 1.00 & 3.13 & 78.85 & 11.07 & 58.00 & 0.06 & 29.00 & 5.85 \\
\hline 81 & 81.1 & 7.00 & 272.00 & 272.00 & 100.00 & 1.00 & 1.00 & 1.00 & 5.88 & 55.13 & 19.82 & 0.00 & 0.00 & 0.00 & 0.00 \\
\hline 82 & 82.1 & 9.00 & 72.00 & 72.00 & 100.00 & 1.00 & 1.00 & 1.00 & 11.11 & 4.49 & 41.46 & 0.00 & 0.00 & 0.00 & 0.00 \\
\hline 83 & 83.1 & 27.00 & 702.00 & 702.00 & 100.00 & 1.00 & 1.00 & 1.00 & 3.70 & 63.46 & 10.73 & 0.00 & 0.00 & 0.00 & 0.00 \\
\hline 84 & 84.1 & 8.00 & 56.00 & 56.00 & 100.00 & .00 & 1.00 & .00 & 12.50 & 63.46 & 30.94 & 0.00 & 0.00 & 0.00 & 0.00 \\
\hline 85 & 85.2 & 17.00 & 272.00 & 272.00 & 100.00 & 1.00 & 1.00 & 1.00 & 5.88 & 55.13 & 19.82 & 0.00 & 0.00 & 0.00 & 0.00 \\
\hline 86 & 86.2 & 5.00 & 20.00 & 20.00 & 100.00 & 1.00 & 1.00 & .00 & 20.00 & 45.51 & 56.35 & 0.00 & 0.00 & 0.00 & 0.00 \\
\hline 87 & 87.2 & 51.00 & 984.00 & 2550.00 & 38.59 & 1.68 & .00 & 1.00 & 1.96 & 95.51 & 10.81 & 783.00 & 0.31 & 313.79 & 24.61 \\
\hline 88 & 88.1 & 6.00 & 1114.00 & 2070.00 & 53.82 & .87 & .00 & .00 & 2.17 & 92.95 & 10.13 & 478.00 & 0.23 & 444.33 & 42.93 \\
\hline 89 & 89.1 & 7.00 & 702.00 & 702.00 & 100.00 & .00 & .00 & .00 & 3.70 & 63.46 & 10.73 & 0.00 & 0.00 & 0.00 & 0.00 \\
\hline 90 & 90.1 & 27.00 & 702.00 & 702.00 & 100.00 & .00 & .00 & .00 & 3.70 & & & 0.00 & .00 & 0.00 & 0.00 \\
\hline 91 & 91.1 & 41.00 & 894.00 & 1640.00 & 54.51 & 1.45 & 2.00 & .00 & 2.44 & 87.18 & 11.26 & 373.00 & 0.23 & 03.04 & 12.57 \\
\hline 92 & 92.1 & 30.00 & 870.00 & 870.00 & 100.00 & 1.00 & 1.00 & .00 & 3.33 & 78.85 & 11.13 & 0.00 & 0.00 & 0.00 & 0.00 \\
\hline 93 & 93.1 & 0.00 & 870.00 & 870.00 & 100.00 & 1.00 & 1.00 & 1.00 & 3.33 & 78.85 & 11.13 & 0.00 & .00 & 0.00 & 0.00 \\
\hline 94 & 94.1 & .00 & 870.00 & 870.00 & 100.00 & .00 & 1.00 & & 3.33 & 8.85 & & & .00 & & 0.00 \\
\hline 95 & 96.1 & 9.00 & 342.00 & 342.00 & 100.00 & 1.00 & 1.00 & .00 & 5.26 & 87.82 & 27 & 0.00 & 0.00 & & 0.00 \\
\hline 96 & 97.1 & 4.00 & 182.00 & 182.00 & 100.00 & .00 & 1.00 & .00 & 7.14 & 46.15 & 19.94 & 0.00 & .00 & & 0.00 \\
\hline 97 & 98. & 6.00 & 240.00 & 240.00 & 100.00 & .00 & 1.00 & .00 & 6.25 & 62.18 & 26.01 & 0.00 & .00 & & 0.00 \\
\hline 98 & 99.1 & 27.00 & 702.00 & 702.00 & 100.00 & 1.00 & 1.00 & .00 & 3.70 & 63.46 & 0.73 & 0.00 & .00 & 0.00 & 0.00 \\
\hline 99 & 00.2 & 9.00 & 72.00 & 72.00 & 100.00 & 1.00 & 1.00 & .00 & 11.11 & & & & .00 & & 0.00 \\
\hline 00 & 101.2 & 19.00 & 342.00 & 342.00 & 100.00 & .00 & 1.00 & .00 & 5.26 & 82 & 27 & 0.00 & .00 & 00 & 0.00 \\
\hline 1 & 2.1 & 0.00 & 1134.00 & 2450.00 & & .54 & 2.00 & & 2.00 & 51 & & 658.00 & .27 & 166.15 & 13.56 \\
\hline 02 & 103.2 & 0.00 & 870.00 & 870.00 & 100. & .00 & 1 & & 3.33 & & & & .00 & & 0.00 \\
\hline 03 & 4.1 & 0.00 & 870.00 & 870.00 & 100.00 & 1.00 & 1.00 & .00 & 3.33 & 78.85 & 11.13 & 0.00 & .00 & 0.00 & 0.00 \\
\hline 04 & 105.3 & 0.00 & 130.00 & 2450.00 & 46.12 & 1.57 & 3.00 & .00 & 2.00 & 82.69 & 8.73 & 660.00 & .27 & 259.27 & 21.16 \\
\hline 5 & 106.1 & 4.00 & & 182.00 & 100 & .00 & 1.00 & & 7.14 & & 19.94 & & .00 & & 0.00 \\
\hline 06 & 107.1 & .00 & & 702 & 100 & & & & 3.70 & & & & & & 0.00 \\
\hline 政 & 108.1 & .00 & & & 100 & 0 & . & & 33.33 & & & & & & 0.00 \\
\hline 108 & 109.2 & 19.00 & 342.00 & 342.00 & 100 & .00 & 1.00 & .00 & 5.26 & 82 & & & .00 & & 0.00 \\
\hline 09 & 10.3 & .00 & 272.00 & 272.00 & 100.00 & 0 & 0 & & 5.88 & & & & .00 & & 0.00 \\
\hline 11 & 111.3 & .00 & 528.00 & 1190.00 & 44.37 & .56 & 2.00 & 00 & 2.86 & 69 & 87 & 331 & .28 & 02 & 18.83 \\
\hline 11. & 112.3 & 19.00 & 342.00 & 342.00 & 100.00 & .00 & 1.00 & .00 & 5.26 & 87.82 & & & .00 & & 0.00 \\
\hline 12 & 3.1 & .00 & 00 & .00 & 100 & 0 & - & 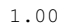 & 5.88 & & & & & & 0.00 \\
\hline 113 & 1012 & .00 & $62 C$ & 1122.00 & & & 2 & 0 & 2.94 & & & 251 & & & 13.58 \\
\hline 14 & 15.3 & & & .00 & & & & & 3.33 & & & & 00 & & 0.00 \\
\hline 15 & 116.3 & .00 & .00 & 272.00 & 100 & 0 & 1 & 00 & 5.88 & & & & 00 & & 0.00 \\
\hline 16 & $117 \%$ & 2.00 & 2.00 & 2.00 & 100 & 00 & 1.00 & .00 & 50.00 & 1.28 & 33 & & .00 & 00 & 0.00 \\
\hline 17 & 118.2 & 3.00 & 00 & .00 & 100 & .00 & .00 & .00 & 3.33 & .92 & .00 & & .00 & & 0.00 \\
\hline 118 & 119.2 & 3.00 & .00 & .00 & & .00 & 1.00 & .00 & 3.33 & 1.92 & .00 & & .00 & 00 & 0.00 \\
\hline & 0.2 & 2.00 & & .00 & & & 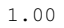 & & 0 & 1.28 & & & & & 0.00 \\
\hline 20 & 1.2 & 8.00 & .00 & .00 & $10 c$ & & 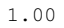 & & 50 & 08 & & & & & 0.00 \\
\hline 12 & 122.2 & 2.00 & .00 & 2.00 & & 0 & 1. & 00 & 0 & 1.28 & 33 & & 00 & & 0.00 \\
\hline 122 & 3.3 & 17.00 & .00 & 72.00 & & & & & & & & & & & 0.00 \\
\hline 12 & 4.1 & 0.00 & 70.00 & 870.00 & & bo & . & 00 & .33 & .85 & .13 & & .00 & & 0.00 \\
\hline & $125 \quad 1$ & .00 & & & & & 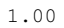 & 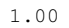 & 3.33 & & & & & & 0.00 \\
\hline 12 & 6.1 & & & & & & .0 & & 12.50 & & & & & & 0.00 \\
\hline 12 & 7.3 & & & & & & & & 5.88 & & & & & & 0.00 \\
\hline & 28.1 .3 & & & & & & & & & & & & & & 0.00 \\
\hline 2 & 9.2 & .00 & 00 & 342.00 & & & 1. & & 5.26 & 82 & & & .00 & & 0.00 \\
\hline 12 & 8 & & & 182.00 & & & & & 7.14 & & & & .00 & & 0.00 \\
\hline 13 & 1.1 & bo & & 00 & & & ( & 0 & 0.00 & & & & 00 & & 0.00 \\
\hline 13 & 2.3 & 00 & & .00 & & & & & 33 & & & & 00 & & 0.00 \\
\hline & 3 & & & & & & & & & & & & & & 0.00 \\
\hline & 1 & & & & & & & & & & & & & & 0.00 \\
\hline 13 & 5.1 & & & & & & & & 70 & & & & 00 & & 0.00 \\
\hline 135 & 61 & & & & & & & & & & & & & & 0.00 \\
\hline & 7.1 & & & & & & & & & & & & 00 & & 0.00 \\
\hline 13 & 3.1 & & & & & & & & & & & & 00 & & 0.00 \\
\hline 13 & 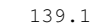 & & & & & & & & & & & & & & 0.00 \\
\hline 139 & 0.1 & .00 & .00 & 870.00 & 100.00 & & 1.00 & & 33 & .85 & .13 & & .00 & 00 & 0.00 \\
\hline 110 & & & & & & & & & & & & & & & 0.00 \\
\hline & 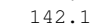 & & & & & & & & & & & & 0 & & 0.00 \\
\hline 14 & 3.1 & .00 & & 870.00 & & & 1. & & & & & & .00 & & 0.00 \\
\hline & ( & & & & & & & & & & & & & & 0.00 \\
\hline 14 & 5.3 & & & & & & & & & & & & 00 & & 0.00 \\
\hline 14 & 5.3 & & & & & & & & & & & & & & 0.00 \\
\hline 1 & 7 & & & & & & & & & & & & 00 & & 0.00 \\
\hline 14 & 8.3 & 0 & .00 & 240.00 & 10 & & & & 25 & 18 & .01 & & .00 & 00 & 0.00 \\
\hline 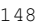 & 9.3 & & & & & & & & & & & & .00 & & 0.00 \\
\hline 14 & 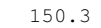 & & & & & & & & & & & & & & 0.00 \\
\hline 15 & 1.1 & & 00 & .00 & 100 & & & & & & .94 & & 00 & & 0.00 \\
\hline 15 & & & & & & & & & & & & & & & \\
\hline 152 & 153.2 & 55.00 & 1324.00 & 2970.00 & 44.58 & & 2.00 & & 1.82 & 87.82 & 8.74 & 823.00 & 0.28 & 228.96 & 15.42 \\
\hline 153 & 54.3 & 7.00 & .00 & .00 & & & & & & & & & 0.00 & & 0.00 \\
\hline & $\cdot$ & & & & & & & & & & & & & & 0.00 \\
\hline 15 & 56.3 & 00 & 272.00 & 272.00 & 10 & & 1. & & & 13 & & & 00 & 00 & 0.00 \\
\hline 15 & & & & .00 & & & & & & & & & 0 & & 0.00 \\
\hline 5 & 158.3 & 17.00 & 272.00 & 272.00 & 100.00 & 1.00 & 1.00 & 1.00 & 5.88 & 55.13 & 19.82 & 0.00 & 0.00 & 0.00 & 0.0 \\
\hline
\end{tabular}

1. Size. Size of ego network.

2. Ties. Number of directed ties.

3. Pairs. Number of ordered pairs.

4. Density. Ties divided by Pairs.

5. AvgDist. Average geodesic distance.

6. Diameter. Longest distance in egonet.

7. nWeakComp. Number of weak components. 
El Estudio Etnográfico de la Actividad Textil como aporte a la Caracterización del Modo de Vida en el Pueblo de Molinos y zona de influencia (Provincia de Salta)

Laura Teves

8. pWeakComp. NWeakComp divided by Size.

9. 2StepReach. \# of nodes within 2 links of ego.

10. ReachEffic. 2StepReach divided Size.

11. Broker. \# of pairs not directly connected.

12. Normalized Broker. Broker divided by number of pairs.

13. Ego Betweenness. Betweenness of ego in own network.

14. Normalized Ego Betweenness. Betweenness of ego in own network.

Ego network measures saved as dataset C: \TESIS \REDESMolinos \BaseDatos \Matrices $\backslash$ Actores $\backslash 18-$ 23Agosto $\backslash$ EgoNet 
Anexo Técnico 4.3: Análisis de conectividad y grafos planares.

Información requerida: 38 Localidades del Dep. de Molinos y Catamarca

\begin{tabular}{|l|}
\hline Alumbre- Luracatao \\
\hline Amaicha \\
\hline Antofagasta de la Sierra- (Catamarca) \\
\hline Banda Grande \\
\hline Barranca-Hualfin \\
\hline Bolivia \\
\hline Brealito \\
\hline Buenos Aires \\
\hline Cabrería- Luracatao \\
\hline Cachi \\
\hline Cachi Adentro \\
\hline Cafayate \\
\hline Churcal \\
\hline Colomé \\
\hline Compuel-Hualfín \\
\hline Córdoba \\
\hline El Colte \\
\hline EIPuente \\
\hline ElRefugio- Luracatao \\
\hline EntreRíos \\
\hline Hualfin \\
\hline Huerta Grande \\
\hline Humanao \\
\hline La Esquina \\
\hline La Puerta- Luracatao \\
\hline Laguadita - Luracatao \\
\hline Luracatao \\
\hline Mayuco- Tacuil \\
\hline Molinos \\
\hline Patos- Catamarca \\
\hline Salta \\
\hline Seclantás \\
\hline SeclantásAd \\
\hline StaMaría-Catamarca \\
\hline StaRosa \\
\hline
\end{tabular}


El Estudio Etnográfico de la Actividad Textil como aporte a la Caracterización del Modo de Vida en el Pueblo de Molinos y zona de influencia (Provincia de Salta)

Laura Teves

Tacuil

Tiopampa

Tomuco 
El Estudio Etnográfico de la Actividad Textil como aporte a la Caracterización del Modo de Vida en el Pueblo de Molinos y zona de influencia (Provincia de Salta)

Laura Teves

RUTAS: Listado de localidades mencionadas por los informantes como sitios de abastecimiento de materia prima, mano de obra y comercialización de textiles.

\begin{tabular}{|l|l|}
\hline 1. Tomuco- Amaicha & Rm \\
\hline 2. Tomuco- Molinos & \\
\hline 3. Amaicha-Tacuil & \\
\hline 4. Tacuil- Patos & \\
\hline 5. Tomuco- Luracatao & \\
\hline 6. Luracatao- Entre Ríos & \\
\hline 7. Entre Ríos- Molinos & \\
\hline 8. Luracatao- Seclantás & Ld \\
\hline 9. Molinos- Humanao & \\
\hline 10. Molinos- Tomuco & \\
\hline 11. Molinos- Huerta Grande & \\
\hline 12. Molinos- Humanao & \\
\hline 13. Molinos- Santa Rosa & \\
\hline 14. Molinos- Banda Grande & \\
\hline 15. Molinos- Amaicha & \\
\hline 16. Barrnaca/Hualfin- Molinos & Ch \\
\hline 17. Salta- Molinos & \\
\hline 18. Cafayate- Molinos & \\
\hline 19. Tomuco- Molinos & \\
\hline 20. Tacuil-Tomuco & \\
\hline 21. Tomuco- Entre Ríos & \\
\hline 22. Cachi Adentro-Tomuco & \\
\hline 23. Seclantás Adentro- Tomuco & \\
\hline 24. Colomé- Tomuco & \\
\hline 25. SantaMaría/Catamarca- Tomuco & \\
\hline 26. Luracatao- Tomuco & \\
\hline 27. Compuel- Tomuco & \\
\hline 28. Salta- Tomuco & \\
\hline 29. Entre Ríos- Luracatao & \\
\hline 30. Luracatao- Entre Ríos & \\
\hline 31. Salta- Luracatao & \\
\hline 32. El Refugio/Luracatao- Entre Ríos & \\
\hline 33. La Puerta/Luracatao - Entre Ríos & \\
\hline 34. Cabrería/Luracatao- Entre Ríos & \\
\hline 35. Alumbre/Luracatao- Entre Ríos & \\
\hline 36. Entre Ríos- Tomuco & \\
\hline 37. Entre Ríos- Salta & \\
\hline 38. Entre Ríos- Molinos & \\
\hline 39. Molinos- El Colte & \\
\hline 40. Molinos- Buenos Aires & \\
\hline
\end{tabular}


El Estudio Etnográfico de la Actividad Textil como aporte a la Caracterización del Modo de Vida en el Pueblo de Molinos y zona de influencia (Provincia de Salta)

\begin{tabular}{|l|l|}
\hline 41. Molinos- Salta & \\
\hline 42. Luracatao- Molinos & \\
\hline 43. Molinos- Córdoba & Lz \\
\hline 44. Molinos- Luracatao & \\
\hline 45. Molinos- Tomuco & \\
\hline 46. Molinos- Santa Rosa & \\
\hline 47. Tacuil- Molinos & \\
\hline 48. Catamarca- Molinos & Ar \\
\hline 49. Molinos- Salta & \\
\hline 50. Cafayate- Molinos & Mt \\
\hline 51. Tomuco- Molinos & Tr \\
\hline 52. Hualfin- Molinos & \\
\hline 53. El Puente- El Churcal & \\
\hline 54. El Puente- Banda Grande & Pn \\
\hline 55. El Puente- Entre Ríos & \\
\hline 56. Tomuco- Santa Rosa & \\
\hline 57. Tomuco- Molinos & \\
\hline 58. Tacuil- Tomuco & \\
\hline 59. Tomuco- Salta & Mu \\
\hline 60. Tomuco- Entre Ríos & \\
\hline 61. Tomuco- Salta & \\
\hline 62. Luracatao- Tomuco & \\
\hline 63. Cafayate- Tomuco & \\
\hline 64. Hualfín- Tomuco & \\
\hline 65. Tomuco- Tiopampa & \\
\hline 66. Tomuco- La Esquina & \\
\hline 67. Colomé- Molinos & \\
\hline 68. Bolivia- Molinos & \\
\hline 69. Patos- Molinos & \\
\hline 70. Brealito- Tomuco & \\
\hline 71. Bolivia- Tomuco & \\
\hline 72. Luracatao- Tomuco & \\
\hline 73. Luracatao- Seclantás & \\
\hline 74. Luracatao- Entre Ríos & \\
\hline 75. Molinos- Tomuco & \\
\hline 76. Tomuco- Amaicha & \\
\hline 77. Amaicha- Tacuil & \\
\hline 78. Tacuil- Patos & \\
\hline 79. Patos- Molinos & \\
\hline 80. Patos- Tomuco & \\
\hline 81. Banda Grande- Molinos & \\
\hline 82. Molinos- Humanao & \\
\hline 83. Banda Grande - Entre Ríos & \\
\hline
\end{tabular}


El Estudio Etnográfico de la Actividad Textil como aporte a la Caracterización del Modo de Vida en el Pueblo de Molinos y zona de influencia (Provincia de Salta)

\begin{tabular}{|l|l|}
\hline 84. Banda Grande - Salta & \\
\hline 85. Entre Ríos- Molinos & Mí \\
\hline 86. Entre Ríos- Cachi & \\
\hline 87. Luracatao- Entre Ríos & \\
\hline 88. Santa María/Catamarca- Entre Ríos & \\
\hline 89. Tacuil- Entre Ríos & \\
\hline 90. Buenos Aires- Entre Ríos & \\
\hline 91. Tomuco- Entre Ríos & \\
\hline 92. Santa Rosa- Entre Ríos & \\
\hline 93. Entre Ríos- Buenos Aires & \\
\hline 94. Banda Grande - Entre Ríos & \\
\hline 95. Salta- Entre Ríos & \\
\hline
\end{tabular}

Listado de pares de localidades referentes a los trayectos en las rutas de circulación de materias primas, mano de obra y comercialización de textiles.

\begin{tabular}{|c|c|}
\hline 69. Alumbre/Luracatao- Entre Ríos & 70. Luracatao- Tomuco \\
\hline 71. Amaicha- Tacuil & 72. Molinos- Amaicha \\
\hline 73. Banda Grande - Entre Ríos & 74. Molinos- Banda Grande \\
\hline 75. Banda Grande - Salta & 76. Molinos- Buenos Aires \\
\hline 77. Banda Grande- Molinos & 78. Molinos- Córdoba \\
\hline 79. Barranca/Tacuil- Molinos & 80. Molinos- El Colte \\
\hline 81. Bolivia- Molinos & 82. Molinos- Huerta Grande \\
\hline 83. Bolivia- Tomuco & 84. Molinos- Humanao \\
\hline 85. Brealito- Tomuco & 86. Molinos- Luracatao \\
\hline 87. Buenos Aires- Entre Ríos & 88. Molinos- Salta \\
\hline 89. Cabrería- Entre Ríos & 90. Molinos- Santa Rosa \\
\hline 91. Cachi Adentro-Tomuco & 92. Molinos- Tomuco \\
\hline 93. Cafayate- Molinos & 94. Patos- Molinos \\
\hline 95. Cafayate- Tomuco & 96. Patos- Tomuco \\
\hline 97. Catamarca- Molinos & 98. Salta - Tomuco \\
\hline 99. Colomé- Molinos & 100. Salta- Entre Ríos \\
\hline 101. Colomé- Tomuco & 102. Salta- Luracatao \\
\hline 103. Compuel- Tomuco & 104. Salta- Molinos \\
\hline 105. El Puente- Banda Grande & 106. Santa María/Catamarca- Entre Ríos \\
\hline 107. El Puente- El Churcal & 108. Santa Rosa- Entre Ríos \\
\hline 109. El Puente- Entre Ríos & 110. SantaMaría/Catamarca- Tomuco \\
\hline 111. El Refugio/Luracatao- Entre Ríos & 112. Seclantás Adentro- Tomuco \\
\hline 113. Entre Ríos - Molinos & 114. Tacuil- Entre Ríos \\
\hline 115. Entre Ríos- Buenos Aires & 116. Tacuil- Molinos \\
\hline 117. Entre Ríos- Cachi & 118. Tacuil- Tomuco \\
\hline 119. Entre Ríos- Luracatao & 120. Tacuil-Patos \\
\hline 121. Entre Ríos- Salta & 122. Tomuco- Amaicha \\
\hline 123. Entre Ríos- Tomuco & 124. Tomuco- Entre Ríos \\
\hline
\end{tabular}


El Estudio Etnográfico de la Actividad Textil como aporte a la Caracterización del Modo de Vida en el Pueblo de Molinos y zona de influencia (Provincia de Salta)

Laura Teves

\begin{tabular}{|ll|ll|}
\hline 125. & Hualfín - Tomuco & 126. & Tomuco- La Esquina \\
\hline 127. & Hualfin- Molinos & 128. & Tomuco- Luracatao \\
\hline 129. & La Puerta/Luracatao - Entre Ríos & 130. & Tomuco- Molinos \\
\hline 131. & Luracatao- Entre Ríos & 132. & Tomuco- Salta \\
\hline 133. & Luracatao- Molinos & 134. & Tomuco- Santa Rosa \\
\hline 135. & Luracatao- Seclantás & 136. & Tomuco- Tiopampa \\
\hline
\end{tabular}


UD en relación con la localización de materias primas, tecnología y productos textiles y con otras actividades desarrolladas en la zona.

\begin{tabular}{|c|c|c|c|}
\hline $\begin{array}{c}\mathrm{UD} \\
\mathbf{1}\end{array}$ & Tomuco & $\begin{array}{l}\text { Hilados } \\
\text { Tejidos }\end{array}$ & $\begin{array}{c}\text { Cultivos } \\
\text { Cría de animales } \\
\text { Agricultura } \\
\text { Abono } \\
\end{array}$ \\
\hline 2 & Molinos & $\begin{array}{c}\text { Hilos } \\
\text { Tejidos } \\
\text { Utensilios } \\
\end{array}$ & $\begin{array}{c}\text { Turismo } \\
\text { Provisiones } \\
\text { Comercialización }\end{array}$ \\
\hline 3 & $\begin{array}{l}\text { Santa María- } \\
\text { Catamarca }\end{array}$ & Hilos & Cueros \\
\hline 4 & Cachi Adentro & Tinturas naturales & \\
\hline 5 & Tacuil & $\begin{array}{c}\text { Nogal para teñir } \\
\text { Utensilios } \\
\text { Sogas } \\
\end{array}$ & $\begin{array}{l}\text { Cría de animales } \\
\text { Semillas de maíz }\end{array}$ \\
\hline 6 & Seclantás Adentro & Nogal para teñir & \\
\hline 7 & Salta & Tinturas industriales & $\begin{array}{c}\text { Artesanías } \\
\text { Comercialización }\end{array}$ \\
\hline 8 & Compuel & $\begin{array}{c}\text { Vellón de lana } \\
\text { Hilos de llama y oveja }\end{array}$ & Plantas Medicinales \\
\hline 9 & Colomé & Hilados & $\begin{array}{c}\text { Cultivos } \\
\text { Cría de animales }\end{array}$ \\
\hline 10 & Humanao & Tejidos & Agricultura \\
\hline 11 & Entre Ríos & $\begin{array}{c}\text { Hilos } \\
\text { Peines } \\
\text { Tejidos }\end{array}$ & $\begin{array}{c}\text { Agricultura } \\
\text { Cría de Vicuñas en } \\
\text { semicautividad } \\
\text { Comercialización } \\
\end{array}$ \\
\hline 12 & Santa Rosa & Tejidos & \\
\hline 13 & Barranca & Lanas & Cría de animales \\
\hline 14 & Hualfin & $\begin{array}{c}\text { Utensilios } \\
\text { Lanas }\end{array}$ & Cría de animales \\
\hline 15 & Luracatao & $\begin{array}{c}\text { Lanas } \\
\text { Hilos }\end{array}$ & Cría de animales \\
\hline 16 & Laguadita - Luracatao & $\begin{array}{c}\text { Lanas } \\
\text { Hilos } \\
\end{array}$ & \\
\hline 17 & Brealito & Tejidos & \\
\hline
\end{tabular}




\begin{tabular}{|c|c|c|c|}
\hline 18 & La Banda Grande & Tejidos & \\
\hline 19 & El Puente & Ponchos & \\
\hline 20 & EIRefugio- Luracatao & Lanas & \\
\hline 21 & Langostura & & \\
\hline 22 & Bolivia & Tinturas & \\
\hline 23 & Buenos Aires & $\begin{array}{l}\text { Tinturas } \\
\text { Telares }\end{array}$ & Comercialización \\
\hline 24 & Mayuco- Tacuil & Lanas & Cría de animales \\
\hline 25 & Tiopampa & Tejidos & \\
\hline 26 & La Esquina & Tejidos & \\
\hline 27 & $\begin{array}{c}\text { Antofagasta de la } \\
\text { Sierra- Catamarca }\end{array}$ & Lanas & Cría de animales \\
\hline 28 & $\begin{array}{c}\text { Patos } \\
\text { Catamarca }\end{array}$ & Lanas & $\begin{array}{c}\text { Cría de animales } \\
\text { Recolección de plantas } \\
\text { medicinales }\end{array}$ \\
\hline 29 & Cafayate & Utensilios & Comercialización \\
\hline 30 & El Colte & Tejidos & \\
\hline 31 & Córdoba & Tejidos & Comercialización \\
\hline 32 & La Puerta- Luracatao & Lanas & \\
\hline 33 & Huerta Grande & Tejidos & Agricultura \\
\hline 34 & Cabrería- Luracatao & Lanas & Cría de animales \\
\hline 35 & Alumbre- Luracatao & Lanas & Cría de animales \\
\hline 36 & Compuel & $\begin{array}{l}\text { Lanas, hilos de llama y } \\
\text { oveja } \\
\quad \text { Peleros }\end{array}$ & $\begin{array}{c}\text { Cría de ovejas, llamas cabras } \\
\text { Recolección de plantas } \\
\text { medicionales }\end{array}$ \\
\hline
\end{tabular}


El Estudio Etnográfico de la Actividad Textil como aporte a la Caracterización del Modo de Vida en el Pueblo de Molinos y zona de influencia (Provincia de Salta)

LISTADO de FINCAS

Departamento de MOLINOS- Provincia de Salta - República Argentina Dirección de Inmuebles - División Cartografía y Registro Gráfico 1993

1. Finca Hacienda Molinos

2. Finca El Churcal

3. Finca Luracatao y Entre Ríos

4. Colomé

5. Tacuil

6. Gualfin

7. Alto La Banda

8. Bajo La Banda

9. Banda Grande

10. Pucarilla

11. Potrero de la Cruz

12. El Churcal

13. El Churcal de Abajo

14. Brealito

15. Angostura

16. El Peñón

17. Rumibola

18. Humanao

19. Tomuco 


\section{La red social de la actividad textil en Molinos}

Los 14 informantes entrevistados proveyeron un listado de personas con las que participan juntos en la actividad textil. Mediante las respuestas obtenidas se localizó a estas personas en diferentes puntos referenciados en los valles interserranos, zonas próximas a las localidades y parajes en otras provincias limítrofes y en puntos más distantes de la región del NOA.

La lista sin repeticiones alcanza a 174 personas que entran en relación con los informantes a partir de las transacciones llevadas a cabo con la materia prima, la disponibilidad de tecnología, la contratación de mano de obra para la elaboración de hilos, tejido y terminación de piezas textiles y la comercialización de las piezas textiles en el mercado.

La red de relaciones encuentra un correlato geográfico en el territorio delimitado por el Departamento de Molinos y otras localidades de la región. A partir de 38 localidades que remiten a 68 pares de tramos en 3 trayectos que atraviesan de norte a sur y de este a oeste a lo largo de los valles, cerros y abras todos los espacios del Departamento de Molinos y se proyectan en la región hacia las ciudades de Antofagasta y Santa María en Catamarca, como a las provincias de Córdoba y Buenos Aires. Al norte la circulación llega hasta la Salta capital y más allá de las fronteras con Bolivia.

\begin{tabular}{|l|l|l|l|}
\hline \multirow{2}{*}{ Localidad } & \multirow{2}{*}{ m.s.n.m. } & \multicolumn{2}{|c|}{ Coordenadas geográficas } \\
\cline { 3 - 4 } & & latitud & longitud \\
\hline & & & \\
\hline & & & \\
\hline & & & \\
\hline
\end{tabular}

\begin{tabular}{|l|l|l|}
\hline Tramos de rutas & Distancias recorridas & Zonas ecológicas \\
\hline & & \\
\hline & & \\
\hline & & \\
\hline
\end{tabular}


El Estudio Etnográfico de la Actividad Textil como aporte a la Caracterización del Modo de Vida en el Pueblo de Molinos y zona de influencia (Provincia de Salta)

Los circuitos en la porción del valle calchaquí en el Departamento de Molinos se diferencian por las diferentes rutas:

1- "la ruta del cerro", trayectos seguidos a través de las huellas por donde los troperos o caravaneros transportan la materia prima y otros objetos de intercambio y venta. Los dos recorridos más habituales son el camino al Luracatao y el camino a Tacuil a Compuel. Extensos trayectos que atravesando los cerros unen ... km caminando o a lomo de burro.

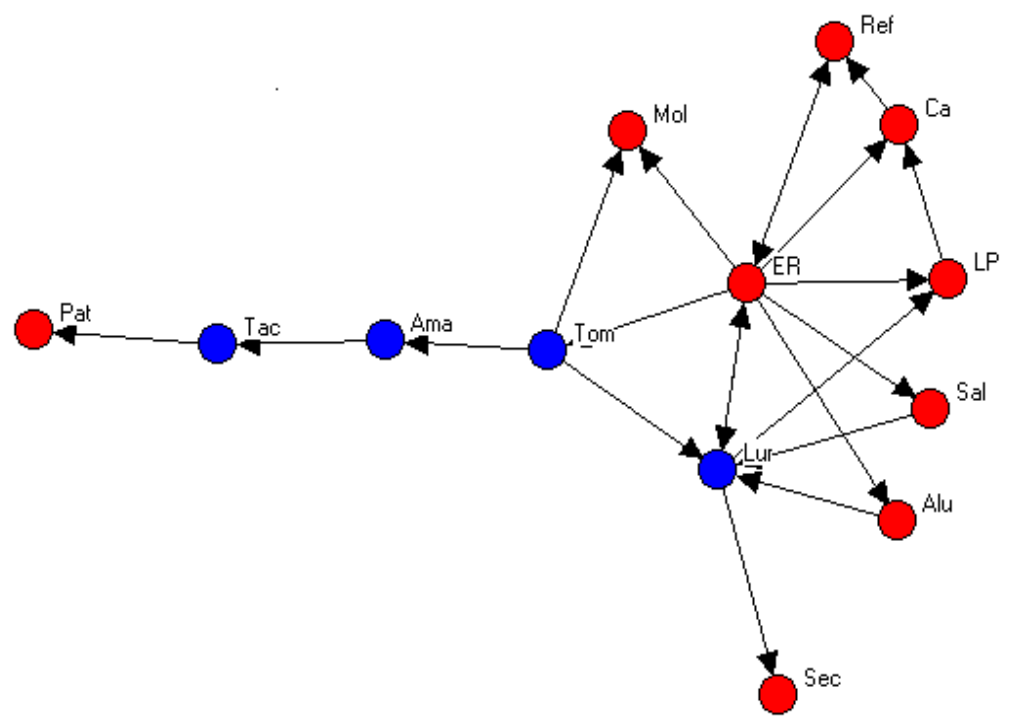

Red con puntos de corte (cutpoint) en azul y esquema

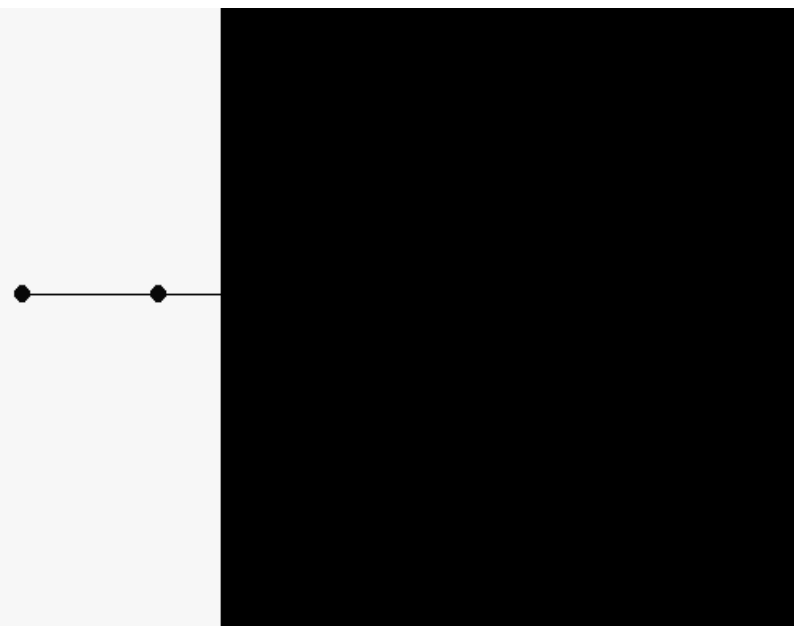


El Estudio Etnográfico de la Actividad Textil como aporte a la Caracterización del Modo de Vida en el Pueblo de Molinos y zona de influencia (Provincia de Salta)

Matriz Adyacente 2 caminos

\begin{tabular}{|l|l|l|l|l|l|l|l|l|l|l|l|l|}
\hline & Alu & Ama & Ca & ER & LP & Lur & Mol & Pat & Ref & Sal & Sec & Tac \\
\hline Alu & & & & & & 1 & & & & & & \\
\hline Ama & & & & & & & & & & & & 1 \\
\hline Ca & & & & & & & & & 1 & & & \\
\hline ER & 1 & & 1 & & 1 & 1 & 1 & & 1 & 1 & & \\
\hline LP & & & 1 & & & & & & & & & \\
\hline Lur & & & & 1 & 1 & & & & & & 1 & \\
\hline Mol & & & & & & & & & & & & \\
\hline Pat & & & & & & & & & & & & \\
\hline Ref & & & & 1 & & & & & & & & \\
\hline Sal & & & & & & 1 & & & & & & \\
\hline Sec & & & & & & & & & & & & \\
\hline Tac & & & & & & & & 1 & & & & \\
\hline Tom & & 1 & & & & 1 & 1 & & & & & \\
\hline
\end{tabular}

Matriz de Alcance (dirección) 2 caminos

\begin{tabular}{|l|c|c|c|c|c|c|c|c|c|c|c|c|c|}
\hline & Alu & Ama & Ca & ER & LP & Lur & Mol & Pat & Ref & Sal & Sec & Tac & Tom \\
\hline Alu & 0 & 1 & 1 & 1 & 1 & 1 & 1 & 1 & 1 & 1 & 1 & 1 & 1 \\
\hline Ama & & 0 & & & & & & & & & & 1 & \\
\hline Ca & 1 & 1 & 0 & 1 & 1 & 1 & 1 & 1 & 1 & 1 & 1 & 1 & 1 \\
\hline ER & 1 & 1 & 1 & 0 & 1 & 1 & 1 & 1 & 1 & 1 & 1 & 1 & 1 \\
\hline LP & 1 & 1 & 1 & 1 & 0 & 1 & 1 & 1 & 1 & 1 & 1 & 1 & 1 \\
\hline Lur & 1 & 1 & 1 & 1 & 1 & 0 & 1 & 1 & 1 & 1 & 1 & 1 & 1 \\
\hline Mol & & & & & & & 0 & & & & & & \\
\hline Pat & & & & & & & & 0 & & & & & \\
\hline Ref & 1 & 1 & 1 & 1 & 1 & 1 & 1 & 1 & 0 & 1 & 1 & 1 & 1 \\
\hline Sal & 1 & 1 & 1 & 1 & 1 & 1 & 1 & 1 & 1 & 0 & 1 & 1 & 1 \\
\hline Sec & & & & & & & & & & & 0 & & \\
\hline Tac & & & & & & & & 1 & & & & 0 & \\
\hline Tom & 1 & 1 & 1 & 1 & 1 & 1 & 1 & 1 & 1 & 1 & 1 & 1 & 0 \\
\hline
\end{tabular}

Matriz de Distancia (pasos) 2 caminos

\begin{tabular}{|l|c|c|c|c|c|c|c|c|c|c|c|c|c|}
\hline & Alu & Ama & Ca & ER & LP & Lur & Mol & Pat & Ref & Sal & Sec & Tac & Tom \\
\hline Alu & 0 & 4 & 3 & 2 & 2 & 1 & 3 & 6 & 3 & 3 & 2 & 5 & 3 \\
\hline Ama & & 0 & & & & & 2 & 2 & & & & 1 & \\
\hline Ca & 3 & 4 & 0 & 2 & 3 & 3 & 3 & 6 & 1 & 3 & 4 & 5 & 3 \\
\hline ER & 1 & 2 & 1 & 0 & 1 & 1 & 1 & 4 & 1 & 1 & 2 & 3 & 1 \\
\hline LP & 4 & 5 & 1 & 3 & 0 & 4 & 4 & 7 & 2 & 4 & 5 & 6 & 4 \\
\hline Lur & 2 & 3 & 2 & 1 & 1 & 0 & 2 & 5 & 2 & 2 & 1 & 4 & 2 \\
\hline
\end{tabular}


El Estudio Etnográfico de la Actividad Textil como aporte a la Caracterización del Modo de Vida en el Pueblo de Molinos y zona de influencia (Provincia de Salta)

\begin{tabular}{|l|l|l|l|l|l|l|l|l|l|l|l|l|l|}
\hline Mol & & & & & & & 0 & & & & & & \\
\hline Pat & & & & & & & & 0 & & & & & \\
\hline Ref & 2 & 3 & 2 & 1 & 2 & 2 & 2 & 5 & 0 & 2 & 3 & 4 & 2 \\
\hline Sal & 3 & 4 & 3 & 2 & 2 & 1 & 3 & 6 & 3 & 0 & 2 & 5 & 3 \\
\hline Sec & & & & & & & & 0 & & & 0 & & \\
\hline Tac & & & & & & & & 1 & & & & 0 & \\
\hline Tom & 3 & 1 & 3 & 2 & 2 & 1 & 1 & 3 & 3 & 3 & 2 & 2 & 0 \\
\hline
\end{tabular}

2- "ruta del valle" o la circulación de las piezas textiles entre el pueblo de Molinos y otros parajes localizados en el valle coincide con la contratación de mano de obra para la confección de los textiles entre los expertos en la actividad textil.

Matriz de la AT en las localidades del valle

\begin{tabular}{|c|c|c|c|c|c|c|c|c|c|c|c|c|c|c|}
\hline & EntreRíos & \begin{tabular}{|l} 
Banda \\
Gr
\end{tabular} & $\begin{array}{l}\text { Huerta } \\
\mathrm{Gr}\end{array}$ & \begin{tabular}{|l|} 
Human \\
ao
\end{tabular} & $\begin{array}{l}\text { Lesquin } \\
\text { a } \\
\end{array}$ & Molinos & \begin{tabular}{|l} 
Santa \\
Rosa \\
\end{tabular} & \begin{tabular}{|l|} 
TioPam \\
pa
\end{tabular} & $\begin{array}{l}\text { Tomuc } \\
\text { o }\end{array}$ & $\begin{array}{l}\text { CachiA } \\
\text { d }\end{array}$ & $\begin{array}{l}\text { Seclant } \\
\text { asAd }\end{array}$ & \begin{tabular}{|l|}
$\begin{array}{l}\text { Epuent } \\
\text { e }\end{array}$ \\
\end{tabular} & Churcal & Brealito \\
\hline EntreRíos & & & & & & 1 & & & 1 & & & & & \\
\hline BandaGr & 1 & & & & & 1 & & & & & & & & \\
\hline \multicolumn{15}{|l|}{ HuertaGr } \\
\hline \multicolumn{15}{|l|}{ Humanao } \\
\hline \multicolumn{15}{|l|}{ LEsquina } \\
\hline Molinos & 1 & 1 & 1 & 1 & & & 1 & & 1 & & & & & \\
\hline SantaRosa & 1 & & & & & & & & & & & & & \\
\hline \multicolumn{15}{|l|}{ TioPampa } \\
\hline Tomuco & 1 & & & & 1 & 1 & 1 & 1 & & & & & & \\
\hline CachiAd & & & & & & & & & 1 & & & & & \\
\hline SeclnatásAd & & & & & & & & & 1 & & & & & \\
\hline EIPuente & 1 & 1 & & & & & & & & & & & $\overline{1}$ & \\
\hline \multicolumn{15}{|l|}{ Churcal } \\
\hline Brealito & & & & & & & & & 1 & & & & & \\
\hline
\end{tabular}

Visualización de la red de la actividad textil en las localidades del valle 
El Estudio Etnográfico de la Actividad Textil como aporte a la Caracterización del Modo de Vida en el Pueblo de Molinos y zona de influencia (Provincia de Salta)

Laura Teves
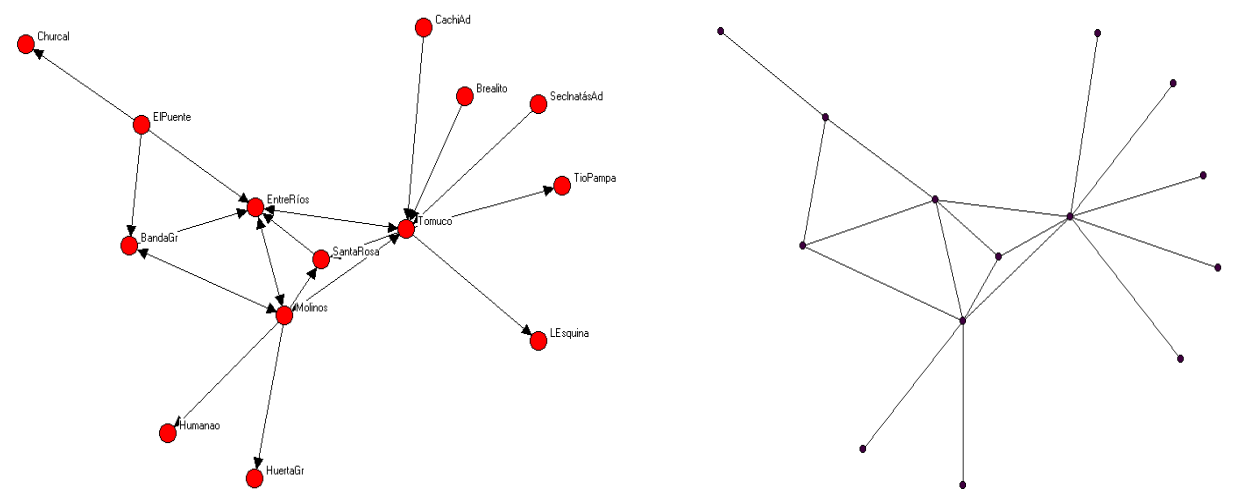

3- "la ruta del mercado", señalada por los caminos de salida del valle y del cerro hacia las grandes ciudades de provincia donde se comercializan las piezas textiles como artesanías.

\section{Matriz Circuito Regional y Trasnacional}

\begin{tabular}{|c|c|c|c|c|c|c|c|c|c|c|c|c|}
\hline & Bolivia & \begin{tabular}{|l} 
Buenos \\
Aires
\end{tabular} & Cachi & Cafayate & Córdoba & ElColte & EntreRío & \begin{tabular}{|l|} 
Patos- \\
Catamar
\end{tabular} & Salta & \begin{tabular}{|l|} 
StaMa- \\
Catamar
\end{tabular} & Tomuco & Molinos \\
\hline Bolivia & & & & & & & & & & & 1 & 1 \\
\hline $\begin{array}{l}\text { Buenos } \\
\text { Aires }\end{array}$ & & & & & & & & & & & & \\
\hline Cachi & & & & & & & & & & & & \\
\hline Cafayate & & & & & & & & & & & 1 & 1 \\
\hline Córdoba & & & & & & & & & & & & \\
\hline ElColte & & & & & & & & & & & & \\
\hline EntreRío & & & 1 & & & & 1 & & & & & 1 \\
\hline $\begin{array}{l}\text { Patos- } \\
\text { Catamar }\end{array}$ & & & & & & & & & & & & 1 \\
\hline Salta & & & & & & & 1 & & & & & \\
\hline $\begin{array}{l}\text { StaMa- } \\
\text { Catamar }\end{array}$ & & & & & & & 1 & & & & 1 & \\
\hline Tomuco & & & & & & & 1 & & & & & 1 \\
\hline Molinos & & 1 & & & 1 & 1 & & & 1 & & & \\
\hline
\end{tabular}


El Estudio Etnográfico de la Actividad Textil como aporte a la Caracterización del Modo de Vida en el Pueblo de Molinos y zona de influencia (Provincia de Salta)

\section{Gráfico de la Red regional}
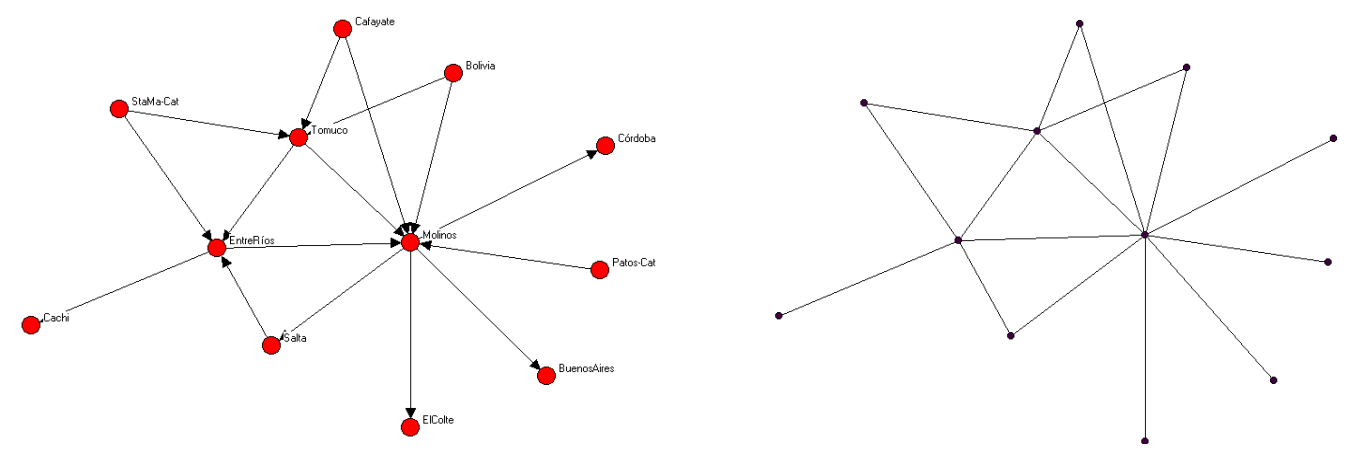
El Estudio Etnográfico de la Actividad Textil como aporte a la Caracterización del Modo de Vida en el Pueblo de Molinos y zona de influencia (Provincia de Salta)

Laura Teves

Sobre la base de la matriz de adyacencia se hicieron los siguientes cálculos de cohesión: distancia y alcance, utilizando los algoritmos del programa UCINET 6.

\section{Distancia - Distance :}

Se construye una matriz de distancia o distancia generalizada entre todos los pares de nodos de un grafo. Permite la transformación de esta matriz de distancia a proximidad.

El largo/recorrido de un "camino" es el número de líneas que este contiene. La distancia entre dos nodos es el tamaño del camino más corto. (Borgatti, 2004 UCINET6)

Para cada par de nodos, el algoritmo encuentra \# de líneas-edges en el camino más corto entre ellos.

\section{Alcance - Reachability.}

Se construye una matriz de alcance valuando cada par de nodos. El alcance -reachabilitypara un par de nodos es el valor de un camino óptimo.

Para cada par de nodos, el algoritmo encuentra si existe un camino de cualquier tamaño que los conecte. 
El Estudio Etnográfico de la Actividad Textil como aporte a la Caracterización del Modo de Vida en el Pueblo de Molinos y zona de influencia (Provincia de Salta)

Laura Teves

\section{DISTANCE}

Type of data:

Nearness transform:

Input dataset: C: \Misdocumentos $\backslash 04-$ Tesis $\backslash S T A N D-$

BY \REDESMolinos $\backslash U$ Cinet 6-Molinos $\backslash 2$ caminos

For each pair of nodes, the algorithm finds the \# of edges in the shortest path between them.

Average distance (among reachable pairs) $=2.717$

Distance-based cohesion $=0.313$ (range 0 to 1 ; larger values indicate greater cohesiveness)

Distance-weighted Fragmentation $=0.687$

\section{Geodesic Distances}

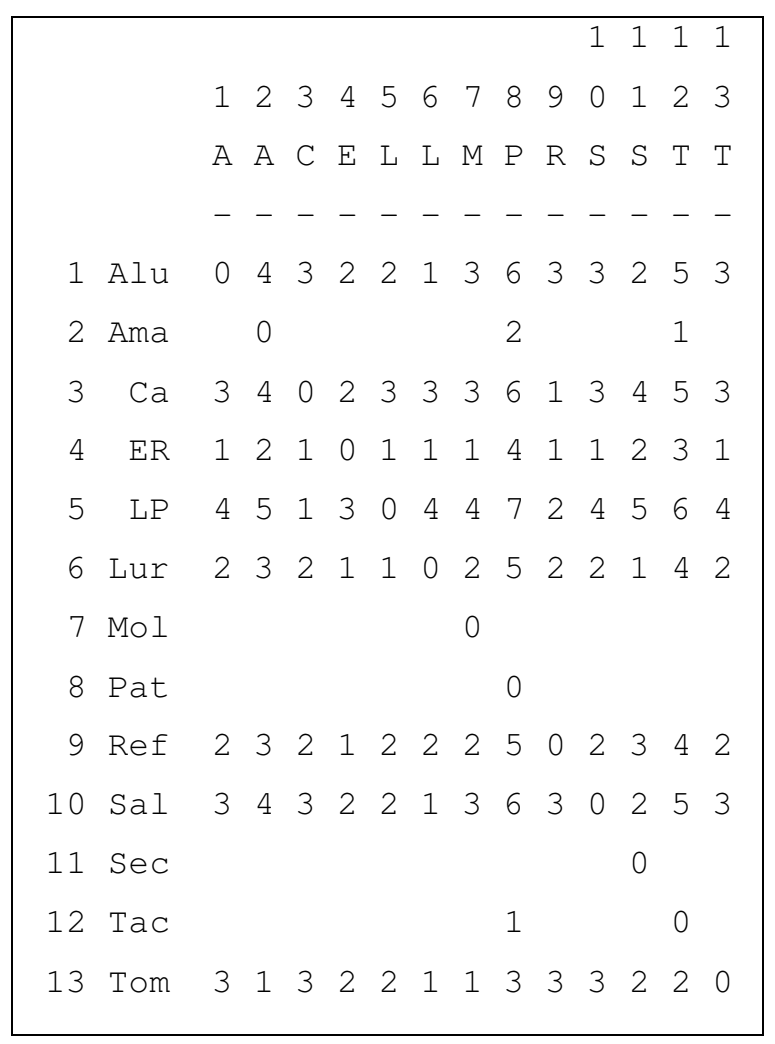

Distance matrix saved as dataset GeodesicDistance 
El Estudio Etnográfico de la Actividad Textil como aporte a la Caracterización del Modo de Vida en el Pueblo de Molinos y zona de influencia (Provincia de Salta)

Laura Teves

Running time: 00:00:01

Output generated: 16 Abr 05 14:46:51

Copyright (c) 1999-2004 Analytic Technologies 
El Estudio Etnográfico de la Actividad Textil como aporte a la Caracterización del Modo de Vida en el Pueblo de Molinos y zona de influencia (Provincia de Salta)

Laura Teves

\section{REACHABILITY}

Type of data: ADJACENCY

Input dataset: C: \Mis documentos $\backslash 04$-Tesis $\backslash$ STANDBY \REDESMolinos $\backslash$ Ucinet $6-M o l i n o s \backslash 2$ caminos

For each pair of nodes, the algorithm finds whether there exists a path of any length that connects them.

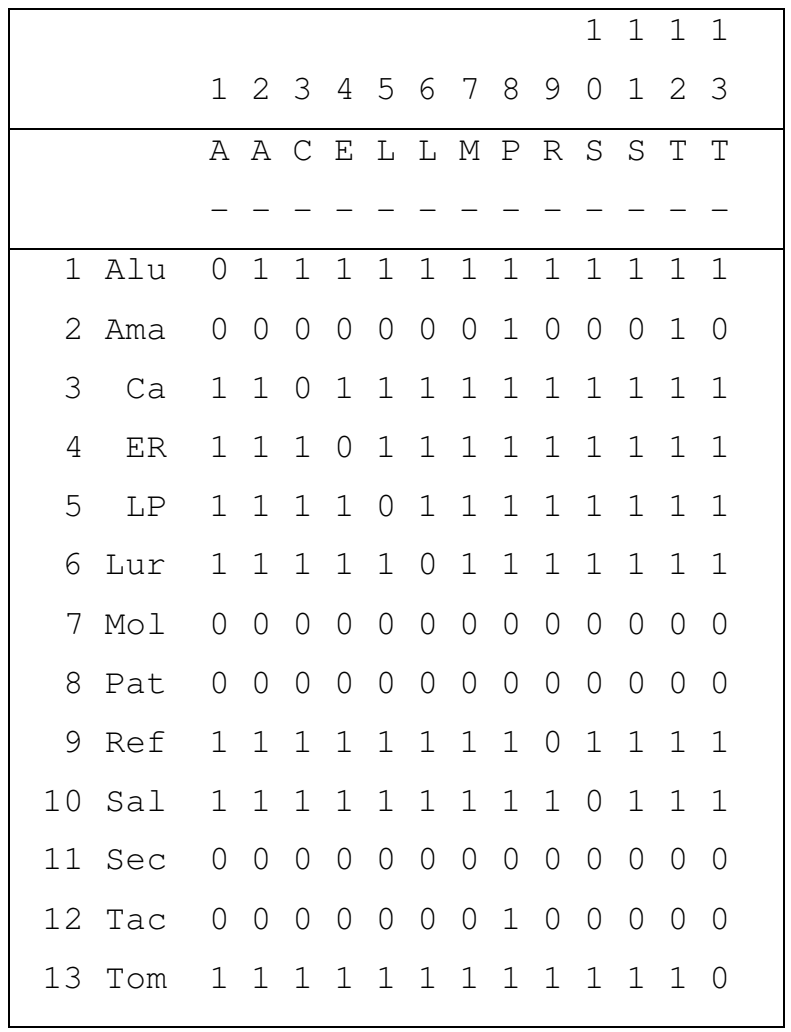

Running time: 00:00:01

Output generated: 16 Abr 05 16:10:44

Copyright (c) 1999-2004 Analytic Technologies 
El Estudio Etnográfico de la Actividad Textil como aporte a la Caracterización del Modo de Vida en el Pueblo de Molinos y zona de influencia (Provincia de Salta)

\section{Representación en el Programa Pajek}

Frecuencia de interacción entre expertos textiles y localidades en líneas gruesas

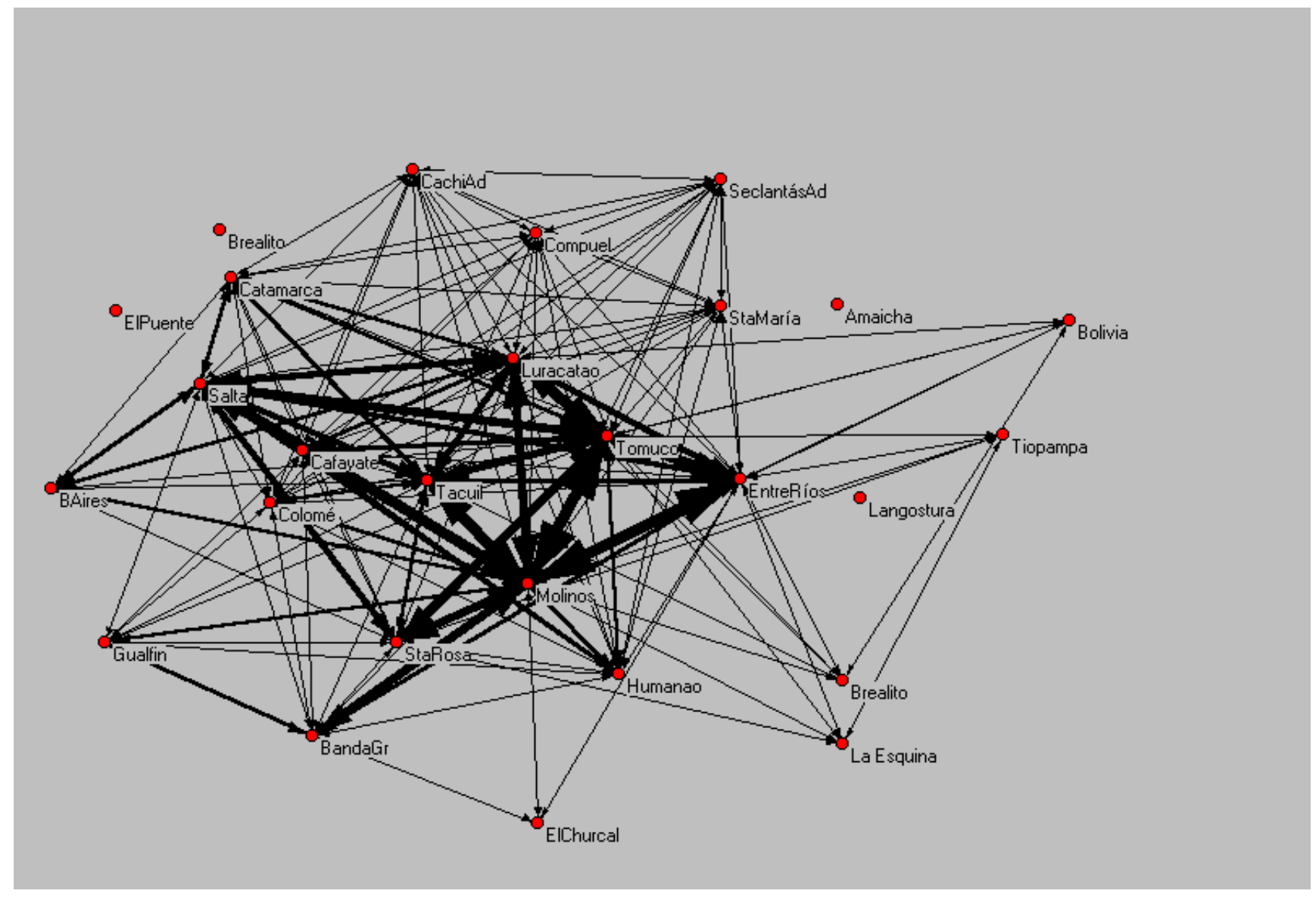


El Estudio Etnográfico de la Actividad Textil como aporte a la Caracterización del Modo de Vida en el Pueblo de Molinos y zona de influencia (Provincia de Salta)

Laura Teves

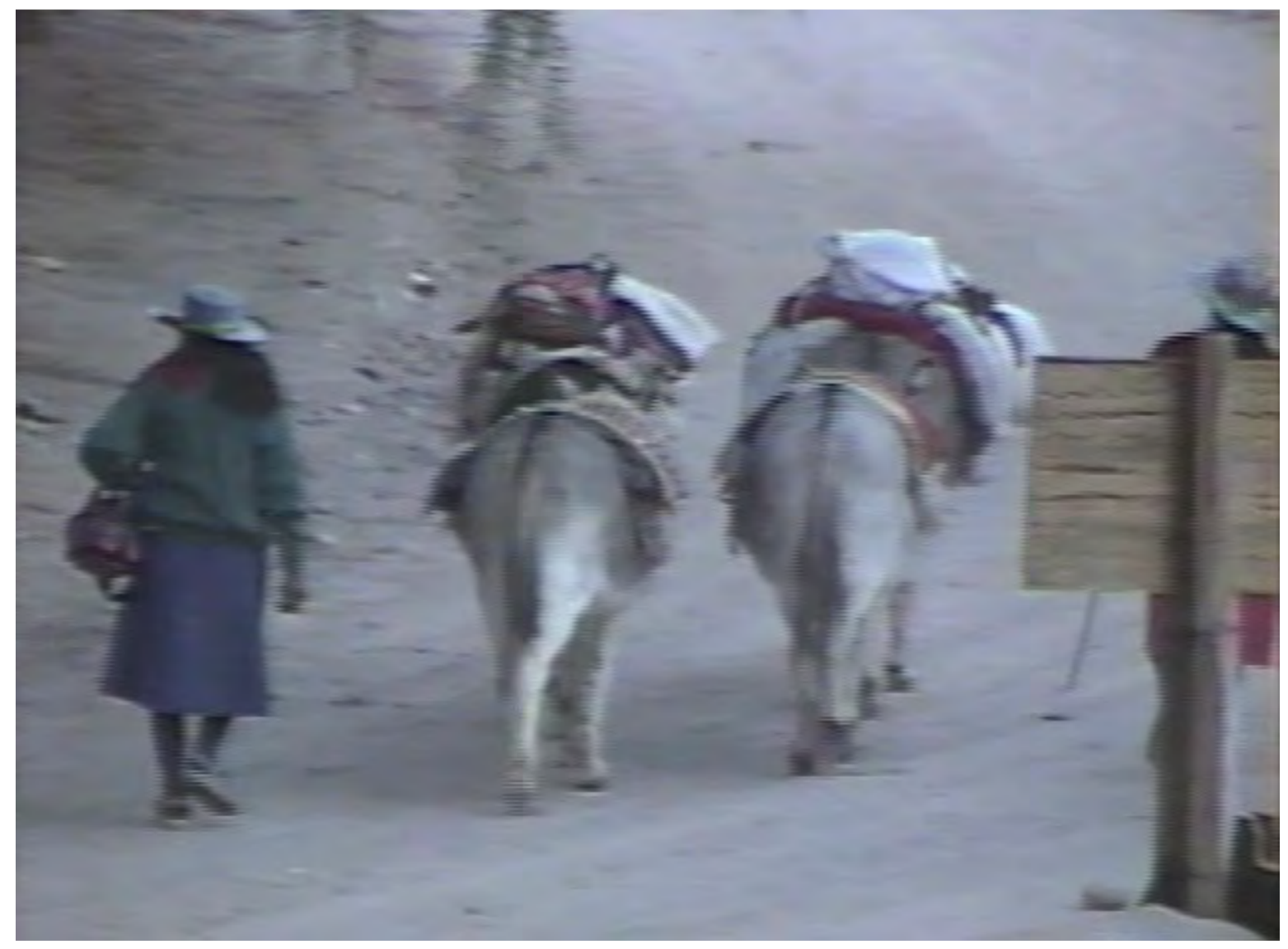

